\title{
Storing and Securing Carbon Dioxide in Depleted Shale Formations
}

\author{
A Dissertation \\ Presented to
}

the faculty of the School of Engineering and Applied Science

University of Virginia

\author{
in partial fulfillment \\ of the requirements for the degree \\ Doctor of Philosophy \\ by
}

Zhiyuan Tao

May 2017 


\title{
APPROVAL SHEET
}

\author{
This Dissertation \\ is submitted in partial fulfillment of the requirements \\ for the degree of \\ Doctor of Philosophy \\ Author Signature: Zhifuem Tao
}

This Dissertation has been read and approved by the examining committee:

Advisor: Dr. Andres Clarens

Committee Member: Dr. James Smith

Committee Member: Dr. Roseanne Ford

Committee Member: Dr. Teresa Culver

Committee Member: Dr. Stephen Macko

Committee Member:

Accepted for the School of Engineering and Applied Science:

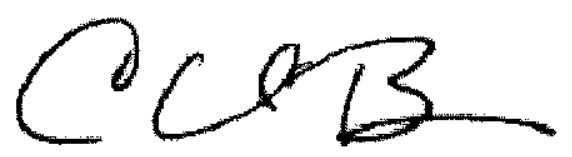

Craig H. Benson, School of Engineering and Applied Science

May 2017 
(C) Zhiyuan Tao 2017 
In memory of my grandmother and grandfather 


\section{Abstract}

Hydraulically fractured shale formations are being developed widely for oil and gas production. These fractured shales have a number of characteristics that could make them attractive candidates for geological carbon sequestration (GCS) once the formations have been depleted of oil and gas. They generally exist deep in the subsurface and have low permeability beyond the artificial fracture network that was created during well completion suggesting that they could be permanent repositories. In addition, gas pipeline and handling infrastructure at the surface that are used to produce gas/oil may be repurposed to inject $\mathrm{CO}_{2}$, minimizing economic and environmental burdens. In spite of this promise, there are a number of technical questions about the viability of this approach. This dissertation seeks to answer critical geochemical and systems-level questions related to the carbon storage capacity in shale formations and strategies to mitigate the leakage risks associated with this technology.

To understand the overall $\mathrm{CO}_{2}$ storage capacity of depleted shale wells, a computational method was developed that is based on a unipore diffusion configuration to characterize governing gas-transport processes. The gas diffusion coefficient was estimated using historical production decline data while the ratio of adsorbed gas to free phase gas, water saturation and gas adsorption isotherms were obtained from the literature. The results suggest that the Marcellus Shale in the Eastern United States could store about 12 Gt of $\mathrm{CO}_{2}$ in 13 years, which is over $1 / 3$ of total $\mathrm{US} \mathrm{CO}_{2}$ emissions from stationary sources (e.g., power plants) over the same time period. The mass transfer kinetics of the system indicate that injection of $\mathrm{CO}_{2}$ would proceed several times faster than production of $\mathrm{CH}_{4}$, 
which for the Marcellus Shale is on the order of several decades. The model is found to be most sensitive to the ratio of adsorbed gas to the total gas which includes both adsorbed and free phase gas. The extension of the model to other locations, together with the harmonization of the results from all the published literature relevant to carbon storage in shale formations, reveals that the major shale formations in US could all store more than $30 \mathrm{Gt}$ of $\mathrm{CO}_{2}$. Different shale formations have distinct petrophysical properties, including their rank, that would affect their storage potential.

To secure the injected $\mathrm{CO}_{2}$ in the fractured shale, a new method was developed to control the fluid flow properties in fractured shale formations. The approach is based on the injection of Ca-based silicate minerals into the fractures and pores as a cation donor. When reacted with $\mathrm{CO}_{2}$, it could alter the fluid conductivity or seal leakage pathways by leveraging the reactivity and kinetics of carbonation reactions of silicates at the depths and pressures of the shale formation. These silicate minerals could be added as either proppant materials during well completion or immediately before shutting down a well. Our results show that the pressures and temperatures of most shale formations are suitable for the carbonation reactions to proceed spontaneously and readily (e.g., >50\% completion can be achieved within 1-2 days). Scanning Electronic Micrographic (SEM) analysis and X-ray Diffraction (XRD) techniques support the hypothesis that calcium carbonate will form in addition to amorphous silica under simulated reservoir conditions. The precipitated carbonate can effectively cement the rock and change the pore size distribution in the porous media. The production of silicate hydrate was also observed. This hydrate phase is likely to form via the re-combination of $\mathrm{Ca}^{2+}$ and amorphous silica, which are derived from the dissolution of Ca-silicate. Although the silicate hydrates have 
porosity of their own, when combined with carbonate precipitates, they may play a synergistic role in narrowing or clogging flow pathways. X-ray Tomography and 3D pore network modeling have been and will be continued to be deployed to better understand the mechanisms through which the reactive transport changes the pore structure and permeability. Future work will also explore ways in which these carbonation and hydration reactions can be leveraged in other applications to provide targeted control of permeability in the deep subsurface. 


\section{Acknowledgement}

It has been a long journey since I came to Charlottesville and I still remember the first summer I joined Clarens' lab five years ago. Here I would like to express my sincerest gratitude to my supervisor, Dr. Andres Clarens. Without your inspiration and careful guidance, I could not get the chance going this far. Thank you for always encouraging and supporting me to pursue excellence and to discover new scientific territory. I'm always motivated by your aspiration and charisma during research, study and career development. I would also like to thank Dr. James Smith, Dr. Teresa Culver and Dr. Stephen Macko for providing valuable insights and guiding me about research and study. Suggestions and wisdoms offered by Dr. Roseanne Ford, Dr. Catherine Peters and Dr. Jeff Fitts relevant to academic research and personal development are deeply appreciated. It is my honor and privilege to have so many great mentors. Hands-on help and discussions from Dr. Lisa Colosi Peterson, Dr. Lindsay Ivy Burden, Dr. Dustin Crandall, Dr. Dan Soder, Dr. Jeff Bielicki, Dr. Hang Deng, Dr. Flo Ling, Dr. Chaozhong Qin and Dr. Tony Singh are indispensable for me as well. The funding support from National Science Foundation (Grant No. CBET-1134397, Grant No. CBET-1254839) and US Department of Energy (Grant No. DE-FOA-0001240) is really appreciated.

I can not forget the countless help from former lab members Dr. Shibo Wang, Dr. Xiaowei Liu and Dr. Brian Weaver. I always enjoy the family-like environment in our lab with Mr. Buddy Wilkins, Mr. Dan Plattenberger, Mr. Bo Liang and Mr. Xiaotong Lyu. Thank you my amazing buddies for bringing so many different and precious perspectives to my graduate school life! Many thanks to fellows in Department of Civil and Environmental Engineering, particularly Ms. Sarah Bauer, Ms. Kassie Grimes, Ms. Katie 
Nunnelley, Ms. Xiaomin Zhao, Ms. Bingrong Sun, Mr. Guannan Wang and Mr. Wenqiong Tu. Best regards to the supportive members in the department, Mr. Keegan Gumbs, Mrs. Peggy Gibson, Mrs. Kimberly Allen and Mrs. Patricia Gibson.

My friends at U.Va are invaluable fortune to me. Heng Shou, Kerui Xu, Xuhui Feng, Jiajun Mei, Kai Wang and Danqing Zhu, thank you for your supports and accompany during my very first and the hardest year here at Charlottesville. Many thanks to Songpan Xu, Zerui Liu, Chong Wang, Zhang Wang, Chao Qin, Tianwei Jin, Yinglun Zhu, Yanshi Wu for creating so many great memories together. I would also like to express my appreciation to Jiguang $\mathrm{Li}$, Chong $\mathrm{Xu}$, Xiaopu Wang, Xiaoye Wang and Meng Wang for your advices and help during our friendship. Yijing Shi, Zhaoxiang Qi, Kehua Yin, Jiahan Xie, Shaojie Zhang, Jing Guo, Ge Song, Long Di, Keye Sun and Jiekun Yang, please accept my great thanks for sharing so much happiness and sadness together. Yige $\mathrm{Wu}$, thank you for bringing me with faith, loyalty and leading me to deeper understanding of life.

Now it's coming to the sweet time. Jinchao, it's hard to imagine how could I even survive my last year at U.Va. without your accompany. Please accept my deepest gratitude for allowing me to be myself and being truly yourself as well. Thank you for being there for me.

My journey can not possibly exist without my family. Mom and Dad, your everlasting love makes me a better and stronger person every day in my life. Thank you for your unconditional and endless support and understanding on my way exploring the world. I feel truly blessed and I'm proud of you. 


\section{Table of Contents}

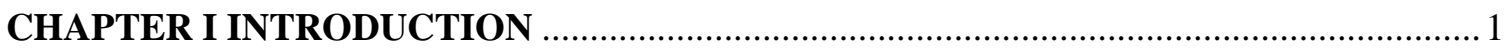

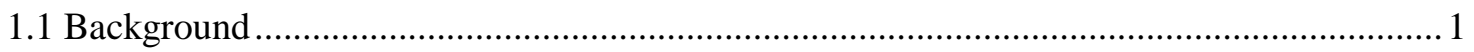

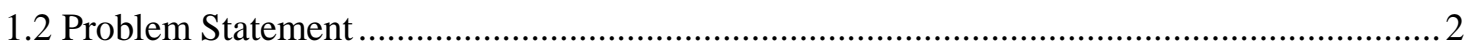

1.3 Research Objective, Scope and Summary of Dissertation............................................... 3

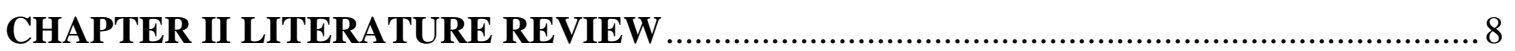

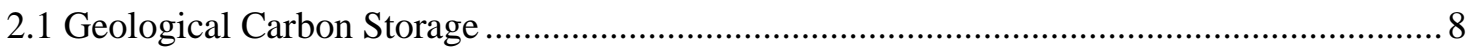

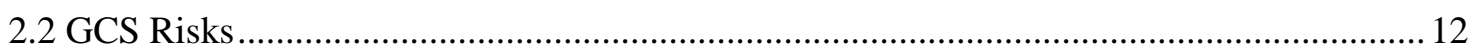

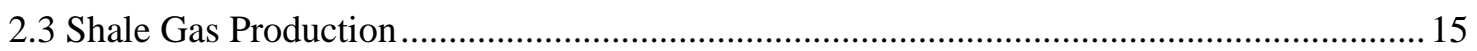

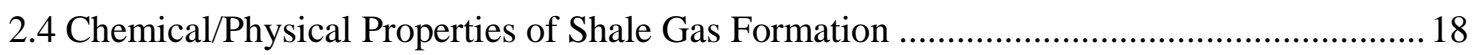

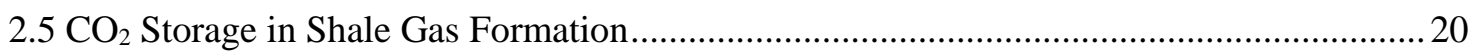

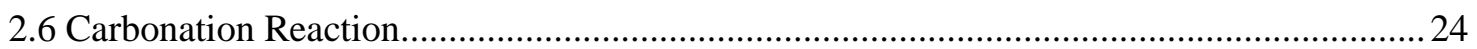

$2.7 \mathrm{CO}_{2}$-induced Structural Change of Porous Media ........................................................... 26

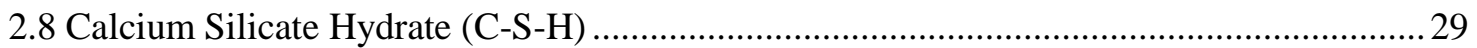

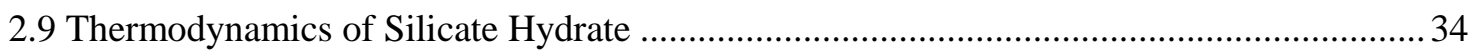

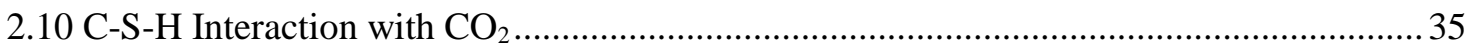

CHAPTER III ESTIMATION OF $\mathrm{CO}_{2}$ STORAGE IN SHALE FORMATIONS................ 39

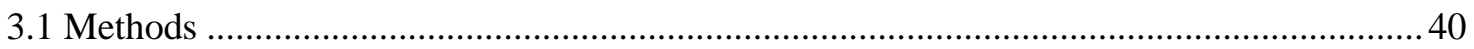

3.2 Estimation of $\mathrm{CO}_{2}$ Storage Capacity in Marcellus Shale .................................................52

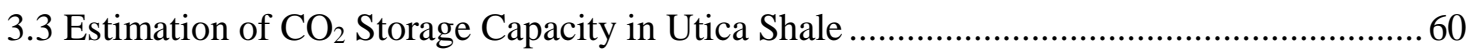

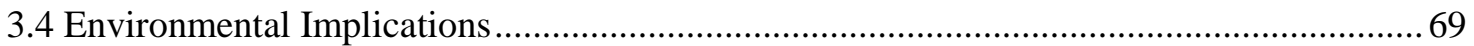

CHAPTER IV META ANALYSIS OF $\mathrm{CO}_{2}$ STORAGE IN US SHALE FORMATIONS... 72

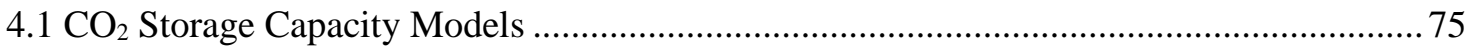

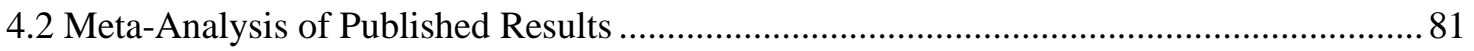

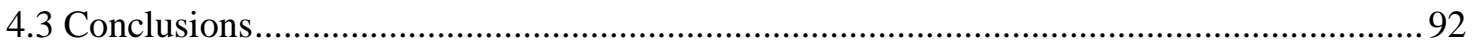

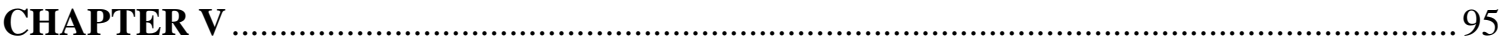

CARBONATION AND HYDRATION OF Ca-SILICATE IN POROUS MEDIA .............. 95

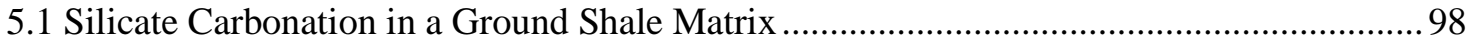

5.2 Carbonation and Hydration Reaction of Silicate in Glass Beads Matrix ........................... 115

5.3 Permeability Control in Shale Play at Different Depth.................................................... 128

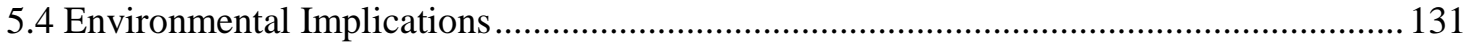




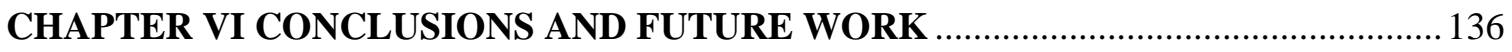

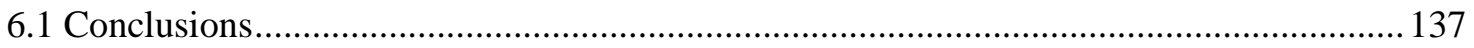

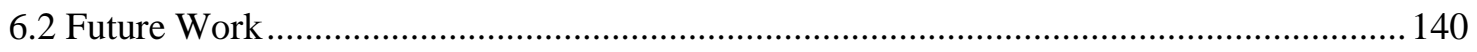

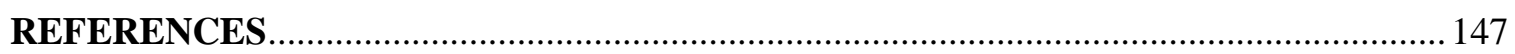

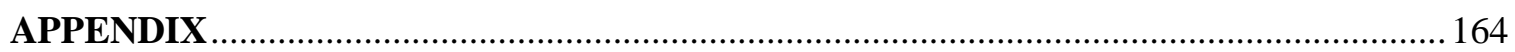




\section{Nomenclature}

A: cross-sectional area of column $\left(\mathrm{m}^{2}\right)$

D: Diffusion coefficient of gas $\left(\mathrm{m}^{2} / \mathrm{s}\right)$

$D_{e}$ : effective diffusivity coefficient for $\mathrm{CH}_{4}$ production/ $\mathrm{CO}_{2}$ injection

$D_{p}:$ particle diameter $(\mathrm{m})$

$\varepsilon$ : porosity of porous media

$E_{a}$ : activation energy $(\mathrm{kJ} / \mathrm{mol})$

$\mathrm{I}_{\mathrm{CaCO}_{3}}: \mathrm{XRD}$ peak intensity for $\mathrm{CaCO}_{3}$

$I_{\mathrm{TiO}_{2}}:$ XRD peak intensity for $\mathrm{TiO}_{2}$

$\kappa:$ permeability $\left(\mathrm{m}^{2}\right)$

$k_{T}$ : reaction rate constant at temperature $T(\mathrm{~K})$

L: length of the column (m)

$\Delta P:$ pressure difference between inlet and outlet $(\mathrm{Pa})$

Q: volumetric flow rate $\left(\mathrm{m}^{3} / \mathrm{s}\right)$

$r_{p}:$ gas transport distance $(\mathrm{m})$

$R$ : the ideal gas constant $\left(8.314 \mathrm{~J} \cdot \mathrm{K}^{-1} \cdot \mathrm{mol}^{-1}\right)$

$S_{w}$ : water saturation in shale formation

$S_{H g}:$ mercury saturation

$V_{t}$ : accumulated gas adsorption (or desorption) volume at time $\mathrm{t}\left(\mathrm{m}^{3}\right)$

$V_{\infty}$ : the total gas desorption (adsorption) capacity $\left(\mathrm{m}^{3}\right)$

$\mu$ : viscosity of air $(\mathrm{Pa} \cdot \mathrm{s})$

$\lambda$ : molecular free pathways $\left(\mathrm{m}^{-1}\right)$ 


\section{CHAPTER I}

\section{INTRODUCTION}

\subsection{Background}

Greenhouse gas emissions from large-scale human activities, such as fossil fuel combustion for power generation, are the primary drivers of climate change. ${ }^{1}$ Strategies for achieving deep reductions in $\mathrm{CO}_{2}$ emissions are needed and geological carbon storage (GCS) has been explored over the past two decades because of the large storage capacity associated with underground formations and because it enables the continued use of fossil fuels over the short and medium term..$^{2-4}$ In a typical GCS project, $\mathrm{CO}_{2}$ is captured and compressed from a concentrated emission point, such as a power plant or chemical processing facility, and is then transported through pipelines to an injection site. ${ }^{3,5,6}$ Saline aquifers, depleted oil/gas reservoirs, and unmineable coal seams are normally considered to be the typical target repositories to store $\mathrm{CO}_{2} \cdot{ }^{3,7}$

In recent years, depleted shale gas/oil production wells have drawn attention for their potential to serve as repositories for $\mathrm{CO}_{2}$ because of their lower injection costs. ${ }^{8-11}$ Site characterization and drilling of the wells are completed during the hydrocarbon production period and the other infrastructures associated with moving and injecting large volumes of gas are generally in place. Because of the large scale of shale gas/oil production during the past decade, significant volumes of pore space have been created in the formations and the associated surface areas of these pore structures are available to be filled or sorbed by $\mathrm{CO}_{2} \cdot{ }^{12}$ However, the large-scale hydrocarbon extraction from shale started just a decade ago and there are currently few wells being retired. In the coming decades, a large number of unconventional wells may be retired, highlighting the 
opportunity and need for more research into the use of hydraulically fractured shale formations as targets for GCS.

\subsection{Problem Statement}

In order to be considered a suitable repository for large scale GCS, it is necessary to determine the $\mathrm{CO}_{2}$ storage capacity and to evaluate the efficiency of the storage process. The US Department of Energy (DOE) and United States Geological Survey (USGS) use volumetric methods to estimate the $\mathrm{CO}_{2}$ sequestration capacity in saline aquifers, abandoned oil/gas wells and unmineable coal seams. ${ }^{13-15}$ These models use macro-scale parameters such as the depth, width, and average porosity of the targeted formation to estimate how much $\mathrm{CO}_{2}$ may be stored. The isotherm adsorption of $\mathrm{CO}_{2}$ on minerals in those formations has also been included in the models. These formations have millidarcyscale permeability and their fluid transport schemes have been studied extensively. However, for shale formations, there is very limited information about detailed geological characterization, such as precise composition characterization, the distribution of pore structure and the heterogeneity of minerals and physical structures. Also, shales have permeability at least 4-5 orders of magnitude lower than other $\mathrm{CO}_{2}$ sequestration targets such as saline aquifers and the migration of $\mathrm{CO}_{2}$ is not well understood. For this reason, the volumetric method is insufficient to evaluate the $\mathrm{CO}_{2}$ storage capacity in shale formations and a new method that is appropriate for shale is needed.

Effective GCS reservoirs will have a large capacity and a low potential for leakage into overlying formations and aquifers. The principal driver for $\mathrm{CO}_{2}$ leakage risks is the buoyant force that results from the density difference between $\mathrm{CO}_{2}$ and the brine in the geological formation. At the depths considered for $\mathrm{CO}_{2}$ injection and storage (deeper than 
$\sim 1 \mathrm{~km}$ ), hydrostatic forces produce pressures greater than $100 \mathrm{bar}$, and thermal gradients result in temperatures greater than $50^{\circ} \mathrm{C} .{ }^{16}$ In shale formations, the pressures and temperatures are even higher $\left(>200 \mathrm{bar}\right.$ and $\left.>80^{\circ} \mathrm{C}\right)$ because normally they are deeper than saline aquifers. Under these conditions, $\mathrm{CO}_{2}$ will exist in the supercritical state but in general it will still be less dense than the connate brines and therefore will be subject to buoyant forces. Although the structural constraints and chemical properties of some formations could provide extra fluid-surface attractive forces to prevent $\mathrm{CO}_{2}$ migration caused by buoyant force, ultimately there will be a persistent buoyant force driving the $\mathrm{CO}_{2}$ toward the surface. ${ }^{5,17}$ Developing viable methods aimed at sealing leakage pathways therefore becomes critical to guarantee the $\mathrm{CO}_{2}$ storage technologies can be deployed efficiently and safely.

\subsection{Research Objective, Scope and Summary of Dissertation}

\subsubsection{Research Objective and Scope}

The objectives of this work are to develop the fundamental chemical and physical understanding of $\mathrm{CO}_{2}$ storage in shale formations with respect to (1) the carbon storage capacity of shale formations and (2) the mitigation of fluid leakage after injection via in situ carbonation reactions. The ultimate goal is to develop a subsurface method that can control the conductivity of fractures and connected pores.

A numerical model based on Fick's law has been developed to estimate the total volume of $\mathrm{CO}_{2}$ that could be injected in the Marcellus and Utica shales. This model uses historical shale gas production data as input and, in order to represent and capture the factors that influence $\mathrm{CO}_{2}$ transport and storage, various physicochemical parameters of 
shale formations are embedded. This is the first time that historical $\mathrm{CH}_{4}$ production data was used to evaluate the $\mathrm{CO}_{2}$ injection volume in the same shale formation. A metaanalysis of published papers with respect to the estimation of $\mathrm{CO}_{2}$ storage volume in depleted shales has been conducted. The results from our numerical model are broadly consistent with other work relevant to $\mathrm{CO}_{2}$ storage capacity in shale and an estimation of the potential of $\mathrm{CO}_{2}$ storage in the major shale formations in US has been conducted. An existing pipeline network model for carbon capture to estimate the economic and logistical viability of this process has been coupled with our numerical model, facilitating its functionality with more realistic factors such as $\mathrm{CO}_{2}$ production rate, carbon price, and pipeline route. ${ }^{18}$

In the laboratory, the viability of stabilizing $\mathrm{CO}_{2}$ in depleted shale formations using silicate mineral carbonation reactions was explored. The experiments were carried out in both sintered glass beads matrices and shale matrices at representative shale formation conditions. Glass beads matrices were used to study the effectiveness of the carbonation reaction in changing of the pore structure and permeability, since the pore structure of sintered beads is stable and any changes of measured porosity and permeability would be concluded to be the result of carbonation. Additionally, the use of shale matrices was included aiming to evaluate the effect of carbonation on "cementing" the mineral matrix. Experimental results have confirmed the carbonation reactivity of silicate minerals at representative shale formation conditions. Additional characterization of these reactions with focus on (1) morphological/compositional change of the minerals and (2) the effectiveness of dissolution/precipitation and the synergies among those reactions as they relate to change in permeability were carried out. 
Collectively, this work contributes to a deeper understanding of the feasibility of $\mathrm{CO}_{2}$ sequestration in shale formations and the viability of in-situ mineral carbonation to mitigate the potential leakage associated with this technology.

\subsubsection{Summary of the dissertation}

This dissertation is composed of six chapters.

Chapter I includes the overall background of this dissertation and a clear definition of the scope and the overarching goal of this work.

Chapter II provides a literature review of the state-of-the-art of (1) GSC technology, the geochemistry/petrophysical background and the risks associated with it; (2) the development of shale gas/oil exploration and its potential as a GCS reservoir; and (3) the interaction of calcium silicate with $\mathrm{CO}_{2}$ in $\mathrm{H}_{2} \mathrm{O}$, such as mineral dissolution/precipitation, carbonation and hydration. The merits and disadvantages of carbonation in the context of GSC and other geotechnical applications are also discussed in this chapter.

Chapter III proposes a new method to estimate the amount of $\mathrm{CO}_{2}$ that can be stored in shale formations. The technique is necessarily different than the techniques used for saline aquifers in that historical $\mathrm{CH}_{4}$ production data is used to derive the chemical/physical parameters that are associated with fluid transport in the formations. It is assumed that these parameters could also be applied to $\mathrm{CO}_{2}$ injection and as a result, the capacity of total $\mathrm{CO}_{2}$ injection was estimated. This model has been applied to both Marcellus and Utica shale formations and it is estimated that the Marcellus shale itself could store more than $1 / 3$ of US $\mathrm{CO}_{2}$ emissions from stationary resources such as power plants. A sensitivity analysis is also conducted of the model. 
Chapter IV presents a meta-analysis of current methods to estimate $\mathrm{CO}_{2}$ storage in US shale formations. The results from various literature sources are widely consistent and it is estimated that totally speaking, storage capacity was found to be on the order of $1 \mathrm{Mt}$ $\mathrm{CO}_{2} /$ well over a 20-year life of a well. Given that overall US emissions are on the order of several Gt/year and hundreds of wells are being drilled each year, GCS in shale has the potential to store a substantial portion of overall US emissions. Much of this storage capacity is geographically concentrated in two regions of the United States and so a major limitation to deploying this technology is the ability to develop a $\mathrm{CO}_{2}$ pipeline distribution network that could link sources and sinks.

Chapter $\mathrm{V}$ focuses on the carbonation and hydration of Ca-bearing silicate minerals in porous media. It is demonstrated that the pressure and temperature conditions in shale formations are suitable for a carbonation reaction to proceed. The dissolution of $\mathrm{Ca}$ bearing silicate is relatively fast and calcite crystals are readily precipitated out. The permeability change of the porous media filled with silicate minerals was measured and found to change by more than one order of magnitude as a result of the carbonation reaction. These experimental results illustrate the effectiveness of carbonation reactions in controlling the fluid flow properties in porous media. Also, the cementitious properties of the carbonate produced in this reaction have been verified in a shale mineral matrix.

This chapter also explores the formation of silicate hydration reactions that occur in parallel with carbonation reactions. The formation of silicate hydrate might proceed from different pathways. Since the structure of hydrate is very porous and it is not enough to change the porosity of the matrix significantly, we suggest its contribution to the permeability of a porous matrix is very limited. In contrast, since the precipitated 
carbonate minerals is more dense and fills smaller pore spaces, it is expected that the synergies between carbonation and hydration could provide a more controllable adjustment of fluid flow in porous media.

Chapter VI proposes several future research directions that build on the work described in Chapters II-V. X-ray tomography and pore network models can be used to explore the dynamics of carbonation/hydration reactions and the underlying schemes of these reactions as they relate to changing the permeability of porous media. Based on current work, polymer coated silicate mineral could be developed to improve the delivery and suspension of the mineral particles in the $\mathrm{CO}_{2}-\mathrm{H}_{2} \mathrm{O}$ interface. Additionally, the temperature-stimuli properties of the polymer will provide more control to the release of silicate minerals at targeted depth within underground formations, allowing better efficacy to realize leakage mitigation in fracture and wellbores. 


\section{CHAPTER II}

\section{LITERATURE REVIEW}

\subsection{Geological Carbon Storage}

Greenhouse gas emission from human activity are driving most of the ongoing changes to our climate. ${ }^{19,20}$ The concentration of carbon dioxide $\left(\mathrm{CO}_{2}\right)$ in the atmosphere keeps increasing and the global annual $\mathrm{CO}_{2}$ emission has increased by almost 3-folds since the 1960s (Figure 2.1). The increase in $\mathrm{CO}_{2}$ concentration is contributing to the elevation of the average temperature of the earth's surface, resulting in sea level rise and desertification among other impacts. ${ }^{21}$ For this reason, there is an urgent need to mitigate the impacts of climate change and develop strategies for achieving deep reductions in greenhouse gas emissions.

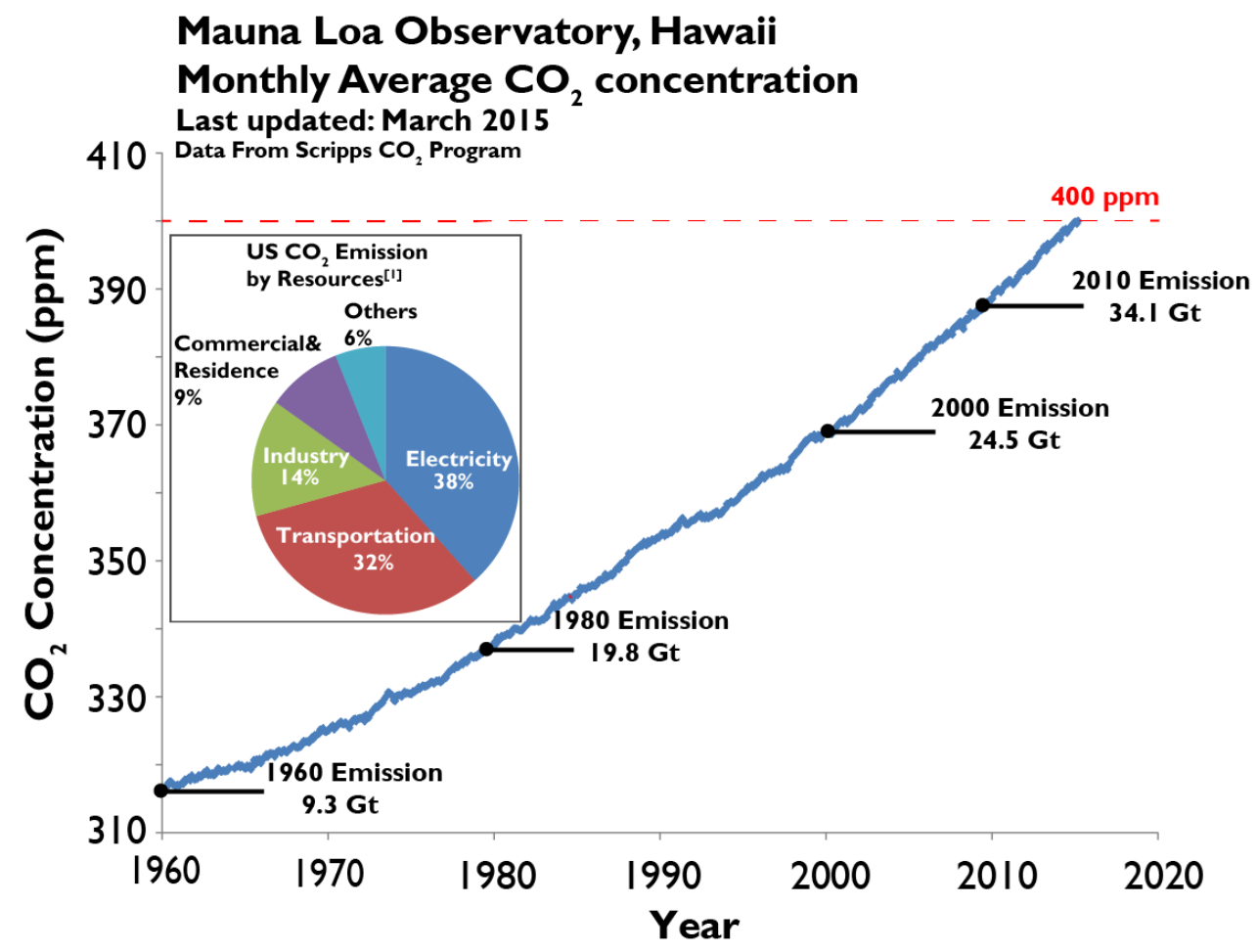

Figure 2.1 Increase of $\mathrm{CO}_{2}$ concentration in atmosphere. Inset: $\mathrm{US} \mathrm{CO}_{2}$ emission by resources. Data from Scripps $\mathrm{CO}_{2}$ program and Mauna Loa Observatory, Hawaii, US. 
Geological Carbon Storage (GCS) involves the injection of large volumes of $\mathrm{CO}_{2}$ into underground geological formations that would otherwise be released into the atmosphere as a byproduct of human activity, such as power plants. It is believed to be an attractive method to mitigate carbon emissions from anthropogenic activities. Its adoption would enable the continued use of fossil fuels in the short- and medium-term and because the storage capacity of underground formations is so large that it can be scaled effectively. ${ }^{1,3,4,22}$ Large emission sources such as power plants, which contribute more than $1 / 3$ of carbon emissions in US, would be the primary targets because of their capacity to provide significant amounts of concentrated $\mathrm{CO}_{2}$. Saline aquifers, depleted oil\&gas reservoirs and unmineable coal seams have all been explored as targets for carbon storage, as shown in Figure 2.2. ${ }^{13-15}$ Normally, $\mathrm{CO}_{2}$ is compressed above ground and injected to a depth of $1-2 \mathrm{~km}$ below the surface, where the pressure and temperature is beyond the supercritical point of $\mathrm{CO}_{2}\left(7.2 \mathrm{MPa}\right.$ and $\left.37^{\circ} \mathrm{C}\right){ }^{3,5,6} \mathrm{It}$ is estimated that up to 10,000 gigatons of $\mathrm{CO}_{2}$ could be stored globally in geological formations. ${ }^{23,24}$ 


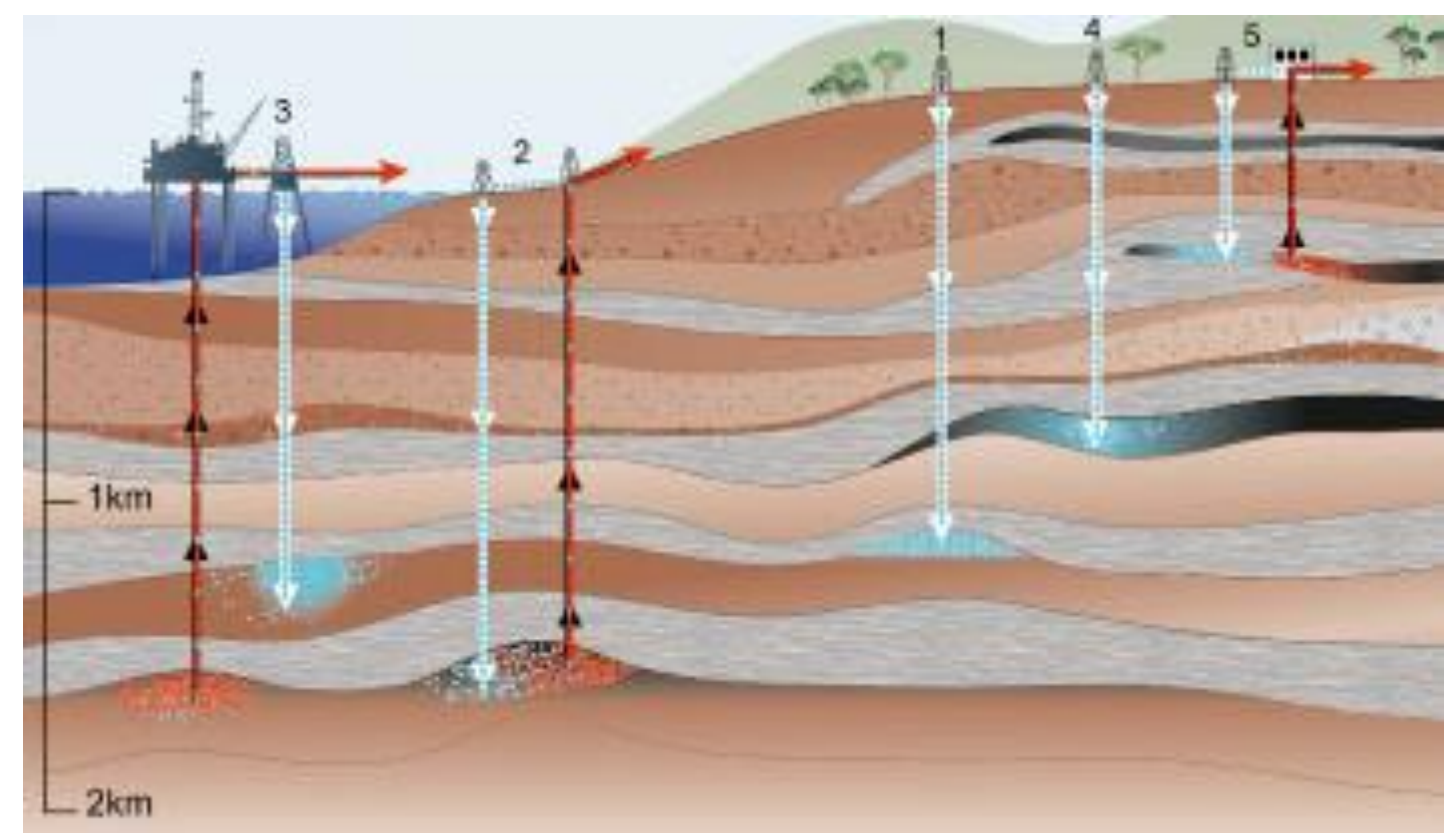

Figure 2.2 Underground $\mathrm{CO}_{2}$ injection scenarios: 1. Depleted oil and gas reservoirs; 2 . Enhanced oil recovery; 3. Deep unused saline water-saturated reservoir rocks; 4 . Deep unmineable coal seams; 5 . Enhanced coal bed methane recovery. Derived from Metz et al. ${ }^{1}$

There are several trapping mechanisms associated with $\mathrm{CO}_{2}$ storage. ${ }^{1}$ Figure 2.3

combines the schematic of different trapping mechanisms and the associated time scale for each of them. The first mechanism is called structural trapping. After injection, supercritical/liquid $\mathrm{CO}_{2}$ will stay above connate brine as a discrete phase due to buoyancy but beneath low-permeability caprocks. Normally, an ideal carbon storage reservoir of this kind requires a caprock, performing as a boundary and sealing layer aiming to prevent the leakage of $\mathrm{CO}_{2}$ caused by buoyancy. ${ }^{3,4}$ When $\mathrm{CO}_{2}$ moves to deadend pores in porous media or in very narrow fractures or pore structures, it may be trapped in the limited space because of fluid surface attractive forces, such as capillary forces. ${ }^{25,26}$ This is another trapping mechanism called residual/capillary trapping. A third mechanism by which $\mathrm{CO}_{2}$ can become permanently immobilized is the dissolution of $\mathrm{CO}_{2}$ into pore water. $\mathrm{CO}_{2}$ is reactive with $\mathrm{H}_{2} \mathrm{O}$ and will dissolve into the pore water 
creating carbonic acid and other dissolved carbonate species at concentrations that are a function of temperature, pressure, and pore water composition. This $\mathrm{CO}_{2}$ will remain in the aqueous phase, which usually has migration rates on the order of centimeters to meters per year. Pilot-scale carbon injection programs such as Sleipner in the North Sea and In Salah at northern Africa have been proven to be effective in accepting $\mathrm{CO}_{2}$ at a rate of more than $1 \mathrm{Mt}$ per year. ${ }^{27}$ Residual trapping and dissolution trapping are the primary mechanisms for storage in these pilot programs. When dissolved carbonates react with various divalent cations such as $\mathrm{Ca}^{2+}$ and $\mathrm{Mg}^{2+}$ to form metal carbonates which would precipitate out of solution and form carbonate minerals, another mechanism called mineralization occurs. ${ }^{28-30}$ Since the liquid phase $\mathrm{CO}_{2}$ is converted to more stable solid phase mineral, this mechanism is considered to be the safest among the different mechanisms. Recently, the FixCarb program in Iceland and the Big Sky Carbon Sequestration Partnership in Washington has demonstrated that the injection of $\mathrm{CO}_{2}$ into basalt formations could be converted to solid carbonate mineral within 2 years as a permanent storage solution, ${ }^{31}$ which is much more faster than pervious understanding about the time scale for mineral trapping. 


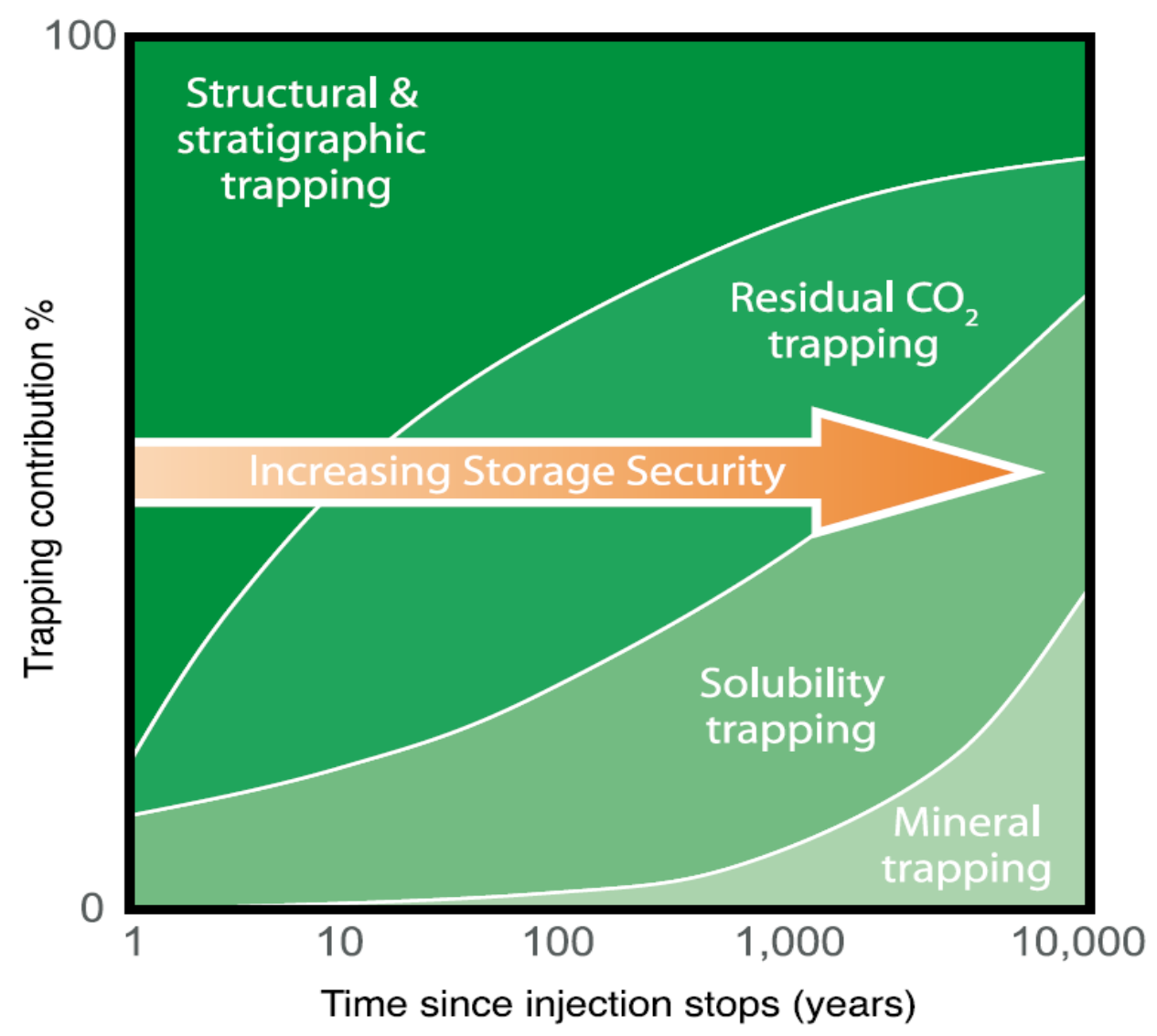

Figure 2.3 The time scale of different GCS mechanisms. Derived from Metz, et al. ${ }^{1}$

\subsection{Ges Risks}

\subsubsection{Seepage and Leakage}

Sedimentary basins have distinct geothermal gradients, and because density differences between $\mathrm{CO}_{2}$ and water drive buoyancy driven flow, these gradients will impact the leakage rate at a particular $\mathrm{CO}_{2}$ storage site. For example, as depicted in Scenario 'a' in Figure 2.4, a fluid injected into the deep surface (the dark black circles indicate $\mathrm{CO}_{2}$ reservoir conditions) will have buoyant forces acting on a rising bubble of $\mathrm{CO}_{2}$. This force may increase as the $\mathrm{CO}_{2}$ expands from the supercritical state to subcritical conditions (i.e., either $\mathrm{CO}_{2}(\mathrm{l})$ or $\left.\mathrm{CO}_{2}(\mathrm{~g})\right) .{ }^{32,33}$ In Scenario ' $\mathrm{b}$ ' of Figure 2.4, the $\mathrm{CO}_{2}$ would also pass through the liquid phase with complex effects on fluid properties. Note 
that both of these scenarios are independent of the leakage pathway (e.g., wellbore, fault, etc.). The density data included in Figure 2.4 illustrates the potential for nonlinear differences between the density of the brine and the $\mathrm{CO}_{2}$ due to the complex relationship between density and phase behavior. Depending on the geothermal gradient, some parcels of $\mathrm{CO}_{2}$ will transition from $\mathrm{CO}_{2}(\mathrm{sc})$ to $\mathrm{CO}_{2}(\mathrm{~g})$ directly. In other regions it will pass through the liquid phase first. ${ }^{34}$ In all cases, the temperature will decrease, increasing the density difference between $\mathrm{CO}_{2}$ and brine as the fluid gets closer to the surface, effectively increasing the buoyant forces driving the $\mathrm{CO}_{2}$ towards the surface.

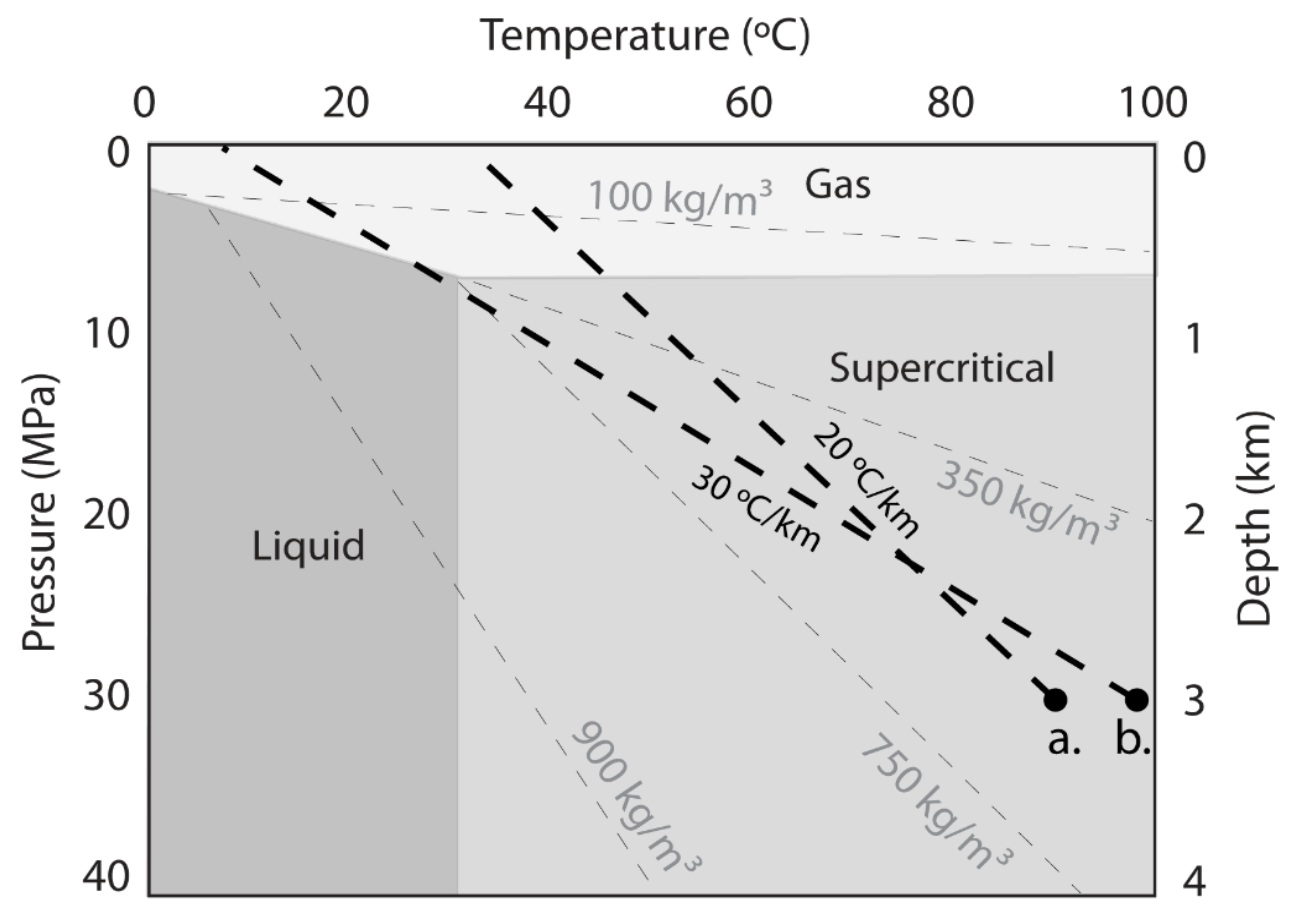

Figure 2.4 Site-specific geothermal gradients and the depth of the target repository will influence the buoyant driving forces that cause $\mathrm{CO}_{2}$ to migrate toward the surface.

$\mathrm{CO}_{2}$ injection could, under certain conditions, exacerbate concerns related to seepage and leakage from shale formations and this would undermine the goal of sequestering $\mathrm{CO}_{2}$. Reservoir expansion, fracturing of seal caprock, seismicity and well bore failure could all be possible reasons of fluid leakage, as suggested by Verson et al. ${ }^{27}$ Ellis et al. reported the 
deterioration of a fractured carbonate caprock in contact with $\mathrm{CO}_{2}$-acidified brine. ${ }^{35}$ They observed mineral dissolution and the increase of fracture opening after one week of exposure. Harvey et al. reviewed the influence of elevated $\mathrm{CO}_{2}$ concentration in the vadose zone and found that the $\mathrm{CO}_{2}$ could, under different circumstances, lead to either immobilization or desorption of some contaminations and would therefore have a very sitespecific impact on the environment. ${ }^{36}$

Aside from direct leakage of $\mathrm{CO}_{2}$, the migration of produced flowback fluid from fractured shale gas/oil wells is also of public concern. The chemical components of hydraulic fracking fluid not only include various elements such as chloride, bromide, strontium, iron, manganese, ${ }^{36}$ but also contains toxic or radioactive constituents such as arsenic, barium and radium. ${ }^{37}$ Recent works suggest that near-surface groundwater bodies do face contamination risk from fracturing operations and that shallow groundwater can be contaminated by leaks from deeper shale formations. ${ }^{37-40}$ Although these target formations are more than $1 \mathrm{~km}$ below the surface, leakage from them into the near surface aquifers is still possible, given enough time for the leakage to develop and impact the shallower formations.

In general, a strategy to minimize leakage of $\mathrm{CH}_{4}, \mathrm{CO}_{2}$ and fracturing chemicals into overlying groundwater resources is a major priority for mitigating the risks from hydraulic fracturing and $\mathrm{CO}_{2}$ sequestration. To date no strategy has been proposed that would mitigate these risks when they emerge from the target repository itself as opposed to the wellbore. 


\subsubsection{Seismicity Risk}

A major source of concern associated with GCS or even wastewater injection is induced seismicity that can result from fluid injections into the deep subsurface. ${ }^{41}$ An earthquake with magnitude 5.7 M was recorded in 2011 in Oklahoma and was believed to be caused by water injection, although most of the induced seismicities that have been recorded near

fluid injection sites have been mild (registering 2-3 M). ${ }^{42}$ The cause and effect relationship between fluid injections and seismicity are poorly understood and different regions naturally respond differently to the injections. ${ }^{27}$ At the Sleipner site in the North Sea off the Norwegian coast where large-scale $\mathrm{CO}_{2}$ injections have been underway for a number of years, only modest pressure gradients have been observed with little seismic activity. In contrast, the Weyburn and In Salah fields, both of which have received $\mathrm{CO}_{2}$ injections on the order of $>1 \mathrm{MT} /$ year, showed significant pressure build up, seismicity, and modification of the subsurface environment, such as geo-mechanical deformation.

\subsection{Shale Gas Production}

During the last decade, unconventional oil and gas exploration from shale formations has created a boom in domestic energy production. This kind of development is known popularly as "fracking" and it is benefited by the advancement of two critical technologies: ${ }^{43,44}$ directional drilling and hydraulic fracturing. The shale layer, which contains oil and gas, is not thick (up to a hundred meters) because of its sedimentary nature. Directional drilling increases the flexibility of the drilling bit to allow operators to precisely reach to the shale layer and enable contact with more of the horizontal bedding plane of the formation. As shale is very tight (the permeability of shale is 4-5 orders of magnitude lower than traditional oil/gas production formations or GCS storage 
formations), hydraulic fracturing is used to crack the rock with high volume and high pressure water and access the hydrocarbons that would otherwise move slowly through the low permeability material. Proppants, typically sand or ceramic beads, are used to keep the fractures open during fracture fluid flowback and hydrocarbon production stages since the shale formation is always very deep ( 1-3 km or deeper $)$ and the hydrostatic pressure could be more than $200 \mathrm{~atm} .{ }^{45}$ Figure 2.5 illustrates a typical shale production scheme. As the production proceeds and the hydrocarbons are depleted, secondary or tertiary fracking is normally needed to create new fractures, aiming to boost production. Enhanced oil recovery (EOR) is also used to increase the production of an already existed well. $^{46}$

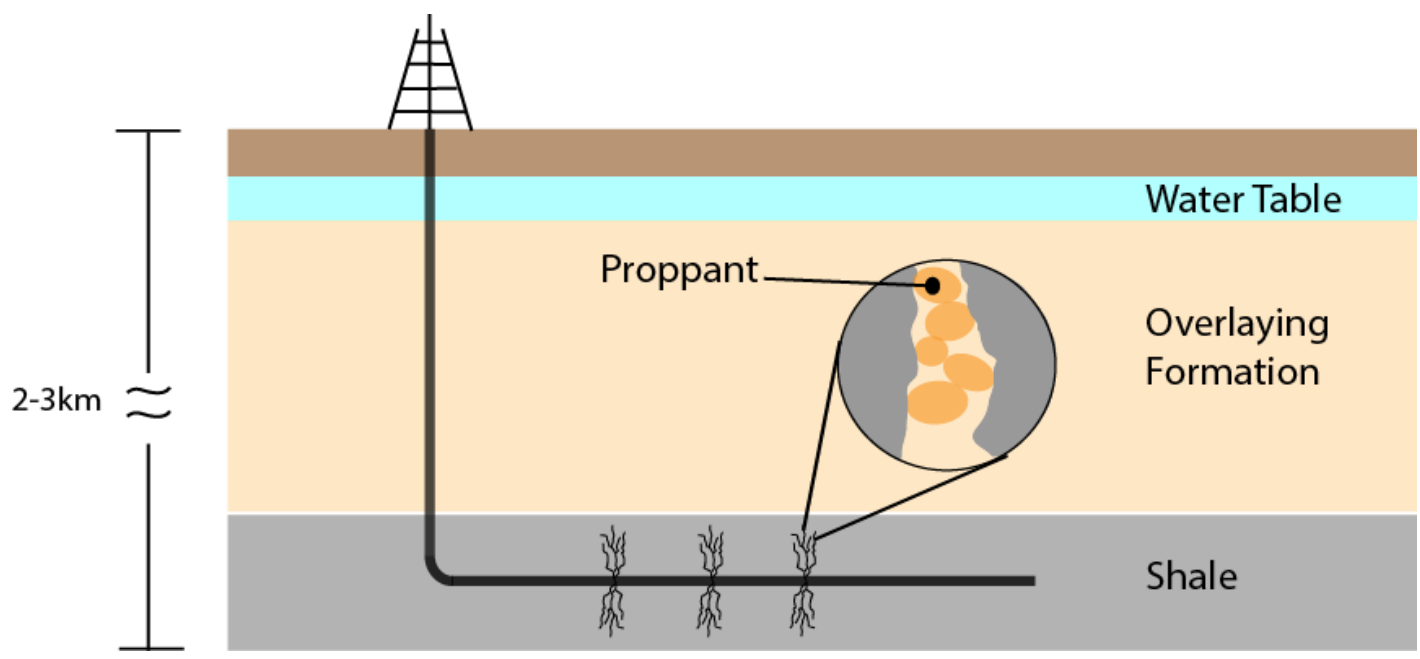

Figure 2.5 Schematic of shale gas production. A typical shale well normally reaches to shale layer 2-3 km underground. Initial fractures are created through perforation and hydraulic fracking is followed to created fracture networks. Proppants are used to keep the fractures open under hydrostatic pressure.

Worldwide, the US, China, and Argentina have the largest shale reserves. In the US, the first large-scale deployment of fracked wells occurred in the Marcellus shale in Pennsylvania at 2005 and many of those wells are still in active production or could have 
the capacity to resume production in a very short period of time. ${ }^{12}$ Since then, many thousands of wells have been drilled across the country. One U.S. government estimate projects that by $2035,50 \%$ of the natural gas consumed in U.S. will be produced from shale, ${ }^{47}$ as shown in Figure 2.6. In the US, there are currently six primary shale gas formations that are producing oil/gas actively and they are Marcellus (PA), Fayetteville (IN), Eagle Ford (TX), Woodford (TX), Haynesville (TX) and Barnet (TX). Although the fluctuation of energy prices could make the production from some areas uneconomical, the extraction of hydrocarbons from shale formations has the advantage that the production procedure could be stopped and resumed quickly within several days. At the same time, advances in directional drilling allow longer production area within the lateral shale formation, which effectively decreases the production cost. As such, oil and gas production from shale will likely remain robust in the near future. 


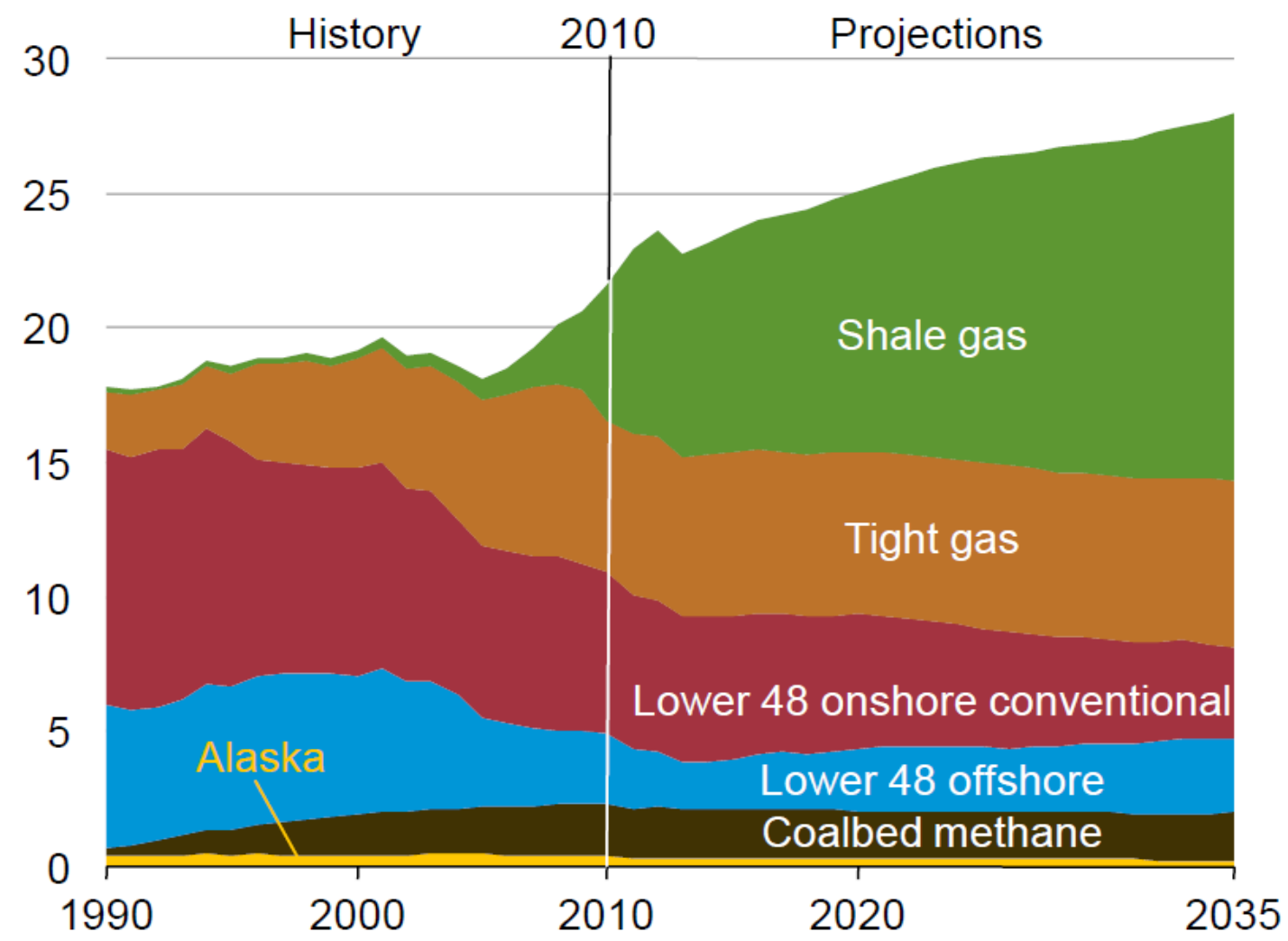

Figure 2.6. US Shale gas production projection to 2035. Modified from U.S. EIA Annual Energy Report. ${ }^{47}$ Unit: trillion cubic feet.

\subsection{Chemical/Physical Properties of Shale Gas Formation}

Shale is composed of both organic and inorganic materials. The main component of shale formations is low permeability sedimentary rocks with highly variable mineral composition of compacted clays, quartz, feldspar and carbonates. ${ }^{48,49}$ The clays (primarily illite, smectite, and kaolinite) as well as the quartz are largely unreactive under carbonation conditions. ${ }^{50}$ Minor components in the shale, including feldspars, sulfide and dolomite are more likely to react with $\mathrm{CO}_{2} \cdot{ }^{51}$ Figure 2.7 summarizes the inorganic mineral content in several different shale formations in US. The organic component of the shale is derived from plant matter and occupies up to $10 \%$ of its total weight. ${ }^{50}$ The pores within this kerogen matrix hold the majority of the hydrocarbons. ${ }^{52}$ Since the rocks 
containing kerogen were heated to $150{ }^{\circ} \mathrm{C}$ to $200{ }^{\circ} \mathrm{C}$, and hydrocarbons are released from the kerogen pores, this rock is also called "source rock". Kerogen is composed primarily of aliphatic, alicyclic, and hydroaromatic hydrocarbons. ${ }^{53}$ Most of the hydrocarbonproducing shales in the U.S. are deeper than $1000 \mathrm{~m}$. The porosity of shale formation is up to $10 \%$ and the pore sizes are widely distributed with most being nano- and mesopores ${ }^{54}$ For this reason, it is considered that the shale formation is a dual-pore system. The intrinsic permeability of shale formations is in the range of $10^{-3}$ microdarcy $(\mathrm{uD})$ to 1 uD. As a comparison, conventional oil and gas reservoirs and tight gas reservoirs have permeability 5-6 orders of magnitude higher than shale. Because of this, shale formations have traditionally been considered an effective "caprock" to overlay $\mathrm{CO}_{2}$ sequestration reservoirs such as saline aquifers, instead of being the storage target itself. However, once the shale has undergone "fracking", the artificial fractures would hold the opening in the range of $\mathrm{mm}$ to $\mathrm{cm}$, increasing the permeability of the shale formation dramatically. 


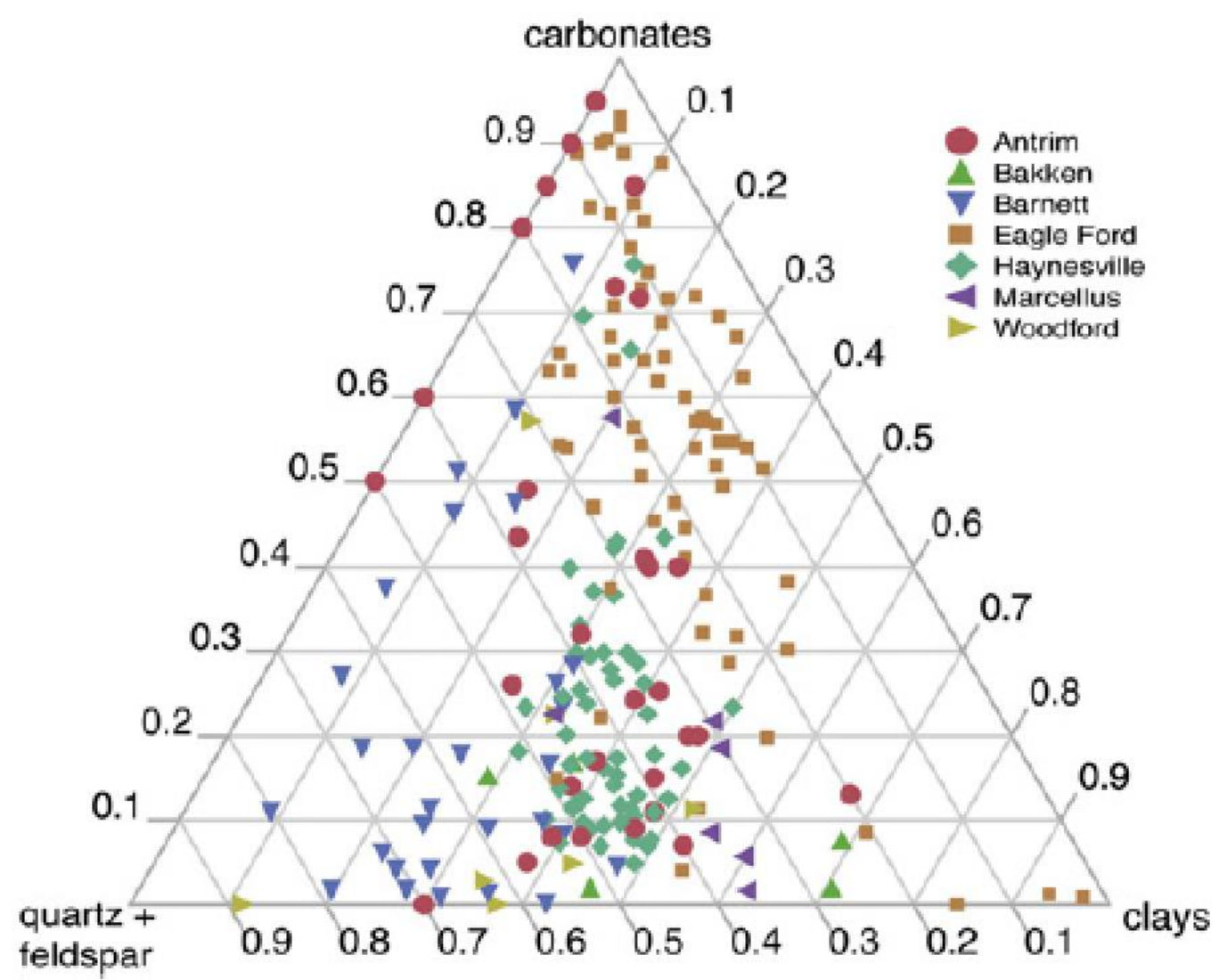

Figure 2.7 The content of the principal species (quartz + feldspar, carbonate, and clay) in the principle shale formations in the United States. Adapted from Chermak et al. ${ }^{50}$

\section{$2.5 \mathrm{CO}_{2}$ Storage in Shale Gas Formation}

GCS is attractive as it can be scaled up to store gigatons (Gt) of carbon each year for many years. ${ }^{22}$ Recently voiced concerns about the cost, ${ }^{6}$ long-term security, ${ }^{34}$ impact on seismicity, ${ }^{55}$ and logistics ${ }^{56}$ of sequestration in saline aquifers have caused some to question the viability of this pathway. As a result, recent efforts have focused on identifying new target formations that may overcome some of these obstacles to GCS deployment.

Unconventional fossil fuels, such as tight oil and coalbed methane extraction are receiving increased interest in a GCS context because of the opportunity to leverage economic benefits and existing infrastructure. ${ }^{57,58}$ The leading examples of such efforts is 
enhanced oil recovery (EOR), wherein $\mathrm{CO}_{2}$ is used to reduce the viscosity and interfacial tension of crude oil, i.e., tight oil, to increase recovery rates ${ }^{59}$ EOR can typically increase production from a reservoir by $30-60 \%,{ }^{60}$ along with a concomitant trapping of $\sim 60 \%$ of the injected $\mathrm{CO}_{2} \cdot{ }^{57,61}$ In $\mathrm{CO}_{2}$-enhanced coalbed methane $\left(\mathrm{CO}_{2}-\mathrm{ECBM}\right)$ production, $\mathrm{CO}_{2}$ is introduced into deep unmineable coal seams to preferentially desorb $\mathrm{CH}_{4}$ and stimulate production of natural gas while permanently storing some $\mathrm{CO}_{2}$ on the mineral surfaces. ${ }^{62}$ There are technical hurdles associated with $\mathrm{CO}_{2}$-ECBM, namely, that coal swells in the presence of $\mathrm{CO}_{2}$ and this can reduce fluid flow through the formation over time. ${ }^{63}$ In both EOR and $\mathrm{CO}_{2}-\mathrm{ECBM}$, fossil fuel extraction is aided and carbon is permanently bound in the reservoir or coal seams. Even though both of these strategies have some potential to sequester $\mathrm{CO}_{2}$, the magnitude is much smaller than current or projected $\mathrm{CO}_{2}$ emissions. ${ }^{57}$ $\mathrm{CO}_{2}$-ECBM sequestration potential is not yet thoroughly characterized and the total US consumption of $\mathrm{CO}_{2}$ via EOR is on the order of 0.5 gigatonnes, ${ }^{46}$ much lower than the total US annual emissions rate of approximately 5 gigatonnes/year. ${ }^{47}$

Shale formations are much more extensive than deep unmineable coal seams or depleted oil reservoirs but they have not been discussed for the purposes of carbon sequestration for several reasons. First, they are largely impermeable formations that restricts fluid transport until the widespread deployment of hydraulic fracturing and horizontal drilling. ${ }^{47}$ In hydraulic fracturing, pressurized fluid is applied to shale to create an artificial fracture network to extract oil and gas. The basic concept has existed for decades but the recent boom is driven by market conditions and technological advancements in the formulation of fracturing fluid chemistry and horizontal drilling, which enables contact with more of the shale formation. ${ }^{64}$ Second, the field 
implementation of fracturing is generally outpacing fundamental science associated with this technology. Research has been conducted with the relevant transport processes and it is understood that after fracturing, a rapid release in interpore methane is followed by a more steady desorption of methane from kerogen surfaces. ${ }^{65}$ Kerogen is the organic material found in sedimentary rock and it constitutes the majority of the solid phase total organic content (TOC) in shale formations. ${ }^{52}$ At the pore or fracture surface, kerogen is important because it controls gas adsorption capacity and numerous studies have shown a clear proportionality between the total organic content of a formation and its gas adsorption capacity. ${ }^{54}$ Despite this basic understanding, shale formations vary considerably in composition and structure and a complete phenomenological understanding of natural gas (written as $\mathrm{CH}_{4}$ in this paper) desorption and transport has not been developed.

Zhou et al. and Szulczewski et al. separately proposed methods to estimate the $\mathrm{CO}_{2}$ storage capacity in saline aquifers. ${ }^{13,14}$ These methods are based on the available brine volume that can be replaced by $\mathrm{CO}_{2}$. These estimates are complicated by the compressibility of $\mathrm{CO}_{2}$ and the fact that its fluid properties are impacted by pressure and temperature profiles at depth. Perhaps the most comprehensive methodology for estimating sequestration capacity comes from the US Department of Energy (US DOE), which developed a model for calculating $\mathrm{CO}_{2}$ sequestration capacity in saline aquifers, coal seams, and depleted oil and gas fields. ${ }^{15,66}$ This model is based on volumetric estimates but provides considerable detail regarding the effective pore space that $\mathrm{CO}_{2}$ can flow into. The DOE model also considers water saturation, porosity and an effective 
storage efficiency factor which considerably increases the data requirements of the model.

Nuttall et al. showed that Devonian shale formations in Kentucky were a highly attractive target formation for carbon sequestration. ${ }^{10}$ Weniger proposed a similar method for the Paraná Basin in Brazil. ${ }^{11}$ Both were early attempts to bound the capacity but probably missed some of the key transport phenomena in the highly heterogeneous fractured shale matrix. Busch et al. supported these claims with column experiments in which they report that unfractured shales have a much greater $\mathrm{CO}_{2}$ adsorption capacity than similar materials that have been explored for sequestration (e.g., coal). ${ }^{8}$ Gas sorption experiments on crushed shale samples by both groups under representative conditions suggest that a high concentration of organic kerogen with methane sorbed to the surface leads to preferential partitioning and immobilization of $\mathrm{CO}_{2}$. Most recently, Kang et al. provided a mechanistic description of $\mathrm{CO}_{2}$ uptake into shales. ${ }^{9}$ They supported the macroscale sorption characteristics identified in previous studies and suggest that the pore geometry, particularly the nanopores of kerogen, can create a molecular sieve in which $\mathrm{CO}_{2}$ can reside, but many other molecules cannot. They emphasized that even though there are similarities between coal and shale in terms of sequestration potential, the uptake processes are much different. The abundance of shales, relative to deep coal seems, supports continued research in this area.

Even though these studies support the viability of using shale formations as repositories for $\mathrm{CO}_{2}$, the literature is limited in a few key areas. Existing analyses are based on ground samples of shale and TOC percentage relative to the total mass of ground sample. ${ }^{8,10}$ Such analyses are limited in predicting the sequestration capacity of a real formation 
because 1) the amount of kerogen (or TOC) that is available for gas exchange at the fracture surface could be different than the amount of total kerogen in the sample; 2) the amount of kerogen in a formation may vary considerable in space; and 3) the exact mass of the formation is difficult to know with any accuracy. ${ }^{11}$ Additionally, the kinetics of $\mathrm{CO}_{2}$ reinjection into geologic formations have not yet been investigated. Injection kinetics have been explored in the context of GCS into saline aquifers. Most of these studies reported that injection of $\mathrm{CO}_{2}$ into sequestration site formations is a nonlinear process wherein both physical and chemical phenomena will control the ultimate sequestration potential. ${ }^{67}$ However, in shale formations, large volumes of pore and fracture space will have been recently vacated during the production phase of the well. ${ }^{68}$ There are also differences in the long-term performance of horizontal and vertical wells. Horizontal wells contact more of the shale formation and consequently increase the subsurface production area of the well with a land footprint that is comparable to a vertical well. ${ }^{69}$ Finally, the role of pressure and temperature conditions, as well as the presence of water in and around the shales formation will impact sequestration potential given how sensitive $\mathrm{CO}_{2}$ density is to pressure near its critical point.

\subsection{Carbonation Reaction}

Mineral carbonation has been studied extensively as a strategy for capturing and storing $\mathrm{CO}_{2} \cdot{ }^{28,70}$ For example, it is considered that $\mathrm{CO}_{2}$ produced from power plants could be captured by silicate minerals. Calcium, magnesium, and iron-bearing silicates (e.g., $\mathrm{CaSiO}_{3}, \mathrm{MgSiO}_{3}$, or $\mathrm{FeSiO}_{3}$ ) react with $\mathrm{CO}_{2}$ at high pressures and temperatures to produce stable solid carbonate products, as shown in Equation 2.1. ${ }^{71}$ 


$$
\begin{array}{ll}
\mathrm{MSiO}_{3(\mathrm{~s})}+\mathrm{CO}_{2(\mathrm{l}, \mathrm{SC})} \rightarrow \mathrm{MCO}_{3(\mathrm{~s})}+\mathrm{SiO}_{2(\mathrm{~s})} & \text { Equation } 2.1 \\
\text { where } \mathrm{M}=\mathrm{Ca}, \mathrm{Mg}, \mathrm{Fe} \ldots & \\
\mathrm{CO}_{2}+\mathrm{H}_{2} \mathrm{O} \leftrightarrow \mathrm{H}_{2} \mathrm{CO}_{3} & \text { Equation } 2.2 \\
\mathrm{H}_{2} \mathrm{CO}_{3} \leftrightarrow \mathrm{H}^{+}+\mathrm{HCO}_{3}^{-} & \text {Equation } 2.3 \\
\mathrm{HCO}_{3}^{-} \leftrightarrow \mathrm{H}^{+}+\mathrm{CO}_{3}^{2-} & \text { Equation } 2.4 \\
\mathrm{CaSiO}_{3}+\mathrm{H}^{+} \rightarrow \mathrm{Ca}^{2+}+\mathrm{SiO}_{2(\mathrm{am} \mathrm{aq})}+\mathrm{H}_{2} \mathrm{O} & \text { Equation } 2.5 \\
\log \mathrm{K}=9.8 \text { at } 120^{\circ} \mathrm{C} & \\
\mathrm{Ca}^{2+}+\mathrm{CO}_{3}^{2-} \rightarrow \mathrm{CaCO}_{3} & \\
\operatorname{logK=8.5} \text { at } 120^{\circ} \mathrm{C} & \text { Equation } 2.6 \\
\mathrm{CaCO}_{3}+\mathrm{H}^{+} \rightarrow \mathrm{Ca}^{2+}+\mathrm{HCO}_{3}^{-} & \\
\log \mathrm{K}=0.5 \text { at } 120^{\circ} \mathrm{C} &
\end{array}
$$

A more detailed description of carbonation reaction is shown in Equation 2.2-2.6. $\mathrm{CO}_{2}$ combines with $\mathrm{H}_{2} \mathrm{O}$ first to form carbonic acid, which would disassociate and release protons, as shown in Equations 2.2-2.4. The protons will then attack the silicate minerals and as a result, cations such as $\mathrm{Ca}^{2+}$ or $\mathrm{Mg}^{2+}$ are leached out from the silicate structure, together with the formation of amorphous silica, shown in Equation 2.5. Following this step, the cations combine with $\mathrm{CO}_{3}{ }^{2-}$, which is released from Equation 2.5, to form carbonate (Equation 2.6). If $\mathrm{pH}$ is kept low, the carbonate minerals would still be subject to dissolving, as shown in Equation 2.7. However, when $\mathrm{pH}$ is higher, carbonate exists as a stable phase..$^{72}$ 
Even though mineral carbonation is considered a safe and permanent means of storing $\mathrm{CO}_{2}$, the energy and logistical burdens have prevented its wide scale adoption. ${ }^{73}$ For exsitu carbonation reaction, the processing of solid carbonate minerals after carbonation would increase the economic costs. Alternatively, in-situ mineral carbonation has been proposed since, once $\mathrm{CO}_{2}$ is injected in the formation and is carbonated, there are no further logistical issues associated with it. Also, the temperature and pressure in underground formations are suitable for the carbonation to occur automatically, which does not need extra energy to catalyze the reaction, like that needed in ex-situ carbonation. Work by Keleman and Matter has shown that geologic formations could be used for in situ mineral carbonation. ${ }^{74}$ In these formations, where only natural fracture networks exist, the mineral precipitation reactions resulted in an increase in permeability because the dissolution/precipitation chemistry within the rock led to complex geochemistry with unexpected outcomes. Understanding the geochemistry of seed mineral injections is likely to result in different, but equally complex, interactions with the host formation. Shale also contains toxic metals and radionuclides, and high concentrations of arsenic, barium, and radium in drill cuttings and flowback wastewater, ${ }^{75}$ arguing for the need to inhibit their mobilization, ideally permanently immobilizing them within the shale formation.

\section{7 $\mathrm{CO}_{2}$-induced Structural Change of Porous Media}

An area of research in $\mathrm{CO}_{2}$-mineral interaction and its effect on flow is focused on the fractured mineral matrix. Primarily, these studies investigate fractured carbonate rock, which act as the caprock above $\mathrm{CO}_{2}$ storage reservoirs, or fractured cement, which is widely used as the primary sealing component in wellbores. Work from Ellis et al. 
indicates that the $\mathrm{CO}_{2}$-mineral interaction in a fractured carbonate caprock material could cause a decrease in permeability due to the mobilization of the less soluble minerals in the matrix into the fractures, induced by the dissolution of the soluble minerals such as calcium and magnesium carbonate. ${ }^{35}$ Further, some of the minerals used as proppants dissolve and the closing of these conduits contributes to the decrease of permeability as well. Huerta et al. carried out the examination of acid flow in a fractured cement core. Depending on flow rate and $\mathrm{pH}$ of the injected fluid, fractures could be created or sealed, causing an increase or decrease in permeability. ${ }^{76}$ For example, the rapid dissolution/precipitation happening at the beginning of the acid injection could create a dead end pore that would divert fluid and as a result, generate a new pathway or fracture. This work indicates that the heterogeneity of the porous media contributes significantly to the structural change of the pores or fractures when acidic fluid (e.g., $\mathrm{CO}_{2} / \mathrm{brine}$ ) is present. Thus, the permeability change is subject to various factors such as $\mathrm{pH}$, mineral composition, porous media morphology, and time.

Another topic that has drawn increasing interest is $\mathrm{CO}_{2}$ storage in basalt rock because of its large volume globally and high reactivity with $\mathrm{CO}_{2} \cdot{ }^{31,74,77}$ Generally, basalt rocks contain silicate-based minerals that are rich in calcium $(\mathrm{Ca})$, magnesium $(\mathrm{Mg})$, and iron (Fe); for example, augite, plagioclase and olivine. Under temperature and pressure conditions that are representative of basalt formations, carbonation reactions could readily occur. Work from Sissmann et al. ${ }^{78}$ indicates that carbonation in an olivine-rich basalt rock is faster than in pure olivine, primarily because miscellaneous components in basalt such as Fe-bearing silicate which hinders the formation of an impermeable secondary silica layer. This is the opposite of the pure olivine scenario with the 
impermeable secondary silica layer blocking further reaction of silicate mineral. As a result, sufficient $\mathrm{CO}_{2}$ can still transfer to the reactive silicate surface under the silica layer, sustaining the kinetics of carbonation reaction. Pilot scale projects such as CarbFix and BSCSP have demonstrated the success of carbon injection into basalt formations with rapid conversion of $\mathrm{CO}_{2}$ into carbonate as a permanent storage method. ${ }^{31,79}$ However, one of the biggest challenges of in-situ carbonation is to maintain reasonable conductivity during $\mathrm{CO}_{2}$ injection. It is suggested that the in-situ carbonation reaction is self-limiting because the volume of the solid phases may increase by up to $50 \%$ after reaction products (carbonate as well as secondary silica) fill the pore space or cover some portion of reactive surface of silicate minerals. ${ }^{74} \mathrm{As}$ a result, the $\mathrm{CO}_{2}$-silicate interaction would be hindered. On the other hand, Zhu et al. suggested that reaction-induced fractures could be generated by the expansion of the precipitates.$^{80}$ Andreani et al. reported the increase of permeability when $\mathrm{CO}_{2}$ reacted with a peridotite matrix. ${ }^{81}$ During the injection of $\mathrm{CO}_{2} /$ brine solution, the heterogeneity of the mineral matrix created a preferential flow pathway that helped maintain and even increase the permeability, although the porosity decreased and the volume of minerals increased. All of the studies above illustrate the complexity of fluid flow in carbonate/silicate mineral matrices, with respect to the extent of carbonation, change of porosity and permeability, as well as the creation of fractures.

Studies of carbonation reactions occurring in idealized, synthetic porous media have also been carried out. Zhang et al. conducted transverse mixing induced $\mathrm{CaCO}_{3}$ precipitation in a micromodel from fabricated silicon. ${ }^{82}$ Different crystal structures of $\mathrm{CaCO}_{3}$ were observed to precipitate along the flow direction when $\mathrm{CaCl}_{2}$ and $\mathrm{CaHCO}_{3}$ flowed together in the micromodel. As a result, the porosity of the matrix decreased and it was 
projected that the permeability decreased as well. Jones et al. measured the carbonation precipitation in a borosilicate glass-based aperture fracture system with different aperture structure, aperture minerology, and surface smoothness. ${ }^{83}$ It was found that precipitated $\mathrm{CaCO}_{3}$ only occupies a small portion of the fracture surface in the preferential flow pathway. Also, the precipitation rate is controlled by local heterogeneity of the aperture and the measured carbonation speed is lower than the ideal case. As a result, the estimated time to seal a fracture or pore structure needs to be prolonged by several folds.

\subsection{Calcium Silicate Hydrate (C-S-H)}

Hydration of silicate minerals, particularly Ca-silicate, has been extensively studied because it is the primary reaction that takes place when cement is mixed with $\mathrm{H}_{2} \mathrm{O}$ during the production of concrete. ${ }^{84,85}$ Tricalcium silicate $\left(\mathrm{Ca}_{3} \mathrm{SiO}_{5}\right.$, abbreviated as $\left.\mathrm{C}_{3} \mathrm{~S}\right)$ constitutes between $50 \%$ and $70 \%$ of the raw mass in typical Portland cement and is often used as the representative species during experimental or modeling studies. Dicalcium silicate $\left(\mathrm{Ca}_{2} \mathrm{SiO}_{4}\right)$ normally contributes another $20 \%-30 \%$ wt of a cement. ${ }^{86}$ The structure of calcium silicate hydrate can be poorly crystalized, which is the dominant case in cement hydration, or have an ordered structure such as in tobermorite or jennite. ${ }^{87}$ Figure 2.8 shows the crystal packing structure of one kind of silicate hydrates. At each layer, it is clear that the primary "building block" of silicate hydrate is silicate tetrahedral monomer. A chain of the monomers may grow and some of the oxygen atoms at the corners of tetrahedral could perform as a bridge connecting different monomers, a scheme shown in Figure 2.9. Cations such as $\mathrm{Ca}^{2+}, \mathrm{Ca}(\mathrm{OH})^{+}$as well as $\mathrm{H}_{2} \mathrm{O}$ exist in the interlayer space. 


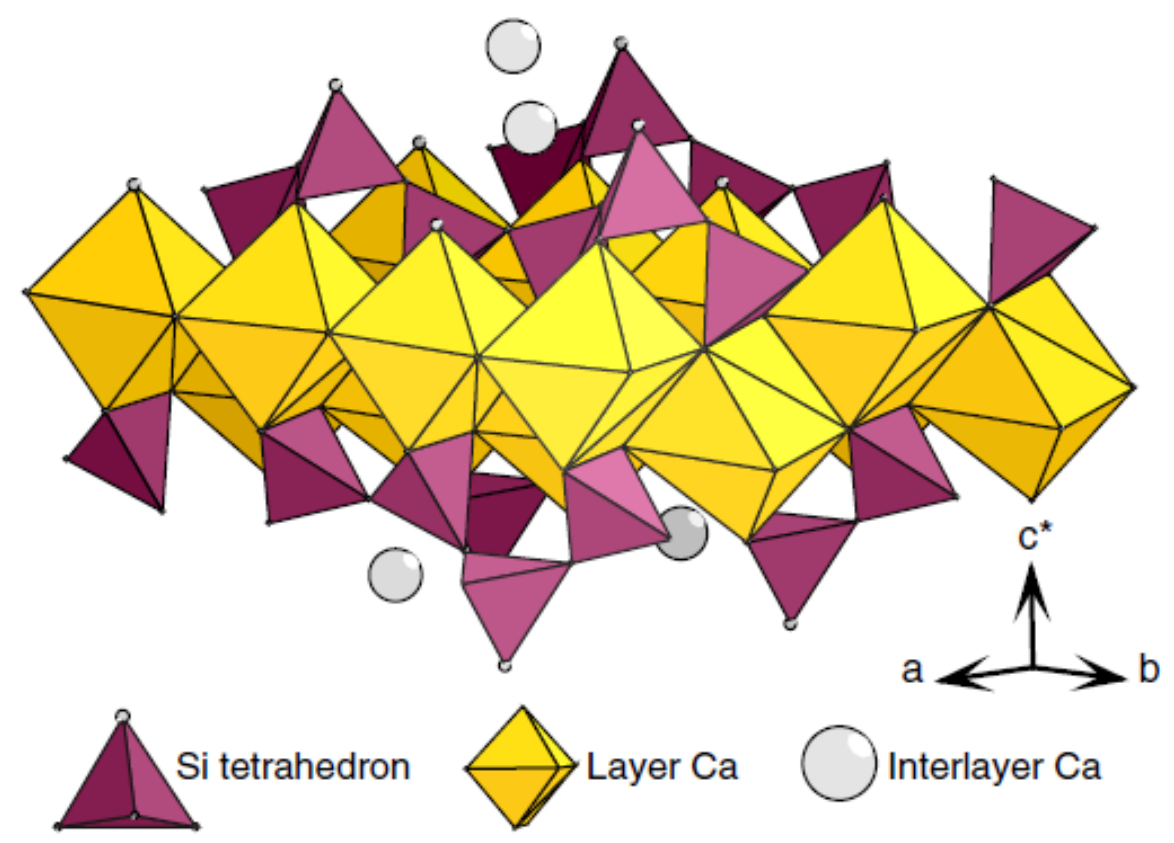

Figure 2.8 Scheme of a typical silicate hydrate. The red tetrahedron structure indicates the $\left[\mathrm{SiO}_{4}\right]$ skeleton structure and the yellow octahedron represents the ordered Ca layer (including $\mathrm{Ca}^{2+}, \mathrm{Ca}(\mathrm{OH})^{-}$species). The grey ball indicates the $\mathrm{Ca}$ species between different layers. It is noteworthy that the Si tetrahedron is the basic building block of the hydrate structure. Derived from the work from Grangeon et al. ${ }^{87}$ 

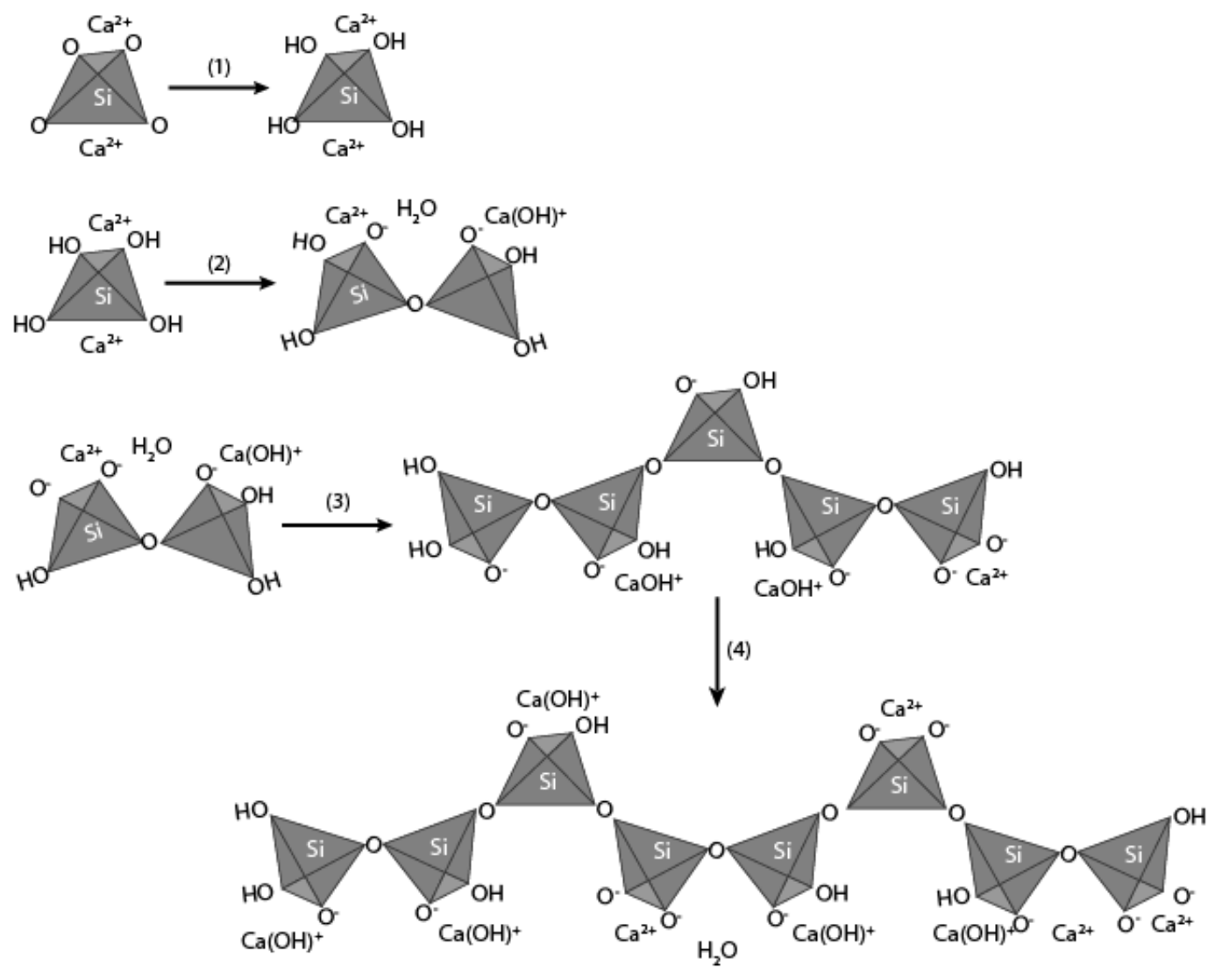

Figure 2.9 Chain growing schemes for silicate hydrate. (1) The hydration of silicate monomer, (2) the formation of dimer, (3) the formation of pentameric and (4) the formation of even longer chains such as octameric.

Although the production of hydrate is routine all the time in the cement industry, the mechanisms and kinetics of this process is not quite clear. The formation of silicate hydrate could proceed via two distinct pathways, either through the direct hydration of unhydrated silicate minerals (Equation 2.8), ${ }^{88,89}$ or through the interaction between $\mathrm{Ca}^{2+}$, $\mathrm{SiO}_{2}$ under alkali conditions (Equation 2.9): ${ }^{87,90,91}$

$$
\begin{aligned}
& \mathrm{C}_{3} \mathrm{~S}\left(\text { or } \mathrm{C}_{2} \mathrm{~S}\right)+\mathrm{H}_{2} \mathrm{O} \rightarrow \mathrm{C}_{x}-\mathrm{S}-\mathrm{H}_{y} \\
& \mathrm{Ca}^{2+}+\mathrm{SiO}_{2(a m a q)}+\mathrm{OH}^{-}+\mathrm{H}_{2} \mathrm{O} \rightarrow \mathrm{C}_{z}-\mathrm{S}-\mathrm{H}_{w}
\end{aligned}
$$


It is asserted that there are primarily three steps associated with the hydration of $\mathrm{C}_{3} \mathrm{~S}$ : induction, acceleration, and deceleration. Researches has shown that the interaction between $\mathrm{C}_{3} \mathrm{~S}$ and $\mathrm{H}_{2} \mathrm{O}$ begins the first moment of wetting with heat release. ${ }^{92,93}$ The enthalpy of $\mathrm{C}_{3} \mathrm{~S}$ dissolution is $-138 \mathrm{~kJ} / \mathrm{mol}$ thus the induction phase is exothermic. ${ }^{89}$ However, the reaction rate decreases at the end of this induction step. Bullard et al. proposed that an intermediate calcium silicate hydrate phase is produced in this step and this intermediate forms a thin layer on the $\mathrm{C}_{3} \mathrm{~S}$ surface, leading to the passivation of the hydration reaction between $\mathrm{C}_{3} \mathrm{~S}$ and $\mathrm{H}_{2} \mathrm{O} .{ }^{89}$ Experimental characterizations leveraging newly developed Nuclear Resonance Reaction Analysis (NRRA) techniques have allowed the measurement of the penetration depth of hydrogen into the $\mathrm{C}_{3} \mathrm{~S}$ mineral, showing strong evidence of the formation of such a passivation layer. ${ }^{94}$ However, direct experimental evidence showing a continuous layer that covers the whole surface of the $\mathrm{C}_{3} \mathrm{~S}$ has not been reported. Alternatively, Barret et al. proposed that the surface of the silicate mineral is "hydroxylated" and the dissociation of ions/cations from this hydroxylated layer is much slower than expected for a bare mineral, thus the decrease in reaction rate is observed. ${ }^{95}$ Recently, Pustovgar et al. validates this hydroxylation hypothesis by using solid-state nuclear magnetic resonance measurements of ${ }^{29} \mathrm{Si}$-riched $\mathrm{C}_{3} \mathrm{~S} .{ }^{96}$ The hydroxyl group, induced from the hydroxylation step, not only controls the induction step, but also controls the following acceleration and deceleration steps.

For the acceleration step, Gartner et al. suggested a mechanism that involves nucleation and growth. ${ }^{97}$ The authors proposed that silicate tetrahedrals attach to growing silicate chains along 2D silicate sheets. As the chain grows, the chances to create defects in the hydrate layer increases, causing disorder in the crystal structure of C-S-H. Thomas et al. 
proposed another mechanism in which the aggregation of C-S-H nanoparticles

contributes to growth. ${ }^{98}$ In their theory, C-S-H nanoparticles grow to about $5 \mathrm{~nm}$ and then stop growing. The aggregated nanoparticles may then stimulate the formation of new nanoparticle seeds or grow from previously nucleated nanoparticles. It is also suggested that these different mechanisms/hypotheses could co-exist and the advancement of chemical characterization methods as well as computational modeling are still needed to further clarify this acceleration step.

The third step of silicate hydration is deceleration and it is considered to be controlled by diffusion. Some literature suggests that the deceleration is the result of a hydrate layer that coats the silicate mineral and the transfer of $\mathrm{H}_{2} \mathrm{O}$ is mitigated due to passivation. ${ }^{99}$ Some other works suggest that the hydrate structure that forms during the induction and acceleration steps have relatively low density and, during the deceleration step, densification occurs. ${ }^{100}$ Experimental results have shown that during the acceleration step there are two forms of C-S-H that are created: high- and low- density C-S-H structures. During the deceleration period, the quantity of longer-chain C-S-H units is increased and these more highly polymerized units contribute to a denser phase that leads to a diffusion barrier. ${ }^{99}$ It is also suggested that during the deceleration stage, the average particle surface area decreases as well, indicating that the effective surface area of silicate minerals that are reactive with $\mathrm{H}_{2} \mathrm{O}$ has been decreased because the formation of the denser layer that has covered some of the reactive sites. ${ }^{89}$ Pustovgar estimated that after hydration, dimeric and octameric silicate species dominate the hydrate species with $42 \%$ and $44 \%$ of the total silicate population. ${ }^{96}$ However, unhydrated and monomeric hydrate 
species together occupy only $7 \%$ of the total Si-containing phases. This also demonstrates that the formation of longer chains of hydrate occurs at the later stage of hydration.

\subsection{Thermodynamics of Silicate Hydrate}

Cement that is used in wellbores in the oil/gas industry is subject to a range of temperatures, which is an important factor in controlling the hydration rate. Escalante et al. reported that temperature has a positive effect on $\mathrm{C}_{3} \mathrm{~S}$ hydration and the hydration rate is higher at $60^{\circ} \mathrm{C}$ than at $10^{\circ} \mathrm{C}$ when the hydrating process begins. ${ }^{101}$ However, the overall extent of hydration is lower at $60^{\circ} \mathrm{C}$. This temperature inversion effect for $\mathrm{C}_{3} \mathrm{~S}$ has also been confirmed by other work, such as that from Flint et al. ${ }^{102}$ The temperature effect of $\mathrm{C}_{2} \mathrm{~S}$ is different from $\mathrm{C}_{3} \mathrm{~S}$ and there is no temperature inversion effect associated with $\mathrm{C}_{2} \mathrm{~S}$. This reveals the mineral specific response to temperature during the hydration process. At the same time, they found out that at lower temperatures, the porosity of the hydrate is higher than at higher temperature. Also, Hill et al. observed that when temperature increases, the hydration rate increases and the porosity decreases. ${ }^{92}$ Verbeck et al. proposed that at lower temperatures, the time for reaction reagents to diffuse is slower than that at high temperature and the reaction matrix could be more homogeneous and less porous. ${ }^{103}$ Bresson et al. reported that regardless of temperature, poorly ordered C-S-H is typically produced first. ${ }^{88}$ However, at room temperature, the chain length of C$\mathrm{S}-\mathrm{H}$ is highly dependent on the $\mathrm{Ca} / \mathrm{Si}$ ratio --- at low $\mathrm{Ca} / \mathrm{Si}$ ratio the hydrate is similar to a tobermorite structure with high chain length, while at high $\mathrm{Ca} / \mathrm{Si}$ ratio the structure tends to have short chains. At high temperature, the formation of long chains is preferred. Gallucci et al. indicates that at higher temperature, the polymerization of silicate hydrate chain is increased. ${ }^{104}$ At the same time, the density of the C-S-H hydrate increases when 
temperature is elevated. However, their work reported that the porosity also increased when temperature is higher because the high degree of polymerization makes the structure coarser and more porous, which is in contrast to what Bresson reported.

Aside from temperature, pressure is also considered to have obvious influence on the hydration reaction. Jupe et al. and Zhou et al. reported that high pressure can accelerate the hydration process significantly, especially the early stage of hydration. ${ }^{84,105}$ Meducin et al. found that pressure could contribute to the formation of different phases. ${ }^{106}$ Under high pressure (under $600 \mathrm{bar}$ ), it is discovered that an intermediate hydrate phase $(\alpha-$ $\mathrm{C}_{2} \mathrm{SH}$ ) is produced first and then is converted to a more stable phase. However, Bresson et al. calculated in their work that thermodynamically, the influence of pressure is less than temperature and every 1000 bar change in pressure would only equate to $5^{\circ} \mathrm{C}$ change in temperature. ${ }^{88}$ It is explained that the pressure dependence is based on the change of the molar volume of each phase and the volume of different reactants/products does not dramatically change compared to the activation energy change caused by temperature.

\subsection{C-S-H Interaction with $\mathrm{CO}_{2}$}

During the $\mathrm{CO}_{2}$ injection process or shale gas production, the primary leakage pathways from the deep subsurface are expected to be in faulty wellbores and fractures or faults that transect impermeable caprock sealing formations. Since the wellbore seals are primarily composed of cements, the understanding of the interaction between hydrated silicate minerals $(\mathrm{C}-\mathrm{S}-\mathrm{H})$ with $\mathrm{CO}_{2}$ is necessary.

A group of studies focuses on the wellbore- $\mathrm{CO}_{2}$ interaction under $\mathrm{CO}_{2}$ injection conditions, aiming to investigate the mechanisms by which a wellbore can be compromised and transport can occur in $\mathrm{CO}_{2}$ injection conditions. As stated above, under 
high pressure (20 Mpa or higher) and temperature $\left(100^{\circ} \mathrm{C}\right.$ or higher), the $\mathrm{pH}$ of brine saturated with $\mathrm{CO}_{2}$ is normally in the range of 3-4. This acidic aqueous solution could attack the wellbore cement and the surrounding formations through complicated pathways. Huerta et al. have reported that the interaction between $\mathrm{CO}_{2}$ saturated brine and wellbore cement under different scenarios can either create or seal fractures, depending on factors such as the original fracture structure of the cement, acid concentration, etc. ${ }^{76}$ While Cheshire et al.'s work has shown that the carbonation reaction between $\mathrm{CO}_{2}$ and cement can decrease the pores sizes and cause the cement to become less permeable. ${ }^{107}$ Kutchko et al. found out that under conditions representative of $\mathrm{CO}_{2}$ sequestration, a brine fully saturated with $\mathrm{CO}_{2}$ can penetrate into the wellbore cement at a rate of $1 \mathrm{~mm} / \mathrm{yr} .{ }^{108}$ Another work studying well cement that was exposed to $\mathrm{CO}_{2}$ for 30 years shows that the degradation of cement is very limited. ${ }^{109}$ This is partly because the reaction-induced carbonate and silica passivate the reactive $\mathrm{CO}_{2}$ front and form a protective rind as suggested from experimental work. However, other work found that the previously existing fractures and cracks in cement could provide $\mathrm{CO}_{2}$ with a high conductivity flow pathway. The supply of $\mathrm{CO}_{2}$ is abundant under these high conductivity flow pathways and as a result the mineral dissolution is more preferred than precipitation, leading to higher permeability. ${ }^{110}$

Efforts to manage leaks from wellbores have focused on developing resistant cements with rheological properties that enable them to flow into the gaps in the wellbore. ${ }^{111}$ This treatment is useful but could compromise the injection well. Other work has focused on engineered coatings for cement that would lower its reactivity and protect it from corrosion. ${ }^{112}$ Beyond that, comparatively little effort has been focused on developing 
scalable technologies that could be used to mitigate leaks if they are detected. Finding and fixing leaks in all cases can be costly and many existing strategies require detailed information about the location of a leak in order to fix it. Few technologies exist to fix leaks associated with a wellbore, limiting injection interruption and avoiding permanent well shutdown - two of the greatest risks to an economically viable geologic $\mathrm{CO}_{2}$ storage projects. ${ }^{113}$ Technologies that fix leaks within the annulus between the steel casing and cement (along with compromised caprock) to solid caprock matrix are especially limited. As a result, there is an urgent need to develop technologies that can plug leakage pathways before they begin in a passive manner that does not require monitoring, while using chemicals that are environmentally benign.

Under acid conditions, the primary deterioration mechanism for a well bore is the attack from protons to the hydrate. Specifically, the carbonation mechanism of the silicate hydrate is shown in Equation 2.10:

$$
\begin{aligned}
& \mathrm{C}-\mathrm{S}-\mathrm{H}+\mathrm{H}^{+} \rightarrow \mathrm{Ca}^{2+}+\mathrm{SiO}_{2(\text { am aq })}+\mathrm{H}_{2} \mathrm{O} \\
& \log \mathrm{K}=10 \text { to } 70 \text { at } 120^{\circ} \mathrm{C} \text { Derived from Clodic et al. }{ }^{114}
\end{aligned}
$$

It is similar to the carbonation in pure silicate minerals in that the $\mathrm{CO}_{2}$ first dissolves into water to form carbonic acid, which provides the capacity to release protons. The protons then degrade the silicate hydrate structure and release $\mathrm{Ca}^{2+}$ cations and silica (usually in the form of amorphous silica). $\mathrm{Ca}^{2+}$ then combines with $\mathrm{CO}_{3}{ }^{2-}$, which is produced from dissociation of $\mathrm{CO}_{2}$, to form calcium carbonate. Hirabayashi reported that under $100^{\circ} \mathrm{C}$ and 20MPa, the reaction between calcium silicate hydrate in cement and $\mathrm{CO}_{2}$ leads to the production of different forms of carbonate, such as calcite, aragonite, and at the same 
time, crystalline and amorphous silica. ${ }^{115}$ Work from Milodowski et al. proposed that carbonation nucleates first as patches or "islands" in C-S-H gel and causes the shrinkage and microfracturing of the silicate hydrate. ${ }^{116}$ Also, the produced carbonate is dense and partially fills the porous hydrate phases. As a result, significant secondary porosity is created that is independent of the original pore structure in the silicate hydrate matrix. 


\section{CHAPTER III}

\section{ESTIMATION OF CO 2 STORAGE IN SHALE FORMATIONS}

Depleted shale formations are attractive geologic carbon sequestration repositories because of the large pore volume and reactive surface area in kerogen that are exposed following hydrocarbon production. ${ }^{117}$ In addition, existing gas production infrastructures could be leveraged to transport and inject $\mathrm{CO}_{2}$, thus minimizing economic and environmental burdens associated with these facets. The nano- or meso-pores within the kerogen and the inorganic portions of the shale provide the primary gas storage capacity. ${ }^{11}$ The pressure and temperature conditions in some shales in the US are comparable to other carbon sequestration reservoirs in which $\mathrm{CO}_{2}$ exists in liquid or supercritical phase. ${ }^{12}$ In addition, $\mathrm{CO}_{2}$ is much more dense than $\mathrm{CH}_{4}$ under the same $\mathrm{P} / \mathrm{T}$ conditions and consequently, considerably more $\mathrm{CO}_{2}$ can be injected into the same wells that are used for production. ${ }^{118}$ Traditional methods attempt to use gas sorption data, along with other published data and methods containing geological information, such as area and thickness of shale formations to project the $\mathrm{CO}_{2}$ injection capacity of fractured shales. These previous methods are primarily based on gas adsorption on ground shale samples, which would overestimate the available fracture surface area on which $\mathrm{CO}_{2}$ could adsorb. The other methods based on the area and thickness of the shale formation not only have the same issues, but also are limited by data availability related to formation thickness and extent as well as the reach of fracture networks. Thus, a more suitable method that can be applied on shale formations is needed.

In this chapter, the sequestration capacity of Marcellus and Utica shale formations are calculated using $\mathrm{CH}_{4}$ production rates gathered from production logs as a basis for 
estimating the capacity of $\mathrm{CO}_{2}$ that could be stored in the same fracture network accessed by the production wells. The model is based on published sorption isotherm data and kinetic models of gas diffusion out of and into kerogen surfaces. This method of estimating the sequestration capacity of a formation has several advantages over existing methods. First, the overall $\mathrm{CO}_{2}$ trapping capacity of a well and a formation will be proportional to its $\mathrm{CH}_{4}$ production capacity, although the exact kerogen content is unknown in the formations. Second, the transport of $\mathrm{CH}_{4}$ out of a fractured shale will be subject to many of the same constraints as $\mathrm{CO}_{2}$ transport back into that same formation and so sorption/desorption kinetics can be used to understand the time horizons over which these types of injection wells would need to operate. Third, estimates of $\mathrm{CH}_{4}$ production over the coming years are well developed and can be used to forecast the sequestration potential of formations over time. The development of the method is first introduced based on the production data from Marcellus shale. Then an improved version of this model taking consideration of parameters such as the aperture length, water saturation, which were not included when the model was initially built on the Marcellus shale, were conducted on Utica Shale.

\subsection{Methods}

\subsubsection{Production data and forecasts}

Well production logs for the Marcellus play from 2004-2012 were obtained from the Department of Environmental Protection for the State of Pennsylvania. Well production logs for Utica shale from 2011-2015 were obtained from Ohio Department of Natural Resources - Division of Oil and Gas Resources Management. Natural gas production 
reports were downloaded as comma separated value (.csv) format and imported into Microsoft Excel. The data had to be processed before being used to account for two factors:

(1) Production data were not available for all wells. Many wells had state permit information but no production data. These wells were excluded from our analysis. Approximately 31\% (3032/9791) of the wells listed for Marcellus shale were used in this analysis and about 34\% (472/1386) of the wells listed for Utica shale were used. This selection process should not impact our estimates because the historical production data was used primarily for estimation of gas diffusivity characteristics in the shale formation.

(2) For some wells, production data was only available for part of the year. For these wells, production was estimated for the rest of the year if adequate information was available for extrapolation. Otherwise, these data were not included in the analysis. Adequate data was typically defined as more than six months of records per year.

Well development in these regions has grown dramatically over the past decade and has resulted in rapid increases in natural gas production, although oil and gas prices temporarily hindered drilling activities. The typical life cycle of a well is as follows: A well site is selected based on seismic analysis and site evaluation and then permits (e.g., air emissions, stormwater, etc.) are obtained. A well pad is prepared and the well is drilled and cased in cement. The well is stimulated using fracturing fluid (a mixture of water, sand, and additives that adjust $\mathrm{pH}$, viscosity, and surface tension), which is subsequently disposed of and the well is brought into production. The production is rapid at first but gradually trails off. Eventually, the well is sealed and the footprint of the well is reclaimed. ${ }^{119}$ Based on historical production data, we assumed that wells had an 
average production life of 13 years. In practice, wells are often sold after internal financial hurdles are met by the original well owner, even though the volume of $\mathrm{CH}_{4}$ remaining after 10 years is generally small and does not impact the calculations here. Before 2004, the majority of wells in the Marcellus Shale were vertical wells. After 2004, however, there was a sharp increase in the number of horizontal wells that were drilled.

$\mathrm{CH}_{4}$ production data for Marcellus shale wells are presented in Figure 3.1. The colors differentiate years in which wells were drilled. These data illustrate how $\mathrm{CH}_{4}$ production has increased dramatically over the past decade in the portions of the Marcellus Shale located in Pennsylvania. They also indicate that the increase in production is dependent on the increase in the number of wells. Historically, vertical wells (Figure 3.1b) have been more common in the Marcellus Shale than horizontal wells (Figure 3.1a) and so even though more of the historical production has come from vertical wells, that trend is shifting. In the coming years, the majority of the production will come from horizontal wells. Finally, Figure 3.1 begins to illustrate how rapidly $\mathrm{CH}_{4}$ production drops off in a particular well over time. For example, looking at those wells drilled in 2010 (light blue triangles), a noticeable drop in production is observed in 2011 and 2012 relative to 2010. Understanding this production decay is important for describing the gas transfer kinetics in these formations. 


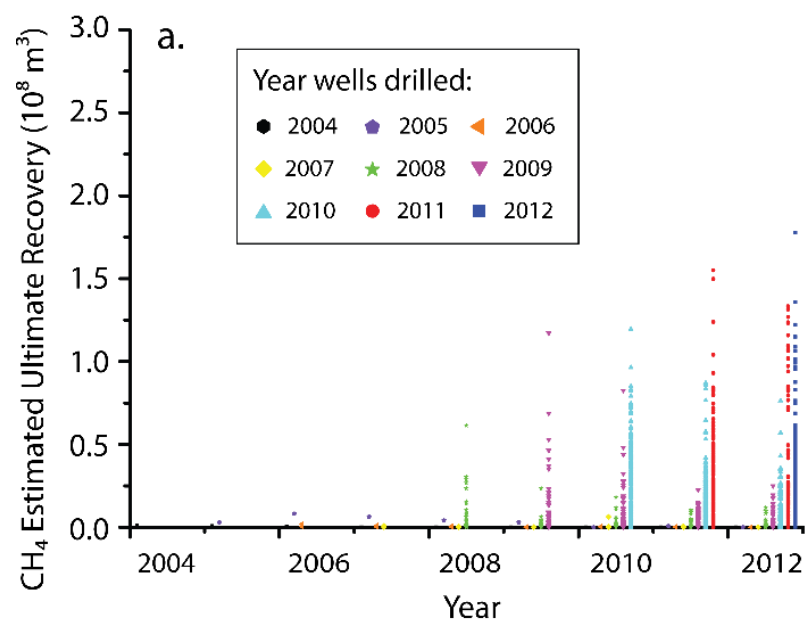

b.

Figure 3.1. $\mathrm{CH}_{4}$ recovery in the Marcellus Shale from both (a) horizontal and (b) vertical wells. The average production for wells drilled in a given year drops off but the overall production of the formation as a whole increases as more wells have been drilled According to EIA Energy Outlook 2012, projected natural gas production will continue to increase linearly from the growth in the entire formation that has been observed in recent years. ${ }^{47}$ For both horizontal and vertical wells, we used the production data of 2009, 2010, 2011 and 2012 to extrapolate production in the coming years. The fitted lines are shown in Figure 3.2 and the $\mathrm{CH}_{4}$ production capacity in years after 2012 is projected based on this linear fit.

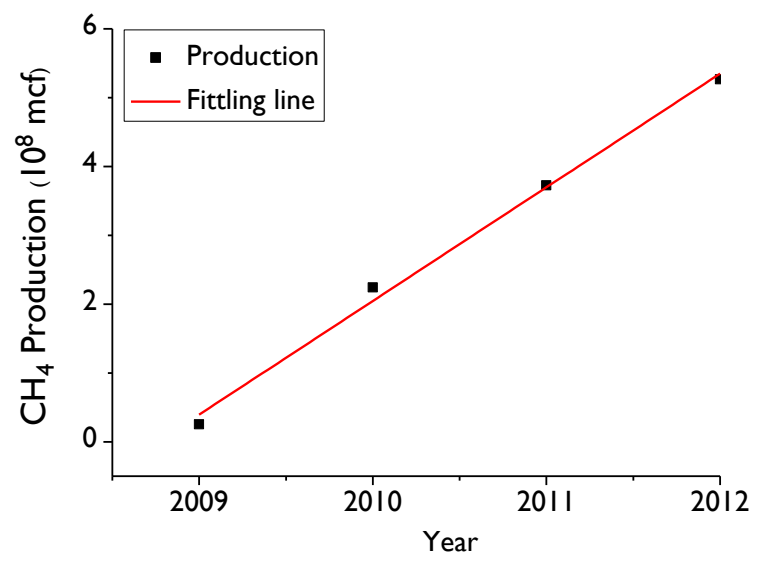

(a)

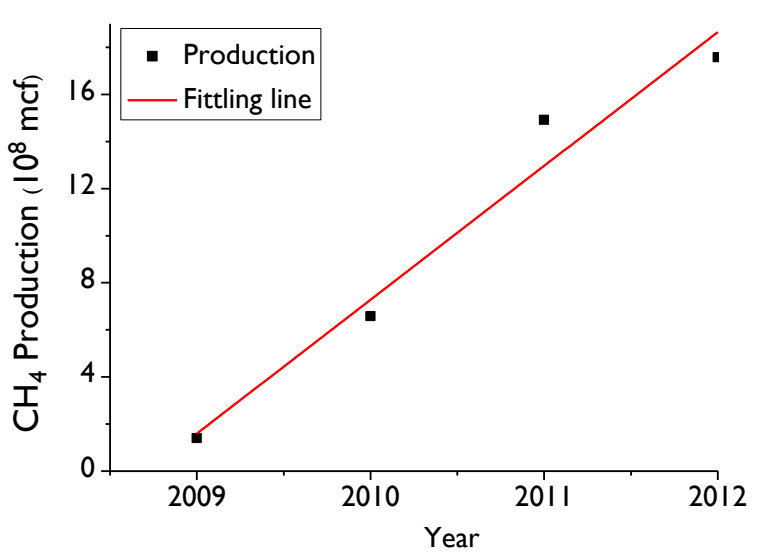

(b)

Figure 3.2. Linear fit of the $\mathrm{CH}_{4}$ production for (a) horizontal wells and (b) vertical wells 
Figure 3.3 provides a schematic representation of the modeling approach proposed here. It is important to distinguish between estimates made at the well-scale and at the formation-scale. The average production for wells drilled in a given year drops off but the overall production of the formation as a whole increases as more wells are drilled. The top line of the schematic shows those calculations that are carried out at the well-scale while those based on the entire Marcellus formation are below. The loops on the top row capture the fact that the entire process is carried out for each well (and over 200 wells are used to obtain representative formation-scale transport parameters) and that the calculation of gas volume must be performed for vertical and horizontal wells separately since the gas transport characteristics in these are different. Raw data was maintained in Microsoft Excel and all modeling was carried out using MATLAB. 


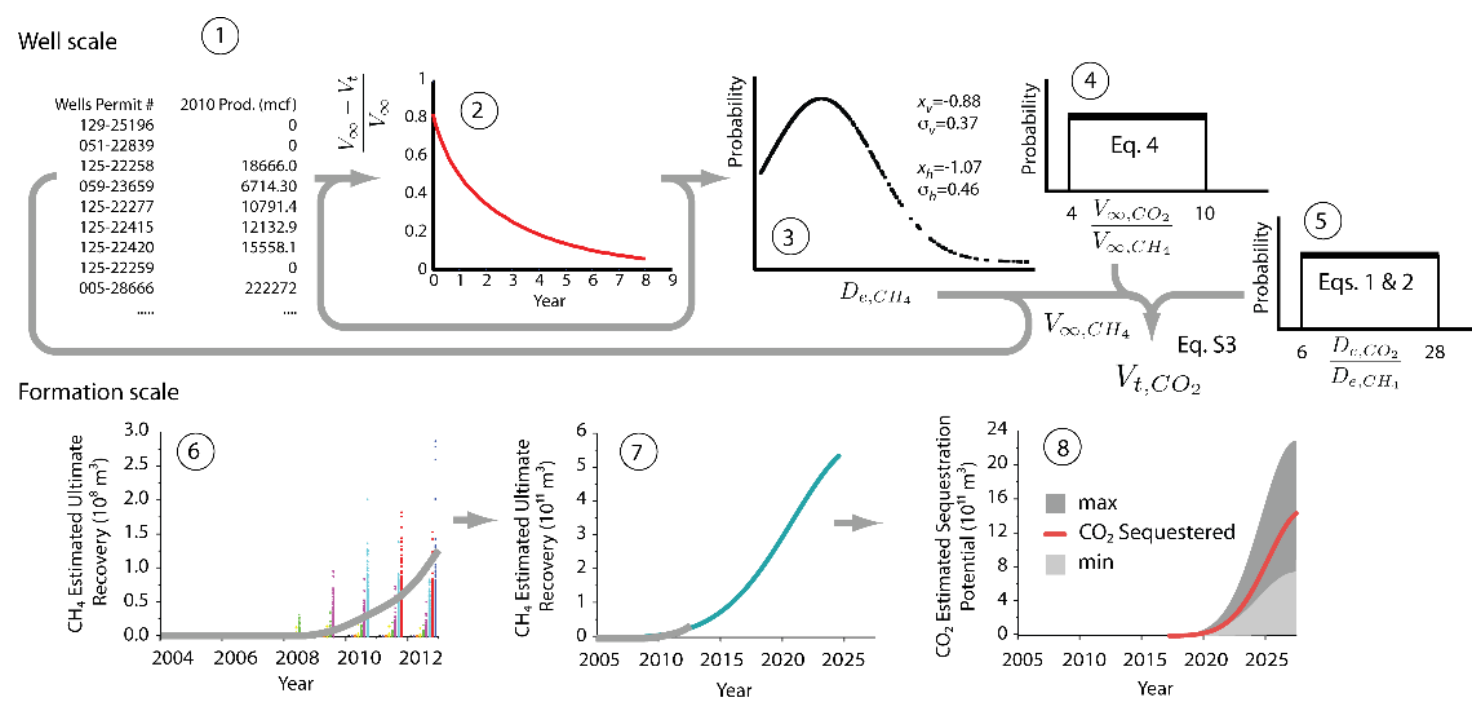

Figure 3.3. Schematic of modeling framework developed here. (1.) Well production data for the Marcellus shale is used to (2.) calculate the ultimate yield and a gas diffusivity constant from existing wells. These data are aggregated to produce (3.) a probability density function of gas diffusivity out of drilled wells. This distribution is combined with stochastic estimates for (4.) the ratio of $\mathrm{CH}_{4}$ volume to $\mathrm{CO}_{2}$ volume that can sorb to the fracture surface and (5.) the ratio of the gas diffusivities at the fracture surface to estimate the volume of $\mathrm{CO}_{2}$ that could be sequestered in these wells. At the formation scale, (6.) historical production data is used to (7.) estimate ultimate recovery for the entire formation. The well and formation-scale data are combined to get a sequestration estimate in (8.). Derived from Tao et al. ${ }^{12}$

Given the $\sim 10$ year lag between when a well would be used for producing $\mathrm{CH}_{4}$ and when it could be transitioned to injecting $\mathrm{CO}_{2}$, the historical $\mathrm{CH}_{4}$ production data were needed to estimate $\mathrm{CO}_{2}$ sequestration capacity. It was also necessary to use production forecasts to extrapolate the potential for using shales as a viable repository in the coming decades. Numerous production forecasting tools are available and we evaluated many of these recognizing that technically recoverable resource (TRR) estimates for a formation as large as the Marcellus Shale are complicated by 1) spatial heterogeneity in formation depth, thickness, carbon content, pore pressure, porosity, etc.; 2) technological developments in extraction techniques; and 3) market factors. For the Marcellus shale, TRR estimates have increased over the past several years. ${ }^{120,121}$ Most sources assume that production will increase linearly in the formation as a whole based on formation 
production rates over the past several years. ${ }^{47}$ Total gas production for the US in 2010 was $6.1 \times 10^{11} \mathrm{~m}^{3} \cdot{ }^{47}$ Shale gas constituted $23 \%$ of that total in 2010 , or $1.4 \times 10^{11} \mathrm{~m}^{3}$. In 2035 , gas production is projected to be $7.9 \times 10^{11} \mathrm{~m}^{3}$ and shale gas will be $48 \%$ of this projection $\left(3.8 \times 10^{11} \mathrm{~m}^{3}\right)$. Based on these data, we calculated that shale gas production in the US will increase by a factor of 2 in the next 20 years and applied this factor to production in the Marcellus play. Our estimates of the sequestration capacity for 2023 and beyond are based on information about wells that are being drilled now. Consequently, we have a reasonably high level of confidence in our forecasts of sequestration potential, even those that extend 20 years into the future.

\subsubsection{Sorption/desorption characteristics}

The sorption properties of $\mathrm{CH}_{4}$ and $\mathrm{CO}_{2}$ on ground shale samples are well described in the literature. ${ }^{8,10}$ These gases are primarily sorbed within the meso/micro pores in kerogen (or the organic fraction of the shale), so that a linear relationship between TOC and adsorption capacity was derived using a number of published datasets (Equations 3.1 and 3.2 and Figure 3.4). Since $\mathrm{CO}_{2}$ has a smaller kinetic diameter than $\mathrm{CH}_{4}(3.3 \AA$ for $\mathrm{CO}_{2}$ vs. $3.8 \AA$ for $\mathrm{CH}_{4}$ ), it is able to diffuse more readily into microporous materials. ${ }^{122} \mathrm{At}$ the same pressure/temperature conditions, $\mathrm{CO}_{2}$ has a higher gas-phase density than $\mathrm{CH}_{4}$. As a result the slope of the $\mathrm{CO}_{2}$ adsorption capacity curve is steeper than the $\mathrm{CH}_{4}$ regression line.

$$
\begin{array}{ll}
\mathrm{CH}_{4}(\mathrm{cc} / \mathrm{g})=0.06+0.31 * \text { TOC }(\%) & \text { Equation } 3.1 \\
\mathrm{CO}_{2}(c c / g)=0.29+1.53 * \text { TOC }(\%) & \text { Equation } 3.2
\end{array}
$$




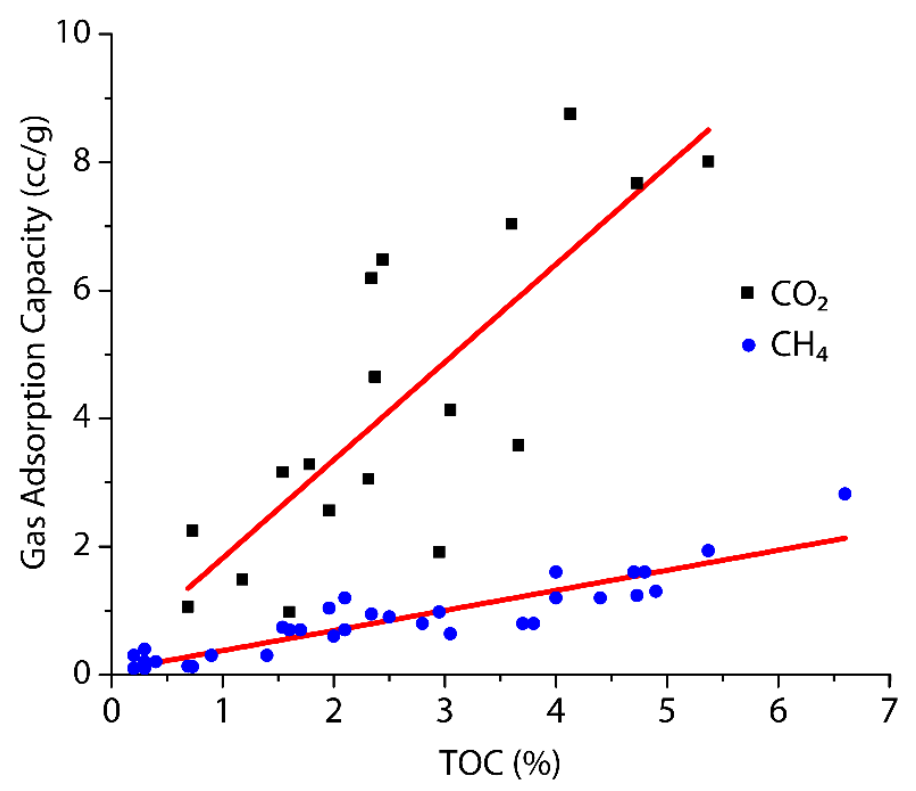

Figure 3.4. Sorption characteristics of $\mathrm{CH}_{4}$ and $\mathrm{CO}_{2}$ on ground shale samples compiled from a variety of published sources. ${ }^{11,123,124}$

\subsubsection{Gas transport properties}

Translating $\mathrm{CO}_{2}$ transport into shale formations using $\mathrm{CH}_{4}$ transport out of the same formations requires an understanding of the physicochemical processes that govern transport kinetics. Some efforts to understand how $\mathrm{CO}_{2}$ and $\mathrm{CH}_{4}$ diffuse into organic pore structures have used molecular sieves to simulate the kerogen pore structures. ${ }^{125} \mathrm{~A}$ considerable amount of phenomenological understanding of gas transport through an organic matrix has been developed for understanding coalbed methane production. ${ }^{126-128}$ Different models have been proposed to characterize these processes including a linear forcing diffusion model, a bidisperse model, and a unipore model. ${ }^{127-129}$ The unipore model, shown in Equation 3, is based on Fick's law for a gas, of concentration $C$, along some coordinate $r$ :

$$
\frac{D}{r^{2}} \frac{\partial}{\partial r}\left(r \frac{\partial c}{\partial r}\right)=\frac{\partial c}{\partial t}
$$


where $D$ is the diffusivity coefficient and $t$ is time. The boundary conditions are:

$t=0,0<r<a, c=0$

$r=0, t>0, \frac{\partial c}{\partial t}=0$

$r=r_{p}, t>0, c=c_{o}$

A solution for Equation 3.3 where gas is sorbing to a solid pore surface is shown in Equation 3.4: ${ }^{130}$

$$
\frac{V_{t}}{V_{\infty}}=1-\frac{6}{\pi^{2}} \sum_{n=1}^{\infty} \frac{1}{n^{2}} \exp \left(\frac{-n^{2} D \pi^{2} t}{r_{p}^{2}}\right)
$$

where $V_{t}$ is the accumulated gas desorption (or adsorption) at time $t, V_{\infty}$ is the total gas desorption (adsorption) capacity of the solid, and $r_{p}$ is the diffusion path length. The unipore model is based on two assumptions: (1) the diffusion coefficient is independent of concentration and location and (2) there is a homogenous pore structure. These two assumptions greatly simplify the calculations and for the purposes of developing a sequestration capacity tool like the one being proposed here, the unipore model is adequate. Note that these equations can also be expressed in terms of mass but volume was used here because it is more common to report gas production in terms of volume. All gas volumes reported here assume that the gas is at standard temperature and pressure. We use the density of $\mathrm{CO}_{2}$ at $\mathrm{STP}\left(1.977 \mathrm{~kg} / \mathrm{m}^{3}\right)$ to calculate the total mass of $\mathrm{CO}_{2}$. It is noted that even though the $\mathrm{CO}_{2}$ would be injected and stored under pressure, volume at STP is the most common way to report gas production data in the industry and so it was adapted here. Within the formation itself, the pressure effects on sorption are captured in the sorption parameters described in Figure 3.4. These adsorption/desorption 
estimates are carried out under carefully controlled pressure and temperature conditions. Indeed, using the data in Figure 3.4, to translate formation production data into sequestration capacity will intrinsically account for the pressure and temperature effects that are certain to influence sorption parameters.

\subsubsection{Production/Sequestration rates}

In order to approximate the kinetics of sequestration in shales, the data for over 200 wells in the Marcellus shale, for which complete multi-year datasets were available, were processed. A similar number of wells in Utica shale was processed using the same method. These data illustrate a consistent decay in production rates over time. This decay process can be modeled by fitting Equation 3.4 to these data. The effective diffusivity coefficient for this $\mathrm{CH}_{4}$ production decay, $D_{e, C H_{4}}$, can be found using Equation 3.5:

$$
D_{e, C H_{4}}=\frac{D_{C_{4}} \pi^{2}}{r_{p}^{2}} \quad \text { Equation } 3.5
$$

where $r_{p}$ was assumed to be $0.002 \mathrm{~m} .{ }^{131}$ We estimated that $D_{C_{4}}$ has a magnitude of $10^{-14}$ $-10^{-15} \mathrm{~m}^{2} / \mathrm{s}$ based on the historical production data. Published results show that the diffusion coefficient of $\mathrm{CH}_{4}$ in carbon molecule sieves and coals is in the range of $10^{-13}$ $10^{-10} \mathrm{~m}^{2} / \mathrm{s} .{ }^{132}$ Our conservative (lower) values reflect the lower permeability of shale (usually $10^{-5}$ to $\left.1 \mathrm{md}\right)^{132,133}$, compared to coal seams (typically 1-100 md). We determined that at least 3 years of data were needed to get an accurate representation of well performance. All the data were fitted using MATLAB. Averaging the diffusivity estimates from the data available for Pennsylvania, we calculated that for horizontal wells, $D_{e, C H_{4}}=0.3814 \pm 0.1844$ and for vertical wells is $D_{e, C H_{4}}=0.4400 \pm 0.1689$. 
The ratio of $D_{e, \mathrm{CO}_{2}}$ to $D_{e, \mathrm{CH}_{4}}$ was assumed to be uniform distribution from 6-28. ${ }^{126,130,134}$ Using the data in Figure 3.4 in the manuscript, we estimated that $\frac{V_{\infty, \mathrm{CO}_{2}}}{V_{\infty, \mathrm{CH}_{4}}}$ is distributed uniformly between 4 and $10 .{ }^{124,135}$ Using the $\mathrm{CH}_{4}$ production data as a basis, we calculated the annual $\mathrm{CO}_{2}$ adsorption potential in the same production wells after they are drained of $\mathrm{CH}_{4}$. According to Equation 3.6, the total $\mathrm{CO}_{2}$ adsorption capacity in the $\mathrm{t}^{\text {th }}$ year is:

$$
V_{t, \mathrm{CO}_{2}}-V_{t-1, \mathrm{CO}_{2}} \quad \text { Equation } 3.6
$$

Based on Equation 3.6, we can calculate this value using the following expanded equation:

$$
\frac{V_{t, C O_{2}}-V_{t-1, C O_{2}}}{V_{t, C H_{4}}-V_{t-1, C H_{4}}}=\frac{V_{\infty, C O_{2}} * \frac{6}{\pi^{2}}\left\{\left(\sum_{n=1}^{3} \frac{1}{n^{2}} \exp \left(-n^{2} D_{e, C O_{2}} t\right)\right)-\left(\sum_{n=1}^{3} \frac{1}{n^{2}} \exp \left(-n^{2} D_{e, C O_{2}}(t-1)\right)\right)\right.}{V_{\infty, C H_{4}} * \frac{6}{\pi^{2}}\left\{\left(\sum_{n=1}^{3} \frac{1}{n^{2}} \exp \left(-n^{2} D_{e, C H_{4}} t\right)\right)-\left(\sum_{n=1}^{3} \frac{1}{n^{2}} \exp \left(-n^{2} D_{e, C H 4}(t-1)\right)\right)\right.}
$$

\section{Equation 3.7}

Combining equation 3.4 and 3.6, we found that after 4 years there is only negligible amounts of $\mathrm{CO}_{2}$ sequestration and so we chose $\mathrm{n}=1-3$. We also assumed that the average life cycle of a $\mathrm{CH}_{4}$ production well is 13 years. So the $\mathrm{CO}_{2}$ sequestration of the first well would begin in 2018, assuming the production well was drilled in 2004.

For each well, the total $\mathrm{CO}_{2}$ adsorption capacity in the $(\mathrm{t}+13)^{\text {th }}$ year can be calculated based on the $\mathrm{CH}_{4}$ production capacity for $\mathrm{t}^{\text {th }}$ year, which is known. It is worth noting that $D_{e, \mathrm{CO}_{2}}, D_{e, \mathrm{CH}_{4}}$, and $\frac{V_{\infty, \mathrm{CO}_{2}}}{V_{\infty, \mathrm{CH}_{4}}}$ all span a range and so the estimation of the $\mathrm{CO}_{2}$ sequestration capacity from $\mathrm{CH}_{4}$ production capacity is calculated using an uncertainty range here. 
Using $\mathrm{CH}_{4}$ production to estimate $\mathrm{CO}_{2}$ sequestration capacity is novel but it requires some distinction between interpore $\mathrm{CH}_{4}$ and $\mathrm{CH}_{4}$ that is sorbed to the kerogen surface. Only the latter provides some physical insight into the sequestration capacity of a formation. $\mathrm{CO}_{2}$ that is reinjected into the formation and does not sorb to the kerogen surface could escape the formation via buoyancy driven forces. Some may remain (via mechanical trapping in the shale matrix) but quantifying this amount was not the focus here. Instead, we wanted to parse production data into its constituent components to base our estimates only on the $\mathrm{CH}_{4}$ sorbed to the surface. As shown in Figure 3.5, for fractured shale, both interpore and sorbed methane exist, and the interpore methane is released rapidly before the pressure in the well begins to decrease and sorbed methane desorbs. Extensive data on the relative magnitude of these values is not available but Patterson et al. estimated that it is approximately a ratio of $1: 1$, which we used in our model. ${ }^{86}$

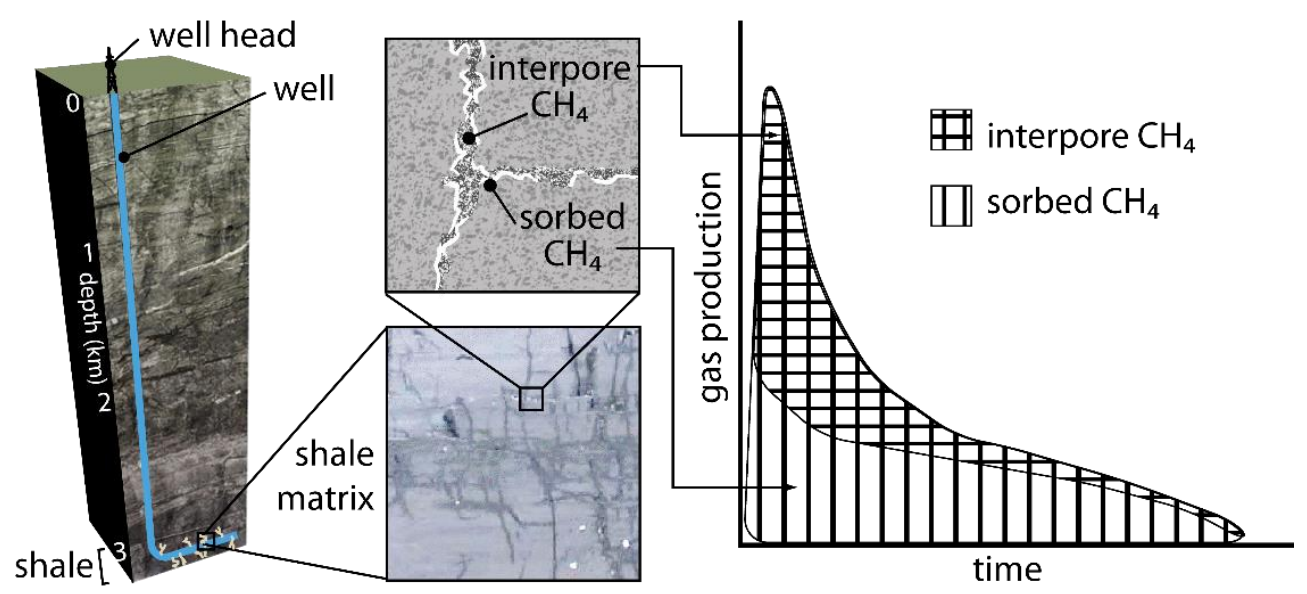

Figure 3.5. The production characteristics of a well depend on both the interpore and the sorbed gas on the fracture or pore walls in the formation. The white in the upper inset schematic indicates kerogen at the fracture surface. The $\mathrm{CO}_{2}$ storage capacity modeled here was estimated using only the sorbed $\mathrm{CH}_{4}$ capacity. 


\subsection{Estimation of $\mathrm{CO}_{2}$ Storage Capacity in Marcellus Shale}

\subsubsection{Total $\mathrm{CO}_{2}$ storage capacity in Marcellus shale}

The Marcellus shale formation in the Eastern United States was selected for this analysis initially because it is one of the larger and more widely developed formations in production today. It has an areal extent of over 600 miles from southwest to northeast (Figure 3.6a) and it is located in several states, primarily New York, West Virginia, and Pennsylvania. High quality production data are available for the latter. The Marcellus shale is estimated to have the capacity of $7.4 \times 10^{12} \mathrm{~m}^{3}$ of gas and production from the formation as a whole is increasing rapidly. ${ }^{68,47}$ From a sequestration standpoint, one of the attractive features of the Marcellus shale is that it is located at a depth where the prevailing pressure and temperature profiles are comparable to those in saline aquifers that are currently being studied for GCS applications (Figure 3.6b). A number of other shale formations have been identified in the US and abroad and many of the domestic shales are shown in Figure 3.6a. Some shale formations are too shallow to be considered for sequestration purposes because the $\mathrm{CO}_{2}$ would be in the gas phase, increasing buoyant forces and reducing the interstitial pressures that would ensure permanent sorption. Many of the most suitable formations are also the biggest like the Marcellus, Utica, Barnett, and Haynesville, formations with characteristic pressure and temperature conditions that are suitable for GCS. 

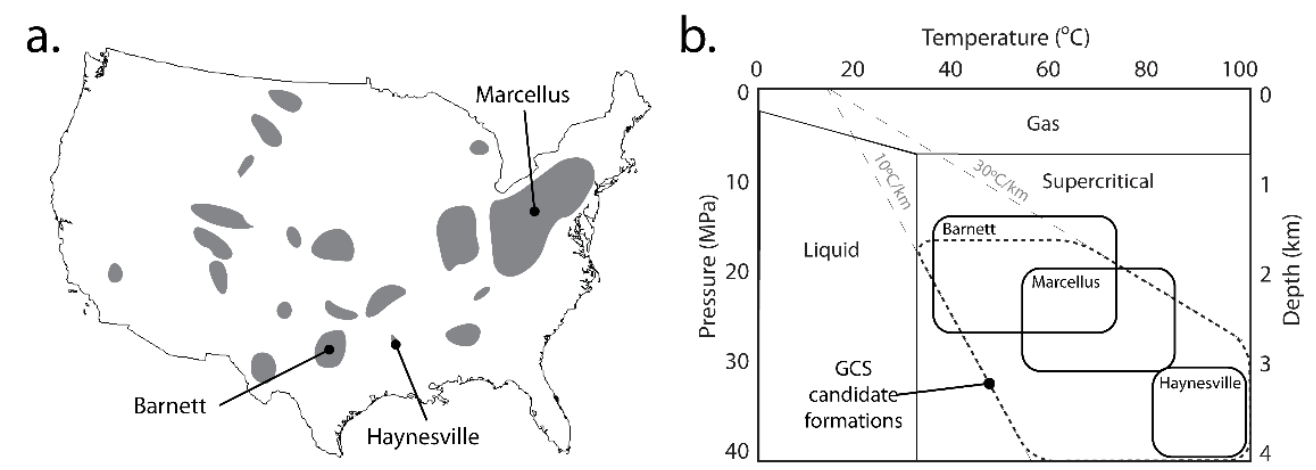

Figure 3.6. (a) A map of the United States with the location of several major shale formations labeled (other shale formations that are currently in production or development are indicated in grey) and (b) a pressure-temperature plot of the subsurface indicating the phase behavior of $\mathrm{CO}_{2}$ and the conditions that prevail in the Marcellus, Barnett, and Haynesville shale formations that illustrates the overlap with conventional GCS candidate formations in saline aquifers. Derived from Tao et al. ${ }^{12}$

The capacity of $\mathrm{CH}_{4}$ production and $\mathrm{CO}_{2}$ sequestration in the Marcellus shale is presented in Figure 3.7. Historical production (blue markers) is differentiated from production forecasts through 2030 (blue line). Assuming that $\mathrm{CO}_{2}$ begins to be sequestered in 2018 , the formation capacity is indicated by the red line. Over this time horizon, the $\mathrm{CH}_{4}$ wells that are currently planned in Pennsylvania could be used to sequester between 10.5 and 18.5 gigatonnes of $\mathrm{CO}_{2}$. This assumes that wells are only used for sequestration once they have been drained of economically recoverable levels of $\mathrm{CH}_{4}$ and are retired from production. There are a number of logistical and technological developments that would need to occur for this to occur including the deployment of large-scale carbon capture processes at power plants and a $\mathrm{CO}_{2}$ distribution network. Most of the wells in the Marcellus Shale drilled over the past decade are still in operation and it will likely still be several years before a large number of drained wells are available as repositories. Given the high uncertainty associated with resource estimates for dry gas shale reservoirs, like the Marcellus shale, we did not project beyond 2030. 
The $\mathrm{CO}_{2}$ sequestration capacity between 2018 and 2022 are derived from $\mathrm{CH}_{4}$ production capacity according to Equation 3.7. We projected the $\mathrm{CO}_{2}$ sequestration capacity in later years based on the projected $\mathrm{CH}_{4}$ production derived from Figure 3.2.

This amount of sequestration capacity is appreciable in the context of other GCS formations that are being considered. Szulczewski at al. estimated that $\sim 100$ gigatonnes of $\mathrm{CO}_{2}$ could be sequestrated in suitable saline aquifers. ${ }^{14}$ As shown in Figure 3.6, there are a large number of shale formations around the US and many others internationally. As a whole, these formations could represent a significant and attractive repository for anthropogenic $\mathrm{CO}_{2}$. Production data was not compiled from all these sites but based on the production estimate from the US DOE, the total sequestration capacity will be on the same order of magnitude as current emissions.

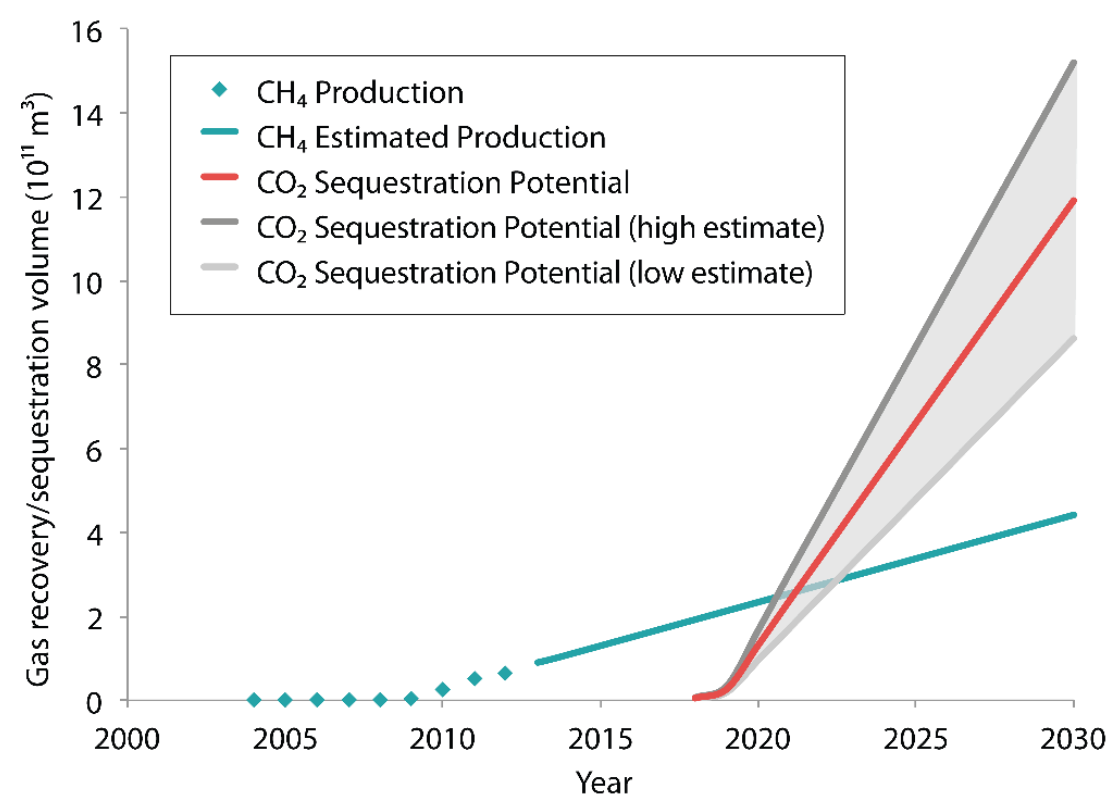

Figure 3.7. Estimate of $\mathrm{CO}_{2}$ storage capacity in the Marcellus Shale based on historical and projected $\mathrm{CH}_{4}$ production. The high and low estimates represent one standard deviation. Derived from Tao et al. ${ }^{12}$ 


\subsubsection{Sensitivity Analysis of the model}

A sensitivity analysis was carried out to understand how these sequestration estimates are impacted by the three primary model inputs $D_{e, \mathrm{CO}_{2}}, \frac{D_{e, C O_{2}}}{D_{e, C \mathrm{CH}_{4}}}$, and $\frac{V_{\infty, \mathrm{CO}_{2}}}{V_{\infty, C \mathrm{CH}_{4}}}$. The results of varying each of these parameters $\pm 10 \%$ suggest that the results are relatively robust. The results, shown in Figure 3.8, reveal that $\frac{V_{\infty, \mathrm{CO}_{2}}}{V_{\infty, \mathrm{CH}_{4}}}$ has the greatest impact on the modeling results. The other two parameters, which deal mainly with the kinetics of gas transport, have a considerably smaller impact on the model results. These results suggest to us that our modeling estimates are driven largely by the immense volume of pore space that is being created in these shale formations and the opportunity that these could represent for permanently storing $\mathrm{CO}_{2}$.

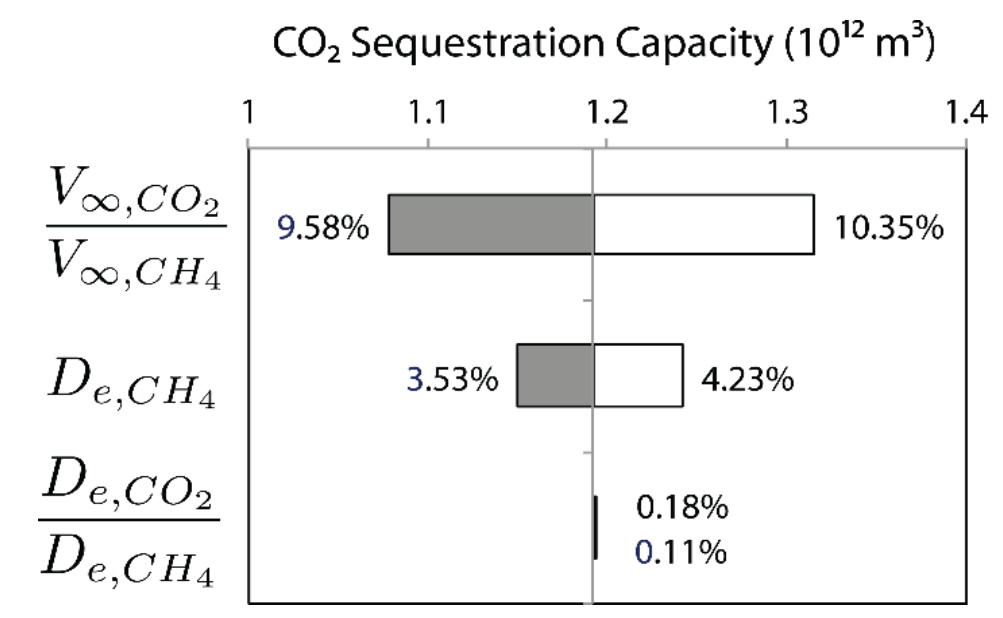

Figure 3.8 Tornado plot reveals how the ultimate sequestration potential of the Marcellus formation is relatively robust to changes in the input parameters. Derived from Tao et al. ${ }^{12}$

\subsubsection{Kinetics about $\mathrm{CO}_{2}$ injection in Marcellus shale}

To further characterize the potential of shale formations to be used as repositories for $\mathrm{CO}_{2}$ sequestration, we estimated the rate at which $\mathrm{CO}_{2}$ could be injected into existing wells. The kinetics of this process is important for assessing the effect of figuratively 
'flipping the switch' on production pumps. The kinetics of well production were evaluated using the production decline data obtained from the 200 wells studied here and it is shown in Figure 3.9. The results suggest that $\mathrm{CO}_{2}$ adsorption into the shale would occur much more rapidly than $\mathrm{CH}_{4}$ production from the same formation. The difference between horizontal and vertical wells is small. Since wells will hold more $\mathrm{CO}_{2}$ than $\mathrm{CH}_{4}$, the results are normalized to their total capacity. The short time it would take to inject $\mathrm{CO}_{2}$ into these formations relative to $\mathrm{CH}_{4}$ is important because it suggests that even though most production wells would need to be operated for more than 10 years to recover the $\mathrm{CH}_{4}$ from that well, a $\mathrm{CO}_{2}$ injection well would only need to operate for $\sim 2$ years before the well was filled. This is an important outcome in terms of controlling the costs associated with reinjection into these formations. 


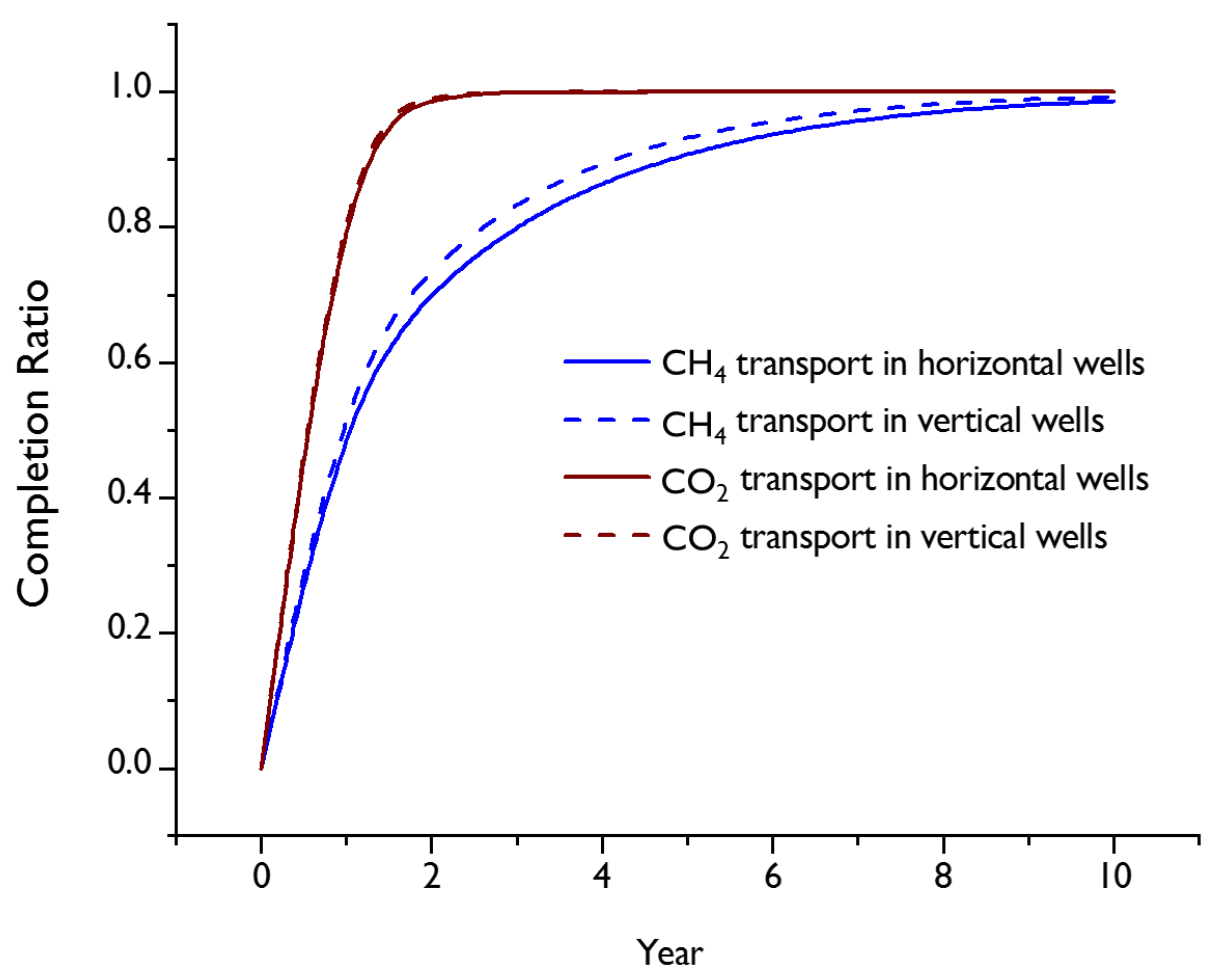

Figure 3.9 $\mathrm{CH}_{4}$ and $\mathrm{CO}_{2}$ sorption/desorption kinetics illustrate that a well would fill with $\mathrm{CO}_{2}$ much more rapidly than it takes to drain it of $\mathrm{CH}_{4}$. These results are largely independent of well configuration (e.g., horizontal, vertical wells). Derived from Tao et al. $^{12}$

Considering both sequestered volume and kinetics together produces Figure 3.10. For this simulation, the ratio of $\frac{D_{e, C O_{2}}}{D_{e, C H_{4}}}$ is 6 and the ratio of $\frac{V_{\infty, C O_{2}}}{V_{\infty, C H_{4}}}$ is 4 . In both cases this is the most conservative lower boundary of the range we tested here. For $\mathrm{CH}_{4}$ extraction, the $\frac{V_{t, C H_{4}}}{V_{\infty, C H_{4}}}$ value is still used. For $\mathrm{CO}_{2}$ injection, $\frac{V_{t, C O_{2}}}{V_{\infty, C O_{2}}}$, instead of $\frac{V_{t, C O_{2}}}{V_{\infty, C H_{4}}}$, is used. The vertical axis is the ratio of gas/gas, which is defined (for $\left.\mathrm{CH}_{4}\right)$ as $\frac{V_{t, C H_{4}}}{V_{\infty, C H_{4}}}$ where $V_{t, C H_{4}}$ is the total mass of $\mathrm{CH}_{4}$ produced at time $\mathrm{t}$ and $V_{\infty, \mathrm{CH}_{4}}$ is the total volume of $\mathrm{CH}_{4}$ that can be produced from the well. For $\mathrm{CO}_{2}$, the ratio is $\frac{V_{t, C O_{2}}}{V_{\infty, C H_{4}}}$, where $V_{t, C O_{2}}$ is the accumulated $\mathrm{CO}_{2}$ 
adsorbed at time t. The results in Figure 3.10 show clearly the dual role that the kerogen pore space in fractured shale formations can play in producing energy and storing carbon.

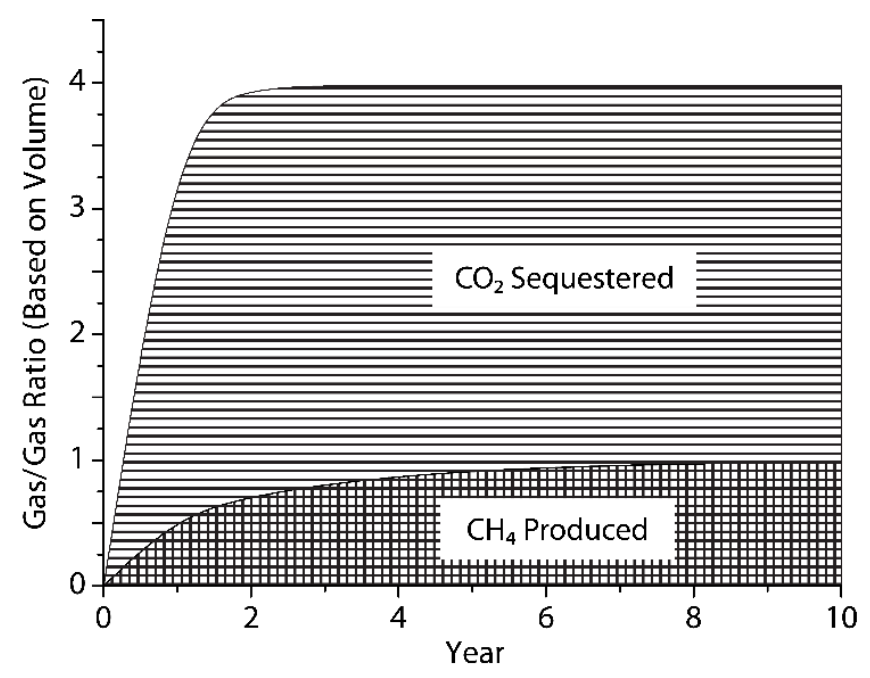

Figure 3.10 The volumetric ratio of $\mathrm{CO}_{2}$ sequestered to $\mathrm{CH}_{4}$. Derived from Tao et al. ${ }^{12}$

The modeling method proposed here is the first to use $\mathrm{CH}_{4}$ production capacity to estimate $\mathrm{CO}_{2}$ sequestration capabilities. The kinetics also suggest that the rate at which $\mathrm{CO}_{2}$ could be injected is considerably higher than the rate at which $\mathrm{CH}_{4}$ is produced from a well. This method is attractive because it allows for rapid estimates of sequestration capacity using $\mathrm{CH}_{4}$ production forecasts. This model is also likely much more accurate than published estimates that rely on samples of crushed rocks and the total mass of the formation. Like all models, ours has an element of uncertainty, but given the magnitude of the estimates produced here, our results suggest that the idea of using these formations merits further consideration. The results suggest that the Marcellus shale alone could store between 10.4-18.4 gigatonnes $\mathrm{CO}_{2}$ between now and 2030, which represents over $50 \%$ of total US $\mathrm{CO}_{2}$ emissions from stationary sources over the same period. Other shale formations with comparable pressure-temperature conditions, such as the Haynesville and 
Barnett, could provide significant additional storage capacity. The mass transfer kinetics results indicate that injection of $\mathrm{CO}_{2}$ would proceed several times faster than production of $\mathrm{CH}_{4}$. Additional considerations not included in this model could either reinforce (e.g., leveraging of existing extraction and monitoring infrastructure) or undermine (e.g., leakage or seismicity potential) this approach, but the sequestration capacity estimated here supports continued exploration into this pathway for producing carbon neutral energy.

The model did not include several factors that are likely to influence the overall sequestration capacity because insufficient experimental data was available. First, the presence of water has been shown to change the gas sorption properties in coal formations and so it stands to reason that the same would be true in shales. In the Marcellus Shale, the majority of water-based fracturing fluids remain in the shale formation after fracturing and these fluids may impact gas transport dynamics. ${ }^{136}$ Second, the presence of liquid hydrocarbons could also interfere with gas transfer at the kerogen surface. Third, the composition of the solid organic material could vary considerably between shales and further classification may be warranted. Fourth, because the kinetic diameter of $\mathrm{CO}_{2}$ is smaller than $\mathrm{CH}_{4}$, contributing to the high sequestration potential for shales, it is also possible that leakage rates over long time scales could impact the efficacy of this strategy. These factors could be better understood experimentally, which could improve the accuracy of the equilibrium and kinetic parameters used in these models or, at a minimum, produce models that are specific to formation characteristics. 


\subsection{Estimation of $\mathrm{CO}_{2}$ Storage Capacity in Utica Shale}

\subsubsection{Model modification}

The primary advantage of the model built in section 3.2 is its simplicity, which allows for the estimation of sequestration capacity with relatively little data input needs. It has two key shortcomings: the first is that some of the parameters described above were chosen as discrete values in the original model. Even though the model was stochastic and the three key parameters were varied using the Monte Carlo method, several other parameters were not. In this work, the previously built-in parameters, whose values were fixed, are set to be statistically distributed.

The goal of this section was to expand our modeling framework to include several physicochemical factors with the potential to improve the predictive capabilities of the model without considerably increasing the data input needs or the computational expense of compiling the results. In particular, the collapse of pores, especially the smallest nanopores that predominate in the kerogen matrix, following production could influence the ultimate mass of $\mathrm{CO}_{2}$ that could be stored in a formation. Similarly, the water content of the shale could have an antagonistic impact on gas transport that may impact the production of $\mathrm{CH}_{4}$ differently than it impacts the injection of $\mathrm{CO}_{2}$. Finally, some of the modeling parameters that were assumed in the first version of the model were varied in magnitude to explore their effect on the modeling estimates. The enhanced model was then applied to the Utica shale in Ohio to provide complementary estimates of sequestration capacity that can help put the original Marcellus estimates into perspective. The results are presented in a way that can help develop cause-and-effect relationships related to the underlying modeling parameters and the effects on predictive capability. 
A comparison of the parameters included in the original model and the current model are listed in Table 3.1.

Table 3.1 Parameters for the unipore model to estimate the $\mathrm{CO}_{2}$ sequestration capacity in shale formations

\begin{tabular}{cccc}
\hline Parameter & Description & Original Model ${ }^{12}$ & This section \\
\hline$\frac{V_{\infty, \mathrm{CO}_{2}}}{V_{\infty, C \mathrm{CH}_{4}}}$ & Adsorption capacity derived from & Uniformally distributed & Uniformally distributed \\
& isothermal adsorption for $\mathrm{CO}_{2}$ and & $4-10$ & $4-10$ \\
& $\mathrm{CH}_{4}$ & & \\
\hline$D_{e, C \mathrm{C}_{2}}$ & Diffusion coefficeint for $\mathrm{CO}_{2}$ and & Uniformally distributed & Uniformally distributed \\
$D_{e, C \mathrm{CH}_{4}}$ & $\mathrm{CH}_{4}$ in shale & $6-28$ & $6-28$ \\
& Gas transport distance before & Fixed at $0.002 \mathrm{~m}$ & Discrete value of $0.002 \mathrm{~m}, 0.01 \mathrm{~m}$, \\
$\mathrm{r}$ & arrive at large fracture surface & & $0.02 \mathrm{~m}, 0.05 \mathrm{~m}$ \\
\hline $\mathrm{A}$ & The ratio of adsorbed gas to total & Fixed at 0.5 & Uniformally distributed \\
& gas & & $0.33-0.67$ \\
\hline $\mathrm{S}_{\mathrm{w}}$ & Water Saturation for shale & Not included & Uniformally distributed \\
& formation & & $0.1-0.3$
\end{tabular}

Table 3.1 lists the modeling parameters but does not offer much insight into the connections between parameters or the underlying physicochemical processes that they describe. Consequently, Figure 3.11 is provided to show the relationships between physicochemical properties, parameters that are abstracted from these fundamental properties, the model and how all these factors are combined to provide a quantitative estimate of sequestration capacity. In particular, Figure 3.11 reveals how certain parameters, e.g., the water saturation of the shale and the ratio of absorbed to total gas in the formation, do not influence the estimates of total sequestration capacity based on the pore model but are used as scaling factos on the final estimates. 


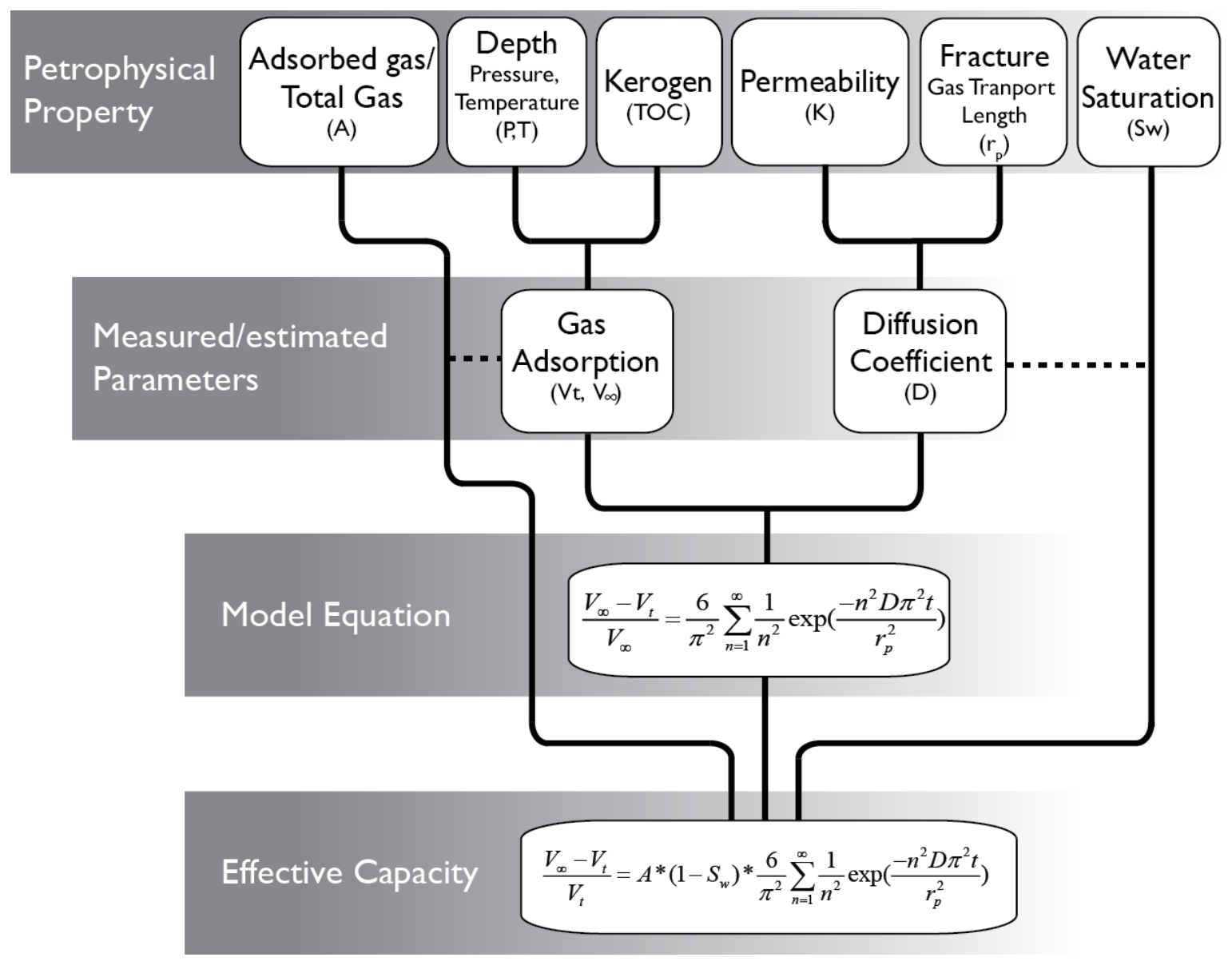

Figure 3.11 The schematic illustration of the relationship between physicochemical parameters and the model used to estimate $\mathrm{CO}_{2}$ sequestration capacity of shale formations. The solid line indicates a direct relationship. The dashed line indicates that the relevant petrophysical property could have influence to the measured parameters, but we do not include the influence in our model. Derived from Tao et al. ${ }^{137}$

\subsubsection{Overall estimate for Utica Shale}

The Utica Shale has been developed more recently than the Marcellus Shale and so less

data are available. It is also smaller than the Marcellus shale in terms of recoverable

resources. The Utica shale is projected to contain $2.1 \times 10^{11} \mathrm{~m}^{3}$ of $\mathrm{CH}_{4}$ while the Marcellus is thought to contain $4.9 \times 10^{11} \mathrm{~m}^{3}$ based on linear projections from the US Department of Energy. ${ }^{12}$ The two formations do share some common petrophysical characteristics. For example, the water saturation profiles of the two formations are similar even though the exact water content can vary regionally. Also, the distribution of the ratio of adsorbed gas 
to free phase gas are thought to be in the same range for various shales. However, there are some important differences. The kerogen types of the Marcellus and Utica shales are different because of their age and this could lead to different gas adsorption and transport properties. Also, the Marcellus shale produces mostly "dry gas" in which $\mathrm{CH}_{4}$ is the primary hydrocarbon component. The Utica shale produces more natural gas liquids, particularly towards the western part of the formation. The diffusivity of $\mathrm{CH}_{4}$ in the Utica shale $\left(4.23 * 10^{-10} \mathrm{~m}^{2} /\right.$ day) that we derived from production data is $3-4$ times lower than the estimate for the Marcellus shale $\left(1.34 * 10^{-9} \mathrm{~m}^{2} /\right.$ day $)$. This could be attributed to the different petrophysical properties of those two shales. It is also worth noting that Utica shale is more than 3000 feet deeper than the Marcellus shale, which results in a pressure differential of nearly $7 \mathrm{MPa}$. The higher stress and pressure within the Utica shale could lead to higher gas flow properties, such as larger absorbed gas amount and higher production rate. But, it could also contribute to pore collapse following hydrocarbon extraction. Taking these factors together, the model indicates that the Utica shale has a much lower sequestration capacity than the Marcellus shale (1.4 Gt vs. $12 \mathrm{Gt})$ based on current projections of recoverable resources in both formations, as shown in Figure 3.12. It is worth noting that the Utica shale has approximately 80-90\% fewer wells than the Marcellus shale and so developing robust parameters from this limited data is a challenge. As estimates are improved, more well data is published, and some key petrophysical characteristics are explored in the lab, these estimates could be further refined. In the meantime, the very large sequestration potential of these formations suggests that additional research into using depleted shales for $\mathrm{CO}_{2}$ sequestration merits further consideration. 
It is also noteworthy that the $\mathrm{CO}_{2}$ storage capacity in Marcellus shale estimated from this updated version of the model is about $30 \%$ lower than that from the original manifestation. This gives demonstration about how the water saturation and free gas adsorption capacity would influence the ultimate estimation of $\mathrm{CO}_{2}$ storage capacity in shale.

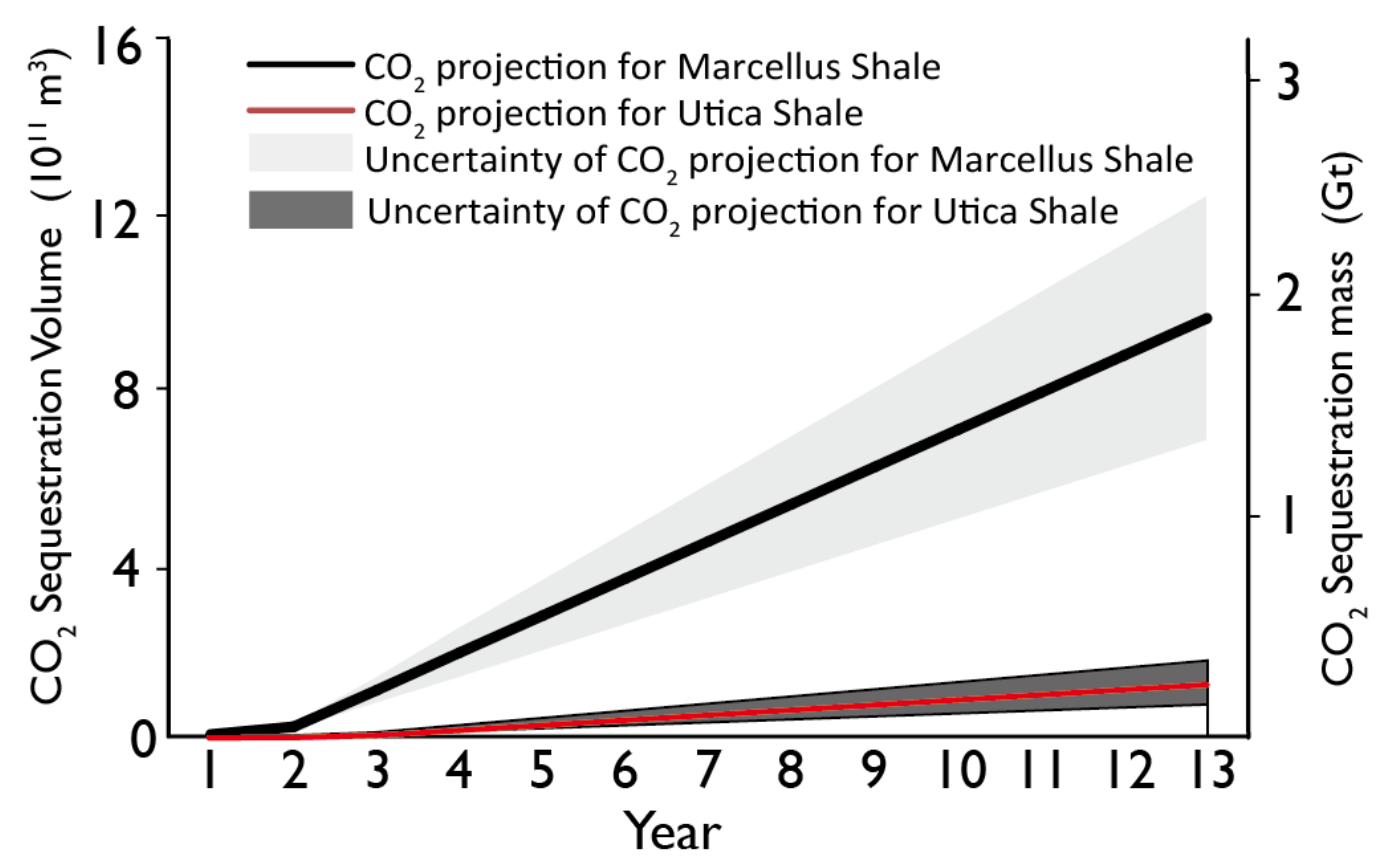

Figure 3.12 Comparison of $\mathrm{CO}_{2}$ sequestration capacity for the Marcellus and Utica shales. The estimates for the Marcellus shale are considerably higher but so are the total recoverable resources from that formation. Derived from Tao et al. ${ }^{137}$

\subsubsection{Sensitivity analysis of the modified model}

In general, the ratio of adsorbed gas to gas in place (GIP, including both adsorbed gas and free phase gas) and the equilibrium adsorption ratio have the biggest impact on the model output. Figure 3.13 presents a sensitivity analysis in which the mean value for each parameter was varied by $10 \%$, without any change to the structure of the distribution, and 
the results show that corresponding change in the model estimate. $A$ and $\frac{V_{\infty, \mathrm{CO}_{2}}}{V_{\infty, \mathrm{CH}_{4}}}$ both elicit a change of approximately $10 \%$ in the model estimate while the other model inputs have a more muted impact on the estimates. Water saturation $\left(S_{W}\right)$ and the ratio of $\mathrm{CH}_{4}$ diffusivity to $\mathrm{CO}_{2}$ diffusivity $\left(\frac{D_{e, C O_{2}}}{D_{e, C H_{4}}}\right)$ have less impact. The effect of $\mathrm{CH}_{4}$ diffusivity $\left(D_{e}\right)$ is the least pronounced.

These sensitivities in the model are consistent with the computational structure of the model presented in Figure 3.10. The ratio of adsorbed and free gas is incorporated into the results as a final step and so it follows that the results are almost directly proportional to changes in the input. The model estimates are also directly correlated with the equilibrium sorption ratio because it appears in the equation outside of the exponential term. In contrast, the ratio of the diffusivity of $\mathrm{CO}_{2}$ and $\mathrm{CH}_{4}$ are negatively correlated with model output (observed by the shading in Figure 3.12). Water saturation also has a negative correlation with the model output because higher water content impacts the availability of pore space and binding sites for $\mathrm{CH}_{4}$ sorption. 


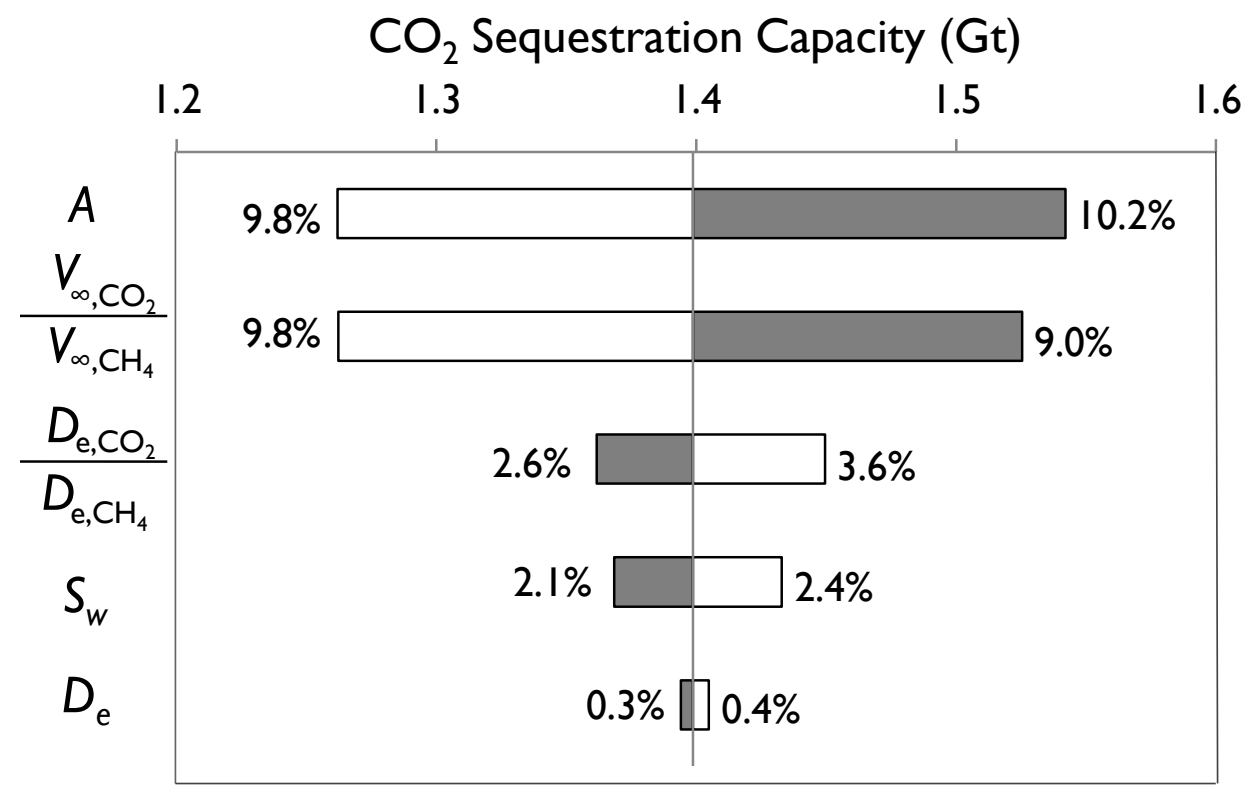

Figure 3.13 Sensitivity analysis of different parameters to the total $\mathrm{CO}_{2}$ sequestration capacity. Gray bars are the capacity when the parameter is increased by $10 \%$. White bars are the capacity when the parameter is decreased by $10 \%$. The percentage changes of the sequestration capacity under different scenarios are also shown in this figure. Derived from Tao et al. ${ }^{137}$

\subsubsection{Characteristic gas transport distance $\left(\mathbf{r}_{\mathrm{p}}\right)$}

Modeling the kinetics of $\mathrm{CH}_{4}$ production and $\mathrm{CO}_{2}$ injection into a kerogen matrix using the unipore model requires some assumptions about the characteristic distance that the $\mathrm{CH}_{4} / \mathrm{CO}_{2}$ needs to diffuse through the pore. We initially modeled this parameter $\left(\mathrm{r}_{\mathrm{P}}\right)$ using a fixed value of $0.002 \mathrm{~m}$. The assumption here is that once the gas leaves the pore and enters the fractures, that the transport is rapid. Picking a fixed value for $\mathrm{r}_{P}$ could ignore some of the complexity that exists in shales in terms of kerogen deposit heterogeneity. It also ignores the possibility that pores can collapse because of the increased effective stress induced by the decrease of pore pressure after $\mathrm{CH}_{4}$ extraction. This could increase the transport distance for $\mathrm{CO}_{2}$ molecules, relative to the $\mathrm{r}_{\mathrm{P}}$ that was assumed based on the $\mathrm{CH}_{4}$ extraction data. To explore the role of $\mathrm{r}_{\mathrm{P}}$ on injection kinetics, 
its effect on completion ratio were calculated. Completion ratio is defined as the time it takes from the start of $\mathrm{CO}_{2}$ injection until the well is saturated with $\mathrm{CO}_{2}$. Four values (1X, 5X,10X and 25X of the original value) for $\mathrm{r}_{\mathrm{P}}$ were selected based on literature analysis of kerogen pore structure, as shown in Figure 3.14. Pore collapse was not explicitly considered here but it could be assumed to have a net effect of raising the effective pore length of a formation. The increase in $\mathrm{r}_{\mathrm{P}}$ from 0.002 to $0.02 \mathrm{~m}$ has a dramatic impact on how long it would take to fill the well with $\mathrm{CO}_{2}$. At the highest lengths of $r_{P}$, the well would not be completed in the 20 years that we modeled.

Developing a better phenomenological relationship among kerogen age/structure, pore pressure change after gas extraction and $\mathrm{r}_{\mathrm{P}}$ would aid greatly in developing accurate forecasts that will directly drive the economics of $\mathrm{CO}_{2}$ injection into depleted shales.

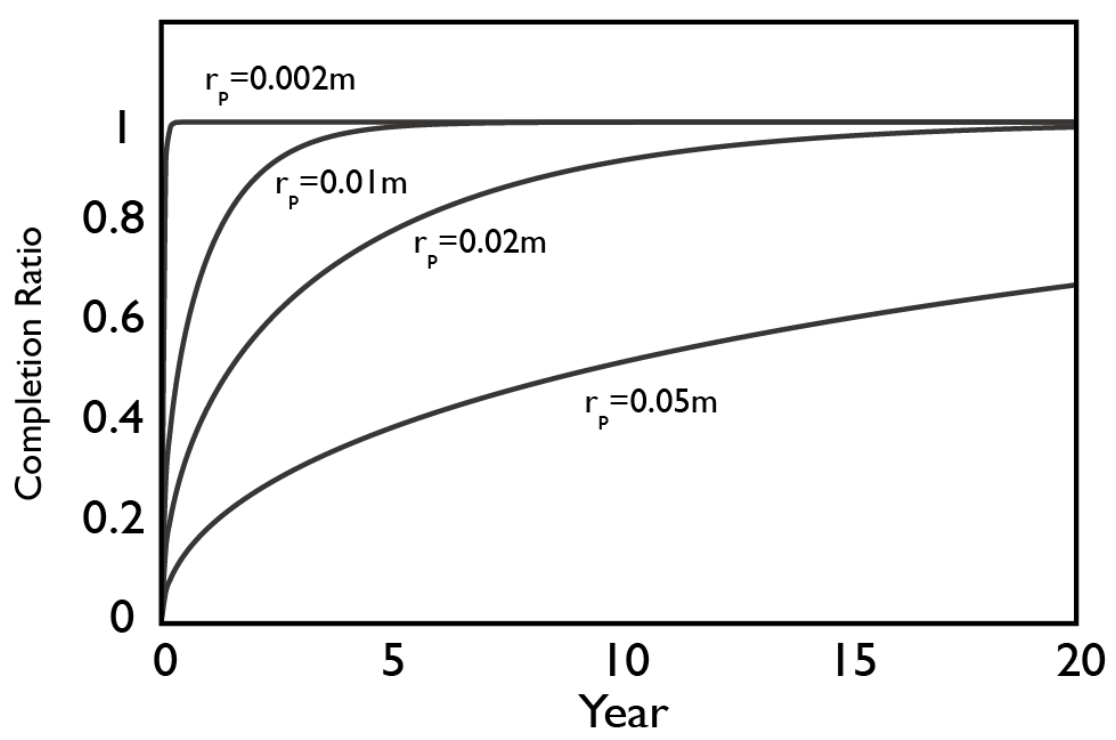

Figure 3.14 The characteristic gas transport distance $\left(r_{p}\right)$, which is a key parameter in the unipore model, has an important effect on the kinetics of gas transport through the shale formation and can greatly increase the time it would take to refill a formation with $\mathrm{CO}_{2}$. Here the completion ratio for a well is plotted as a function of time for a variety of representative $\mathrm{r}_{\mathrm{P}}$ values. Derived from Tao et al. ${ }^{137}$ 


\subsubsection{Water saturation and free gas ratio}

Two parameters, water saturation in the shale and the ratio of sorbed gas to GIP, will have important impacts on the predictive capabilities of shale sequestration models but do not factor into the interpore model. Water saturation has important impacts on multiphase flow and wettability characteristics in the formation, which can interfere with gas transport through meso- and nano-scale pores. This water would also compete with $\mathrm{CO}_{2}$ for free pore space and the time between $\mathrm{CH}_{4}$ production and $\mathrm{CO}_{2}$ injection (which would typically be on the order of years) would be enough for many of the pores to fill with connate brines from surrounding formations. Free gas ratio is important because, as described earlier, many of the pores that are being accessed in the fracturing process are not being resealed during the reinjection process. We model only the $\mathrm{CO}_{2}$ that is sorbed in the kerogen matrix and assume that the $\mathrm{CO}_{2}$ in the fractures and pores may be mobile and/or replaced by $\mathrm{CO}_{2}$ saturated brines. Both the Marcellus and the Utica formations are considered to be relatively dry shales and so the water saturation was set to a uniform distribution between $10 \%$ and $30 \%{ }^{138-140}$ The Adsorbed/Free gas ratio is set between $1 / 2$ and 2/1 for both shales. The results on the sequestration potential in the Utica shale are presented in Figure 3.15. 

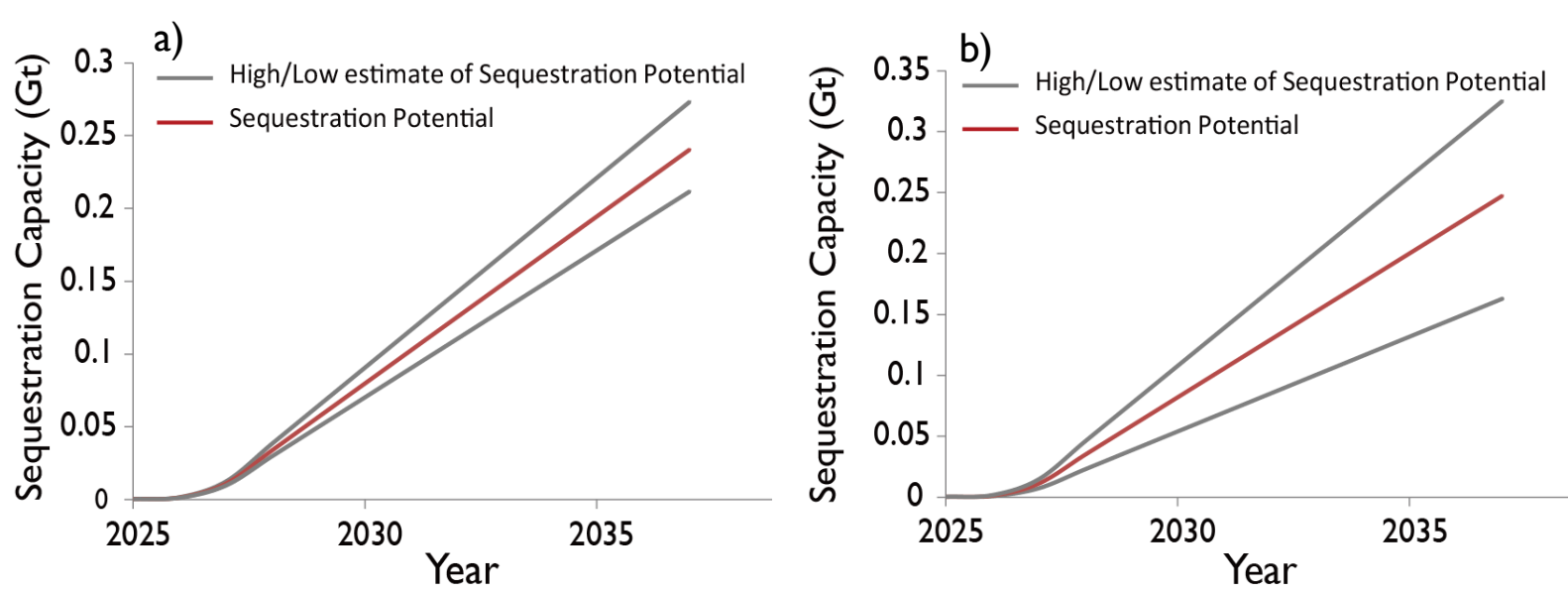

Figure 3.15 a) Water saturation $\left(S_{\mathrm{w}}\right)$ and $\left.b\right)$ adsorbed/gas in place are both important parameters that are not captured using the unipore model but are included as a postprocessing step to produce estimates that are sensitive to these effects. Here, high estimates are water content $=10 \%$, free gas ratio $=33 \%$ and low estimates are water content $=30 \%$, free gas ratio $=67 \%$. Derived from Tao et al. ${ }^{137}$

\subsection{Environmental Implications}

Beyond the technical merits of this modeling approach, the broader social and economic advantages and limitations associated with using shale formations as repositories for $\mathrm{CO}_{2}$ should be considered. There are at least three logistical and economic factors that could, possibly negatively, impact the viability of sequestration in shales. First, shale formations have traditionally been considered the most attractive form of caprock in a GCS context and the relationship with sequestration potential in deeper aquifers has been explored. ${ }^{141}$ Second, even assuming that sequestration in underlying formations is not pursued, there are a wide variety of practical factors that could slow or hinder sequestration efforts in shales since their primary role as a source rock will take economic precedence over its role as a carbon repository. For example, so called 'infill' drilling practices influence the manner in which wells are spaced geographically to increase hydrocarbon recovery. If some wells in a region are used for sequestration, this could influence the long-term 
prospects of using other nearby wells for additional production. Third, it is possible that $\mathrm{CO}_{2}$ could enhance $\mathrm{CH}_{4}$ production or otherwise interfere with long-term slow release of $\mathrm{CH}_{4}$ from shales. In a related way, hydrological communication and leakage from one fracture to another through abandoned wells or natural heterogeneities in the formation could lead to leakage of $\mathrm{CH}_{4}$ or $\mathrm{CO}_{2} .{ }^{39}$ The model presented here is not intended to evaluate the importance of these factors but rather to present a straightforward method for estimating the sequestration capacity of shale formations.

There are a number of equally important reasons that sequestration in shales might be attractive. First, since wells are already being drilled for $\mathrm{CH}_{4}$ production purposes, the logistical and economic costs of putting gas back into the ground should be lower than injection into saline aquifers. Even though questions about whether the same infrastructure could be used, and how the gases would be transported still need to be resolved, it is reasonable to expect that because the physical footprint of gas production is already in place, that infrastructure could be repurposed for sequestration, thereby providing important synergies. Today, only small regions of the Marcellus are being drilled and if forced pooling legislation moves forward, this could mean that certain regions would be developed together, eventually making them well suited for sequestration. Certainly, any opportunities to capitalize on existing infrastructure, trunk lines, well heads, etc. will need to be weighed against the costs and benefits of developing a deep saline aquifer for the sole purpose of carbon sequestration. Second, since gases would be drained and later introduced into the formation, the risks to seismicity could be lower than in saline aquifers, though the causal relationships between gas withdrawals/injections and seismicity are still poorly understood. It is reasonable to 
expect that relative to sequestration in saline aquifers or hydrothermal energy where large volumes of gas are injected into the subsurface displacing connate fluids, this approach may have advantages. Third, since a significant fraction of the $\mathrm{CO}_{2}$ would be sorbed to kerogen surfaces rather than existing as a free fluid, the leakage potential of this injected $\mathrm{CO}_{2}$ may be lower. Also, since shale formations are inherently impermeable, and natural bedding planes result in fractures that propagate horizontally, the injected fluid would effectively be encased within the man-made fracture network that was created for $\mathrm{CH}_{4}$ extraction.

The magnitude of the pore space being generated in shale formations (e.g., the Marcellus shale alone would have enough capacity to hold an estimated 12 gigatonnes of $\mathrm{CO}_{2}$ between 2018 and 2030 and the Utica shale can provide 1.4 gigatonnes of $\mathrm{CO}_{2}$ storage capacity) suggests that the potential technical, logistic, and economic opportunities and challenges of this approach should be evaluated. The US emitted 2.32 gigatonnes of $\mathrm{CO}_{2}$ from stationary sources in 2010 and so the Marcellus shale alone could hold more than one third of those emissions each year. This is a significant potential repository and one that should be carefully considered in light of other options for creating carbon neutral energy in the medium term. ${ }^{142}$ 


\section{CHAPTER IV}

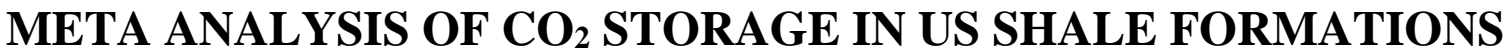

The physicochemical processes that govern gas transport, both into and out of, a fractured shale formation are an active area of research. ${ }^{143-148}$ Shale formations have intrinsically low permeability and so the dramatic yield increases associated with hydraulic fracturing were initially surprising. ${ }^{149,150}$ Intact (pre-fracture) shale has a permeability $<10^{-6} \mathrm{mD}$ and most of the pores in a shale have diameters on the order of tens of nanometers. In these small pores, gas molecules near the pore wall are subject to strong wall effects and a relatively static adsorption layer forms on the solid pore walls. This layer can be as thick as ten gas molecules, which further constrains transport through these pores. The Knudson number $\left(\mathrm{K}_{\mathrm{n}}\right)$, which is defined as the ratio of mean free path for gas and characteristic length of the pore space (i.e., the pore radius) as shown in Equation 4.1, is used to describe this behavior. Once $K_{n}$ is greater than $0.1-1$, the molecule - wall interaction could be comparable or overwhelm the interaction between gas molecules. Under such conditions, Darcy flow cannot describe the gas transport mechanisms in these pores and instead, diffusion is the dominant mechanism for mass transport. ${ }^{151}$

$\lambda$ : molecular free pathways $\left[\mathrm{L}^{-1}\right]$

$$
K_{n}=\frac{\lambda}{L}
$$

Equation 4.1

$L$ : representative physical length scale $\left[\mathrm{L}^{-1}\right]$

The processes of directional drilling and hydraulic fracturing create a network of artificial pathways (boreholes, fractures, etc.) that connect to natural cleats and lenses in the rock to significantly enhance the gas permeability of the shale formation. Figure 4.1 provides a schematic representation of shale fracturing activities. Most shale formations in the United States are several kilometers below the surface. The horizontal laterals that extend 
into the shale layer can be as long or longer than the vertical extent of the wellbore. Socalled perforation clusters around the individual openings in the wellbore represent a discrete region of rock in contact with one of these fracture pathways. The intact shale contains both free natural gas within the pores and sorbed natural gas on the pore walls. Immediately following the fracturing process much of the free natural gas existing within pores is released. This natural gas travels through the fracture network, where conductivity is much higher, to reach the wellbore. As the pressure drops within these pores, natural gas is desorbed from the surfaces and this subsequently follows the same transport pathways to and through the wellbore.

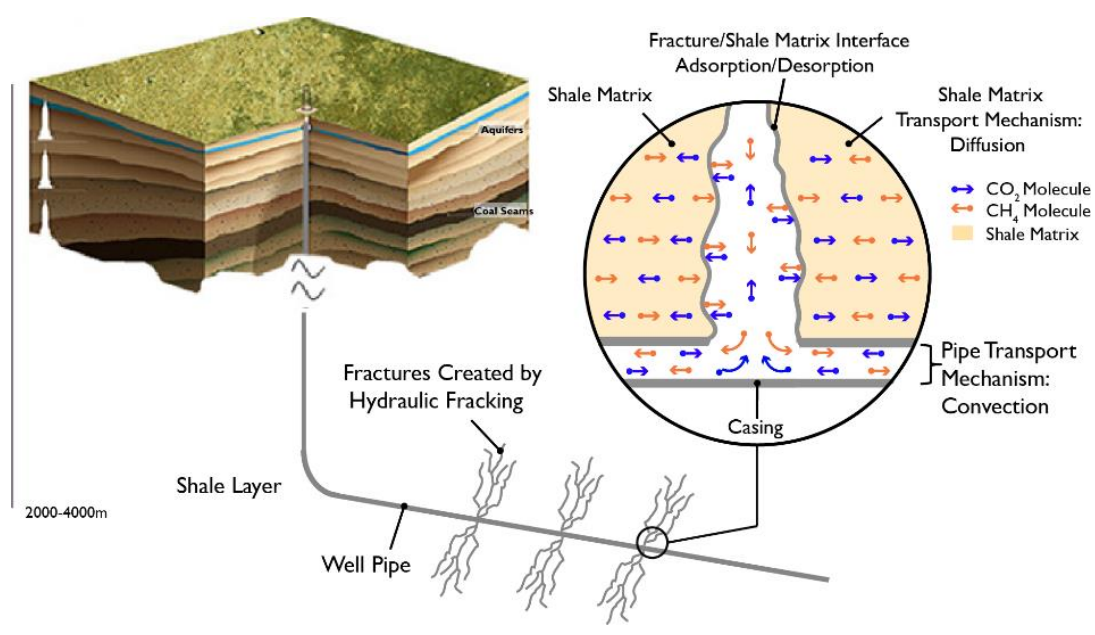

Figure 4.1. Schematic of the underlying processes that control gas production (and injection) from (or into) fractured shale formations. Derived from Bažant's work. ${ }^{152}$

Figure 4.2 presents production curves for the primary shale gas formations in the US. The data are derived from EIA's report Annual Energy Outlook 2012. ${ }^{47}$ These production decline curves all have approximately the same shape, consistent with this two-stage process of initial production of free natural gas followed by a longer tail dominated by 
transport through the low permeability shale matrix. The figure inset in Figure 4.2 shows the kinetics in terms of the percentage of the total estimated ultimate recovery (EUR) for each formation. The figure shows that after 15-20 years, most of the gas in place that is recoverable has been produced in all formations. In some formations, e.g., the Haynesville formation in Texas, this limit is reached much sooner.

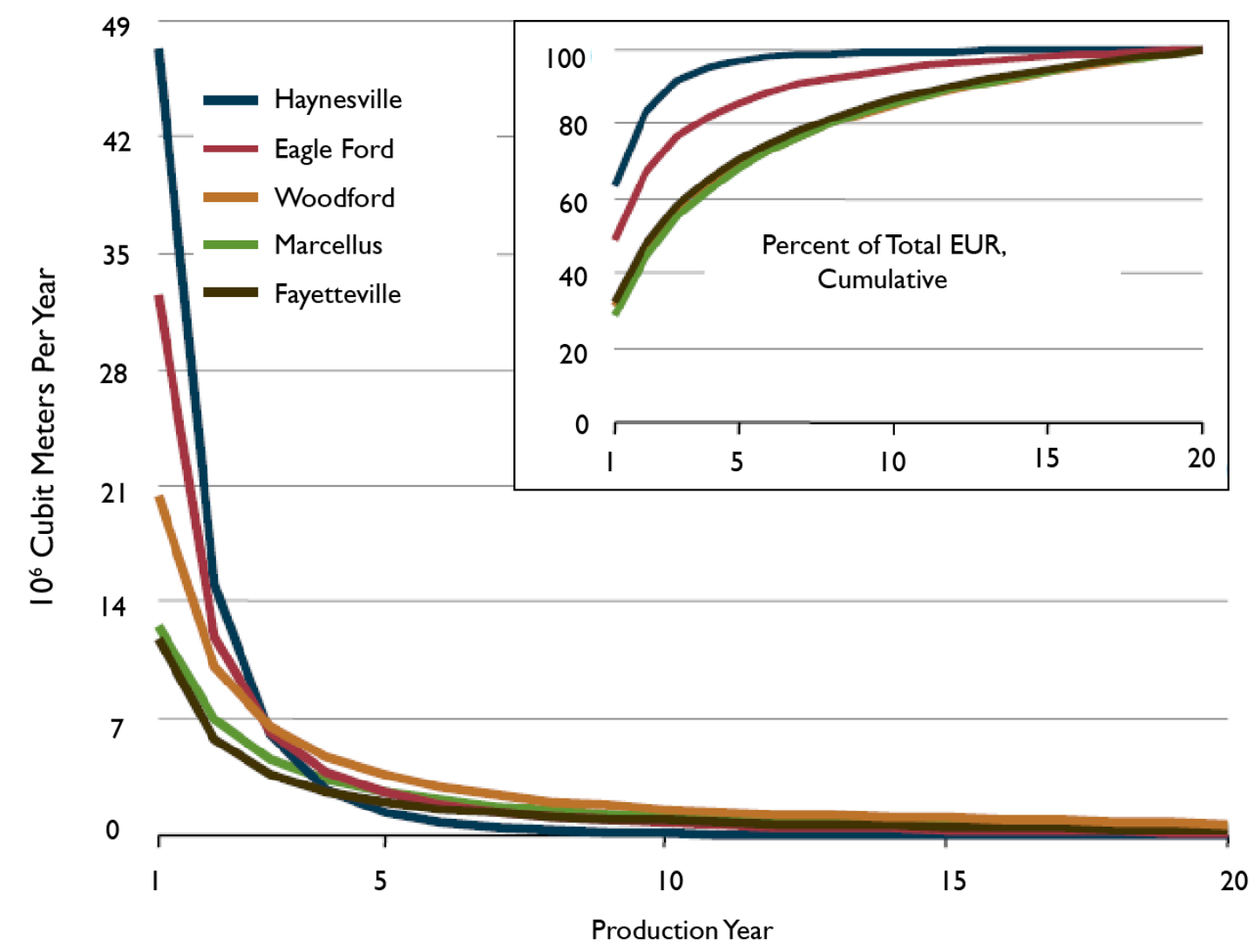

Figure 4.2. Average production profiles for shale gas wells in major U.S. shale plays by years of operation. Derived from EIA's report. ${ }^{47}$

The processes that govern gas transport out of a shale formation can provide a great deal of insight into the processes that control gas injection back into the same formation, as shown in Chapter 3. Once a well is ready to be retired because its production is low, $\mathrm{CO}_{2}$ could be injected into the same wellbore. Pumping would be needed to overcome residual pressures within the formation as well as friction losses through the wellbore. The $\mathrm{CH}_{4}$ 
transport processes that control during production would impact $\mathrm{CO}_{2}$ transport during injection though the two molecules have a few important differences in this context. The kinetic molecular diameter of $\mathrm{CO}_{2}$ is a little bit smaller than $\mathrm{CH}_{4}$ and so it would be able to enter regions of the rock that were harder for $\mathrm{CH}_{4}$ to penetrate. ${ }^{122}$ In addition, the solid organic species, kerogen, preferentially sorbs $\mathrm{CO}_{2}$ which would partition to these surfaces. ${ }^{52}$ At comparable pressures and temperatures, $\mathrm{CO}_{2}$ is denser than $\mathrm{CH}_{4}$ and so it is expected to store more mass in the same pore space. It also stands to reason that the lithostatic and hydrostatic pressures within the formation would close many of the fractures and pores between the time that the natural gas is produced and the $\mathrm{CO}_{2}$ is injected. This has yet to be demonstrated in the field. ${ }^{153}$ In light of these facts, a growing number of papers have sought to model the processes that would govern $\mathrm{CO}_{2}$ transport back into a fractured shale formation and produce an estimate of sequestration capacity.

\section{1 $\mathrm{CO}_{2}$ Storage Capacity Models}

The papers that have estimated a $\mathrm{CO}_{2}$ storage capacity in hydrocarbon-depleted shale formations have applied a variety of different modeling approaches ranging in complexity from relatively simple first-principles calculations of formation volume up to complex reservoir simulations. Most papers focused on using these formations as repositories for $\mathrm{CO}_{2}$ solely but a subset looked at the viability of deploying enhanced methane recovery using $\mathrm{CO}_{2}$ in fractured shale formations. This section provides a brief overview of modeling approaches and the findings of these papers.

The first report to propose the use of shale formations as possible repositories for GCS came from the Kentucky Geological Survey in 2005 when Nuttall et al. attempted to quantify the sequestration capacity of the Devonian Big Sandy formation. ${ }^{10}$ To estimate 
the sequestration capacity, the authors conducted gas sorption experiments on ground samples and used these sorption isotherms along with estimated thickness and areal extent of the formation to estimate the amount of gas that could be sorbed to the existing

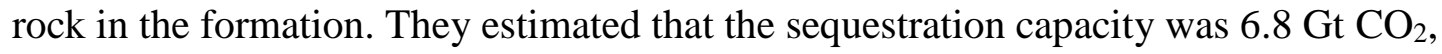
which is approximately equivalent to all US greenhouse gas (GHG) emissions in one year. The report did not, however, consider mass transfer limitations that are dominant in any fluid transport through a low permeability shale. By using sorption isotherms obtained from batch experiments of well sorted and well mixed shale grains, the authors provided an approximation of the theoretical upper limit on the amount of $\mathrm{CO}_{2}$ that could be stored in the Devonian formation.

Busch and colleagues attempted to quantify the sequestration capacity of shales in an effort to quantify the suitability of caprocks in the context of $\mathrm{CO}_{2}$ sequestration. ${ }^{8}$ Like the Nuttall's work, they conducted gas sorption experiments on well-characterized shale samples from the Muderong Shale in Australia but they also added a diffusive transport element to their estimate. They focused specifically on the clay minerals within the shale to understand the role of seal integrity and $\mathrm{CO}_{2}$ transport potential. Even though $\mathrm{CO}_{2}$ would preferentially sorb to kerogen, certain clay species such as smectite could trap $\mathrm{CO}_{2}$ between their expandable surface layers and provide additional capture potential and permeability reductions. ${ }^{154}$

Using a similar volume-based approach, the National Energy Technology Laboratory of the US DOE developed a screening tool to assess the storage capacity of depleted shale formations before more detailed site specific analysis can be performed. ${ }^{15}$ Their model is based on formation volume, porosity, and sorption data. To account for the large amount 
of uncertainty intrinsic in such an approach, the DOE applied efficiency factors that help address limitations associated with the development of wells and the mass transfer of gas through the formation. Though simple to use, the primary drawback to all of these volume-based methods is the need for these factors that adjust for uncertainties in mass transfer, formation thickness, and other critical parameters.

Kang et al. advanced the understanding of gas transport through shale by developing a novel modeling platform based on their experimental analyses. ${ }^{9}$ Their group collected multiple-stage isothermal adsorption measurement and pulse-decay tests to estimate the diffusion coefficient of both $\mathrm{CH}_{4}$ and $\mathrm{CO}_{2}$. They then proposed a mathematical model that combines both the diffusion in organic and inorganic substances as well as adsorption on kerogen surface to describe the overall mass transfer process. Their model includes the isothermal pore compressibility effect (effective stress) and the presence of an adsorption layer. One of their primary findings was that $\mathrm{CO}_{2}$ moves through the inorganic matrix to reach the organic material that is interspersed but not connected in the bulk rock. They suggest that even though Darcy flow can be used to understand transfer through the bulk fractured rock, other processes govern on smaller scales. Their pulsedecay results were used to derive the gas diffusivity in shales and they combined these data with isothermal adsorption results and modeling to predict $\mathrm{CO}_{2}$ sequestration capacity. However, no carbon storage capacity in a specific formation was targeted in their work.

A different, and much simpler approach, based on historical $\mathrm{CH}_{4}$ production was proposed by our research group, ${ }^{12}$ as shown in Chapter 3. In this approach, $\mathrm{CH}_{4}$ production data from the shale formations such as Marcellus Shale in Pennsylvania and 
Utica Shale in Ohio were used to estimate the gas diffusivity through these unconventional wells. Production decline curves from a large number of wells (>200) were collected and these curves were used to fit a diffusion model of the volume of gas in place to estimate an effective diffusivity. Gas sorption isotherms and the ratio of $\mathrm{CO}_{2}$ diffusivity to $\mathrm{CH}_{4}$ diffusivity were obtained from the literature. Details about the estimation could be found at Chapter 3. We estimated that between 2018-2030, the Marcellus shale could store between $10.5-18.5 \mathrm{Gt}$ of $\mathrm{CO}_{2}$ and Utica shale can provide the carbon storage capacity around $1.4 \mathrm{Gt}$.

Edwards et al. expanded on this approach using a multi-component model that took into account the transient response of the shale wells to understand how this approach could be deployed over time. ${ }^{155}$ Similar to Tao et al.'s work, a diffusion model was coupled with gas adsorption data. Two injection scenarios were studied: constant injection pressure and constant injection rate. Their group estimated that under a constant injection rate of 100 tonnes of $\mathrm{CO}_{2}$ per day, the pressure would reach the formation pressure within 10 years. Alternatively, if $\mathrm{CO}_{2}$ were to be injected at constant pressure, they found that the injection rate would decline very quickly. The authors concluded that a constant pressure injection mode would minimize the risk of refracturing the rock. It is estimated that the Marcellus shale in Pennsylvania could store 7.2-9.6 Gt of $\mathrm{CO}_{2}$ in existing and permitted wells (March 2015) and the average capacity per well is $0.6 \mathrm{Mt}$. The authors argue that this storage capacity per well is smaller than would be expected in a saline aquifer.

Chen et al. proposed a pressure transient method that is based on techniques developed for estimating the carbon storage capacity of saline aquifers. ${ }^{156}$ Those techniques were 
based on the assumption that the volume of displaced connate fluid is proportional to that of cumulative injected $\mathrm{CO}_{2}$, which can be calculated by average pressure buildup in the storage formations and some basic petrophysical characteristics of the formation (including the total volume of the formation). This model was applied to the New Albany Shale and the authors report that $2.64 \times 10^{9} \mathrm{~m}^{3}$ (equivalent to $4.7 \mathrm{Mt}$ when the density of $\mathrm{CO}_{2}$ is $1.81 \mathrm{~kg} / \mathrm{m}^{3}$ ) could be stored for a single well until the pressure builds up to the constrained pressure. The authors used a numerical reservoir simulation as a benchmark and found that their results were generally consistent. They also performed a sensitivity analysis suggesting that their results are highly sensitive to the stress sensitivity coefficient, because increasing pressures would increase the permeability of the rock.

Several papers have reported on models developed for the dual purpose of estimating enhanced $\mathrm{CH}_{4}$ production and storing $\mathrm{CO}_{2}{ }^{157-159}$ Such an approach would have several key advantages. In particular, it could avoid the drop in pressure during $\mathrm{CH}_{4}$ production and could help increase $\mathrm{CH}_{4}$ production because of preferential sorption of $\mathrm{CO}_{2}$. Godec et al. applied such a model to the Marcellus formation using well-log data (TOC content, etc.) and formation volume to estimate the maximum $\mathrm{CO}_{2}$ storage capacity and enhanced gas recovery factor. ${ }^{157}$ Then the authors used a reservoir simulator (COMET3) with a triple porosity/dual permeability configuration to estimate the amount of additional gas recovery that could be achieved by using $\mathrm{CO}_{2}$ to stimulate the well. The authors reported that theoretical storage capacity in the Marcellus Shale is $1.6 \mathrm{Mt} / \mathrm{km}^{2}$ (equivalent to $55 \mathrm{Gt}$ for the entire Marcellus shale) and that production can be increased by $7 \%$ using $\mathrm{CO}_{2}$ injection wells spaced $65-70 \mathrm{~m}$ from the production well. Like the volumetric models described above (e.g., Nutall et al.), this model makes many assumptions about formation 
thickness, area, porosity, water saturation, etc. all of which introduce uncertainty to the model. Their results do, however, match historical gas production logs effectively.

Liu et al. reported on a model for estimating the enhanced gas recovery (EGR) potential of the New Albany Shale. ${ }^{159}$ Their model is based on a dual porosity/dual permeability configuration that combines both Darcy flow and diffusion. Adsorption/desorption, residual trapping and solubility trapping are also all included. They estimate that $4 \times 10^{4}$ tonnes of $\mathrm{CO}_{2}$ could be injected into a single shale well over a 5-year period. Their model suggests that $90 \%$ of that gas would exist sorbed to the shale while residual and solubility trapping would account for less than $5 \%$ of the total storage capacity. The authors did look at geochemical interactions between the $\mathrm{CO}_{2}$ and the chemical components of the shale but concluded that mineralization would contribute little to overall trapping. As for EGR efficiency, the authors found little benefit to injecting $\mathrm{CO}_{2}$ to stimulate $\mathrm{CH}_{4}$ concluding that it only improved yields by $1 \%$. Part of this could be explained by the fact that the authors chose the New Albany Shale to test their model. Unlike most other major shale plays, the New Albany is relatively shallow (420m) and so at the bottom bole pressure of 7.4 $\mathrm{MPa}$, the $\mathrm{CO}_{2}$ may still exist as a gas.

Sun et al. developed a dual porosity model to account for the differences in transport processes between fractures and pores in the bulk. ${ }^{158}$ Their so-called Dusty Gas Model (DGM) incorporated viscous flow, Knudsen flow and diffusion. A finite element simulation software (COMSOL) was used to validate this dual porosity behavior. The authors estimated that for a single well, a total of 70 tonnes $\mathrm{CO}_{2} /$ year could be buried in an injection well adjacent to a $\mathrm{CH}_{4}$ production well. They found that $\mathrm{CO}_{2}$ would stimulate $\mathrm{CH}_{4}$ production and that the displacement front would arrive at the $\mathrm{CH}_{4}$ 
production well within 200 days of beginning the $\mathrm{CO}_{2}$ injection. The authors assumed that the wells would be pressurized up to $7 \mathrm{MPa}$, which is lower than most large shale formation in US but it provides a margin of safety. Given that in these shallow formations reservoir pressure and temperature conditions are near the critical point for $\mathrm{CO}_{2}$, estimates would be highly sensitive to $\mathrm{CO}_{2}$ phase behavior and density, which can vary greatly near its critical point.

\subsection{Meta-Analysis of Published Results}

The papers described above provide a range of estimate for the storage capacity of depleted shale formations. Some of these estimates are not immediately comparable, either because the basis for the analysis is different (e.g., per well or per $\mathrm{km}^{2}$ ) or because the formation for which the sequestration capacity is estimated are different (e.g., New Albany or Marcellus). As a first step toward conducting a meta-analysis of these studies, the raw data are presented in Table 4.1. The Table also presents information about the formation that was used to validate the model as well as the type of model that the authors employed. 
Table 4.1. Published estimates for $\mathrm{CO}_{2}$ storage in hydrocarbon-depleted shale formations

\begin{tabular}{|c|c|c|c|}
\hline Resource & Method & Shale formation & Storage capacity \\
\hline Nuttal et al. (2005) & Volumetric & Devonian & $1-3.6 \mathrm{Mt} / \mathrm{km}^{2}$ \\
\hline Busch et al (2008) & Volumetric & - & - \\
\hline Kang et al. (2011) & $\begin{array}{l}\text { Multi-scale } \\
\text { transport }\end{array}$ & - & - \\
\hline Tao et al. (2013) & Production & Marcellus & $\begin{array}{l}1.04-1.84 \times 10^{4} \\
\text { Mt (in } 13 \text { years) }\end{array}$ \\
\hline \multirow{2}{*}{$\begin{array}{l}\text { Edwards et al. } \\
\qquad(2015)\end{array}$} & \multirow{2}{*}{ Production } & Marcellus & $7.2-9.6 \times 10^{3} \mathrm{Mt}$ \\
\hline & & Barnett & $2.1-3.1 \times 10^{3} \mathrm{Mt}$ \\
\hline Chen et al. (2015) & $\begin{array}{l}\text { Pressure } \\
\text { transient } \\
\text { analysis }\end{array}$ & $\begin{array}{l}\text { New Albany } \\
\text { Shale }\end{array}$ & 4.7 Mt/well \\
\hline Godec et al. (2013) & $\begin{array}{l}\text { Volumetric/re } \\
\text { servoir } \\
\text { simulation }\end{array}$ & Marcellus & $5.5 \times 10^{4} \mathrm{Mt}$ \\
\hline Liu et al. (2013) & $\begin{array}{l}\text { Reservoir } \\
\text { Simulation }\end{array}$ & $\begin{array}{l}\text { New Albany } \\
\text { Shale }\end{array}$ & $\begin{array}{l}0.04 \mathrm{Mt} / \text { well (in } \\
5 \text { years) }\end{array}$ \\
\hline Sun et al. (2013) & $\begin{array}{l}\text { Reservoir } \\
\text { Simulation }\end{array}$ & - & $\begin{array}{l}2.8 \times 10^{-5} \\
\text { Mt/well/year }\end{array}$ \\
\hline
\end{tabular}

\subsubsection{Harmonization}

To facilitate direct comparison of these results, the $\mathrm{CO}_{2}$ storage capacity of each formation was harmonized on a per-well basis over a 20-year time horizon. In practice, wells would be used as injection sites until pressures in the borehole reached some maximum safe value. In practice, using downhole pressure without a full reservoir model for each location was not feasible and so assuming that an injection process would last 20 years was an effective approximation based on the work of Edwards and others.

For Edwards et al., Godec et al., and Tao et al., the total amount of $\mathrm{CO}_{2}$ in the Marcellus or Barnett shale was estimated and the capacity for an individual well was derived from 
the total well numbers in those formations, e.g., 18273 wells for Marcellus and 16663 wells for the Barnett as of March 2015, according to the estimates used in Edwards et al. In Liu et al. and Sun et al., $\mathrm{CO}_{2}$ injection capacity was reported for a single well over a period of 5 or 1 years, respectively. Their estimates were harmonized to a 20 -year time horizon as a result. Nuttal et al reported the storage capacity based on the area of the Devonian shale and estimated that 1-3.6 $\mathrm{Mt}$ of $\mathrm{CO}_{2}$ could be injected per $\mathrm{km}^{2}$. Assuming that well spacing would require a footprint of $4.7 \mathrm{~km}^{2}$ per well, the $\mathrm{CO}_{2}$ storage capacity per well was derived.

The results of the harmonization are presented in Table 4.2 and in Figure 4.3. Overall, the results are remarkably consistent given the range of modeling approaches used by the authors. Nuttal's estimate for the Devonian shale is the biggest outlier at $8.7 \mathrm{Mt} / \mathrm{well}$ but the uncertainty in this report is large and authors acknowledge that the sequestration capacity per well could be much lower. Sun et al. provide an estimate that is obviously lower than others because they focused on enhanced shale gas production through $\mathrm{CO}_{2}$ injection and the well they simulated is just around $140 \mathrm{~m}$ long as they proposed at this distance the $\mathrm{CO}_{2}$ front could move to a shale gas production well within one year. As a comparison, a typical shale gas well would extend for many kilometers and could provide much more storage capacity. We assume that a shale gas well extends 1.6 kilometers laterally and for each wellpad that there are 10 wells drilled for the multi-well drilling technology. Based on this updated well configuration, the Sun's estimate for storage would be $0.064 \mathrm{Mt} /$ well/20 years, which is still at least one order of magnitude lower than other estimates. Edward et al. and Tao el al. based their estimates on production curves and, as such, the results are largely comparable even though the estimates from 
Edward et al. are lower because of their more complete treatment of pressure build up in the shale and the limitations that pressure would create for injection rate. Godec et al. have an estimate that is on a high end of the others because, like the other volume-based methods, it may not fully capture mass transfer limitations.

Table 4.2. Summary of harmonized $\mathrm{CO}_{2}$ storage capacity in shale formations

\begin{tabular}{lll}
\hline Resource & Shale formation & $\begin{array}{l}\text { Average Storage capacity } \\
(\text { min, max estimates })(M t / w e l l / 20 y e a r)\end{array}$ \\
\hline Edwards et al. (2015) & Marcellus & $0.46(0.39,0.52)$ \\
\cline { 2 - 3 } & Barnett & $0.16(0.13,0.19)$ \\
\hline Chen et al. (2015) & New Albany & 4.7 \\
\hline Tao et al. (2013) & Marcellus & $1.2(0.87,1.55)$ \\
\hline Godec et al. (2013) & Marcellus & 3.0 \\
\hline Liu et al. (2013) & New Albany & 0.16 \\
\hline Sun et al. (2013) & N/A & 0.064 \\
\hline Nuttal et al. (2005) & Devonian & $8.70(0.47,16.92)$ \\
\hline
\end{tabular}

The average total storage capacity for a well is on the magnitude of 1 Mt over the whole life cycle of the well. This harmonization is, of course, very coarse and there are a number of factors that would impact these estimates specifically the use of a 20 year well life and the nominal assumption that well architecture will be similar in different formations. The production decline curves, and hence the length of time a well is in production or used for injection, and the well architecture (e.g., the number of laterals is 
different, etc.) will impact these estimates. Also, the different depths of these formations and the resulting pressure profiles will impact the injection rates and the storage capacity. The degree to which these uncertainties overwhelm others associated with these estimates and which were not directly quantified in any of the models (e.g., stress-induced hysteresis) remains to be determined.

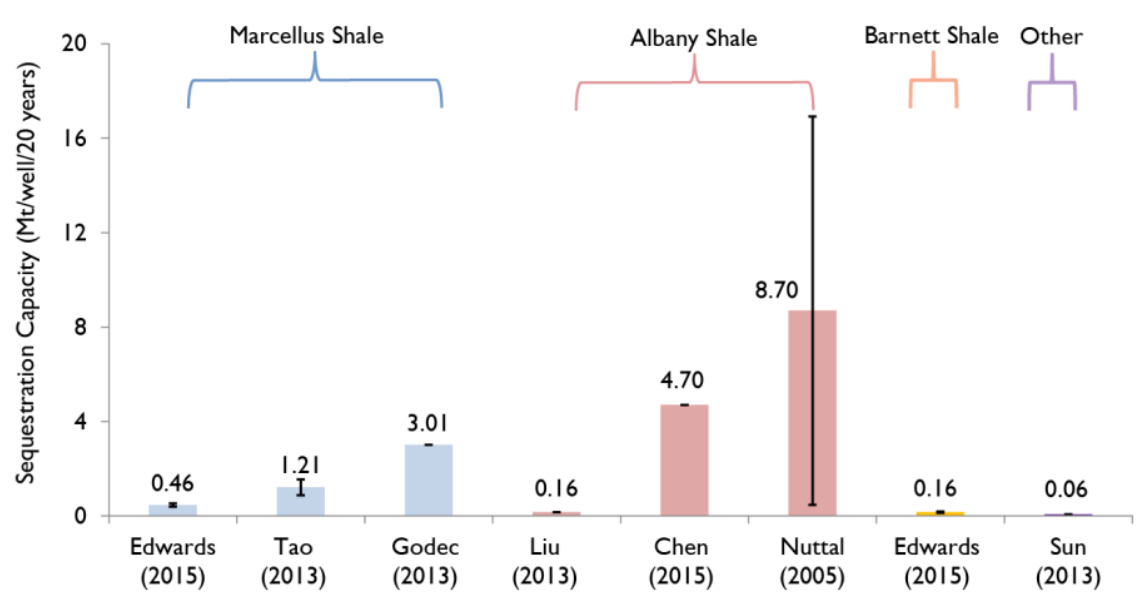

Figure 4.3 Harmonized estimates of $\mathrm{CO}_{2}$ sequestration capacity for a single well per 20 years. The results are clustered by different formations (Marcellus, Albany and Barnett formations) according to the target shale the authors studied.

\subsubsection{Sequestration capacity of the United States}

In light of these harmonized estimates for sequestration capacity, we attempted to develop an overall sequestration capacity for the entire United States using an updated version of our model. ${ }^{137}$ To facilitate comparison with the papers reviewed here, we updated and expanded the scope of our model. In particular, we incorporated some of the phenomenological relationships reported in these other papers. In particular, we updated diffusivity numbers for the top shale gas producing formations in the United States, we added water saturation, and updated our ratio of free phase gas to adsorbed gas in our method. Water saturation was assumed to be between 0.1 and 0.3 , and the free phase gas to adsorbed gas ratio was assumed to be between 0.5 and 2 . This adjusted model was then 
used to produce a high-level estimate for the top producing shale formations in active development. The six largest gas shale formations in the US: The Marcellus (in Pennsylvania, New York, and West Virginia), Haynesville (Texas/Louisiana), Barnett (Texas), Fayetteville (Arkansas), Woodford shale (Oklahoma) and Eagle Ford shale (Oklahoma) were included in our analysis since they contain an estimated $88 \%$ of US domestic shale gas production (through 2040). To enable this modeling, we derived the prediction of gas production and newly drilled wells according to their current status for each shale formation.

We made a variety of simplifying assumptions to enable this modeling effort, which impacted the absolute estimates of shale sequestration capacity but aided in comparing the results with the harmonized data. We assumed that shale gas production wells would be operated for 20 years before they would be retired and available for $\mathrm{CO}_{2}$ storage. To predict the $\mathrm{CO}_{2}$ storage capacity in a 20-year time frame, we projected newly drilled well numbers for each formation according to their current activity. The $\mathrm{CH}_{4}$ diffusivity of different formations were derived from the decline curve, shown in Figure 4.2, by fitting the gas diffusion model previously described by our group. ${ }^{12}$ Coupled with the EUR for each well, the prediction of $\mathrm{CO}_{2}$ storage capacity for those six shale formations was calculated. The parameters used as inputs for this modeling exercise are summarized in Table 4.3. 
Table 4.3 Summary of formation-scale modeling parameters used to estimate the $\mathrm{CO}_{2}$ storage capacity in the six largest shale plays in the United States.

\begin{tabular}{llll}
\hline $\begin{array}{l}\text { Shale } \\
\text { formation }\end{array}$ & $\begin{array}{l}\text { Shale gas resources } \\
(\mathrm{Tcf})^{\mathrm{a}}\end{array}$ & $\begin{array}{l}\text { Projected newly drilled } \\
\text { well/year }^{\mathrm{b}}\end{array}$ & $\begin{array}{l}\text { EUR for a single well } \\
(\mathrm{Bcf})^{\mathrm{c}}\end{array}$ \\
\hline Marcellus & 410 & 300 & $2.58 \pm 10 \%$ \\
\hline Haynesville & 75 & 700 & $1.69 \pm 10 \%$ \\
\hline Barnett & 43 & 500 & $1.28 \pm 10 \%$ \\
\hline Fayetteville & 32 & 400 & $2.89 \pm 10 \%$ \\
\hline Woodford & 22 & 800 & $1.78 \pm 10 \%$ \\
\hline Eagle Ford & 21 & & \\
\hline
\end{tabular}

a Estimates of undeveloped technically recoverable shale gas and resources remaining in discovered shale plays as of January $1,2009 .{ }^{120} 1 \mathrm{Tcf}=2.83 * 10^{10} \mathrm{~m}^{3}$, $1 \mathrm{Bcf}=2.83 * 10^{7} \mathrm{~m}^{3}$

b Data derived from the work published by Hughes ${ }^{160}$, EIA $^{120}$ and Baihly ${ }^{161}$

c Data derived from EIA ${ }^{162}$

The results of this analysis are shown in Figure 4.4. They suggest that overall $\mathrm{CO}_{2}$ storage capacity in shale formation ranges between $21.8 \mathrm{Gt}$ and $38.7 \mathrm{Gt}$ over a 20-year period. That represents nearly $100 \%$ of $\mathrm{CO}_{2}$ emissions from US power plants assuming that emission rates stay constant ( $2 \mathrm{Gt} \mathrm{CO}_{2}$ emitted per year). This storage capacity is somewhat concentrated geographically with most of the capacity in the region of the Marcellus shale (Pennsylvania, New York, West Virginia) and then in Texas, Oklahoma, Louisiana, and Arkansas where all the other shale formations modeled here are located. The location of these shale formations is important because the transport of $\mathrm{CO}_{2}$ via pipelines is costly and having the injection wells located near urban centers and power plants is critical for successful deployment of this approach. In addition, the storage capacity for a single well would generally not be large enough to store all the emissions from a single power plant, as highlighted by Edwards. ${ }^{155}$ Therefore, this approach has the 
best chance of being deployed in a region where clusters of wells could be developed for injection.

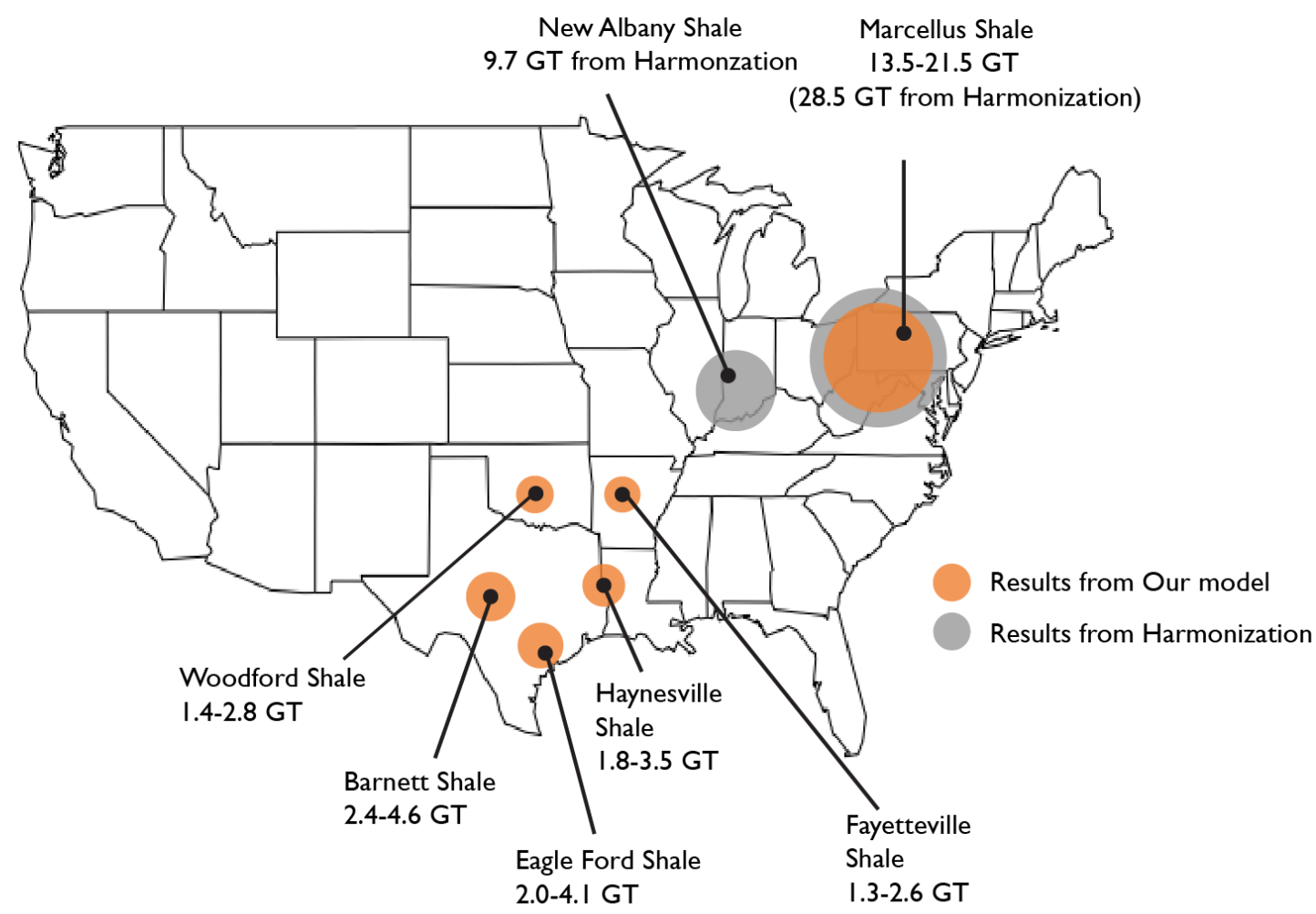

Figure 4.4. The estimation of $\mathrm{CO}_{2}$ storage capacity in seven primary shale formations in US based on harmonization results and the model by Tao et al. ${ }^{12}$

The estimation of the $\mathrm{CO}_{2}$ storage capacity derived from harmonization in Marcellus and New Albany shales are also shown in Figure 4.4. The average amount of $\mathrm{CO}_{2}$ that Marcellus could sequester is $28.5 \mathrm{Gt}$, which is relatively consistent with our model, taking into consideration the differences among the values derived from different authors as shown in Figure 4.3. Similarly, the New Albany Shale could store 9.7 Gt of carbon (we assume 4000 wells would be drilled in 20 years) according to the harmonization 
result. However, because of the sizable difference between Liu and Chen's work, there is further opportunity to improve the accuracy of this estimation.

It is valuable here to consider the opportunities and limitations of storing $\mathrm{CO}_{2}$ in depleted shale wells in terms of the availability of other reservoirs like saline aquifers. Saline aquifers are attractive target formations because they are widely distributed and they have a large storage capacity. One estimate is that the storage capacity of saline aquifers in the United States is over $8000 \mathrm{Gt} \mathrm{CO}_{2} \cdot{ }^{163}$ Even though on a national scale, this is a very large storage capacity, on a regional scale the storage potential is comparable. In the Marcellus region, for example, saline aquifers in Ohio, Pennsylvania, and West Virginia could store $11 \mathrm{Gt}, 19 \mathrm{Gt}$ and $21 \mathrm{Gt}$ of $\mathrm{CO}_{2}$ respectively. This is on the same order of magnitude as the estimates reported here for depleted shale formations. In contrast, Texas and Louisiana have an enormous saline aquifer capacity (1665 Gt and 753 Gt, respectively) and so here the impacts to sequestration in shale formations will have to be weighed against their capacity to serve as caprocks. In light of recent seismicity concerns in this region, the pore pressure impacts of storing in these formations will also need to be considered. Of course, there are many regions of the country where shale formations are not available, but for those with a choice between saline aquifers and depleted shale formations, the marginal economic, regulatory, and safety impacts of these two repositories will need to be weighed to decide which is more advantageous.

\subsubsection{Uncertainty and data needs}

The papers surveyed here used a wide range of data sources and different methods and yet their findings were generally consistent and suggest that hydrocarbon-depleted shale formations have a significant storage potential. Some of the papers included here, 
particularly those using the volumetric approach, cited uncertainty in petrophysical parameters (e.g., permeability, organic content, water saturation, formation thickness, etc.) as the biggest limitation to their estimates. Certainly for those models, better data would lead to better estimates. Those papers that relied on historical production curve fitting were able to bundle many of these uncertainties into effective empirical parameters and in that sense avoided much of the uncertainty inherent in making these forecasts. Those papers did point to a few critical research questions that need to be better understood to facilitate site specific projections and pilot scale demonstrations of the technology.

Highest on this list is understanding how these formations will respond to geomechanical stresses created by changes in pressure associated with gas production/injection and the impacts on these stresses on permeability. ${ }^{164}$ Many of the models reported here use historical curve fitting of natural gas production to calibrate their models and even though most of these acknowledge that changes in permeability are likely and they may include a coefficient to account for this effect, quantitative, data-based estimates for this effect are generally lacking in the literature. ${ }^{165}$ Qualitatively, we expect that many of the nanopores within the bulk shale will likely become inaccessible after the pore pressure reaches some lower limit during gas production. In larger fractures, proppants, typically sand, are already used to maintain fracture aperture during production but these fracture and pore networks are likely to succumb to geotechnical forces over time as the pressure in the formation declines. This permeability hysteresis is likely to have important impacts on storage capacity. ${ }^{166}$ 
Geochemical reactions, like geomechanical forces, can impact the permeability of these formations. The underlying mechanisms are different but the effect on permeability reduction could undermine this approach in much the same way. The most significant geochemical effect is likely to be swelling of shale formations with high carbon and/or clay content. The primary limitation for enhanced coal-bed methane production using $\mathrm{CO}_{2}$ is swelling in the organic phase of the rock. Shales typically have much lower carbon content than coals so this effect is less likely to be limiting but it may be a factor. Moreover, some shale formations contain appreciable concentrations of clay species that expand when $\mathrm{CO}_{2}$ is taken up within the clay surface layers. The effects of these swelling properties have been recently reported in saline aquifers but their marginal impact on shale permeability, which is so much lower to begin with, could appreciably reduce the efficiency of this approach.

The time dependency of these injection processes is something that only a few papers investigated in detail. Injection rates would be constrained by factors including pump configuration and efficiency and wellbore pressure response. It is very likely that formations would need to be overpressurized to drive $\mathrm{CO}_{2}$ into the bulk shale matrix in order to maximize the amount of $\mathrm{CO}_{2}$ that could be stored within the rock. However, the response of these formations to this pressurization is likely to differ and as a consequence, the impact on overall storage capacity will depend on how the formation responds to this pressurization. The mechanical properties of these target formations must be better characterized in order to prevent undesirable seismic activities.

Finally, the papers included here focused on (dry) gas formations because these are likely to be more easily repurposed for $\mathrm{CO}_{2}$ storage. Mass transfer limitations through fluid 
phases could impact the effective gas diffusivity through these formations. Water has been shown to have an antagonistic effect on equilibrium gas sorption for both $\mathrm{CO}_{2}$ and $\mathrm{CH}_{4}$ (though to differing extents). ${ }^{167}$ Most hydraulically fractured shale wells contain residual moisture associated with the fluids used to fracture the well. Understanding how the presence of this water can impact sorption is important for improving on the estimates reported here.

\subsection{Conclusions}

A meta-analysis was performed on eight studies that reported on the $\mathrm{CO}_{2}$ storage potential of hydraulically fractured shale formations depleted of hydrocarbons. The purpose of this meta-analysis was to catalog the methodologies, harmonize the findings of these studies, and make broad recommendations for research needs that would help further understand this process. The papers surveyed here brought a variety of experimental and modeling techniques to bear on this problem. Experimentally, some papers report isothermal sorption data, mineral characterization and TOC content measurements. The modeling approaches ranged from those involving volume-based estimation of storage capacity, those based on curve fitting and historical production, and those based on more complex reservoir simulation. A subset of these studies attempted to model the enhanced natural gas production using $\mathrm{CO}_{2}$ as a working fluid coupled with $\mathrm{CO}_{2}$ storage.

The results of these studies were broadly consistent. The scale of current shale gas production activities and the need to develop emissions management strategies for this activity suggest that at a minimum, this could be part of a broader suite of technologies used to mitigate carbon emissions associated with power production. 
Based on the lessons learned from comparing these papers, we modified our model for estimating $\mathrm{CO}_{2}$ storage potential in depleted shales and used it to estimate the storage potential for the largest shale formations in the United States. The results suggest that over the coming decades, these formations could store almost all of the $\mathrm{CO}_{2}$ generated from stationary sources, such as power plants. Much of this storage capacity is geographically concentrated in two regions of the United States and so a major limitation to deploying this technology is the ability to develop a $\mathrm{CO}_{2}$ pipeline distribution network that could link sources and sinks. Our model did not include time effects and efforts to deploy this technology would require that the relationship between injection rates and pressure build up in the formation be better understood to predict how quickly individual wells could be pressurized without re-fracturing the well.

This chapter has not addressed the economic and regulatory issues that could drive (or impede) this approach. Safety and risk issues associated with this strategy would need to be quantified in light of the seismic risks posed by fluid reinjection. The costs of using these depleted wellbores would also need to be compared to the cost of injection into saline aquifers, which are more abundant and geographically distributed. Given that most of the costs associated with carbon capture and storage come from $\mathrm{CO}_{2}$ capture, a valuable research question would be to understand the extent to which mixed gases (e.g., flue gas or $\mathrm{CO}_{2}$ containing other acid gas species) might react when injected into a shale formation.

Currently there are no pilot-scale $\mathrm{CO}_{2}$ injection facilities planned or operated in the United States in shale formations. For the time being, that is driven by the fact that most shale wells are still in active production. In the coming decade, many of these wells will 
be retired, which will provide the opportunity for this technology to be deployed. Pilot scale implementation of this technology would shed light on a number of the research questions identified herein, specifically the impacts of geomechanical and geochemical alternation in these rocks during the production and subsequent injection phases of the well life cycle. 


\section{CHAPTER V}

\section{CARBONATION AND HYDRATION OF Ca-SILICATE IN POROUS MEDIA}

Securing underground formations and wellbores is critical for geological applications such as geological carbon storage (GCS) and hydraulic fracking. Leakage risks not only undermine engineering efficiency, but also create issues such as contamination of groundwater and induced seismicity. ${ }^{3,32,41}$ Fractures and degraded materials associated with wellbores and natural faults and fractures in the subsurface present the greatest risk for leakage. ${ }^{3,17}$ Fluid leakage from wellbores has drawn more attention recently. Normally, the parallel bedding slip within or above the reservoir or the expansion of the reservoir towards the overburden could cause damage to the well casing and lead to leakage risks. ${ }^{27}$ Kang et al. estimated that methane leakage from abandoned natural gas wells in Pennsylvania could account for $4-7 \%$ of the total anthropogenic methane emissions in the state. ${ }^{168}$ Research has been conducted to understand the mechanism behind wellbore degradation under $\mathrm{CO}_{2}$ injection conditions, where the brine is acidified by $\mathrm{CO}_{2}$ and the aqueous $\mathrm{pH}$ is approximately 3 . Kutchko et al. found that the corrosion rate of cement under $\mathrm{CO}_{2}$ sequestration conditions is about $10 \mathrm{~mm} / \mathrm{year}$ and this rate decreases over time. ${ }^{109}$ A number of studies proposed that the formation of carbonate or amorphous phase can provide a barrier for continuous diffusion and as a result, the cement surface is passivated and the corrosion process is self-limiting. ${ }^{76,83,109,169}$ However, Cao et al. reported that the flow through of $\mathrm{CO}_{2}$ saturated brine in a cement fracture may actually increase permeability by 8 times. ${ }^{110}$ Factors such as mineral heterogeneity, temperature, and mineral surface roughness could all contribute to the 
alteration of the cement. Thus, the influence of $\mathrm{CO}_{2}$ on the structure change of cement is complicated and it is challenging to create a method to mitigate wellbore material degradation and eventual leakage.

Efforts to design cements with acid resistivity have focused on using epoxy/polymer coatings and these are generally capable of protecting cement from corrosion for some time. ${ }^{170}$ In addition, carbonation methods have been developed, which improve the stability of cements. Jacquemet et al. found that cement exposed to $\mathrm{CO}_{2}$ is more resistant to further acid attack than the cement exposed to $\mathrm{SO}_{2}$, because the formation of a carbonation layer under $\mathrm{CO}_{2}$ conditions passivates the mineral surface, leading to lower reactivity. ${ }^{112}$ Also, cement with specific rheological properties that may be squeezed into wellbore gaps has been developed. This cement aims to control leaks, although this treatment may have the negative consequence of rendering the injection well unusable. For these reasons, there is a need to develop technologies that control the leakage pathways in wellbores and in the annulus between the steel casing and cement that can be deployed after the well has been completed.

In this chapter, the concept of leveraging the reaction between wollastonite (the Ca-based silicate mineral) and $\mathrm{CO}_{2}$ as a way to control the fluid flow in situ within either underground formations (e.g., in the bulk shale formations) or within the wellbore is proposed. Six hypotheses have been proposed and tested:

- The pressure and temperature conditions in shale formations are suitable for silicate carbonation to proceed spontaneously,

- The kinetics of the reactions are relatively rapid and the reaction completion time is expected to be on the order of days, 
- The mineral precipitation reactions will take place in close spatial proximity to the dissolution reactions,

- The precipitated mineral has the ability to be cementitious to help agglomerate different mineral particles,

- Mineral precipitation will decrease the porosity and permeability of porous media that is otherwise unreactive with dense $\mathrm{CO}_{2}$, and

- The hydration of calcium silicate could happen at the same time as carbonation. However, its effectiveness in changing the permeability is limited compared to carbonate minerals produced from the carbonation reaction.

This chapter has three sub-sections. The first section explores the silicate- $\mathrm{CO}_{2}$ interaction in a ground shale matrix. The primary focus in this section is the validation of hypotheses (1)-(4) with experiments in ground shale matrix. The second section focuses on the effectiveness of carbonation/hydration in changing the permeability of porous media. Instead of ground shale, sintered glass beads are used as a surrogate for porous media. The primary purpose of using sintered glass beads is matrix stability, both chemically and structurally. This means that any measured changes in permeability are due only to the interaction between silicate minerals and $\mathrm{CO}_{2}$. Additionally, the use of glass beads enables us to use x-ray tomography $\mathrm{xCT}$ imaging techniques in the near future because of superior contrast between mineral phases and glass. The use of sintered glass beads also benefits our ongoing computational modeling approach because they have a more regular pore structure than a shale matrix. This advantage could help generate better agreement between experimental work and modeling. The third section projects the application of 
the carbonation/hydration of silicate minerals under different temperature and pressure conditions. The last section discusses the environmental impacts of this novel technology.

\subsection{Silicate Carbonation in a Ground Shale Matrix}

\subsubsection{Methods and Materials}

\subsubsection{Experimental Setup}

To evaluate the behavior of silicate minerals' dissolution/precipitation in a porous shale matrix, stirred-batches and columns of ground, sorted shale at representative temperature and pressure conditions were used as chemically representative surrogates for real shale formations, as shown in Figure 5.1(a) and 5.1(b). The focus of this setup was to observe the physicochemical change of the mineral mixture in the system. The ground shale particles used in the experiments had diameters in the range of 39-177 $\mu \mathrm{m}$. Pore diameters are considered as $20-30 \%$ of the particle size $(5-30 \mu \mathrm{m})$. Here, we sought to explore the possibility of deploying these reactions within the pore spaces between shale particles (i.e., interparticle), not the nanopores present within individual shale grains (i.e., intraparticle). Recent work has used artificial fractures in rocks to characterize the role of dissolution/precipitation reactions. ${ }^{29,35,171}$ But for the reasons related to reproducibility and chemical heterogeneity listed above, we chose to explore the physicochemical characteristics of these reactions in packed columns of granular shale samples. Although these experimental configurations do not represent the physics of a deep subsurface formation, in which most of the matrix is not in powder form, they provided reproducible experimental conditions within which to perform proof-of-concept experiments. Specifically, these experimental configurations provided two advantages for the experiments carried out here. First, experiments involving natural minerals always have 
the issue of heterogeneity. However, by using ground shale particles, mineralogical heterogeneities within the rock can be evenly distributed throughout the samples to minimize experimental artifacts from spatial differences in the rock composition. Second, the goal of this work is to understand the physicochemical characterizations of the silicate carbonation reaction and the effects of precipitation reactions on porosity within the shale-particle packed columns. Our experimental configurations allow for quantification and extrapolation to large spatial extents. When selecting grain sizes for our experiments, we took care to create conditions in which the Damköhler number was comparable to what would be expected in a fracture network in the field -- on the order of $10^{-1}-10^{-3} \cdot{ }^{172}$

Shale samples were obtained from Ward's Scientific (Oil Shale \#47E7477). $\mathrm{CaSiO}_{3}$ (99\%) and $\mathrm{CaCO}_{3}(99.95 \%-100.05 \%$ dry) were obtained from Sigma-Aldrich. Foodgrade liquid $\mathrm{CO}_{2}$ was supplied by Robert's Oxygen (Rockville, MD). Shale samples were crushed and sieved. All other reagents were used as received.

Two different experimental setups were deployed:

- Well mixed batch reaction (Figure 5.1(a))

This setup was used to characterize the rate and extent of carbonation in the presence of shale over a range of formation $\mathrm{P} / \mathrm{T}$ conditions. Solid shale samples were ground using miller jars and sieved to obtain particles with diameters in the range of $39-177 \mu \mathrm{m}$. Reactants were packed in a stainless-steel reactor (MS-13, 10mL, HIP) with a mixture of $0.8 \mathrm{~g}$ ground shale sample $(39-177 \mu \mathrm{m})$ and $0.8 \mathrm{~g} \mathrm{CaSiO}_{3}$ followed by the injection of $8 \mathrm{~g}$ $\mathrm{H}_{2} \mathrm{O}$. One end of the reactor was sealed and the other end was connected to the highpressure $\mathrm{CO}_{2}$ supply system controlled by a syringe pump (500HP Teledyne Inc.). The 
reactor was fixed horizontally on Model 75 Waist Action ${ }^{@}$ shaker from Burrell Inc. for continuous shaking, aiming to eliminate the influence of mass transfer to the carbonation reaction. The reactor was placed in a LBB1-43A-1 oven from Despatch Inc. for constant temperature. The accuracy of temperature reading was $\pm 0.1^{\circ} \mathrm{C}$. The tested pressure and temperatures were set in the range of $15.2-21.4 \mathrm{MPa}$ and $75-95^{\circ} \mathrm{C}$, representing the upper and lower boundaries of the P/T conditions in the Marcellus shale formation.

- Flow through in a porous media (Figure 5.1(b))

Unlike the batch reactions, in which the shale and wollastonite particles were well mixed, in the column experiments the shale and wollastonite powders were packed into two distinct layers in a tubular reactor (316 stainless-steel, $5 \mathrm{~cm}$ length with $0.794 \mathrm{~cm}$ OD and $0.653 \mathrm{~cm} \mathrm{ID)} \mathrm{and} \mathrm{separated} \mathrm{with} \mathrm{glass} \mathrm{wool} \mathrm{to} \mathrm{prevent} \mathrm{advective} \mathrm{transport} \mathrm{of} \mathrm{wollastonite}$ powders into the shale region of the column. $\mathrm{CO}_{2}$ saturated water was then pumped through the column at temperatures and pressures representative of shale formations and the pressure within the column was maintained via a back-pressure regulator. A particlefiltering stainless-steel porous disc with average opening of $2 \mu \mathrm{m}$ was placed at the top and bottom of the column to prevent movement of grains, preserving any cementation of grains that occurred during the reaction. These discs were critical for enabling these columns to be tested without being disturbed in the mercury intrusion porosimeter. The brine $/ \mathrm{CO}_{2}$ mixture was pumped through the column at a flow rate of $0.1 \mathrm{ml} / \mathrm{min}$ so as not to disturb the column packing. 
a.

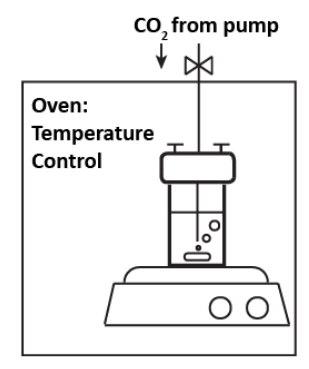

b.

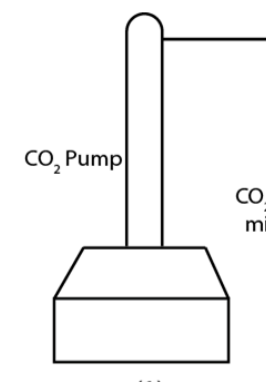

(1)

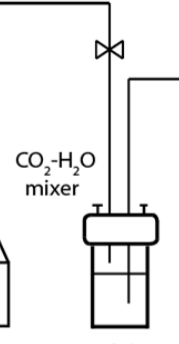

(2)

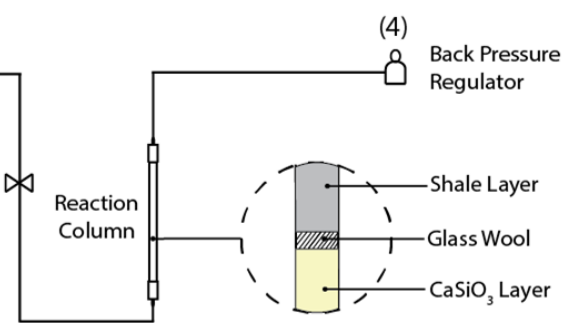

(3)

Figure 5.1. (a) Experimental setup for batch reaction and (b) flow-through experiments. An Isco syringe pump was used to supply $\mathrm{CO}_{2}$ to a pre-mixer where the brine and $\mathrm{CO}_{2}$ were equilibrated. The reaction column was housed inside an oven to ensure accurate temperature control and a backpressure regulator was used to maintain a constant pressure within the column.

\subsubsection{Characterization Method}

The morphological and elemental composition changes of mineral samples were characterized using a Quanta 650 Scanning Electron Microscope (SEM) coupled with energy dispersive X-ray spectroscopy (EDS). Au/Pd was used to coat the samples before SEM/EDS analysis. The samples were fixed on PELCO Tabs ${ }^{\mathrm{TM}}$ with carbon conductive tabs. EDS measurements were carried out at $15 \mathrm{kV}-20 \mathrm{kV}$. The chances in the composition of the samples were quantified using a PANalytical X'Pert Pro Multipurpose Diffractor (XRD) unit with monochromatic $\mathrm{Cu}-\mathrm{K} \alpha$ radiation. $\mathrm{TiO}_{2}$ was chosen as the internal reference for its distinguishable peaks relative to shale and $\mathrm{CaCO}_{3}$. Mercury Injection Porosimetry (MIP, Micromeritics ${ }^{@}$ Autopore IV) was used to analyze the effect of carbonation reactions on pore size distribution and porosity. Since there were no volume constraints for the batch samples, and the purpose of the MIP was to characterize the pore space between particles, only the samples from flow-through reactions were characterized by MIP. 
Figures 5.2 includes the $\mathrm{X}$-Ray diffraction patterns for shale, $\mathrm{CaCO}_{3}, \mathrm{CaSiO}_{3}, \mathrm{TiO}_{2}$ and the mixture of shale $+\mathrm{CaCO}_{3}+\mathrm{CaSiO}_{3}$.
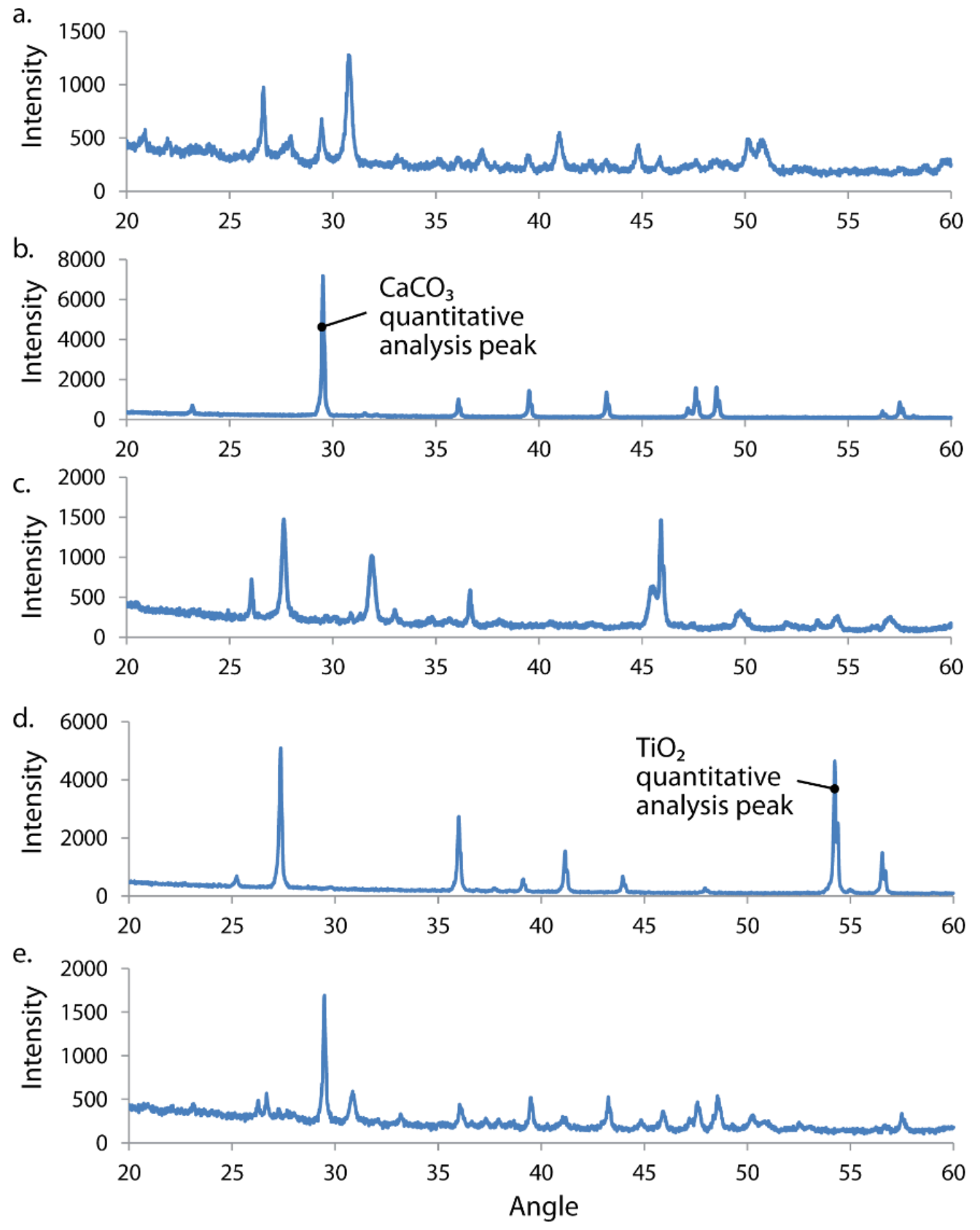

Figure 5.2. Diffraction patterns for (a) shale, (b) $\mathrm{CaCO}_{3}$, (c) $\mathrm{CaSiO}_{3}$, (d) $\mathrm{TiO}_{2}$ and (e) the mixture of shale $+\mathrm{CaCO}_{3}+\mathrm{CaSiO}_{3}$. Derived from Tao et al. ${ }^{172}$ 
Since $\mathrm{TiO}_{2}$ was used as the internal standard to quantify the mineralization extent after reaction, the ratio between the area of a specific peak from $\mathrm{CaCO}_{3}$ (with arrow in Figure $5.2 \mathrm{~b}$ ) and the area of a specific peak from $\mathrm{TiO}_{2}$ (with arrow in Figure 5.2d) was used to calculate the amount of $\mathrm{CaCO}_{3}$ produced because the amount of $\mathrm{TiO}_{2}$ reference is known based on Equation 5.1.

$$
\frac{I_{\mathrm{CaCO}_{3}}}{I_{\mathrm{TiO}_{2}}}=k \frac{X_{\mathrm{CaCO}_{3}}}{X_{\mathrm{TiO}_{2}}}
$$

$I_{\mathrm{CaCO}_{3}}$ is the XRD intensity of the selected peak for $\mathrm{CaCO}_{3}, \mathrm{I}_{\mathrm{TiO}_{2}}$ is the XRD intensity of the selected peak for $\mathrm{TiO}_{2}, \mathrm{X}_{\mathrm{CaCO}_{3}}$ is the weight fraction of $\mathrm{CaCO}_{3}, X_{\mathrm{TiO}_{2}}$ is the weight fraction of $\mathrm{TiO}_{2}$, and $k$ is an experimental constant.

A standard curve was used to derive the $\mathrm{CaCO}_{3}$ mass from the XRD diffraction peak intensity. The composition for standard samples and the standard curve are shown in Figure 5.3. The $\mathrm{x}$-axis is the mass ratio of standard $\mathrm{CaCO}_{3} / \mathrm{TiO}_{2}$ and the $\mathrm{y}$-axis is the XRD intensity ratio of $\mathrm{CaCO}_{3} / \mathrm{TiO}_{2}$. The signal ratio linearly correlated with the mass ratio with $\mathrm{R}^{2}$ value 0.96 . For a reacted sample, a fixed amount of $\mathrm{TiO}_{2}$ was added and mixed homogeneously. According to the signal ratio of $\mathrm{CaCO}_{3} / \mathrm{TiO}_{2}$, the amount of $\mathrm{CaCO}_{3}$ present in each sample was derived. The mass ratio of $\mathrm{CaCO}_{3} / \mathrm{TiO}_{2}$ in our samples fell into the same range of the standard curve. 


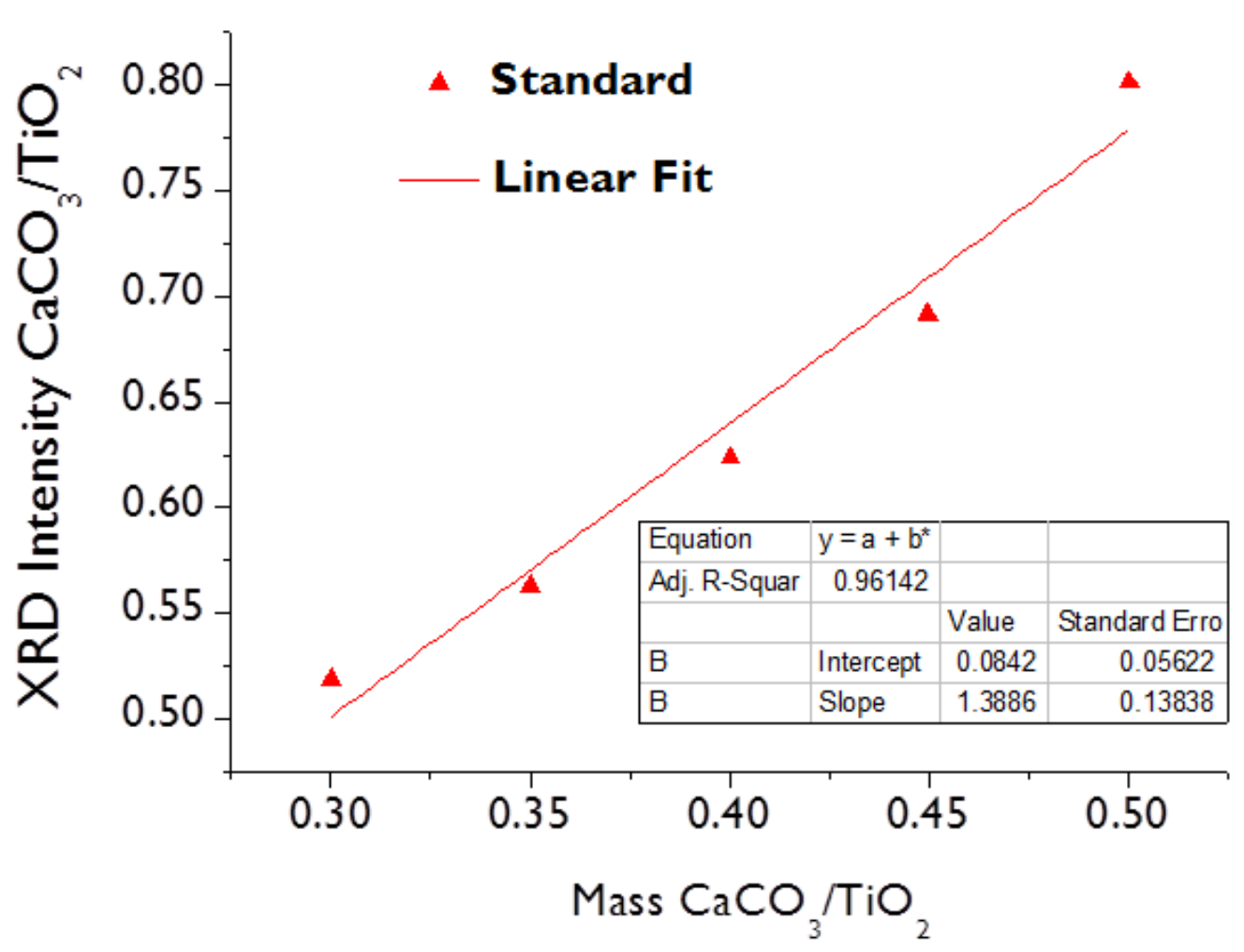

Figure 5.3. Standard curve for quantitative XRD analysis. Derived from Tao et al. ${ }^{172}$

MIP is based on the fact that mercury entry into pores is inversely proportional to applied pressure. As pressure is increased, smaller and smaller pores are filled. MIP can effectively reach pores with radius between $2 \mathrm{~nm}$ and $400 \mu \mathrm{m} .{ }^{173}$ Even though most of the porosity within the bulk shale rock has a diameter toward the lower limit of this scale, our interest was in quantifying the effect on the pores between grains, not within them, and so most of the pores we observed had a diameter on the scale of $10 \mu \mathrm{m}$. In column flow through setup as shown in Figure 5.1(b), to provide an accurate measure of permeability shift within the shale region of the column alone, the wollastonite layer of the column was removed following reaction but before MIP. 
Figure 5.4 presents a pore size distribution for a single test for a sample. The inset includes all the pore structures with diameters up to $50 \mu \mathrm{m}$ but we primarily focused on the pore size range between $0.1 \mu \mathrm{m}$ and $20 \mu \mathrm{m}$. For each flow-through experimental condition, the pore size distribution of a carbonated sample was compared to a control sample, in which the wollastonite layer was replaced by non-reactive glass beads while all other conditions were kept constant. This setup lowered the potential for reactions to impact the pore structure of the packed column and maximized the likelihood that any measured differences between the carbonated and control sample were attributed to the carbonation reaction. The mercury intrusion volume for the particle-filtering stainlesssteel porous disc in the tubular reactor was treated as background and was subtracted from the measurements. Experiments were conducted in duplicate for each condition and the pore size percentage for each condition was the average value of the different trials.

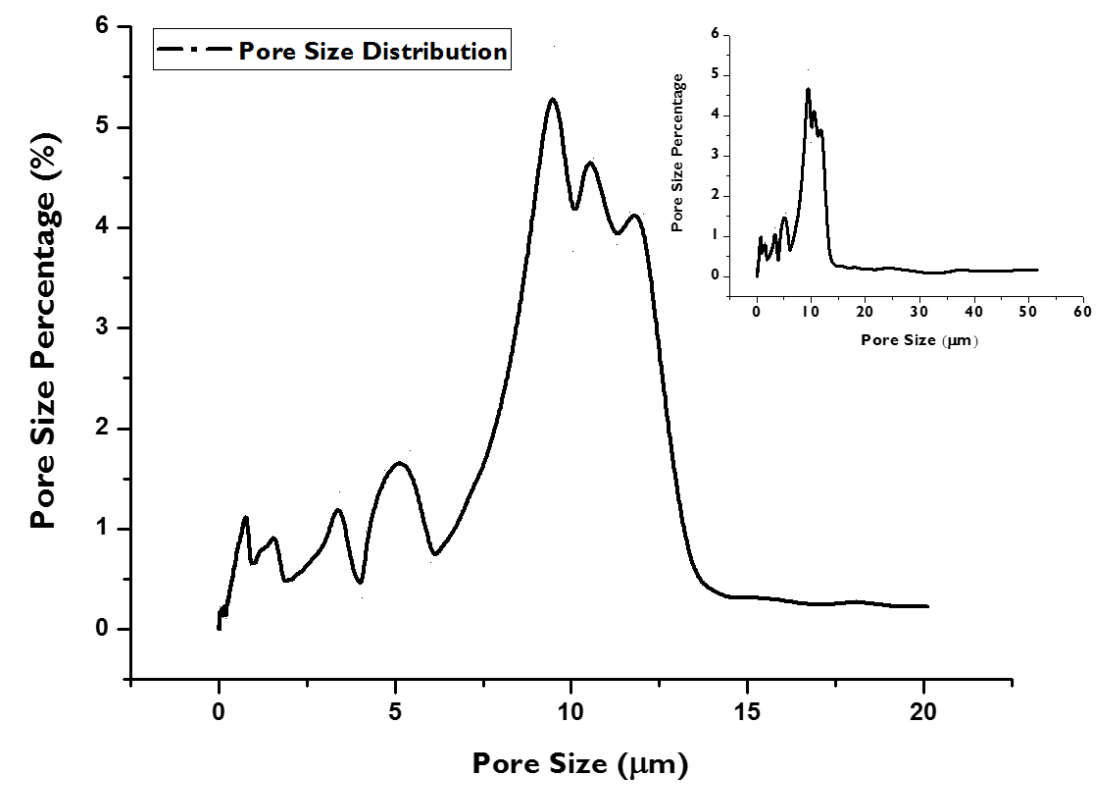

Figure 5.4. A representative MIP measurement result. The inset includes the pore sizes up to $50 \mu \mathrm{m}$. Because there are few pore spaces in the range of 20 to $50 \mu \mathrm{m}$ according to the MIP results, we truncated the figure and focused on the pores with diameters up to 20 $\mu \mathrm{m}$. Derived from Tao et al. ${ }^{172}$ 
To translate the porosity data measured experimentally using MIP into permeability estimates, we used two common quantitative relationships. Berg (1970) derived a relationship between porosity, particle size, sorting with permeability: ${ }^{174}$

$$
k=80.8 * \varepsilon^{5.1} * D_{p}^{2} * e^{-1.385 p} \quad \text { Equation } 5.2
$$

where $k$ is permeability ( $\mathrm{mD}$ or $10^{-15} \mathrm{~m}^{2}$ ), $\varepsilon$ is the porosity of the porous media, $D_{p}$ is the particle diameter (m), and $p$ is a sorting term (unity in this calculation).

Instead of correlating the porosity, particle size, and sorting index with permeability as shown in previous models, Swanson proposed an empirical relationship that we could adapt and use the MIP data to derive permeability based on more than 300 sandstone and carbonate samples. Permeability is calculated using the following equation:

$$
k=431 *\left(\frac{S_{H g}}{P}\right)_{\text {apex }}^{2.109}
$$

Equation 5.3

where, $k$ is permeability (Darcy, or $10^{-12} \mathrm{~m}^{2}$ ), $S_{H g}$ is mercury saturation, and $P$ is applied pressure (psi) for mercury. The Swanson model has been effectively used in the past to calculate permeability from MIP data. ${ }^{175}$

\subsubsection{Results and Discussions}

\subsubsection{Validation of the formation of carbonate under $\mathrm{CO}_{2}$ sequestration conditions}

Batch experiments under well-mixed conditions were used to demonstrate the production of carbonate minerals from the interaction of silicate and $\mathrm{CO}_{2}$ in the shale matrix. Wollastonite was found to react readily with $\mathrm{CO}_{2}$ to form calcite precipitates on the 
surface of the shale particles at temperatures and pressures typically encountered in the Marcellus shale formation. Representative XRD patterns of batch experiment reactants and products are shown in Figure 5.5. In Figure 5.5a, the patterns of the control shale sample before and after reaction are shown to be highly consistent. This suggests that the composition of the shale matrix does not change considerably following reaction with $\mathrm{CO}_{2}$ at high pressure and temperature. In Figure 5.5b, the same reaction is carried out with the shale matrix in the presence of $\mathrm{CaSiO}_{3}$, and here the characteristic scan results are quite different. These scans show a clear increase in the intensity of the peaks that are associated with $\mathrm{CaCO}_{3}$ following reaction. A correlated drop in the intensity of the $\mathrm{CaSiO}_{3}$ peak was also observed. The profiles of these scans qualitatively confirm the underlying hypothesis of this work, namely, that mineral carbonation reactions can be carried out in a shale matrix without an antagonistic effect from the shale itself.
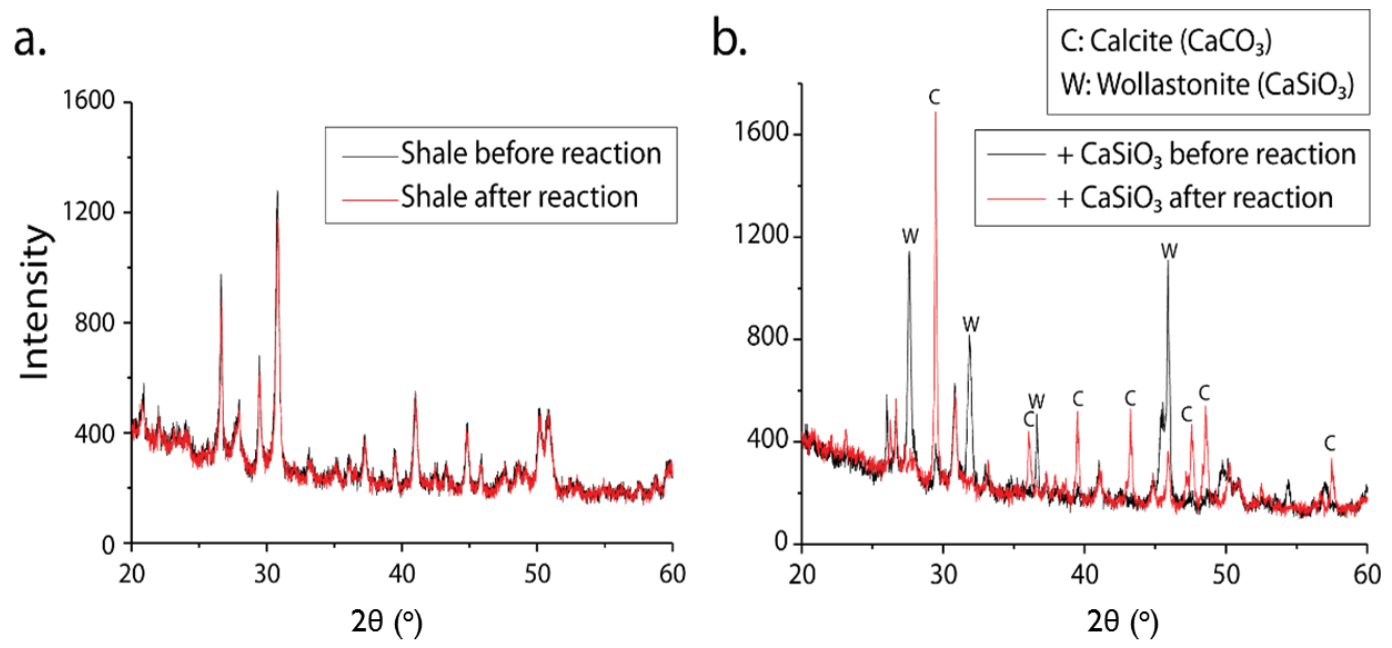

Figure 5.5. XRD patterns for shale before and after reaction. (a) In the absence of $\mathrm{CaSiO}_{3}$ very little change is observed in the shale matrix following carbonation, whereas in (b) the addition of $\mathrm{CaSiO}_{3}$ leads to a significant change in the diffraction pattern. The consumption of $\mathrm{CaSiO}_{3}$ following reaction is correlated with the production of $\mathrm{CaCO}_{3}$. The labeled Bragg peaks clearly show the conversion. Derived from Tao et al. ${ }^{172}$ 
Semi-quantitative XRD analyses were carried out to determine the extent of reaction and conversion of wollastonite to calcite at typical pressure and temperature combinations characteristic of shale formations. An internal $\mathrm{TiO}_{2}$ standard was used to calibrate the intensity of calcite peaks. We found that the reaction achieved greater than $50 \%$ conversion (measured in terms of $\mathrm{CaCO}_{3}$ generation) after 24 hours. Consistent with published studies of ex situ carbonation, the conversation rate increased with increasing temperature. ${ }^{30}$

\subsubsection{Spatial distribution and morphology of carbonation products}

The electron micrograph in Figure 5.6 shows bulky coatings on the shale particles only occur after reaction (Figure 5.6b) with $\mathrm{CO}_{2}$ in the presence of wollastonite particles at T/P conditions $\left(75^{\circ} \mathrm{C} / 15.2 \mathrm{MPa}\right)$ equivalent to an approximate depth of $2100 \mathrm{~m}$ in the Marcellus shale play. ${ }^{153}$
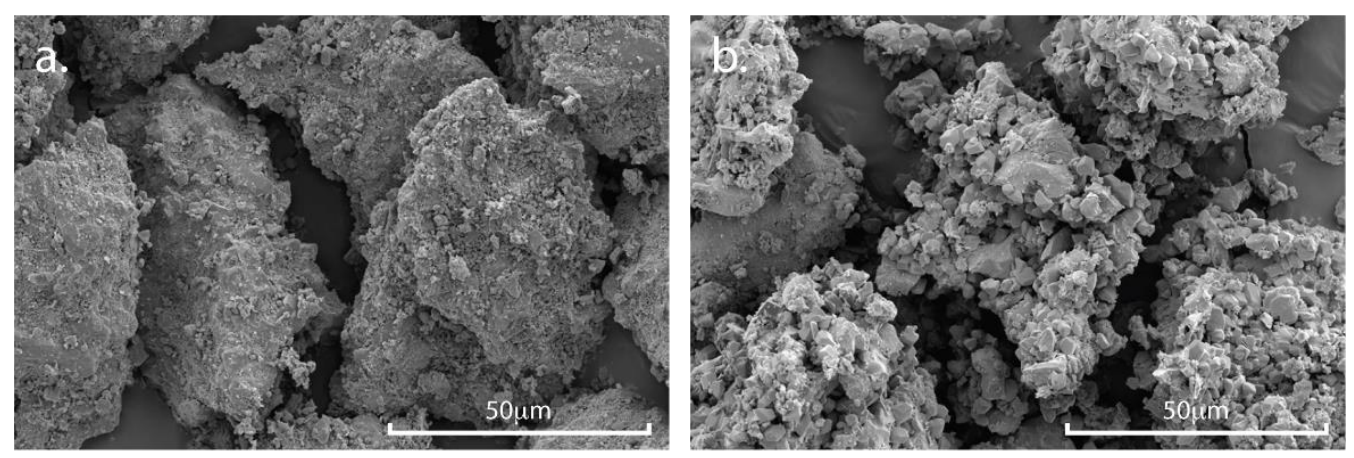

Figure 5.6. Electron micrograph of ground shale and wollastonite particles (a) before and (b) after reaction with $\mathrm{CO}_{2}$ at elevated $\mathrm{P} / \mathrm{T}\left(75^{\circ} \mathrm{C} / 15.2 \mathrm{MPa}\right)$. Precipitated calcite is visible as a bulky surface coating in Figure 5.6b. Derived from Tao et al. ${ }^{172}$

A closer look at these surfaces before and after carbonation revealed that the bulky precipitate, which formed on the shale surface only when wollastonite was present, exhibited both the elemental composition and morphology of calcite. Figure 5.7 shows 
the surface of the shale particles in the absence of wollastonite before (Figure 5.7a) and after (Figure 7b) reaction. EDS elemental maps (below Figure 5.7a and 5.7b micrographs) show very little change in the elemental composition of the shale surface prior to and following exposure to high pressure $\mathrm{CO}_{2}$ in the absence of wollastonite. When wollastonite is present, however, the results were quite different (Figure 5.7c and Figure 5.7d). Before reaction, the shale particles looked like the controls with the exception of the existence of wollastonite particles that can be clearly identified in the silicon EDS map in Figure 5.7c. Following carbonation (Figure 5.7d), silicon fluorescence is attenuated while carbon fluorescence is more intense, which is consistent with the EDS fingerprint of calcite. Most definitive is that precipitates displaying calcite's characteristic rhombohedral morphology were only observed following carbonation when wollastonite was present in the starting materials (Figure 5.7d). 

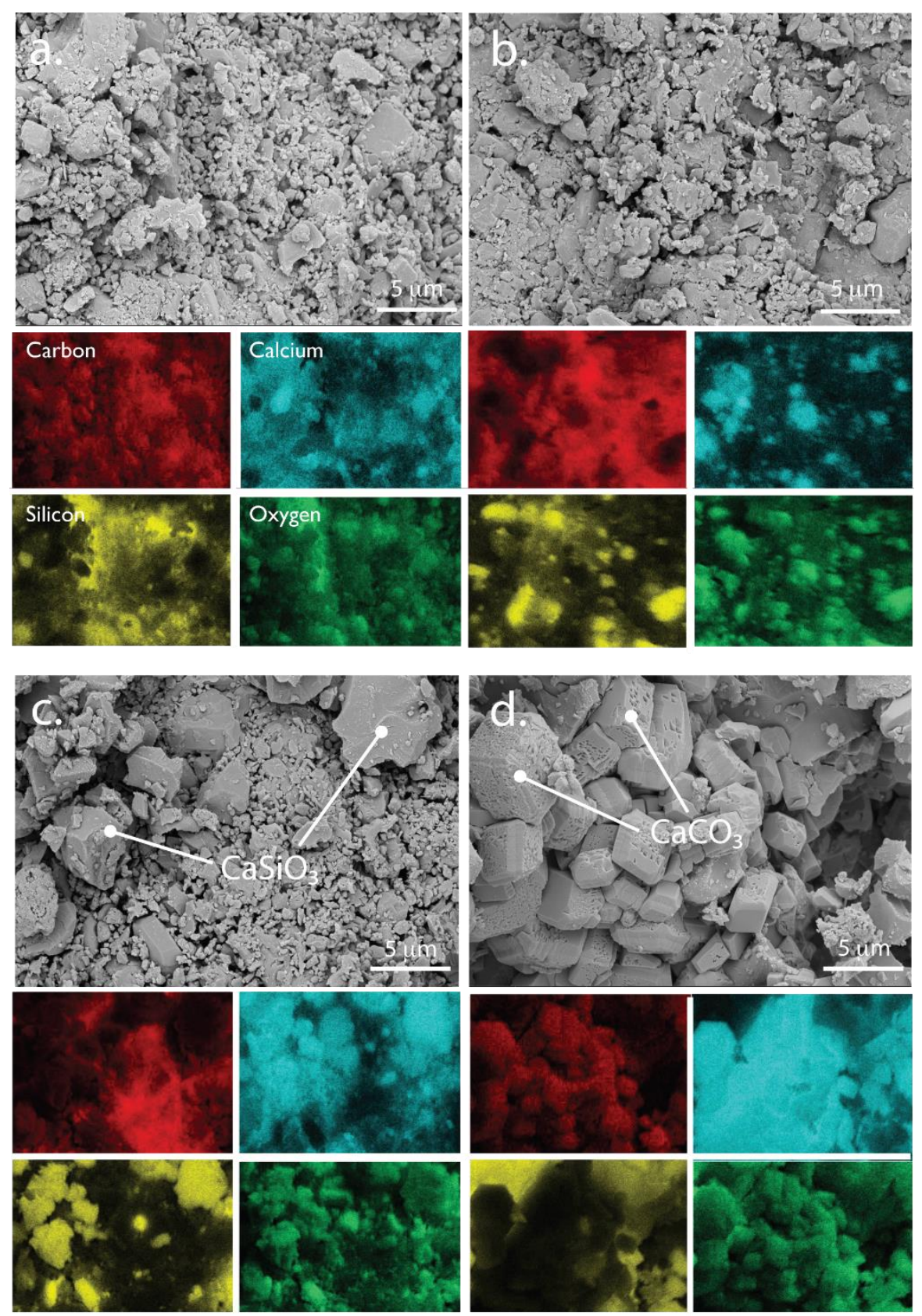

Figure 5.7. Electron micrographs of the shale surface without wollastonite (a) before and (b) after carbonation, and with wollastonite added (c) before and (d) after reaction. Note the precipitation of calcite on the surface of the shale particles in Figure 5.7d. The colored images show corresponding EDS maps of carbon (red), calcium (cyan), silicon (yellow), and oxygen (green). Derived from Tao et al. ${ }^{172}$

In addition to the $\mathrm{CaCO}_{3}$, an amorphous silica layer is known to form as a result of the dissolution of $\mathrm{CaSiO}_{3}{ }^{176}$ Although this phase could have an antagonistic effect on the 
reaction proceeding by coating the reactants, we did not observe significant inhibition of the carbonation process. Alternately in this application, amorphous silica could instead coat the shale surface and provide additional sealing, inhibiting liquid/gas migration and the mobilization of hazardous elements within the shale. In practice, time may not be limiting given the relatively long time periods over which these sequestration and sealing processes would continue. But the precise time scales at play would depend on the way in which they are deployed (e.g., to seal a formation at some radius around the wellbore for a slow-moving fluid or to close a fracture during a rupture event).

Compared to the loose powder property of the shale particles before carbonation, the particles formed a cohesive, solid mass after reaction, as shown in Figure A1 in Appendix. This observation provides evidence that the carbonation reaction produced cementitious properties and as a result, could potentially lead to the blockage or clogging of pore spaces or fractures.

\subsubsection{Impacts of carbonation products on flow in shale}

Column experiments showed how the carbonation of wollastonite particles could reduce porosity and inhibit flow in an idealized porous media of shale particles. The results from the MIP analysis are shown in Figure 5.8. In Figure 5.8A, which was carried out at T/P conditions $\left(12.4 \mathrm{MPa} / 55^{\circ} \mathrm{C}\right)$ equivalent to a depth of around $1200 \mathrm{~m}$, there is little evidence of a change in pore structure before and after carbonation. The story is quite different at higher $\mathrm{T} / \mathrm{P}$ conditions $\left(15.2 \mathrm{MPa} / 75^{\circ} \mathrm{C}\right)$, which are equivalent to a depth of around $2100 \mathrm{~m}$. Figure 5.8B shows an appreciable drop in pore size following carbonation, compared to the control column, which only differs in that wollastonite is replaced with equivalently-sized unreactive glass beads, under the same conditions 
$\left(15.2 \mathrm{MPa} / 75^{\circ} \mathrm{C}\right)$. The width of the lines corresponds to the upper and lower bounds of the pore size distributions from duplicated samples. Before carbonation, the mean pore diameter was $13.4 \mu \mathrm{m}$. After, the average pore diameter was $9.5 \mu \mathrm{m}$. This shift in pore size suggests that the carbonation reactions effectively reduce overall pore sizes. The porosity of the sample also changed after carbonation from $0.38 \pm 0.06$ to $0.26 \pm 0.02$.

These results highlight the importance of pressure and temperature on wollastonite carbonation. This sensitivity has been noted in the literature, though it has new and different dimensions in this context because of the application to geothermal gradients in the subsurface. Published reports of ex situ carbonation suggest that the optimal range for carbonation occur between $100-175^{\circ} \mathrm{C}$ and $15-25 \mathrm{MPa} .{ }^{30} \mathrm{O}^{\prime} \mathrm{Connor}$ et al. concluded that the carbonation of wollastonite is less sensitive to $\mathrm{PCO}_{2}$ than $\mathrm{Mg}$-bearing silicate minerals, such as olivine. ${ }^{70}$ In their work, high conversion of calcium silicate to carbonate could be realized at $100{ }^{\circ} \mathrm{C}$ even at pressures as low as $4 \mathrm{MPa}$. Huijgen et al. suggested that the carbonation of silicate minerals would perform differently in two temperature regimes. ${ }^{30}$ Below an optimal temperature, the reaction is rate-limited by the dissolution of the silicate. Above some optimal temperature, the carbonation is controlled by the precipitation of carbonate. In their work, the optimal temperature is different based on various pressures, but the lowest temperature is still considerably higher than $100^{\circ} \mathrm{C}$. Both O'Connor and Huijgen's work indicate that the carbonation of $\mathrm{CaSiO}_{3}$ occurs preferentially at higher temperature but is less sensitive to pressure. It is worth noting that the critical point for $\mathrm{CO}_{2}$ is $7.4 \mathrm{MPa} / 31^{\circ} \mathrm{C}$ and both of our reaction conditions are above the critical point, which means the reactivity difference is not likely induced by the phase characteristics of $\mathrm{CO}_{2}$. Instead, it indicates that the kinetics of the silicate carbonation is 
not favored under the lower temperature conditions of the shallow subsurface. As a result, there would be very little dissolution-precipitation happening and the pore structure would mostly remain unchanged.

a.

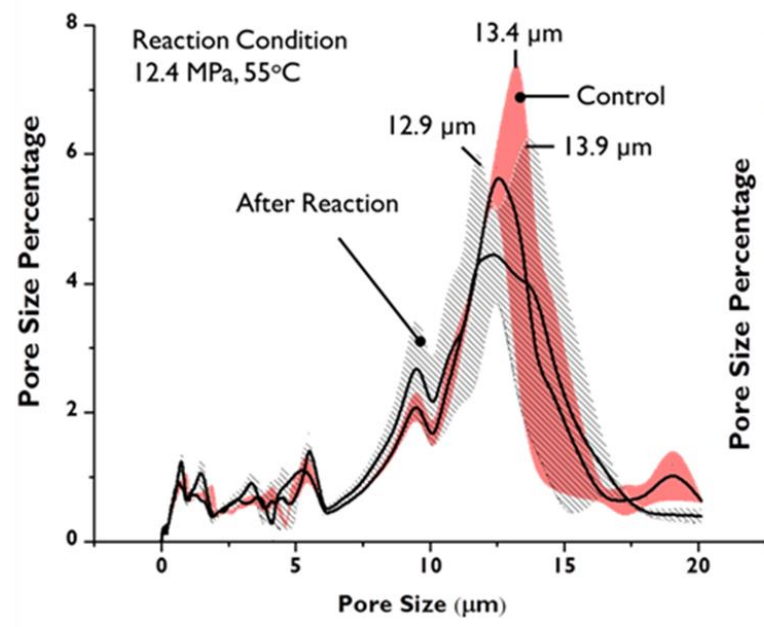

b.

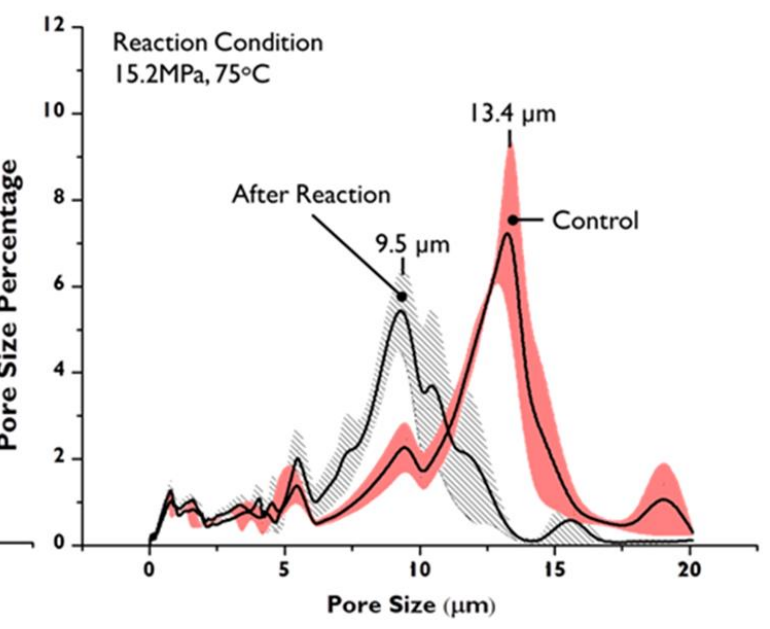

Figure 5.8. MIP result for a) carbonation reaction under low pressure and temperature conditions and b) carbonation reaction under high pressure and temperature conditions. The black line represents the average value from two replicates and the shaded region represents one standard deviation. Derived from Tao et al. ${ }^{172}$

The porosity measurements were used to estimate the change in permeability that could be expected in these samples. The Berg equation was used to predict the permeability as a function of grain size and porosity while the Swanson empirical model used input values from the MIP experiments directly. It is worth noting that the Berg equation needs both the particle size and porosity information to estimate permeability. The MIP data can be used directly to calculate permeability according to Swanson model without information about grain size or porosity. The comparison of those methods is shown in Table 5.1. The results suggest that the two models are relatively consistent and predict an appreciable permeability drop under the higher temperature conditions tested here. The low P/T 
sample shows a statistically insignificant reduction in permeability as reflected in the porosity data. It is important to note here that Berg's model is particularly sensitive to porosity since porosity is raised to the power of 5.1. In contrast, Swanson's relationship depends only on the mercury injection porosimetry data and provides an empirical estimate of permeability. The permeability decrease of $50 \%$ after the carbonation under high $\mathrm{P} / \mathrm{T}$ conditions provides additional support for our hypotheses that these reactions can be effectively used to control the fluid flow properties and reduce permeability in the deep subsurface.

Table 5.1 Estimates of permeability in our samples using different models.

\begin{tabular}{|c|c|c|c|}
\hline Condition & Porosity $^{*}$ & \multicolumn{2}{|c|}{ Permeability (Darcy) } \\
\cline { 3 - 4 } & & Berg Method & Swanson Method \\
\hline Control & $0.38 \pm 0.06$ & $0.51 \pm 0.33$ & $0.31 \pm 0.10$ \\
\hline Low P/T & $0.33 \pm 0.06$ & $0.28 \pm 0.22$ & $0.31 \pm 0.05$ \\
\hline High P/T & $0.26 \pm 0.02$ & $0.06 \pm 0.03$ & $0.16 \pm 0.05$ \\
\hline
\end{tabular}

* To calculate the permeability according to Berg's equation, we used the same particle size before and after reaction

The results shown here validate that the carbonation reaction happens spontaneously under the P/T conditions of a typical shale formation. The kinetics of the carbonation reaction are fast (in the range of days) and are faster in $\mathrm{CO}_{2}$-saturated $\mathrm{H}_{2} \mathrm{O}$ than in watersaturated $\mathrm{CO}_{2}$. The shales tested here do not appear to contain mineral species that would have antagonistic or synergistic impacts on these reactions. We recognize that the geochemistry of shale formations is very diverse and for those that contain higher concentrations of carbonates or clays, this class of reactions may be less appropriate because of reactivity with $\mathrm{CO}_{2}$. The dissolution and precipitation reactions occur in close spatial proximity so the injection of concentrated cation solutions with $\mathrm{CO}_{2}$ would result 
in a drop in permeability near the injection site. Injection of cation donor mineral silicates into the formation followed by subsequent injection of a $\mathrm{CO}_{2}$-rich aqueous phase will result in better spatial distribution of carbonation precipitates throughout the rock. Our results also show that the precipitated minerals are capable of changing the porosity of the shale matrix and as a result, the permeability as well.

\subsection{Carbonation and Hydration Reaction of Silicate in Glass Beads Matrix}

\subsubsection{Methods and materials}

\subsubsection{Experimental setup and materials}

To illustrate how carbonation proceeds and how effective the precipitation of minerals is in influencing a change in pore structure, a batch reaction system with only diffusion involved was designed and deployed. Different from the batch reaction with sufficient mixing, this system provided insights into the alteration of pore structures under diffusion-controlled conditions, which in the real formation, represent the locations that are not well mixed, such as dead end of pores. The chemical parameters, such as cation conditions and $\mathrm{pH}$, etc., associated with those structures are far from equilibrium and the local reactions as well as their influence on the flow properties were able to be studied through this setup. Also, we used sintered glass beads instead of ground shale particles in these experiments, with the objective of eliminating the influence of the matrix itself on the change of pore structure and permeability.

$\mathrm{CaSiO}_{3}(99 \%)$ was obtained from Sigma-Aldrich. Food-grade liquid $\mathrm{CO}_{2}$ was supplied by Robert's Oxygen, Inc. Glass Beads were obtained from Mo-Sci Corporation and the diameter range was 595-841 $\mu \mathrm{m}$. All other reagents were used as received. For each experiment, glass beads were first placed into a stainless-steel tube (OD: 1/4”, Wall 
thickness: 0.049", Length: 1") and the whole tube was put into a high temperature kiln (Model\# RMII 2322. Evenheat Kiln, Inc) and sintered at $680^{\circ} \mathrm{C}$. The temperature setup procedure is similar to the method in Berge et al.'s work. ${ }^{177}$ Photos of the sintered glass beads columns as well as the assembly of the samples are shown in Figure A2 in Appendix.

After the sintering, $\mathrm{CaSiO}_{3}$ powders were packed at one end of the stainless-steel column and connected to a $3 \mathrm{~L}$ water reservoir with elevated pressure (approximately $75 \mathrm{PSI}$ ). The other end of the column was fitted with a temporary stainless-steel filter. The $\mathrm{CaSiO}_{3}$ powders were then carried into the sintered glass beads via pressurized water and, because of the existence of the filter, most of the powders remained in the pores in the glass bead matrix. After the delivering process, the temporary filter was removed and the column was put into an oven at $105^{\circ} \mathrm{C}$ for $24 \mathrm{~h}$. A permeability measurement was carried out for the dried sample. Then, this column was placed into a stainless-steel pressure vessel (Parr, 300ml) filled with $250 \mathrm{ml} \mathrm{H}_{2} \mathrm{O}$ again. Pressure and temperature were increased and the reactions ran between $4 \mathrm{~h}-168 \mathrm{~h}$. The pressure is kept at $15 \mathrm{MPa}$ and the temperature of the reaction is $120^{\circ} \mathrm{C}$. After the reaction, the column was taken out of the vessel and dried again at $105^{\circ} \mathrm{C}$ for $24 \mathrm{~h}$. Another permeability reading was made for the sample before the stainless-steel tube was cut open for SEM, XRD and Raman analysis. The experimental setups are shown in Figure 5.9.

The SEM and XRD characterization procedure is the same with that in section 5.1.1.2. Thermal Gravity Analysis (TGA) was conducted using Q50 Thermogravimetric Analyzer from TA Instrument. TGA is commonly used to detect the weight lost subject to heat. ${ }^{178}$ The temperature increasing rate of $5^{\circ} \mathrm{C} / \mathrm{min}$ is applied and the maximum temperature is 
$600^{\circ} \mathrm{C}$. Raman scanning of the samples were conducted by using Reinishaw inVia microRaman Spectrometer that delivered a $532 \mathrm{~nm}$ laser through a 50x working-distance objective. An air permeameter was built to measure the permeability and the design is shown in Figure A3 in Appendix. The calculation of permeability is based on Darcy's law as shown in Equation 5.4.

$$
Q=\frac{\kappa A \Delta P}{\mu L}
$$

Q: volumetric flow rate $\left(\mathrm{m}^{3} / \mathrm{s}\right)$

$\kappa$ : permeability $\left(\mathrm{m}^{2}\right)$

A: cross-sectional area of column $\left(\mathrm{m}^{2}\right)$

$\Delta P$ : pressure difference between inlet and outlet $(\mathrm{Pa})$

$\mu$ : viscosity of air (Pa.s)

L: length of the column (m)

Since the volumetric flow rate, cross-sectional area, length of column, pressure difference and air viscosity can all be measured or derived from experiments, permeability is the only unknown in Equations 5.4 and can be readily derived.

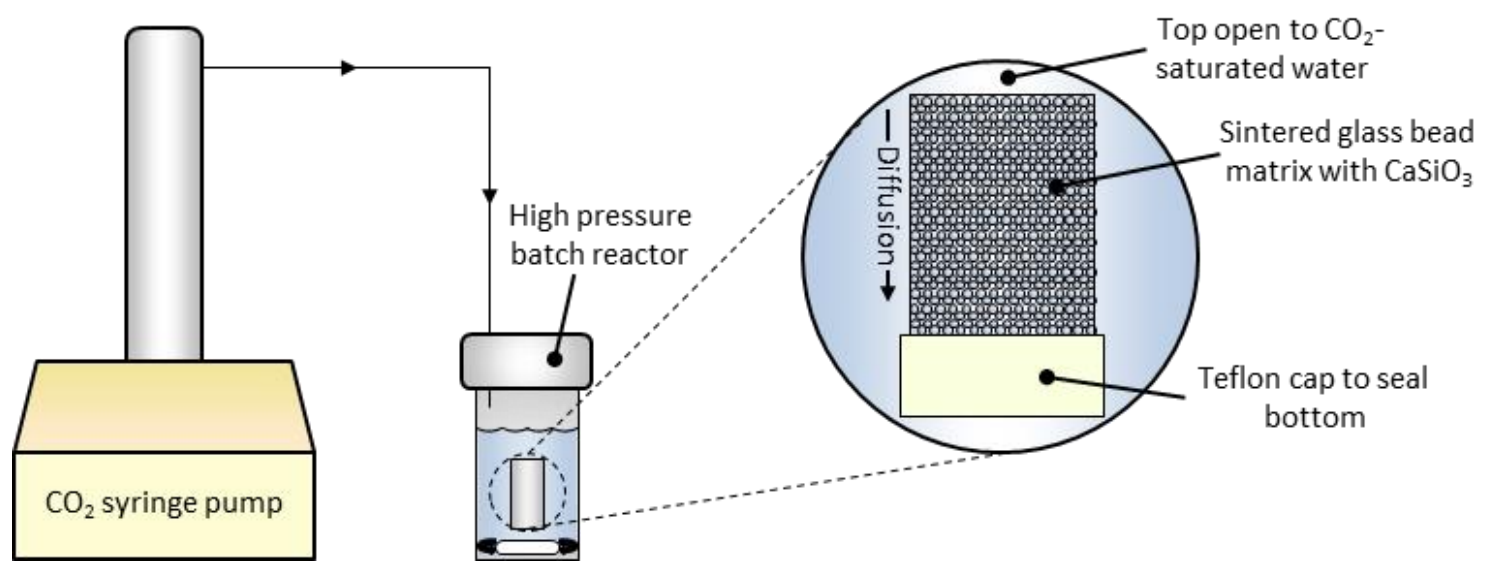

Figure 5.9 Experimental setup for the diffusion-controlled batch reactor. Note the bottom of the column is sealed with a Teflon cap and $\mathrm{CO}_{2}$-saturated water may only diffuse into the column from the top of the column. 


\subsubsection{Results and Discussion}

\subsubsection{Mineral Characterization}

Characterization of the precipitated minerals through SEM reveals different

morphologies after the $\mathrm{CO}_{2}$-silicate reaction. Two prominent mineral phases are shown in

Figure 5.10 (a). One phase is well-formed crystals at the upper right part of the image and EDS analysis further demonstrates that these crystals are calcite, as shown in Figure 5.10 (b). The other prominent phase is the structure with flower-like morphology. In Figure 5.10 (a), they are surrounding the calcite. Elemental analysis from EDS of these flower structures shows that $\mathrm{Si}, \mathrm{O}$, and $\mathrm{Ca}$ are dominant in this area and the signal of $\mathrm{Na}$ is also non-negligible (Figure 5.10(c)). However, the morphology of this area is different than unreacted $\mathrm{CaSiO}_{3}$ (Figure 5.10(d)). The Ca to Si ratio from EDS is in the range of 0.30.5 , which is obviously lower than in wollastonite which is with 1:1 ratio. Further analysis through XRD attributes the correlated diffraction peaks of the flower structure to silicate hydrate with the formula $\mathrm{Ca}_{12} \mathrm{Si}_{20} \mathrm{O}_{45} \cdot 36 \mathrm{H}_{2} \mathrm{O}(\mathrm{C}-\mathrm{S}-\mathrm{H})$. It has been reported that some hydrated minerals or clay minerals, such as chlorite, with layered structures could have similar flower-like microstructures. ${ }^{179,180}$ For this reason, we believe the flower-like structures are calcium silicate hydrate. One of the possible reasons for the fact that the $\mathrm{Ca} / \mathrm{Si}$ ratio derived from $\mathrm{EDS}$ is less than the ratio in $\mathrm{CaSiO}_{3}$ is because the $\mathrm{X}$-ray used in EDS to map the element distribution may penetrate the thinner part of the hydrate phase and reach the surface of the glass beads (X-ray beam can penetrate to up to $20 \mu \mathrm{m}$, which is similar to the thickness of the mineral precipitation layer), which could induce a high concentration of Si signals. The composition of glass beads is shown in Table A1 in Appendix and the Si content is dominant. Also, the precipitation of calcite could leads to 
higher Si percentages in the silicate hydrate (because a fraction of the $\mathrm{Ca}$ is deposited as calcite), the Ca:Si ratio in silicate hydrate is expected to be lower than in wollastonite.

The XRD characterization of the hydrate phase is shown in Figure 5.11.

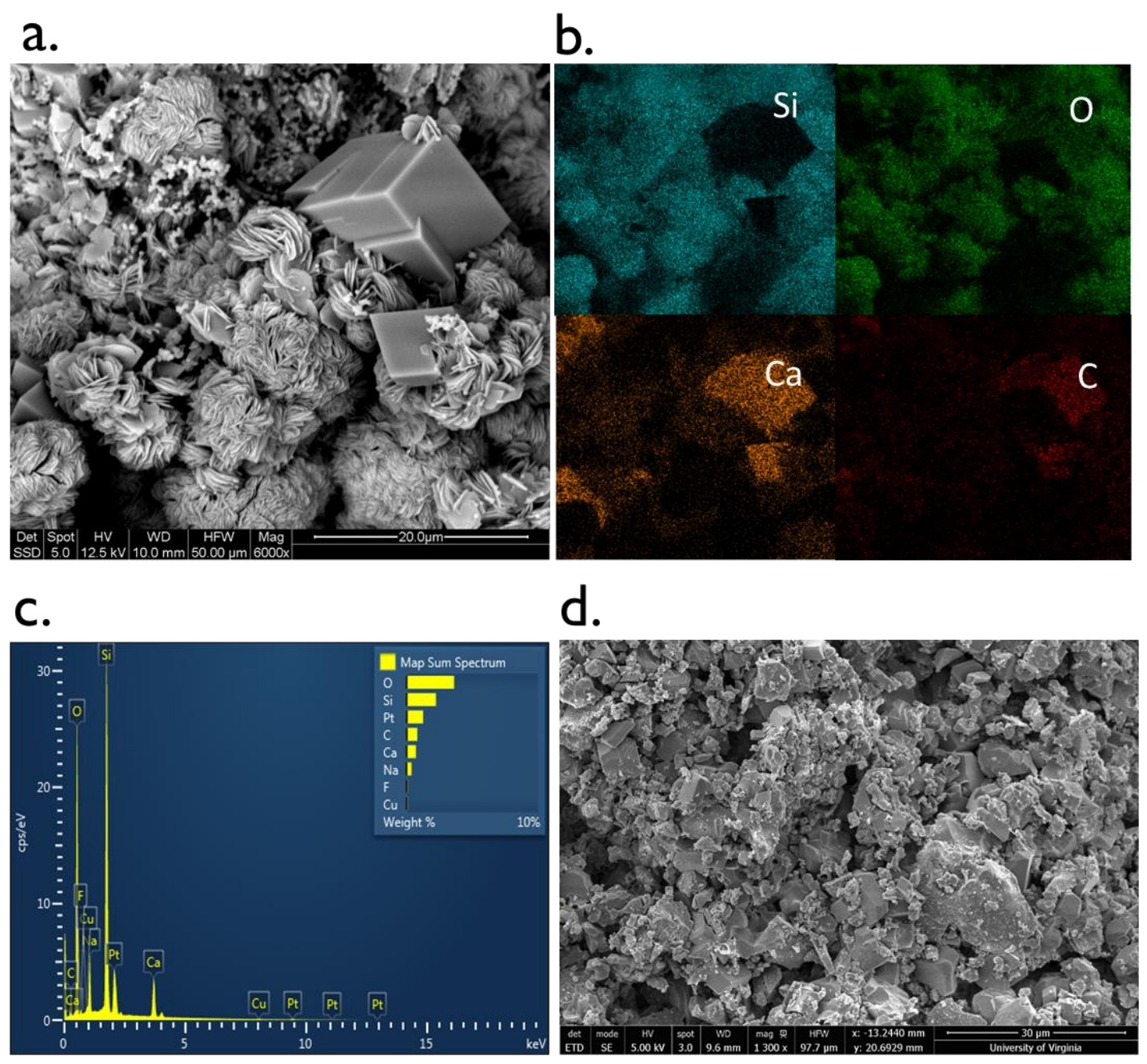

Figure 5.10 a) SEM micrograph of the morphology of a reacted area. Both carbonate crystals and flower-like structures exist. b) The EDS map of the image shown in (a). c) The correlated EDS of the SEM shown in (a). d) SEM micrograph of unreacted $\mathrm{CaSiO}_{3}$ 


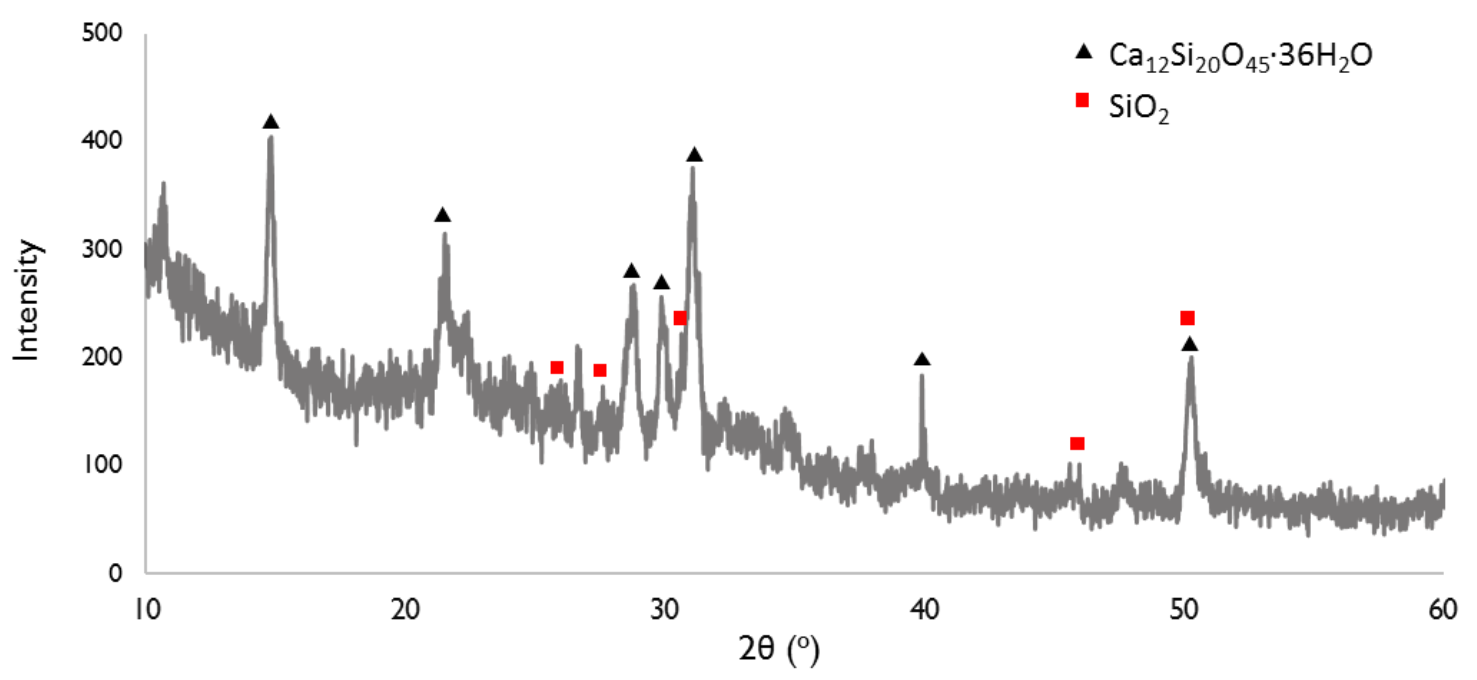

Figure 5.11 XRD diffraction pattern of a hydrate phase in the reacted sample.

To further verify our assertion, a TGA analysis of a small piece of the glass bead matrix together with the minerals precipitated on it was carried out and the results are presented in Figure 5.12. The first weight loss (Stage I) occurs around $100^{\circ} \mathrm{C}$ and is attributed to adsorbed $\mathrm{H}_{2} \mathrm{O}$ on the mineral surfaces. The weight of the sample continues to decrease in the temperature range of $100-600^{\circ} \mathrm{C}$ (Stage II). This gradual weight decrease can be attributed to the loss of $\mathrm{H}_{2} \mathrm{O}$ in the different layers in the mineral structure. $\mathrm{The}_{2} \mathrm{O}$ encapsulated in mineral layers is expelled at this stage while there is no obvious change of the mineral crystallinity. Similar patterns of water loss have also been observed when hydrate minerals are subject to heat and the weight lost is due to the water evacuation between different layers of the hydrate structure. ${ }^{178,181,182}$ 


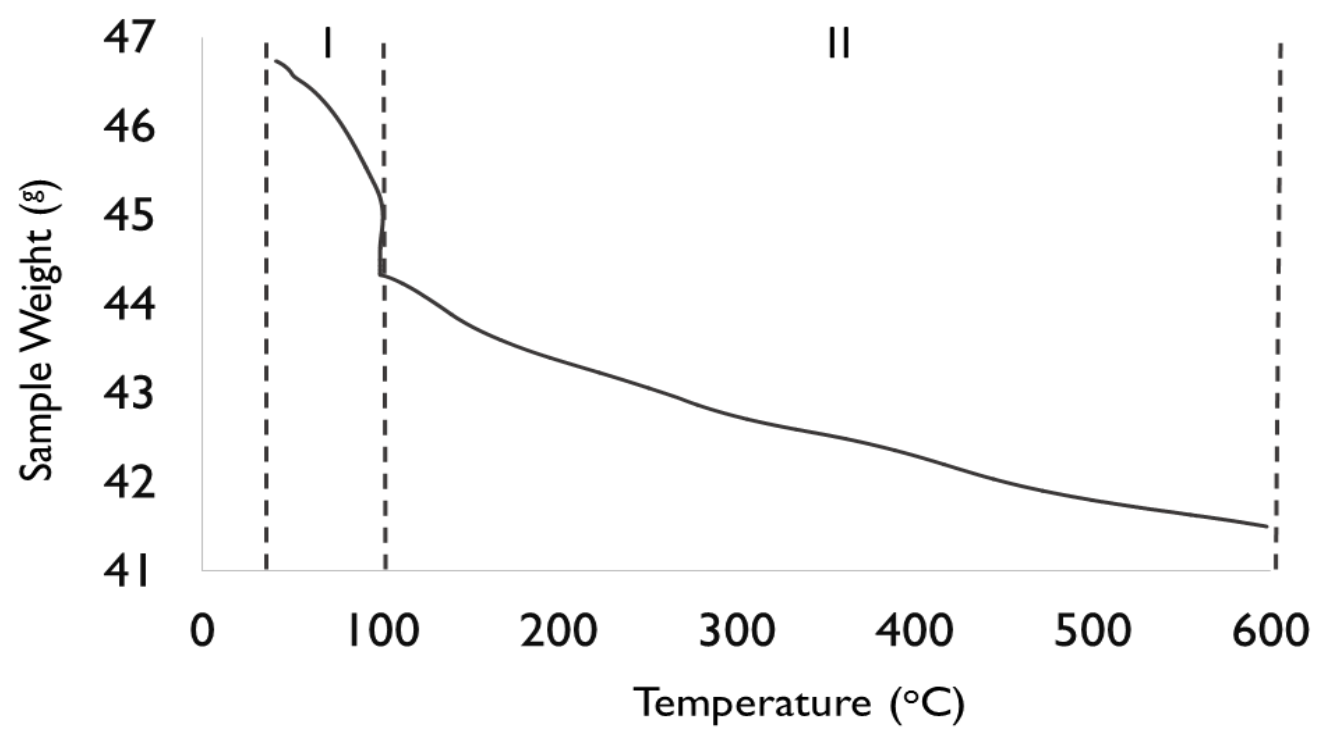

Figure 5.12 TGA of a reacted sample. The weight lost around $100^{\circ} \mathrm{C}$ is attributed to the adsorbed $\mathrm{H}_{2} \mathrm{O}$. Further weight lost is attributed to the $\mathrm{H}_{2} \mathrm{O}$ existing in mineral layers.

\subsubsection{Reaction and permeability evolution}

Under $\mathrm{CO}_{2}$ storage conditions, carbonation of silicate minerals starts with the dissolution of $\mathrm{CO}_{2}$ in $\mathrm{H}_{2} \mathrm{O}$, as shown in Equation 5.5-5.7. Since wollastonite is acid reactive, it dissolves to release $\mathrm{Ca}^{2+}$ and amorphous silica, as shown in Equation 5.8. In geological formations, the $\mathrm{pH}$ of aqueous phase increases once the protons released from $\mathrm{CO}_{2}$ dissolution are consumed and the combination of $\mathrm{CO}_{3}{ }^{2-}$ and $\mathrm{Ca}^{2+}$ to generate carbonate proceeds, as shown in Equation 5.9. However, the carbonate is prone to acid attack under low $\mathrm{pH}$, which is shown in Equation 5.10. Deng et al. reported that in experiments with $\mathrm{CO}_{2}$ flowing through carbonate fractures, the carbonate minerals exposed to highconcentration $\mathrm{CO}_{2}$ could be dissolved. ${ }^{171}$ However, the carbonate dissolution will not happen in the areas where $\mathrm{H}^{+}$is depleted or $\mathrm{CO}_{2}$ does not penetrate. This gives insight to the fact that under different flow conditions, where the supply of protons varies, the mineral dissolution and precipitation could be absolutely different. The existence as well as the concentration of $\mathrm{H}^{+}$is critical in this process. 
The studies about hydration of wollastonite are limited, with most of them using wollastonite as a model to study the molecular level hydration mechanism with silicate minerals. It is proposed that the initial hydration of the wollastonite surface with just one layer of $\mathrm{H}_{2} \mathrm{O}$ could facilitate the carbonation by lowering the reaction energy barrier. ${ }^{183,184}$ However, the hydration of tricalcium silicate $\left(\mathrm{Ca}_{3} \mathrm{SiO}_{5}\right.$, or $\left._{3} \mathrm{~S}\right)$ and dicalcium silicate $\left(\mathrm{Ca}_{2} \mathrm{SiO}_{4}\right.$, or $\left.\mathrm{C}_{2} \mathrm{~S}\right)$ is widely studied and applied and it can lead to the formation of C-S-H under different conditions. ${ }^{85,86,91,185}$ The $\mathrm{C}-\mathrm{S}-\mathrm{H}$ gels formed during cement hydration is important in providing the strength to concrete and to bond the aggregates together. ${ }^{85}$ It is noteworthy that the C-S-H phases are more porous and less dense than precipitated carbonate and the production of this phase does not necessarily lead to the change of permeability. ${ }^{104}$

Theoretically, the formation of C-S-H could proceed via either direct hydration of silicate minerals or the interaction between $\mathrm{Ca}^{2+}$ and amorphous silica under basic conditions, shown in Equation 5.11 and 5.12. ${ }^{87-89,184}$ However, under acid conditions, the dissolution of C-S-H is thermodynamically favored, as shown in Equation 5.13, with the equilibrium constant ranging between $10^{10}$ and $10^{74}$ for different silicate hydrates, according to Clodic et al. ${ }^{114}$

$$
\begin{array}{lr}
\mathrm{CO}_{2}+\mathrm{H}_{2} \mathrm{O} \leftrightarrow \mathrm{H}_{2} \mathrm{CO}_{3} & \text { Equation } 5.5 \\
\mathrm{H}_{2} \mathrm{CO}_{3} \leftrightarrow \mathrm{H}^{+}+\mathrm{HCO}_{3}^{-} & \text {Equation } 5.6 \\
\mathrm{HCO}_{3}^{-} \leftrightarrow \mathrm{H}^{+}+\mathrm{CO}_{3}^{2-} & \text { Equation } 5.7 \\
\mathrm{CaSiO}_{3}+\mathrm{H}^{+} \rightarrow \mathrm{Ca}^{2+}+\mathrm{SiO}_{2(\text { am aq })}+\mathrm{H}_{2} \mathrm{O} & \text { Equation } 5.8 \\
\operatorname{logK}=9.8 \text { at } 120^{\circ} \mathrm{C} &
\end{array}
$$




$$
\begin{aligned}
& \mathrm{Ca}^{2+}+\mathrm{CO}_{3}^{2-} \rightarrow \mathrm{CaCO}_{3} \\
& \log \mathrm{K}=8.5 \text { at } 120^{\circ} \mathrm{C} \\
& \mathrm{CaCO}_{3}+\mathrm{H}^{+} \rightarrow \mathrm{Ca}^{2+}+\mathrm{HCO}_{3}^{-} \\
& \log \mathrm{K}=0.5 \text { at } 120{ }^{\circ} \mathrm{C} \\
& \mathrm{CaSiO}_{3}+\mathrm{H}_{2} \mathrm{O} \rightarrow \mathrm{C}_{x}-\mathrm{S}-\mathrm{H}_{y} \\
& \mathrm{Ca}^{2+}+\mathrm{SiO}_{2(\text { am aq })}+\mathrm{OH}^{-}+\mathrm{H}_{2} \mathrm{O} \rightarrow \mathrm{C}_{z}-\mathrm{S}-\mathrm{H}_{w} \\
& \mathrm{C}-\mathrm{S}-\mathrm{H}+\mathrm{H}^{+} \rightarrow \mathrm{Ca}^{2+}+\mathrm{SiO}_{2(\mathrm{am} a q)}+\mathrm{H}_{2} \mathrm{O} \\
& \operatorname{logK}=10 \text { to } 70 \text { at } 120{ }^{\circ} \mathrm{C}
\end{aligned}
$$

Raman scanning with 2-4mm intervals of the reacted column was used to monitor the evolution of chemical reaction and Figure 5.13 shows an evolution of the signals at different depths into the columns. $\mathrm{CO}_{2}$ and $\mathrm{H}_{2} \mathrm{O}$ diffuse into the column from the inlet as shown with the arrow. The peak at $1088 \mathrm{~cm}^{-1}$ in Raman is attributed to the symmetric stretching $\left(v_{1}\right)$ of the $\mathrm{CO}_{3}{ }^{2-}$ group and it is the strongest peak for calcite. The two weak peaks at $700 \mathrm{~cm}^{-1}$ and $290 \mathrm{~cm}^{-1}$ are attributed to antisymmetric bending vibration $\left(v_{4}\right)$ and lattice vibration of carbonate. ${ }^{186}$ The peak at $980 \mathrm{~cm}^{-1}$ is attributed to ( $\mathrm{Si}-\mathrm{O}-$ ) symmetric stretching in wollastonite. ${ }^{187,188}$ The peak at approximately $610 \mathrm{~cm}^{-1}$ is attributed to the formation of hydrate. ${ }^{189-191}$ The carbonate signal is very strong and within the fully carbonated area there is no signal of wollastonite or hydrate. While for the area containing the carbonation front, where the carbonate signals gradually disappear, Raman results reveal the co-existence of carbonate, unhydrated silicate hydrate, and silicate hydrate. There is no carbonate signal in the uncarbonated area. Along with the diffusion of $\mathrm{CO}_{2}$, the carbonation front moved deeper into the column with time. After 4 hours of 
reaction, the carbonation front penetrated $2 \mathrm{~mm}$ into the column. The location of the carbonation front moved further into the column with longer reaction time and it arrived at $11 \mathrm{~cm}$ at the end of 48 hours and reached to $13 \mathrm{~cm}$ after 96 hours of reaction, as shown in Figure 5.14 (a).

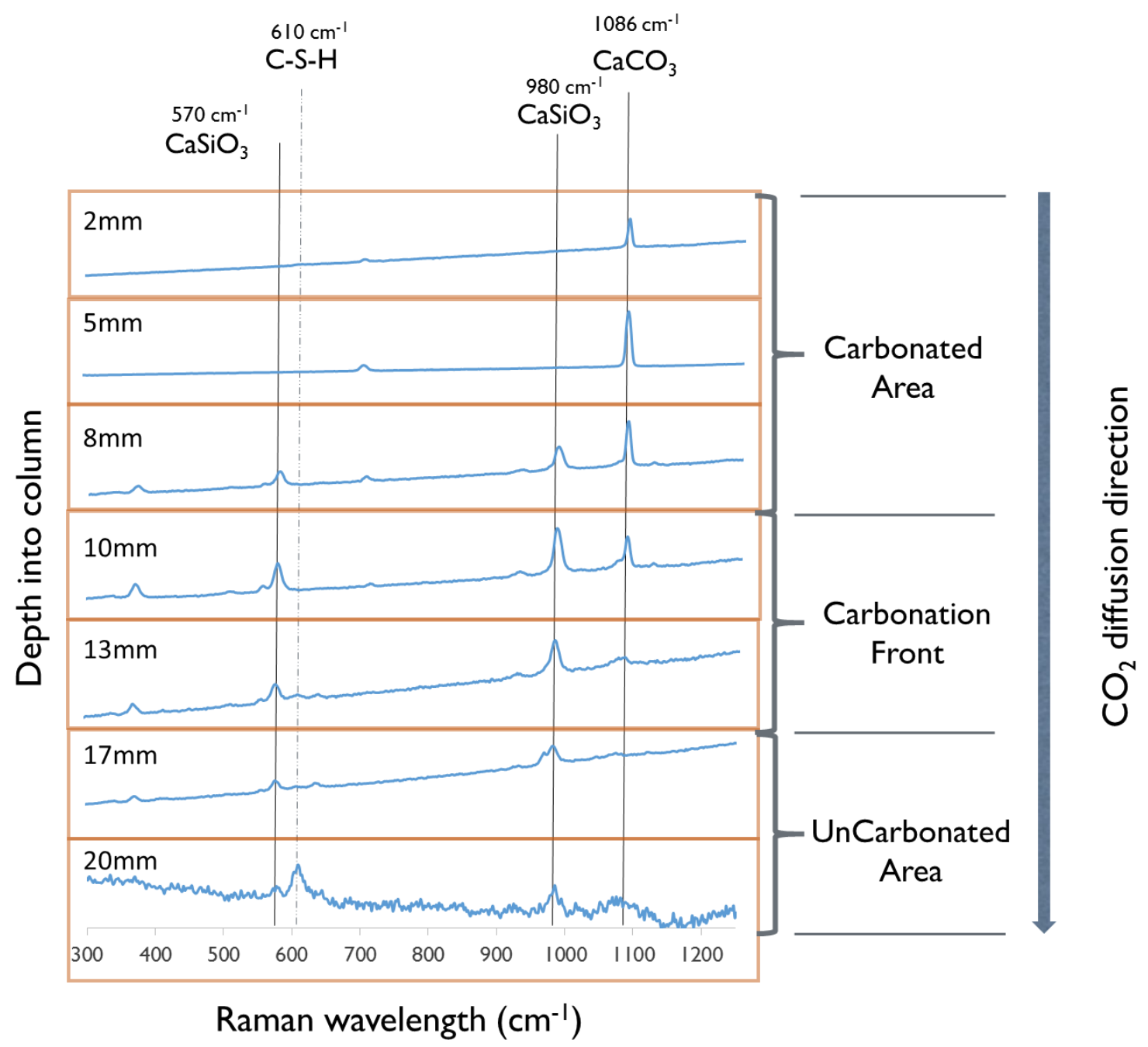

Figure 5.13 Raman spectrum at different depth of a column 96h sample. Attribution of peaks is as following: $1088 \mathrm{~cm}^{-1}, 700 \mathrm{~cm}^{-1}$, and $290 \mathrm{~cm}^{-1}\left(\mathrm{CaCO}_{3}\right), 980 \mathrm{~cm}^{-1}, 570 \mathrm{~cm}^{-1}$ $\left(\mathrm{CaSiO}_{3}\right), 610 \mathrm{~cm}^{-1}(\mathrm{C}-\mathrm{S}-\mathrm{H})$ 


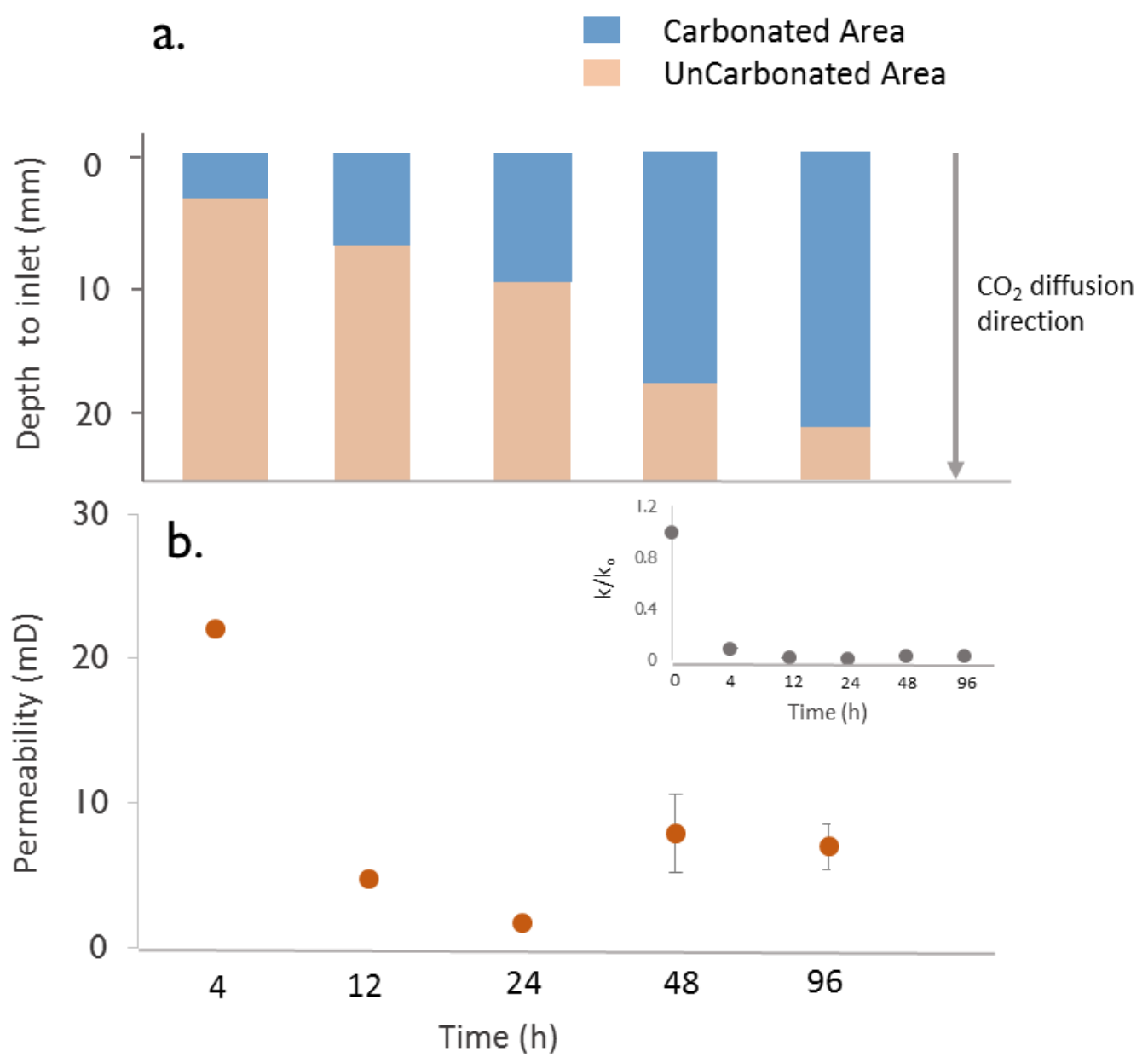

Figure 5.14 (a) The movement of the carbonation front at different times. The $\mathrm{CO}_{2}$ inlet is at the top of the column. (b) The permeability of reacted samples at different time. The inset in (b) shows the change of permeability relative to $\mathrm{k}_{\mathrm{o}}$, which is the permeability before reaction (at time zero).

The movement of the carbonation front and the formation of hydrate are both due to reaction as well as transport. The diffusion and consumption of $\mathrm{CO}_{2}$ is controlling the $\mathrm{pH}$ in the aqueous phase. People have used geochemical simulators such as SUPCRT92 to derive the value of $\mathrm{pH}$ or the concentration of different chemical species. ${ }^{29,71}$ Giammar et al. estimated that when $\mathrm{CO}_{2}$ is equilibrated with water under our reaction conditions, the $\mathrm{pH}$ of the solution is 3.0. Data derived from Schott et al's work reveals that under $\mathrm{pH}=3$, the reaction rate of wollastonite dissolution as shown in Equation 4 is around $7 * 10^{-5}$ 
$\mathrm{mol} / \mathrm{m}^{2} \cdot \mathrm{s}$ at $120^{\circ} \mathrm{C} .{ }^{192}$ Bullard et al. has reported that the hydration rate of $\mathrm{C}_{3} \mathrm{~S}$ is approximately $5^{*} 10^{-7} \mathrm{~mol} / \mathrm{m}^{2} \cdot \mathrm{s}$ at room temperature. ${ }^{98} \mathrm{We}$ estimated that at $120^{\circ} \mathrm{C}$, the reaction rate is about $2.5^{*} 10^{-5} \mathrm{~mol} / \mathrm{m}^{2} \cdot \mathrm{s}$, according to Arrhenius equation. Since $\mathrm{C}_{3} \mathrm{~S}$ is normally considered to be the most readily hydrated calcium silicate mineral, the hydration rate of wollastonite should not exceed this value. As a result, in the $\mathrm{CO}_{2}-$ abundant area near the inlet of our column, the silicate dissolution reaction dominates. Wang et al. proposed from reactive-transport models that in columns similar to ours but filled with pure $\mathrm{MgSiO}_{3}, \mathrm{pH}$ increases quickly after the first $1 \mathrm{~cm}$ into the column after $42 \mathrm{~h}$ of reaction, indicating the effectiveness of the carbonation reaction in consuming $\mathrm{CO}_{2}{ }^{29}$ Similarly in our system, at the area of the $\mathrm{CO}_{2}$ diffusion front, almost all of the $\mathrm{CO}_{2}$ was consumed and the $\mathrm{pH}$ was likely not as low as where $\mathrm{CO}_{2}$ was abundant and carbonate formed through the combination of $\mathrm{CO}_{3}{ }^{2-}$ and $\mathrm{Ca}^{2+}$. In locations where the concentration of $\mathrm{H}^{+}$is low, the silicate minerals existed either in the original unhydrated phase or hydrated phase, depending on the kinetics of the formation of silicate hydrate. Since the formation of hydrate proceeds at a relatively slower speed (normally in the range of days to weeks), ${ }^{85,86,96}$ it is hypothesized that the unhydrated and hydrated silicate co-existed during our experimental timescale.

It is noteworthy that permeability did not change gradually as the carbonation front progressed. Instead, once it decreased sharply after 4 hours of reaction, it did not decrease further or increase significantly, according to Figure 5.14 (b). Precipitated carbonate minerals have the capacity to fill in pore spaces of original porous structure and change the flow pathways. ${ }^{76,107}$ However, our results also show that although the carbonation front moved steadily into the column, the permeability remained nearly constant after 4 
hours. As discussed earlier, in our column, the inlet is open to the $\mathrm{CO}_{2}$-saturated $\mathrm{H}_{2} \mathrm{O}$ and the proton concentration is high. The carbonate formed in this region was subject to acid attack and was likely partially dissolved. Consequently, we suspect that the precipitated minerals in this area were less dense than deeper areas in the column. As a result, we suggest that the dense precipitation near the carbonation front controlled the overall permeability of the column. However, further experimental validation of this assertion is needed. It is interesting that the permeability of the reacted sample measured here is lower (in the range of one order of magnitude) than the value estimated from empirical equations, as shown in Table 5.1, although the data in Table 5.1 associates with the scenario in which the ground shale, instead of glass beads, are used as the reaction matrix. The differences between the comparisons reveal the sensitivity of different methods used to derive permeability and the importance to apply consistence method when illustrating permeability data.

A run without $\mathrm{CaSiO}_{3}$ present in the glass beads under the same $\mathrm{CO}_{2}$ pressure and temperature was conducted. Neither carbonate nor hydrate was produced and the permeability of the matrix was the same as that of a newly sintered glass beads matrix. This indicates the chemical stability of the glass beads matrix. When $\mathrm{CO}_{2}$ was replaced with $\mathrm{N}_{2}$ (in the presence of $\mathrm{CaSiO}_{3}$ ), only hydrate was produced under the same pressure and temperature. This observation suggests that under our experimental conditions, wollastonite could be directly converted to C-S-H as shown in Equation 5.11. However, the permeability of the column remained at around 0.3 Darcy, which was the same before exposing to $\mathrm{N}_{2}$. It has been reported that $\mathrm{CaCO}_{3}$ deposits in smaller pore spaces when $\mathrm{CO}_{2}$ interacts with silicate hydrate. ${ }^{107}$ Previous studies also show that the precipitation of 
carbonate could even change the pore size distribution and permeability of the original porous structure of the silicate hydrate matrix. Our experimental results demonstrate that the formation of carbonate minerals can cause a reduction in permeability of a porous structure. The carbonate can be formed either from direct interaction between $\mathrm{CO}_{2}$ and silicate as shown in Equation 5.9, or as a result of the dissociation of silicate hydrate C-S$\mathrm{H}$ under acid conditions (shown in Equation 5.13) and the consequent carbonation of the $\mathrm{Ca}^{2+}$. The formation of calcium silicate hydrate may provide suitable pore sizes that the carbonate minerals can fill and clog. The mechanism by which these hydrates are forming in our system are still not clear. The run with $\mathrm{N}_{2}$ indicates that the direct conversion of wollastonite to silicate hydrate is possible. While the contribution of the other mechanism as shown in Equation 5.12 hasn't been quantified in our work. Considering that our experiment is diffusion controlled, at locations where the silicate minerals has been dissolved but $\mathrm{H}^{+}$has been depleted, it is possible that the $\mathrm{Ca}^{2+}$ can combine with amorphous silica together with $\mathrm{H}_{2} \mathrm{O}$ to generate hydrate as well. Further studies about the exact mechanism of hydrate formation under our conditions is needed. Also, the synergies between the hydrate formation and the change in flow properties needs be further studied.

\subsection{Permeability Control in Shale Play at Different Depth}

To help understand where in the subsurface this approach could be deployed, the chemical kinetics of the underlying precipitation/dissolution reactions was evaluated using first-principal relationships and published data. A heat map describing the results of this analysis across a range of representative geothermal gradients and hydrostatic pressures is presented in Figure 5.15. The average properties of several shale formations 
in the United States are presented as a benchmark. These formations occur generally deeper than $1 \mathrm{~km}$ and can occur at different temperatures given the range of lithostatic gradients found in the subsurface. To derive the heat map, the activation energy of the carbonation reaction was calculated at a reference state $\left(25^{\circ} \mathrm{C}, 1 \mathrm{~atm}\right)$ and found to be 36.4 $\mathrm{kJ} / \mathrm{mol} .{ }^{193}$ We assumed the activation energy was constant with temperature. The reaction rate constant was derived using the Arrhenius equation, ${ }^{194}$ as shown in Equation 5.14:

$$
k_{T}=A e^{-\frac{E a}{R T}} \quad \text { Equation } 5.14
$$

where $k_{T}$ is the reaction rate constant at temperature $T(\mathrm{~K}), A$ is the pre-factor, $E_{a}$ is the activation energy $(\mathrm{kJ} / \mathrm{mol}), R$ is the ideal gas constant $\left(8.314 \mathrm{~J} \cdot \mathrm{K}^{-1} \cdot \mathrm{mol}^{-1}\right)$.

Equation 5.15 can be modified to calculate the change in the reaction rate constant from temperature $T_{0}$ to $T$ :

$$
\frac{k_{T}}{k_{T_{0}}}=e^{\frac{E a}{R}\left(\frac{1}{T_{0}}-\frac{1}{T}\right)}
$$

Like most aqueous complexation reactions, the carbonation of wollastonite is less dependent on pressure than temperature. There is some empirical evidence that pressure, especially near the critical point of $\mathrm{CO}_{2}$ can have an important effect because of the dramatic increase in molecular density for $\mathrm{CO}_{2}$ around this value. Huijgen et al. ${ }^{30}$ reports a modest increase of carbonation reaction rate from $2 \mathrm{MPa}$ to $4 \mathrm{MPa}$ at $100^{\circ} \mathrm{C}$.

Gerdemann et al. indicates that the reaction rate of carbonation reaction for different minerals is weakly related to pressure change (compared to temperature) and it is projected that the increase of reaction rate from the critical pressure of $\mathrm{CO}_{2}(7.4 \mathrm{MPa})$ to the highest pressure in our range $(40 \mathrm{MPa})$ is in on the order of 1-3 times. ${ }^{28}$ To capture the 
effect of pressure, we assume that the reaction rate constant would double over the pressure range evaluated here under a constant temperature.

The heat map in Figure 5.15 is expressed in terms of factor increase in reaction rate constant relative to the reference state at the critical point. The reaction rate constant increases with temperature and pressure as indicated by the transition from blue to yellow to red. The color bar on the right side indicates how many times the rate constant changes compared with the benchmark value of $\mathrm{k}$ at the $\mathrm{CO}_{2}$ critical point (illustrated here in the upper right hand corner of the figure). The maximum point occurs at the bottom right hand corner of the figure. It is worth noting that the carbonation of Mg-bearing silicates would generally require higher temperatures and pressures $\left(185^{\circ} \mathrm{C}, 15 \mathrm{MPa}\right)$ than the $\mathrm{Ca}$ bearing silicates modeled here. ${ }^{70}$ So, while calcium silicates like wollastonite would be suitable for shallower formations, magnesium silicates would be more suitable for deeper formations. 


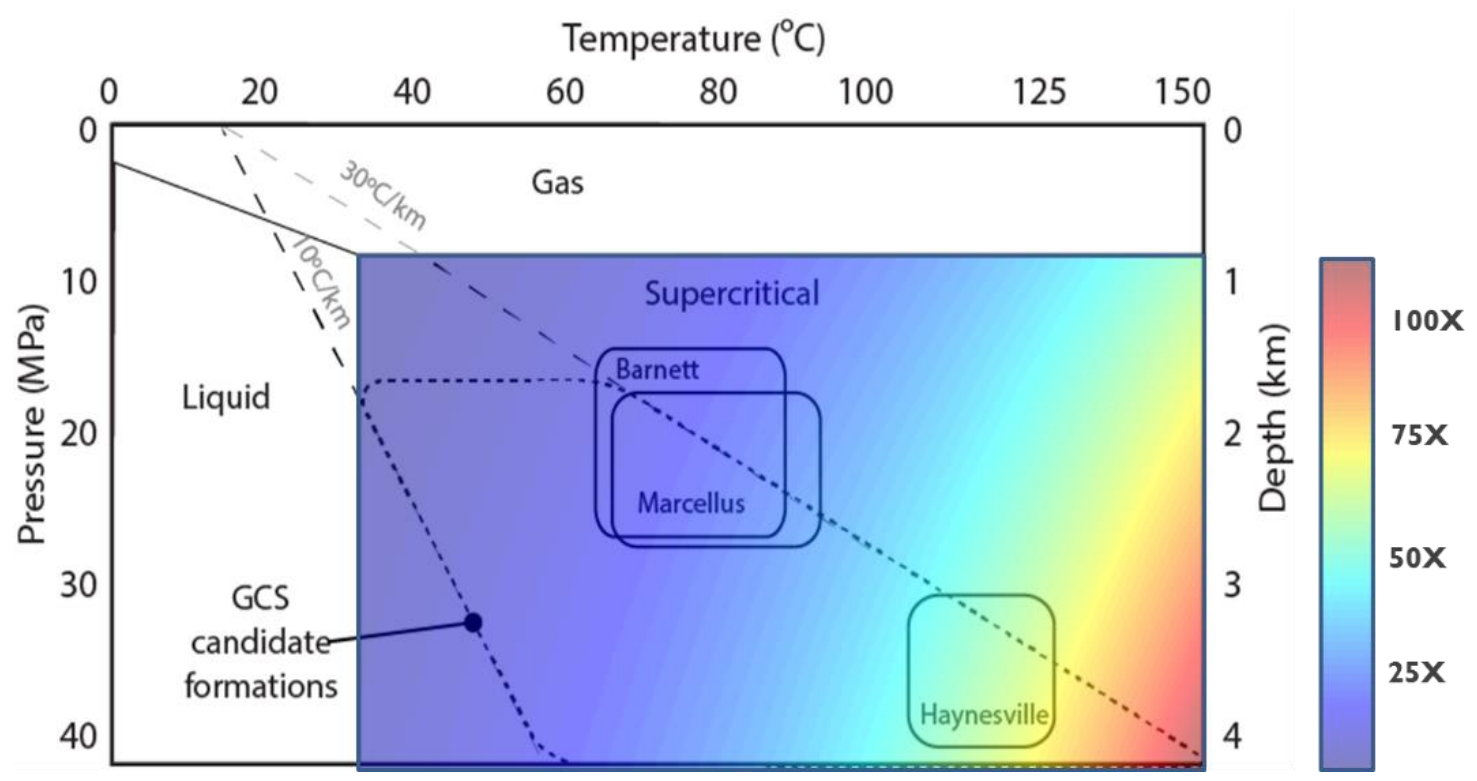

Figure 5.15 Pressure-temperature plot of the subsurface indicating the phase behavior of $\mathrm{CO}_{2}$ and the conditions that prevail in the Marcellus, Barnett, and Haynesville shale formations. The gradient map of rate constant for carbonation reaction is inserted as the cover for the area in which $\mathrm{CO}_{2}$ is in supercritical phase. Most of the primary shale formations provide suitable pressure and temperatures for carbonation of calcium bearing silicates. Derived from Tao et al. ${ }^{137}$

\subsection{Environmental Implications}

Controlling permeability as a way of securing either underground formations or fractures existing in the formation is critical in the context of geological carbon sequestration and oil/gas production. The work done in this chapter suggests that mineral carbonation of wollastonite can be carried out effectively in the presence of shale under the pressure and temperature conditions representative of the Marcellus formation. The results are expected to apply generally to many other shale plays at similar or greater depths where conditions will promote in situ mineral carbonation. Shale fracturing activities could lead to a variety of environmental risks and these mineral carbonation reactions could have important implications in developing strategies for reducing the hydraulic connectivity of 
disturbed shale formations during the post-closure phase of a well life cycle. A further understanding of how these in-situ carbonation strategies impact flow will require benchscale studies on fractured shale cores and field trials, but the morphology of the precipitated $\mathrm{CaCO}_{3}$ and its association with the shale matrix surface suggests that this process would reduce meso- and macro-scale fluid flow within the shale matrix and fracture networks alike. The proposed process could also play an important role in efforts to re-engineer depleted shale plays as secure $\mathrm{CO}_{2}$ storage reservoirs and/or impervious caprock seals for deeper saline aquifers. Finally, even though the experiments reported here are for one representative mineral carbonation reaction, it is likely that similar reactions, such as those containing $\mathrm{Mg}$-bearing species, would behave in much the same way. The presence of $\mathrm{CH}_{4}$ and other hydrocarbons is not likely to trigger the carbonation of the mineral silicate minerals since they are not acid and there is no way for them to chemically interact with the silicate. However, there could be a physical influence. For example, if the silicate minerals are covered by a thick layer of hydrocarbon, the capacity for $\mathrm{CO}_{2}$ to attack the silicate minerals would be diminished.

In addition to shale fracturing, there are other emerging energy technologies that are being deployed in the deep subsurface where selective permeability control would be desirable. Carbon capture and sequestration activities in saline aquifers are being studied as a means of permanent storage of $\mathrm{CO}_{2}$ and techniques for sealing leaks or maintaining wellbore integrity are of great interest. Fluid injection associated with produced water disposal is contributing to seismicity that is of great concern to the oil and gas industry. Some of these risks could be potentially mitigated if target formations were cemented during or following fluid injection. Finally, fluid or gas storage in the deep subsurface 
would be an effective means of energy storage as long as risks from leakage could be prevented.

Recent work by Kang et al. and others suggests that the legacy risks from gas wells accounts for a significant amount of greenhouse gas emissions to the atmosphere. ${ }^{168}$ These emissions are generally not accounted for in many climate models and could contribute to the underestimation in carbon budgets globally. Most work on abandoned wells suggests that leaks around wellbores are due to faulty construction and/or wellbore integrity failures over decades and centuries following closure of the well. A method to stabilize the entire formation, or at a minimum the region of the formation closest to the wellbore could provide a much more robust strategy for stabilizing geologic formations that have been disturbed during the hydrocarbon extraction. In an increasingly carbonconstrained economy, such methods for mitigating leakage and seepage of gases into the atmosphere will be critical.

Interestingly, we found that calcium-based silicate minerals have the potential to be converted to silicate hydrate under diffusion-controlled conditions. In the cement industry, these hydrates provide the primary strength and cementitious properties for cured cement. Our results reported here do not directly validate the effectiveness of hydrates in changing flow pathways in a porous matrix. However, the existence of the hydrate may provide a porous environment in which the precipitated minerals from carbonation reactions may easily deposit. This potential synergy warrants further study. Mg- and Fe- based silicates minerals, which tend to be more abundant in certain formations like basalts, do not typically form hydrates. Thus, the selection of a geological 
formation with a specific mineral composition is critical for the silicate hydrate synergy to exist.

These results suggest that this carbonation method could be used to manage many of the legacy risks associate with shale gas production or wellbore integrity in theory. In practice, methods will be needed to deploy this technique in the field. An obvious method for deploying this technology, as described in Figure 5.16, would be to substitute $\mathrm{CaSiO}_{3}$ proppants for sand, during the initial fracturing of the well and then flood the well with $\mathrm{CO}_{2}$ at the end of its life. Such an approach would depend on the gas and water composition in the well to prevent undesirable drops in permeability while it is still in the production phase. This technology can also be applied at wellbores where there is a degradation of the cement materials and a leakage is detected. In other applications, such as geologic carbon sequestration, the calcium or magnesium silicates might be injected with coatings to limit their reactivity to only regions where flow is undesirable, such as fractures where leaks from a target repository may be occurring. This work suggests that the technique could form an enabling method for controlling the properties of porous media in a range of applications in the deep subsurface. 

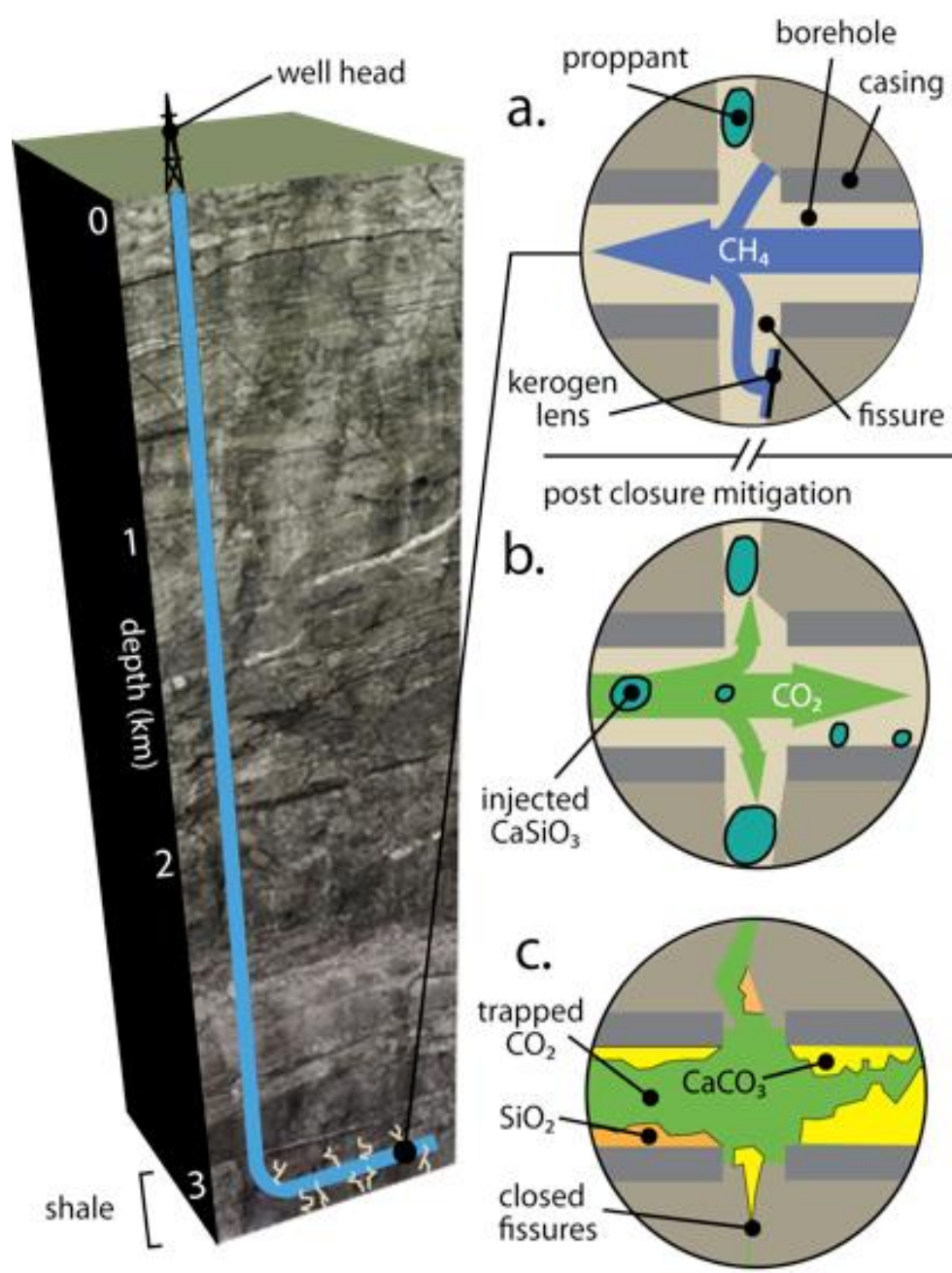

Figure 5.16 Schematic illustration of how mineral carbonation reactions would be used to mitigate many of the risks that could result from shale fracturing activity. The fracture networks and proppants that are initially put in place to produce natural gas (Figure 5.16a) would be flooded with $\mathrm{CO}_{2}$ and a divalent cation donor (e.g., $\left.\mathrm{CaSiO}_{3}\right)($ Figure 5.16b). The resulting dissolution/precipitation chemistry (Figure 5.16c) would seal fracture networks and permanently trap $\mathrm{CO}_{2}$. 


\section{CHAPTER VI}

\section{CONCLUSIONS AND FUTURE WORK}

Geological carbon storage is an attractive technology for storing significant amounts of $\mathrm{CO}_{2}$ in deep underground formations and avoiding its release into the atmosphere where it contributes to climate change. Two key factors are critical in determining the viability of a GCS reservoir. The first is the storage capacity of the target formation and its receptivity to the injection of $\mathrm{CO}_{2}$. The second pertains to the risks associated with the injection and storage, particularly the risk of leakage. Saline aquifers are traditionally considered to be the most ideal GCS reservoirs because of their large potential capacity but safety concerns have been widely debated. The migration of $\mathrm{CO}_{2}$, driven by buoyancy, could cause leakage that would severely undermine the efficiency and safety of the storage process. Further, the injection of $\mathrm{CO}_{2}$ into oil/gas reservoirs for storage or for enhanced oil recovery only provides very limited carbon storage volume. Thus, the exploration of new geological formations for the purpose of safely storing large amounts of $\mathrm{CO}_{2}$ is an important topic to help deploy GCS on a large scale.

Hydrocarbon production from shale formations over the past decade has provided an opportunity to investigate these formations as possible repositories for $\mathrm{CO}_{2}$ storage. Large volumes of oil/gas produced from these wells free up pore space in which to store $\mathrm{CO}_{2}$. However, mass transfer in shale formations is still poorly understood, which has led to poor estimations of storage capacity and injectivity. For this reason, methods that are suitable for evaluating carbon storage potential as well as the associated kinetics are needed. 
Similar to other carbon storage reservoirs, methods for preventing leakage need to be considered in shale formations. Although the low intrinsic permeability of the shale matrix would reduce the $\mathrm{CO}_{2}$ leakage potential, fractures and degrading wellbores provide large leakage pathways. In this dissertation, a method based on silicate mineral carbonation is proposed as a new route for controlling fluid flow properties and its capability to be deployed as a leakage prevention/mitigation mechanism to secure carbon injection in shale formations is presented.

\subsection{Conclusions}

\subsection{1 $\mathrm{CO}_{2}$ storage capacity in shales}

A novel method to estimate the $\mathrm{CO}_{2}$ storage capacity in shale formations has been developed. Unlike traditional methods, which use petrophysical parameters, such as formation width, thickness, porosity, etc. to evaluate gas volume, our method is based on historical shale gas production data to derive the $\mathrm{CO}_{2}$ storage volume. The underlying assumption is that the chemical/physical factors that are influencing the methane production process also control the $\mathrm{CO}_{2}$ injection process. The rate-controlling step in fluid transport in a shale formation is diffusion and a mathematical model based on Fick's law was developed to simulate this process. A number of parameters, including the gas diffusion coefficient, the ratio of adsorbed gas to free phase gas, water saturation, and gas adsorption isotherms were considered and their effect on modeling estimates were explored. This model was applied to different shale formations in US and it was estimated that the Marcellus shale play can store more than $10 \mathrm{Gt}$ of $\mathrm{CO}_{2}$ in $10-15$ years, which is more than one third of US $\mathrm{CO}_{2}$ emissions from stationary resources. Other US shale formations, such as Utica, Barnett, and Haynesville plays can also store 1-5Gt of 
carbon. The large storage capacity of these shales provides incentive to further study this carbon storage technology. A study of $\mathrm{CO}_{2}$ mass transfer indicates that injection rates of $\mathrm{CO}_{2}$ could proceeds several times faster than the production of $\mathrm{CH}_{4}$.

Sensitivity analyses show that the parameters that influence the percentage of adsorbed gas to the total gas and the ratio of adsorbed $\mathrm{CO}_{2}$ to $\mathrm{CH}_{4}$ in shale with specific area surface are the two most sensitive factors in estimating $\mathrm{CO}_{2}$ sequestration capacity. It is interesting that another factor, the characteristic gas transport distance, which captures the travel distance of gas molecules in fractured shale formations and the effect of pore collapse following production, has a large influence on the kinetics of $\mathrm{CO}_{2}$ injection. Increasing this characteristic length by five times triples the amount of time it takes to complete the injection of $\mathrm{CO}_{2}$ into the formation. Similarly, an increase in water content in the formation or in the ratio of free $\mathrm{CH}_{4}$ to sorbed $\mathrm{CH}_{4}$ decrease the sequestration potential of the formation.

To extend these findings, a meta-analysis analysis was performed which combined and harmonized all the published results relevant to carbon storage capacity in different shale formations. Studies published after the modeling effort described above have been largely consistent in their estimates. Storage capacity was found to be on the order of $1 \mathrm{Mt}$ $\mathrm{CO}_{2} /$ well over a 20-year life of a well. Given that overall US emissions are on the order of several Gt/year and hundreds of wells are being drilled each year, this technology has the potential to store a substantial portion of overall US emissions. The scale of current shale gas production activities and the need to develop emissions management strategies for this activity suggest that at a minimum, this could be part of a broader suite of technologies used to mitigate carbon emissions associated with power production. It is 
noteworthy that much of this storage capacity from shale is geographically concentrated in two regions of the United States and so a major limitation in deploying this technology is the ability to develop a $\mathrm{CO}_{2}$ pipeline distribution network that would link sources and sinks. Our model did not include time effects and efforts to deploy this technology would require that the relationship between injection rates and pressure build up in the formation be better understood to predict how quickly individual wells could be pressurized without re-fracturing the well.

\subsubsection{Deploying mineral carbonation to control the fluid flow in shale or porous}

\section{media}

The reactivity of silicate minerals with $\mathrm{CO}_{2}$ makes them capable of controlling flow properties through the dissolution and precipitation of secondary minerals. Our results indicate that $\mathrm{Ca}$-bearing silicate can be readily reacted with $\mathrm{CO}_{2}$ and can form crystalized carbonate as well as amorphous silica under the pressure and temperature conditions of shale formations. The reaction proceeds faster under higher temperature. The time scale for observing the effects of the carbonation reaction is in the range of hours or days under different conditions. It is noteworthy that these time scales are relatively short compared to that of natural geological carbon storage, which is normally thousands of years. The carbonate minerals that are produced from the reaction are cementitious and could help to form of a cohesive mineral mixture. Analysis from MIP indicated that the carbonation reaction changes the pore size distribution obviously. Also, the permeability of core-sized samples decreased by one order of magnitude after the carbonation reaction. Our analysis suggests that the carbonation with calcium silicate is effective in altering the pore structure of porous media and subsequently decreasing permeability. It is also interesting 
that the Ca-bearing silicate minerals have the capacity to form a hydrate phase when interacting with aqueous phase solutions. Our results indicate that this hydrate phase is not directly correlated with a decrease in permeability. The mechanism of the hydrate formation under our conditions is still not very clear and further experimental/modeling work are needed. However, it is suggested that carbonate precipitates readily on the hydrate pore structure and the result is that fluid flow properties can be significantly altered.

\subsection{Future Work}

\subsubsection{D-imaging through $\mathrm{xCT}$ and reactive transport modeling of the} carbonation in porous media

The relationship between mineral dissolution/precipitation, permeability change and pore structure evolution is complicated. Ellis et al. reported these complex behaviors in fracture flow experiments. ${ }^{35}$ To capture important geometric complexities of targeted carbonation, high-resolution 3D reconstructions of the pore networks are needed. For example, Figure 6.1includes an image of the preliminary xCT runs of one of our glass beads sample. The top and side view of a glass beads matrix from $\mathrm{xCT}$ are shown in Figure 6.1(a) and (b). While SEM images provide informative high-resolution images, the small image area cannot be used to create the exact 3D reconstructions, which could be used as input for software or models to further analyze the structures. Synchrotronbased differential absorption $\mathrm{xCT}$ takes advantage of the significant difference in $\mathrm{x}$-ray attenuation between $\mathrm{xCT}$ images that are collected at incident $\mathrm{x}$-ray energies just below and above the absorption edge of a particular chemical element. ${ }^{195}$ The difference between these two images provides a 3D map of the element of interest. We propose to 
use Iodine-loaded epoxy to fix the geometry of sub-core samples upon completion of the targeted carbonation of porous media and fractured wellbore material. Differential absorption xCT measurements above and below the Iodine K-edge (34.56keV) will provide a 3D map of the fracture geometry. Because the magnitude of the difference between the two images depends solely on the amount of Iodine in any particular volume element (i.e., voxel), the 3D map is quantitative and provides sub-voxel resolution, which in this case is a measure of the portion of each voxel that is occupied by epoxy. This method will provide accurate quantification of void geometry within the porous media and fractured materials.

The xCT images will be processed by Avizo 3D software developed by FEI. Figure 6.1(c) and (d) give an example about the image processing result. Figure 6.1(c) shows the pore network of a glass beads matrix with delivered $\mathrm{CaSiO}_{3}$ before carbonation reaction and most of the pores are connected. However, after reaction, significant amounts of pores are isolated and these volumes are highlighted with different colors. We plan to use this technology to illustrate the evolution of pore structures.

Aside from the 3D imaging techniques, multiphase flow and reactive transport models will be applied to represent different aspects of the proposed targeted carbonation. 3D pore network reconstruction with reactive transport modeling will be used to predict how characteristics of the $\mathrm{CO}_{2}$ plume (temperature, pressure, physical state, water content) and treatment slurry (colloid concentration, coating properties, $\mathrm{pH}$ ) will affect the fluid movement, delivering of the calcium-donor mineral to the target treatment zone, and the carbonation reaction. A previously developed reactive transport model from our collaborators will be adapted to predict the influence of precipitation on fluid flow and pore 
network permeability. ${ }^{196,197}$ The 3D imaging mentioned above will inform these models by defining mineralogical distributions at fine resolution and will enable $\mathrm{xCT}$-number/density mineral mapping that distinguishes calcite and silica precipitates from the original rock matrix. Methods have been developed for calibrating xCT-number/density to specific mineral phases by using SEM element mapping of representative thin sections from a rock core.

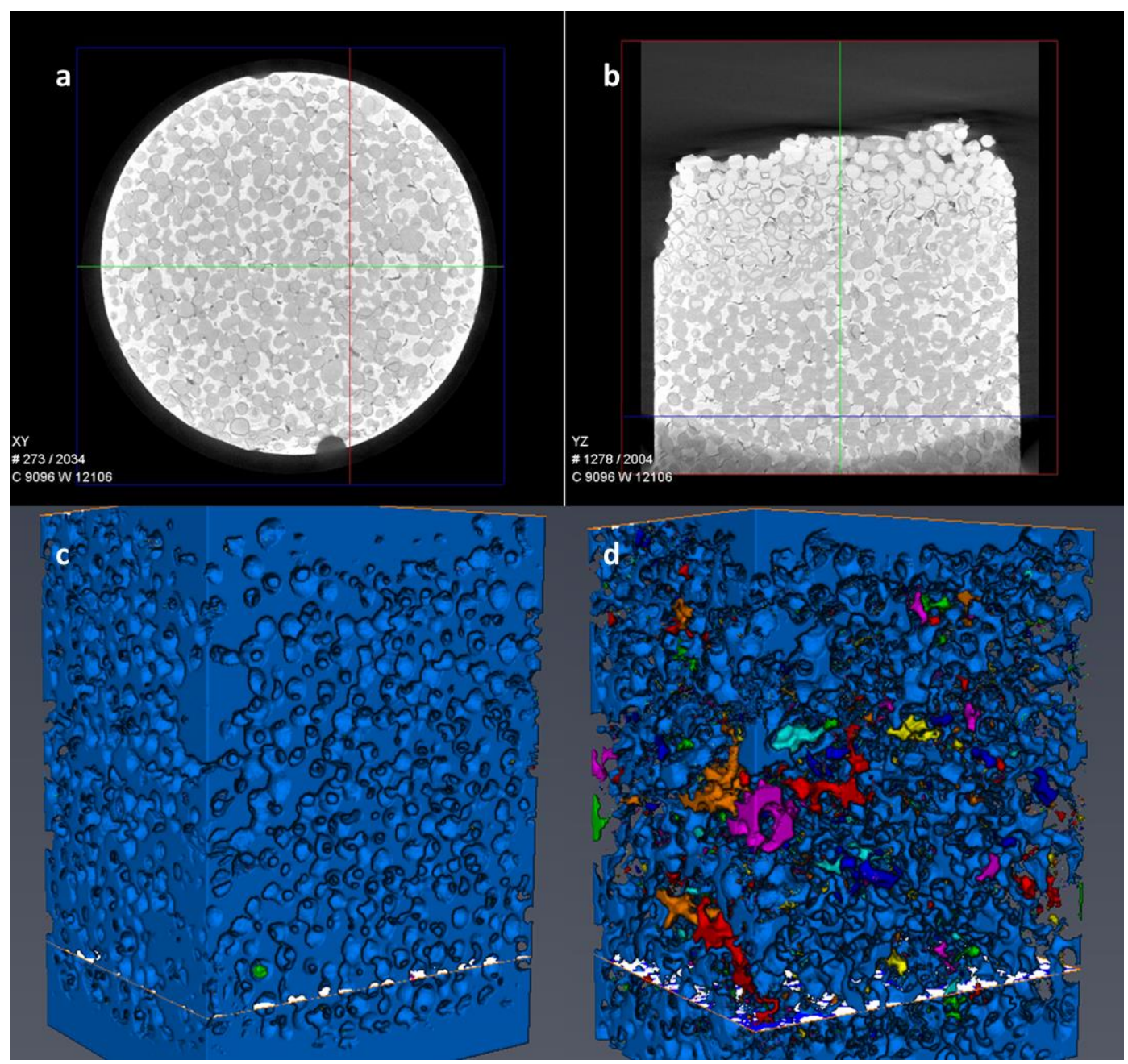

Figure 6.1. (a) Top view of xCT image of a glass beads matrix with $\mathrm{CaSiO}_{3}$ delivered after reaction. (b) Side view of xCT image of a glass beads matrix with $\mathrm{CaSiO}_{3}$ delivered after reaction. (c) The pore network after image processing of an glass beads matrix delivered with $\mathrm{CaSiO}_{3}$ before carbonation reaction. (d) The pore network after image processing of a glass beads matrix delivered with $\mathrm{CaSiO}_{3}$ after carbonation reaction. 


\subsubsection{Effectiveness of polymer-coated silicate minerals in controlling hydrologic and mechanical characteristics of subsurface pores and fractures}

The work in this dissertation has shown the effectiveness of mineral carbonation in controlling the permeability of porous media, aimed at preventing subsurface leakage in $\mathrm{CO}_{2}$ injection and storage processes. In practice, delivering these mineral silicates to the regions where the $\mathrm{CO}_{2}$ is leaking is the next technical challenge associated with deploying this technology and a new body of chemical and physical knowledge is needed to make this approach viable. The technology we proposed here will be based on surfaceactive materials that will partition into the regions of the subsurface where leaks are most likely to occur and selectively clog pores and fractures. One way to achieve this goal is to coat the silicate minerals with functional polymers.

Polymer coatings may provide two primary functions. The first is to impart temperature sensitivity and switching. In the subsurface, temperature is an effective surrogate for depth so polymers could be synthesized to collapse when temperature is below some critical value above the target formation. This collapse in the polymer coating of the mineral silicate would release the cations into solution, resulting in rapid carbonation and precipitation of the solid phase and $\mathrm{SiO}_{2}$. These precipitates could then seal pores and block the vertical migration of $\mathrm{CO}_{2}$. The second function of the polymer coating could be to have the particles selectively partition at the interface between the supercritical $\mathrm{CO}_{2}$ and the injected aqueous slurry. This could be achieved by designing the polymer chains on the surface to have an intermediate solubility in both water and $\mathrm{CO}_{2}$. Having the mineral silicate particles partition to the interface is critical so that they exist near the 
leading edge of $\mathrm{a} \mathrm{CO}_{2}$ plume or vertical leakage event to induce precipitation once coating collapse is triggered.

This new body of knowledge will need to include information on stimuli-responsive coatings, transport of colloidal particles in porous media, and dissolution/precipitation reactions at the $\mathrm{CO}_{2}$-brine-mineral interface. In order to develop this body of knowledge, four fundamental research objectives should be pursued: (i) the binding of stimuliresponsive coatings on cation-donor minerals; (ii) the structure-activity relationships between coatings and phase partitioning in high-pressure $\mathrm{CO}_{2}$-brine-mineral systems; (iii) the nature, form, and rates of carbonation reactions in porous media and fractures and; (iv) the effects of these reactions on permeability in multi-phase, multi-component, highpressure systems.

Recent work by Lee et al., Ma et al., and others has shown that stimuli-responsive coatings can be created by mimicking the properties of muscle linkage proteins. ${ }^{198,199}$ The approach is relatively facile, inexpensive, and safe and has already been applied in a variety of applications including drug delivery and slow-release fertilizers. Efforts to develop temperature-responsive polymers are generally based on the deposition of a polydopamine (Pdop) layer on a salty substrate using spontaneous self-polymerization in a weak alkaline solution. Once the Pdop layer is attached to the substrate, an applicationspecific stimuli-responsive compound can be attached to the Pdop layer. Surface-initiated atom transfer radical polymerization (SI-ATRP) is the process used to bind responsive moieties to the Pdop-based initiator. Ma et al. developed temperature responsive fertilizers using a "polydopamine-g-polymer brush" structure with a grafted stimulisensitive polymer brush corona. They also proposed a three-step procedure to synthesize 
the coated sample. In the first, the dopamine polymerization produces a coating on the salty core. In the second step, the particles are treated with an initiator for the polymerization reaction using 2-bromoisobutyryl bromide (BIBB)). In the last step, NIsopropylacrylamide is polymerized on the surface of the particles to create the temperature sensitive brushes.

In the Ma et al. work, the reacted particles are designed to become soluble below a socalled lower critical solution temperature $(\mathrm{LCST})$ of $32^{\circ} \mathrm{C}$. At temperatures above this, the polymer brushes are in a collapsed state, which makes the water permeability of the multilayered coating low, limiting release of the soluble core. When the temperature drops below $32^{\circ} \mathrm{C}$, the thermosensitive chains become soluble and expand to become channels for water that favor release of the material in the core. In practice, a LCST of $32^{\circ} \mathrm{C}$ would correspond to a depth of $1-2 \mathrm{~km}$ below the surface depending on the site. But this temperature would be one of the design parameters considered in creating these coatings. Finally, it is important to note that some of the core will be released even at high temperatures, which will result in some background precipitation. One of the goals for this work should be to assess how much the silicate release under deep (non-leakage) conditions would influence fluid flow.

This future work will produce a novel method to seal leakage pathways that transect the primary caprock seal and are associated with active injection, extraction, or monitoring wells (e.g., wellbore casing and cement, and proximal caprock matrix). The polymercoated silicate minerals is a critical extension of the work in Chapter 5, focusing not only on the $\mathrm{CO}_{2}$-mineral interaction, but also on the targeted delivery of the particles into leakage locations. The temperature-stimuli property of the coating will allow the 
controlling of the release of the cation donors at specific depths or locations, increasing the efficacy of the method to mitigate leakage while decreasing the likelihood of clogging the areas in the wellbore that do not need to be sealed. The $3 \mathrm{D}$ imaging techniques here is helpful in facilitating the fundamental understanding of the factors that could have an impact on the change of pore structure or permeability, such as flow speed, $\mathrm{pH}$, temperature, pressure, cation donor concentration, the heterogeneity of the pore structure, etc. This fundamental understanding will not only be used to verify the efficacy of the sealing technology, but also to develop a multiphase fluid flow model and a reactive transport model that will enable simulations of treatment scenarios within the complex and highly variable chemical and physical environments within wellbore zones at the depth of injection formations and the primary caprock seal - a variable matrix that is too vast to explore experimentally. Finally, the results from these pore-scale models will be used to create simplified forward models of the leakage pathway mitigation technology in the field to predict mitigated wellbore integrity in the future. 


\section{REFERENCES}

(1) Metz, B.; Davidson, O.; Coninck, H. de; Loos, M.; Meyer, L. IPCC Special Report: Carbon Dioxide Capture and Storage; IPCC: Geneva, Switzerland, 2005.

(2) Bachu, S.; Gunter, W. D.; Perkins, E. H. Aquifer Disposal of $\mathrm{CO}_{2}$ : Hydrodynamic and Mineral Trapping. Energy Convers. Manag. 1994, 35 (4), 269-279.

(3) Bruant, R.; Guswa, A.; Celia, M. A.; Peters, C. A. Peer Reviewed: Safe Storage of $\mathrm{CO}_{2}$ in Deep Saline Aquifiers. Environ. Sci. Technol. 2002, 36 (11), 240A-245A.

(4) U.S. Department of Energy. United States Carbon Utilication and Storage Atlas 4th Edition; US DOE: Washington, DC, 2012.

(5) Wang, S.; Edwards, I.; Clarens, A. F. Wettability Phenomena at the $\mathrm{CO}_{2}$-BrineMineral Interface: Implications for Geologic Garbon Sequestration. Environ. Sci. Technol. 2013, 47, 234-241.

(6) Eccles, J.; Pratson, L.; Newell, R.; Jackson, R. Physical and Economic Potential of Geological $\mathrm{CO}_{2}$ Storage in Saline Aquifers. Environ. Sci. Technol. 2009, 43 (6), 1962-1969.

(7) Brennan, S.; Burruss, R. C.; Merrill, M. D.; Freeman, P. A.; Ruppert, L. F. A Probabilistic Assessment Methodology for the Evaluation of Geologic Carbon Dioxide Storage; USGS: Reston, Virginia, 2010.

(8) Busch, A.; Alles, S.; Gensterblum, Y.; Prinz, D.; Dewhurst, D.; Raven, M.; Stanjek, H.; Krooss, B. Carbon Dioxide Storage Potential of Shales. Int. J. Greenh. Gas Control 2008, 2 (3), 297-308.

(9) Kang, S. M.; Fathi, E.; Ambrose, R. J.; Akkutlu, I. Y.; R.F., S. Carbon Dioxide Storage Capacity of Organic-rich Shales. SPE 134583 2010, 1-17.

(10) Nuttall, B.; Eble, C.; Drahovzal, J.; Bustin, M. Analysis of Devonian Black Shales in Kentucky for Potential Carbon Dioxide Sequestration and Enhanced Natural Gas Production; Kentucky Geological Survey: Lexington, KY, 2005.

(11) Weniger, P.; Kalkreuth, W.; Busch, A.; Krooss, B. M. High-Pressure Methane and Carbon Dioxide Sorption on Coal and Shale Samples from the Paraná Basin, Brazil. Int. J. Coal Geol. 2010, 84 (3-4), 190-205.

(12) Tao, Z.; Clarens, A. Estimating the Carbon Sequestration Capacity of Shale Formations Using Methane Production Rates. Environ. Sci. Technol. 2013, 47 (19), 11318-11325.

(13) Zhou, Q.; Birkholzer, J. T.; Tsang, C.; Rutqvist, J. A Method for Quick 
Assessment of $\mathrm{CO}_{2}$ Storage Capacity in Closed and Semi-closed Saline Formations. Int. J. Greenh. Gas Control 2008, 2 (4), 626-639.

(14) Szulczewski, M. L.; MacMinn, C. W.; Herzog, H. J.; Juanes, R. Lifetime of Carbon Capture and Storage as a Climate-Change Mitigation Technology. Proc. Natl. Acad. Sci. 2012, 109 (14), 5185-5189.

(15) Goodman, A.; Hakala, A.; Bromhal, G.; Deel, D.; Rodosta, T.; Frailey, S.; Small, M.; Allen, D.; Romanov, V.; Fazio, J.; et al. U.S. DOE Methodology for the Development of Geologic Storage Potential for Carbon Dioxide at the National and Regional Scale. Int. J. Greenh. Gas Control 2011, 5 (4), 952-965.

(16) Van der Meer, L. G. H. The Conditions Limiting $\mathrm{CO}_{2}$ Storage in Aquifers. Energy Convers. Manag. 1993, 34 (9-11), 959-966.

(17) Nordbotten, J. M.; Celia, M. A.; Bachu, S. Injection and Storage of $\mathrm{CO}_{2}$ in Deep Saline Aquifers: Analytical Solution for $\mathrm{CO}_{2}$ Plume Evolution During Injection. Transp. Porous Media 2005, 58 (3), 339-360.

(18) Middleton, R. S.; Bielicki, J. M. A Scalable Infrastructure Model for Carbon Capture and Storage: SimCCS. Energy Policy 2009, 37, 1052-1060.

(19) Cai, W.; Santoso, A.; Wang, G.; Yeh, S.; An, S.; Cobb, K. M.; Collins, M.; Guilyardi, E.; Jin, F.; Kug, J.; et al. ENSO and Greenhouse Warming. Nat. Publ. Gr. 2015, 5 (9), 849-859.

(20) Barker, T. Climate Change 2007: An Assessment of the Intergovernmental Panel on Climate Change; IPCC: Valencia, Spain, 2007.

(21) Solomon, S.; Plattner, G.; Knutti, R.; Friedlingstein, P. Irreversible Climate Change Due to Carbon Dioxide Emissions. Proc. Natl. Acad. Sci. 2009, 106 (6), 1704-1709.

(22) Figueroa, J. D.; Fout, T.; Plasynski, S.; McIlvried, H.; Srivastava, R. D. Advances in $\mathrm{CO}_{2}$ Capture Technology-The U.S. Department of Energy's Carbon Sequestration Program. Int. J. Greenh. Gas Control 2008, 2 (1), 9-20.

(23) U.S. Geological Survey. Carbon Sequestration to Mitigate Climate Change; USGS: Reston, VA, 2008.

(24) Aydin, G.; Karakurt, I.; Aydiner, K. Evaluation of Geologic Storage Options of $\mathrm{CO}_{2}$ : Applicability, Cost, Storage Capacity and Safety. Energy Policy 2010, 38 (9), 5072-5080.

(25) Al Mansoori, S. K.; Itsekiri, E.; Iglauer, S.; Pentland, C. H.; Bijeljic, B.; Blunt, M. J. Measurements of Non-Wetting Phase Trapping Applied to Carbon Dioxide Storage. Int. J. Greenh. Gas Control 2010, 4 (2), 283-288. 
(26) Bachu, S. $\mathrm{CO}_{2}$ Storage in Geological Media: Role, Means, Status and Barriers to Deployment. Prog. Energy Combust. Sci. 2008, 34 (2), 254-273.

(27) Verdon, J. P.; Kendall, J.-M.; Stork, A. L.; Chadwick, R. A.; White, D. J.; Bissell, R. C. Comparison of Geomechanical Deformation Induced by Megatonne-Scale $\mathrm{CO}_{2}$ Storage at Sleipner, Weyburn, and In Salah. Proc. Natl. Acad. Sci. U. S. A. 2013, 110, E2762-71.

(28) Gerdemann, S. J.; O’Connor, W. K.; Dahlin, D. C.; Penner, L. R.; Rush, H. Ex Situ Aqueous Mineral Carbonation. Environ. Sci. Technol. 2007, 41 (7), 25872593.

(29) Giammar, D. E.; Wang, F.; Guo, B.; Surface, J. A.; Peters, C. A.; Conradi, M. S.; Hayes, S. E. Impacts of Diffusive Transport on Carbonate Mineral Formation from Magnesium Silicate- $\mathrm{CO}_{2}$-Water Reactions. Environ. Sci. Technol. 2014, 48, 14344-14351.

(30) Huijgen, W. J. J. J.; Witkamp, G.-J.; Comans, R. N. J. J. Mechanisms of Aqueous Wollastonite Carbonation as A Possible $\mathrm{CO}_{2}$ Sequestration Process. Chem. Eng. Sci. 2006, 61 (13), 4242-4251.

(31) Matter, J. M.; Stute, M.; Snabjornsdottir, S. O.; Oelkers, E. H.; Gislason, S. R.; Aradottir, E. S.; Sigfusson, B.; Gunnarsson, I.; Alfredsson, H. A.; Wolff-boenisch, D.; et al. Rapid Carbon Mineralization for Permanent Disposal of Anthropogenic Carbon Dioxide Emissions. 2016, 352 (6291), 10-13.

(32) Oldenburg, C. M. Migration Mechanisms and Potential Impacts of $\mathrm{CO}_{2}$ Leakage and Seepage. Carbon Capture Geol. Sequestration Integr. Technol. Monit. Regul. 2007, 127-146.

(33) Pruess, K. Leakage of $\mathrm{CO}_{2}$ from Geologic Storage: Role of Secondary Accumulation at Shallow Depth. Int. J. Greenh. Gas Control 2008, 2 (1), 37-46.

(34) Oldenburg, C. M.; Lewicki, J. L. On leakage and seepage of $\mathrm{CO}_{2}$ from geologic storage sites into surface water. Environ. Geol. 2006, 50 (5), 691-705.

(35) Ellis, B.; Peters, C.; Fitts, J.; Bromhal, G.; McIntyre, D.; Warzinski, R.; Rosenbaum, E. Deterioration of a Fractured Carbonate Caprock Exposed to $\mathrm{CO}_{2}-$ Acidified Brine Flow. Greenh. Gases Sci. Technol. 2011, 1 (3), 248-260.

(36) Harvey, O. R.; Qafoku, N. P.; Cantrell, K. J.; Lee, G.; Amonette, J. E.; Brown, C. F. Geochemical Implications of Gas Leakage Associated with Geologic $\mathrm{CO}_{2}$ Storage: A Qualitative Review. Environ. Sci. Technol. 2013, 47, 23-36.

(37) Fontenot, B. E.; Hunt, L. R.; Hildenbrand, Z. L.; Carlton, D. D.; Oka, H.; Walton, J. L.; Hopkins, D.; Osorio, A.; Bjorndal, B.; Hu, Q. H.; et al. An Evaluation of Water Quality in Private Drinking Water Wells Near Natural Gas Extraction Sites in the Barnett Shale Formation. Environ. Sci. Technol. 2013, 47, 10032-10040. 
(38) Abdoulghafour, H.; Luquot, L.; Gouze, P. Characterization of the Mechanisms Controlling the Permeability Changes of Fractured Cements Flowed Through by $\mathrm{CO}_{2}$-rich Brine. Environ. Sci. Technol. 2013, 47 (18), 10332-10338.

(39) Osborn, S. G.; Vengosh, A.; Warner, N. R.; Jackson, R. B. Methane Contamination of Drinking Water Accompanying Gas-well Drilling and Hydraulic Fracturing. Proc. Natl. Acad. Sci. 2011, 108 (20), 8172-8176.

(40) U.S. Environmental Protection Agency. Hydraulic Fracturing for Oil and Gas: Impacts from the Hydraulic Fracturing Water Cycle on Drinking Water Resources in the United States; US EPA: Washington, D.C., 2016.

(41) Ellsworth, W. L. Injection-Induced Earthquakes. Science. 2013, 341 (2013), 142149.

(42) Verdon, J. P. Significance for Secure $\mathrm{CO}_{2}$ Storage of Earthquakes Induced by Fluid Injection. Environ. Res. Lett. 2014, 9, 64022.

(43) King, G. Thirty Years of Gas Shale Fracturing - What Have We Learned. SPE1334562010.

(44) Kerr, R. A. Natural Gas From Shale Bursts Onto the Scene. Science. 2010, 328 (5986), 1624-1626.

(45) Weaver, J. D.; Nguyen, P. D.; Parker, M. A.; Batenburg, D. Van. Sustaining Fracture Conductivity. SPE 94666 2005, 1-10.

(46) US DOE. National Energy Technology Laboratory. Carbon Dioxide in Enhanced oil Recovery: Untapped Domestic Energy Supply and Long Term Carbon Storage Solution; NETL: Pittsburgh, PA, 2010.

(47) U.S. Department of Energy/International Energy Agency. Annual Energy Outlook 2012; US DOE/EIA: Washington, DC, 2012.

(48) Lash, G. G.; Engelder, T. Thickness Trends and Sequence Stratigraphy of the Middle Devonian Marcellus Formation, Appalachian Basin: Implications for Acadian Foreland Basin Evolution. Am. Assoc. Pet. Geol. Bull. 2011, 95 (1), 61103.

(49) Slatt, R. M.; Rodriguez, N. D. Comparative Sequence Stratigraphy and Organic Geochemistry of Gas Shales: Commonality or Coincidence? J. Nat. Gas Sci. Eng. 2012, 8, 68-84.

(50) Chermak, J. A.; Schreiber, M. E. Mineralogy and Trace Element Geochemistry of Gas Shales in the United States: Environmental Implications. Int. J. Coal Geol. 2014, 126, 32-44.

(51) Haluszczak, L. O.; Rose, A. W.; Kump, L. R. Geochemical Evaluation of 
Flowback Brine from Marcellus Gas Wells in Pennsylvania, USA. Appl. Geochemistry 2013, 28, 55-61.

(52) Curtis, J. Fractured Shale-Gas Systems. Am. Assoc. Pet. Geol. Bull. 2002, 86 (11), 1921-1938.

(53) Schmide-Collerus, J. J.; Prien, C. H. Investigations of the Hydrocarbon Structure of Kerogen from Oil Shale of the Green River Formation. Prepr. Pap.Am. Chem. Soc., Div. Fuel Chem 1974, 100-108.

(54) Ross, D. J. K.; Marc Bustin, R. The Importance of Shale Composition and Pore Structure Upon Gas Storage Potential of Shale Gas Reservoirs. Mar. Pet. Geol. 2009, 26 (6), 916-927.

(55) National Research Council. Induced Seismicity Potential in Energy Technologies; National Academies Press: Washington, DC, 2012.

(56) Chen, W. J.; Black, T. A.; Yang, P. C.; Barr, A. G.; Neumann, H. H.; Nesic, Z.; Blanken, P. D.; Novak, M. D.; Eley, J.; Ketler, R. J.; et al. Effects of Climatic Variability on the Annual Carbon Sequestration by a Boreal Aspen Forest. Glob. Chang. Biol. 1999, 5 (1), 41-53.

(57) Jaramillo, P.; Griffin, W. M.; McCoy, S. T. Life Cycle Inventory of $\mathrm{CO}_{2}$ in an Enhanced Oil Recovery System. Environ. Sci. Technol. 2009, 43 (21), 8027-8032.

(58) US DOE. National Energy Technology Laboratory. Carbon Sequestration Technology Roadmap: Pathways to Sustainable Use of Fossil Energy; NETL: Pittsburgh, PA, 2002.

(59) Li, R. F.; Yan, W.; Liu, S.; Hirasaki, G.; Miller, C. A. Foam Mobility Control for Surfactant Enhanced Oil Recovery. SPE 113910 2010, 1-15.

(60) Rogner, H.-H. Energy Resources. In Energy for Development SE - 12; Toth, F. L., Ed.; Environment \& Policy; Springer Netherlands, 2012; Vol. 54, pp 149-160.

(61) Gozalpour, F.; Ren, S. R.; Tohidi, B. $\mathrm{CO}_{2}$ Eor and Storage in Oil Reservoir Mendeley. 2005, 60 (3), 537-546.

(62) White, C. M.; Smith, D. H.; Jones, K. L.; Goodman, A. L.; Jikich, S. A.; Lacount, R. B.; Dubose, S. B.; Ozdemir, E.; Morsi, B. I.; Schroeder, K. T. Sequestration of Carbon Dioxide in Coal with Enhanced Coalbed Methane Recovery: A Review. Energy \& Fuels 2005, 19 (3), 659-724.

(63) MIT. The Future of Coal; MIT: Cambridge, MA, 2007.

(64) Martineau, D. F. History of the Newark East field and the Barnett Shale as a Gas Reservoir. Am. Assoc. Pet. Geol. Bull. 2007, 91 (4), 399 LP-403. 
(65) Strapoc, D.; Mastalerz, M.; Schimmelmann, A.; Drobniak, A.; Hasenmueller, N. R. Geochemical Constraints on the Origin and Volume of Gas in the New Albany Shale (Devonian-Mississippian), eastern Illinois Basin. Am. Assoc. Pet. Geol. Bull. 2010, 94 (11), 1713-1740.

(66) Popova, O. H.; Small, M. J.; McCoy, S. T.; Thomas, A. C.; Rose, S.; Karimi, B.; Carter, K.; Goodman, A. Spatial Stochastic Modeling of Sedimentary formations to Assess $\mathrm{CO}_{2}$ Storage Potential. Environ. Sci. Technol. 2014, 48, 6247-6255.

(67) Durucan, S.; Shi, J.-Q. Improving the $\mathrm{CO}_{2}$ Well Injectivity and Enhanced Coalbed Methane Production Performance in Coal Seams. Int. J. Coal Geol. 2009, 77 (12), 214-221.

(68) Ground Water Protection Council and ALL Consulting. Modern Shale Gas Development in the United States: A Primer; Oklahoma City, OK, 2009.

(69) Kargbo, D. M.; Wilhelm, R. G.; Campbell, D. J. Natural gas plays in the Marcellus Shale: challenges and potential opportunities. Environ. Sci. Technol. 2010, 44 (15), 5679-5684.

(70) O’Connor, W. K.; Dahline, D. C.; Rush, G. E.; Gerdemann, S. J.; Penner, L. R.; Nilsen, D. N. Aqueous Mineral Carbonation: Mineral Availability, Pretretment, Reaction Parametrics and Process Studies; NETL: Pittsburgh, PA, 2005.

(71) Xiong, W.; Giammar, D. Forsterite Carbonation in Zones with Transport Limited by Diffusion. Environ. Sci. Technol. Lett. 2014, 1 (8), 333-338.

(72) Pokrovsky, O. S.; Schott, J. Kinetics and mechanism of forsterite dissolution at 25 degrees C and pH from 1 to 12. Geochim. Cosmochim. Acta 2000, 64 (19), 33133325 .

(73) Khoo, H. H.; Bu, J.; Wong, R. L.; Kuan, S. Y.; Sharratt, P. N. Carbon Capture and Utilization: Preliminary Life Cycle $\mathrm{CO}_{2}$, Energy, and Cost Results of Potential Mineral Carbonation. Energy Procedia 2011, 4, 2494-2501.

(74) Matter, J. M.; Kelemen, P. B. Permanent Storage of Carbon Dioxide in Geological Reservoirs by Mineral Carbonation. Nat. Geosci. 2009, 2 (12), 837-841.

(75) Barbot, E.; Vidic, N. S.; Gregory, K. B.; Vidic, R. D. Spatial and Temporal Correlation of Water Quality Parameters of Produced Waters from Devonian-Age Shale following Hydraulic Fracturing. Environ. Sci. Technol. 2013, 47 (6), 25622569.

(76) Huerta, N. J.; Hesse, M. A.; Bryant, S. L.; Strazisar, B. R.; Lopano, C. L. Experimental Evidence for Self-Limiting Reactive Flow through a Fractured Cement Core: Implications for Time-Dependent Wellbore Leakage. Environ. Sci. Technol. 2013, 47 (1), 269-275. 
(77) Oelkers, E. H. An Experimental Study of Forsterite Dissolution Rates as a Function of Temperature and Aqueous Mg and Si Concentrations. Chem. Geol. 2001, $175(3-4), 485-494$.

(78) Sissmann, O.; Daval, D.; Brunet, F.; Guyot, F.; Verlaguet, A.; Pinquier, Y.; Findling, N.; Martinez, I. The Deleterious Effect of Secondary Phases on Olivine Carbonation Yield: Insight from Time-Resolved Aqueous-Fluid Sampling and FibTem Characterization. Chem. Geol. 2013, 357, 186-202.

(79) McGrail, B. P.; Schaef, H. T.; Spane, F. A.; Cliff, J. B.; Qafoku, O.; Horner, J. A.; Thompson, C. J.; Owen, A. T.; Sullivan, C. E. Field Validation of Supercritical CO 2 Reactivity with Basalts. Environ. Sci. Technol. Lett. 2016, acs.estlett.6b00387.

(80) Zhu, W.; Fusseis, F.; Lisabeth, H.; Xing, T.; Xiao, X.; De Andrade, V.; Karato, S. I. Experimental Evidence of Reaction-Induced Fracturing During Olivine Carbonation. Geophys. Res. Lett. 2016, 43 (18), 9535-9543.

(81) Andreani, M.; Luquot, L.; Gouze, P.; Godard, M.; Gibert, B. Experimental Study of Carbon Sequestration Reactions Controlled by the Percolation of $\mathrm{CO}_{2}$-Rich Brine through Peridotites. Environ. Sci. Technol. 2009, 43 (4), 1226-1231.

(82) Zhang, C.; Dehoff, K.; Hess, N.; Oostrom, M.; Wietsma, T. W.; Valocchi, A. J.; Fouke, B. W.; Werth, C. J. Pore-Scale Study of Transverse Mixing Induced $\mathrm{CaCO}_{3}$ Precipitation and Permeability Reduction in a Model Subsurface Sedimentary System. Environ. Sci. Technol. 2010, 44 (20), 7833-7838.

(83) Jones, A. T.; Detwiler, R. L. Fracture Sealing by Mineral Precipitation: The Role of Small-Scale Mineral Heterogeneity. Geophys. Res. Lett. 2016, 43 (14), 75647571.

(84) Jupe, A. C.; Wilkinson, A. P.; Luke, K.; Funkhouser, G. P. Class H Cement Hydration at 180 degree $\mathrm{C}$ and High Pressure in the Presence of added Silica. Cem. Concr. Res. 2008, 38 (5), 660-666.

(85) Richardson, I. G. The Calcium Silicate Hydrates. Cem. Concr. Res. 2008, 38 (2), 137-158.

(86) Peterson, V. K.; Neumann, D. A.; Livingston, R. A. Hydration of Rricalcium and Dicalcium Silicate Mixtures Studied Using Quasielastic Neutron Scattering. $J$. Phys. Chem. B 2005, 109 (30), 14449-14453.

(87) Grangeon, S.; Claret, F.; Lerouge, C.; Warmont, F.; Sato, T.; Anraku, S.; Numako, C.; Linard, Y.; Lanson, B. On the Nature of Structural Disorder in Calcium Silicate Hydrates with a Calcium/Silicon Ratio Similar to Tobermorite. Cem. Concr. Res. 2013, 52, 31-37.

(88) Bresson, B.; Meducin, F.; Zanni, H.; Noik, C. Hydration of Tricalcium Silicate $\left(\mathrm{C}_{3} \mathrm{~S}\right)$ at High Temperature and High Pressure. J. Mater. Sci. 2002, 37 (24), 5355- 
5365.

(89) Bullard, J. W.; Jennings, H. M.; Livingston, R. A.; Nonat, A.; Scherer, G. W.; Schweitzer, J. S.; Scrivener, K. L.; Thomas, J. J. Mechanisms of Cement Hydration. Cem. Concr. Res. 2011, 41 (12), 1208-1223.

(90) García Lodeiro, I.; Fernández-Jimenez, A.; Palomo, A.; Macphee, D. E. Effect on Fresh C-S-H Gels of the Simultaneous Addition of Alkali and Aluminium. Cem. Concr. Res. 2010, 40 (1), 27-32.

(91) Shaw, S.; Clark, S. M.; Henderson, C. M. B. Hydrothermal Formation of the Calcium Silicate Hydrates, Tobermorite $\left(\mathrm{Ca}_{5} \mathrm{Si}_{6} \mathrm{O}_{16}(\mathrm{OH})_{2} \cdot 4 \mathrm{H}_{2} \mathrm{O}\right)$ and Xonotlite $\left(\mathrm{Ca}_{6} \mathrm{Si}_{6} \mathrm{O}_{17}(\mathrm{OH})_{2}\right)$ : An in Situ Synchrotron Study. Chem. Geol. 2000, $167(1-2)$, 129-140.

(92) Hill, J.; Whittle, B.; Sharp, J.; Hayes, M. Effect of Elevated Curing Temperature on Early Hydration and Microstructure of Composite Cements. In MRS Proceedings, 757; 2002.

(93) Chen, J. J.; Thomas, J. J.; Taylor, H. F. W.; Jennings, H. M. Solubility and Structure of Calcium Silicate Hydrate. Cem. Concr. Res. 2004, 34 (9), 1499-1519.

(94) Schweitzer, J. S.; Livingston, R. a; Cheung, J.; Rolfs, C.; Becker, H.; Kubsky, S.; Spillane, T.; Zickefoose, J.; Castellote, M.; Bengtsson, N.; et al. Progress in Nanoscale Studies of Hydrogen Reactions in Construction Materials. In Nanotechnology in Construction 3; Springer, Berlin, Heidelberg, 2009; pp 131138.

(95) Barret, P.; Ménétrier, D. Filter dissolution of $\mathrm{C}_{3} \mathrm{~S}$ as a function of the lime concentration in a limited amount of lime water. Cem. Concr. Res. 1980, 10, 521534.

(96) Pustovgar, E.; Sangodkar, R. P.; Andreev, A. S.; Palacios, M.; Chmelka, B. F.; Flatt, R. J.; d'Espinose de Lacaillerie, J.-B. Understanding Silicate Hydration from Quantitative Analyses of Hydrating Tricalcium Silicates. Nat. Commun. 2016, 7, 10952.

(97) Gartner, E. M. A Proposed Mechanism for the Growth of C-S-H During the Hydration of Tricalcium Silicate. Cem. Concr. Res. 1997, 27 (5), 665-672.

(98) Thomas, J. J.; Biernacki, J. J.; Bullard, J. W.; Bishnoi, S.; Dolado, J. S.; Scherer, G. W.; Luttge, A. Modeling and Simulation of Cement Hydration Kinetics and Microstructure Development. Cem. Concr. Res. 2011, 41 (12), 1257-1278.

(99) Bullard, J. W. A determination of hydration mechanisms for tricalcium silicate using a kinetic cellular automaton model. J. Am. Ceram. Soc. 2008, 91 (7), 20882097. 
(100) Muller, A. C. A.; Scrivener, K. L.; Gajewicz, A. M.; McDonald, P. J. Densification of C-S-H Measured by 1H NMR Relaxometry. J. Phys. Chem. C 2013, 117 (1), 403-412.

(101) Escalante-García, J. I.; Sharp, J. H. Effect of Temperature on the Hydration of the Main Clinker Phases in Portland Cements: Part II, Blended Cements. Cem. Concr. Res. 1998, 28 (9), 1259-1274.

(102) Flint, E. P.; McMurdie, H. F.; Wells, L. S. Formation of Hydrated Calcium Silicates at Elevated Temperatures and Pressures. J. Res. Natl. Bur. Stand. (1934). 1938, $21,617$.

(103) Verbeck, G. J.; Helmuth, R. H. Structures and Physical Properties of Cement Pastes. In Proceedings of 5th Intl. Conf. Chem. Cem; Tokyo, 1968.

(104) Gallucci, E.; Zhang, X.; Scrivener, K. L. Effect of Temperature on the Microstructure of Calcium Silicate Hydrate (C-S-H). Cem. Concr. Res. 2013, 53, $185-195$.

(105) Zhou, Q.; Beaudoin, J. J. Effect of Applied Hydrostatic Stress on the Hydration of Portland Cement and $\mathrm{C}_{3} \mathrm{~S}$. Adv. Cem. Res. 2003, 15 (1), 9-16.

(106) Meducin, F.; Zanni, H.; Noik, C.; Hamel, G.; Bresson, B. Tricalcium Silicate $\left(C_{3} S\right)$ Hydration Under High Pressure at Ambient and High Temperature (200 degree C). Cem. Concr. Res. 2008, 38 (3), 320-324.

(107) Cheshire, M. C.; Stack, A. G.; Carey, J. W.; Anovitz, L. M.; Prisk, T. R.; Ilavsky, J. Wellbore Cement Porosity Evolution in Response to Mineral Alteration during $\mathrm{CO}_{2}$ Flooding. Environ. Sci. Technol. 2017, 51 (1), 692-698.

(108) Kutchko, B. G.; Strazisar, B. R.; Lowry, G. V.; Dzombak, D. a.; Thaulow, N. Rate of $\mathrm{CO}_{2}$ Attack on Hydrated Class $\mathrm{H}$ Well Cement under Geologic Sequestration Conditions. Environ. Sci. Technol. 2008, 42 (16), 6237-6242.

(109) Kutchko, B. G.; Strazisar, B. R.; Dzombak, D. A.; Lowry, G. V; Thaulow, N. Degradation of Well Cement by $\mathrm{CO}_{2}$ under Geological Sequestration Conditions. Env. Sci Technol 2007, 41 (13), 4787-4792.

(110) Cao, P.; Karpyn, Z. T.; Li, L. Dynamic Alterations in Wellbore Cement Integrity due to Geochemical Reactions in $\mathrm{CO}_{2}$-Rich Environments. Water Resour. Res. 2013, 49 (7), 4465-4475.

(111) Hovorka, S. D.; Benson, S. M.; Doughty, C.; Freifeld, B. M.; Sakurai, S.; Daley, T. M.; Kharaka, Y. K.; Holtz, M. H.; Trautz, R. C.; Nance, H. S.; et al. Measuring Permanence of $\mathrm{CO}_{2}$ Storage in Saline Formations: The Frio Experiment. Environ. Geosci. 2006, 13 (2), 105-121.

(112) Jacquemet, N.; Pironon, J.; Lagneau, V.; Saint-Marc, J. Armouring of Well 
Cement in $\mathrm{H}_{2} \mathrm{~S}-\mathrm{CO}_{2}$ Saturated Brine by Calcite Coating - Experiments and Numerical Modelling. Appl. Geochemistry 2012, 27 (3), 782-795.

(113) Bielicki, J. M.; Pollak, M. F.; Fitts, J. P.; Peters, C. A.; Wilson, E. J. Causes and Financial Consequences of Geologic $\mathrm{CO}_{2}$ Storage Reservoir Leakage and Interference With Other Subsurface Resources. Int. J. Greenh. Gas Control 2014, 20, 272-284.

(114) Clodic, L.; Meike, A. Thermodynamics of Calcium Silicate Hydrates Development of a Database to Model Concrete Dissolution at 25 degree C Using the EQ3/6 Geochemical Modeling Code. Concrete 1997.

(115) Hirabayashi, D.; Sawada, K.; Enokida, Y. Carbonation Behavior of Pure Cement Hydrates under Supercritical Carbon Dioxide Conditions. Waste Manag. 2012 Conf. Improv. Futur. waste Manag. 2012, 1-10.

(116) Milodowski, A. E.; Rochelle, C. A.; Lacinska, A.; Wagner, D. A Natural Analogue Study of $\mathrm{CO}_{2}$-Cement Interaction: Carbonation of Calcium Silicate HydrateBearing Rocks from Northern Ireland. Energy Procedia 2011, 4, 5235-5242.

(117) Busch, A.; Alles, S.; Krooss, B. M.; Stanjek, H.; Dewhurst, D. Effects of Physical Sorption and Chemical Reactions of $\mathrm{CO}_{2}$ in Shaly Caprocks. Energy Procedia 2009, 1 (1), 3229-3235.

(118) Pruess, K.; Oldenburg, C. M.; Benson, S. M. Process Modeling of $\mathrm{CO}_{2}$ Injection into Natural Gas Reservoirs for Carbon Sequestration and Enhanced Gas Recovery. Energy and Fuels 2001, 15 (6), 293-298.

(119) Jenner, S.; Lamadrid, A. J. Shale Gas vs. Coal: Policy Implications from Environmental Impact Comparisons of Shale Gas, Conventional Gas, and Coal on Air, Water, and Land in the United States. Energy Policy 2013, 53, 442-453.

(120) U.S. Energy Information administration. Review of Emerging Resources: U.S. Shale Gas and Shale Oil Plays; US EIA: Washington, DC, 2011.

(121) US EIA/INTEK. Oil Shale Research in the United States; Intek Inc for US DOE, 2011.

(122) Aguilar-Armenta, G.; Hernandez-Ramirez, G.; Flores-Loyola, E.; UgarteCastaneda, A.; Silva-Gonzalez, R.; Tabares-Munoz, C.; Jimenez-Lopez, A.; Rodriguez-Castellon, E. Adsorption Kinetics of $\mathrm{CO}_{2}, \mathrm{O}_{2}, \mathrm{~N}_{2}$, and in CationExchanged Clinoptilolite. J. Phys. Chem. B 2001, 105 (7), 1313-1319.

(123) Harpalani, S.; Prusty, B. K.; Dutta, P. Methane/ $\mathrm{CO}_{2}$ Sorption Modeling for Coalbed Methane Production and $\mathrm{CO}_{2}$ Sequestration. Energy \& Fuels 2006, 20 (4), 1591-1599. 
(124) Busch, A.; Gensterblum, Y.; Krooss, B. M. Methane and $\mathrm{CO}_{2}$ sorption and desorption measurements on dry Argonne premium coals: pure components and mixtures. Int. J. Coal Geol. 2003, 55 (2-4), 205-224.

(125) Chen, Y. D.; Yang, R. T. Preparation of Carbon Molecular Sieve Membrane and Diffusion of Binary Mixtures in the Membrane. Ind. Eng. Chem. Res. 1994, 33 (12), 3146-3153.

(126) Charrière, D.; Pokryszka, Z.; Behra, P. Effect of Pressure and Temperature on Diffusion of $\mathrm{CO}_{2}$ and $\mathrm{CH}_{4}$ into Coal from the Lorraine Basin ( France ). Int. J. Coal Geol. 2010, 81 (4), 373-380.

(127) Loughlin, K. F.; Hassan, M. M.; Fatehi, A. I.; Zahur, M. Rate and Equilibrium Sorption Parameters for Nitrogen and Methane on Carbon Molecular Sieve. Gas Sep. Purif. 1993, 7 (4), 264-273.

(128) Montoya, A.; Mondragón, F.; Truong, T. N. $\mathrm{CO}_{2}$ Adsorption on Carbonaceous Surfaces: a Combined Experimental and Theoretical Study. Carbon N. Y. 2003, 41 (1), 29-39.

(129) Cabrera-Sanfelix, P. Adsorption and Reactivity of $\mathrm{CO}_{2}$ on Defective Graphene Sheets. J. Phys. Chem. A 2008, 113 (2), 493-498.

(130) Clarkson, C. R.; Bustin, R. M. The Effect of Pore Structure and Gas Pressure upon the Transport Properties of Coal: A Laboratory and Modeling Study: 2. Adsorption Rate Modeling. Fuel 1999, 78 (11), 1345-1362.

(131) Schloemer, S.; Krooss, B. M.; Ju, F. Molecular Transport of Methane, Ethane and Nitrogen and the Influence of Diffusion on the Chemical and Isotopic Composition of Natural Gas Accumulations. 2004.

(132) Luffel, D. L.; Hopkins, C. W.; Schettler Jr., P. D. Matrix Permeability Measurement of Gas Productive Shales. SPE-26633-MS 1993, 261-270.

(133) Soeder, D. J. Porosity and Permeability of Eastern Devonian Gas Shale . SPE Formation Evaluation. 1988, pp 116-124.

(134) Marecka, A. Sorption and Diffusion Investigations of Gases on Coals in the Aspect of Carbon Dioxide Sequestration and Methane Recovery. Miner. Resour. Manag. 2007, 23, 129-137.

(135) Busch, A.; Gensterblum, Y.; Krooss, B. M.; Littke, R. Methane and Carbon Dioxide Adsorption-Diffusion Experiments on Coal: Upscaling and Modeling. Int. J. Coal Geol. 2004, 60 (2-4), 151-168.

(136) Bennion, D. B.; Thomas, F. B.; Bietz, R. F. Optimizing Production from Low Permeability Gas Reservoirs. In Calgary Sectiono f the Petroleum Society of CIM 
Technical Meeting; 1995.

(137) Tao, Z.; Bielicki, J. M.; Clarens, A. F. Physicochemical Factors Impacting CO2 Sequestration in Depleted Shale Formations: The case of the Utica shale. Energy Procedia 2014, 63, 5153-5163.

(138) U.S. Department of Energy - National Energy Technology Laboratory. A Comparative Study of the Mississippian Barnett Shale, Fort Worth Basin, and Devonian Marcellus Shale, Appalachian Basin; NETL: Pittsburgh, PA, 2011.

(139) Wickstrom, L. Geology and Activity of the Utica-Point Pleasant of Ohio. Adapt. from Present. Tulsa Geol. Soc. 2013.

(140) A.Bowder, K.; D.Reed, J. Clues to the Utica/Point Pleasant. Oil Gas Investro. Hart Energy Publ. LLP 2012.

(141) Elliot, T. R.; Celia, M. A. Potential Restrictions for CO2 Sequestration Sites due to Shale and Tight Gas Production. Environ. Sci. Technol. 2012, 46 (7), 4223-4227.

(142) Muradov, N. Z.; Veziroğlu, T. N. "Green" Path from Fossil-based to Hydrogen Economy: An Overview of Carbon-neutral Technologies. Int. J. Hydrogen Energy 2008, 33 (23), 6804-6839.

(143) Curtis, M.; Ambrose, R. J.; Energy, D.; Sondergeld, C. H.; Rai, C. S. Structural Characterization of Gas Shales on the Micro- and Nano-Scales. CUSG/SPE 1376932010.

(144) Heller, R.; Vermylen, J.; Zoback, M. Experimental Investigation of Matrix Permeability of Gas Shales. Am. Assoc. Pet. Geol. Bull. 2014, 98 (5), 975-995.

(145) Akkutlu, I. Y.; Efendiev, Y.; Savatorova, V. Multi-scale Asymptotic Analysis of Gas Transport in Shale Matrix. Transp. Porous Media 2015, 107 (1), 235-260.

(146) Alnoaimi, K. R.; Kovscek, A. R. Experimental and Numerical Analysis of Gas Transport in Shale Including the Role of Sorption. SPE Annu. Tech. Conf. Exhib. Soc. Pet. Eng. 2013.

(147) Fathi, E.; Akkutlu, I. Y. Multi-Component Gas Transport and Adsorption Effects During CO2 Injection and Enhanced Shale Gas Recovery. Int. J. Coal Geol. 2014, $123,52-61$.

(148) Fathi, E.; Akkutlu, I. Y. Matrix Heterogeneity Effects on Gas Transport and Adsorption in Coalbed and Shale Gas Reservoirs. Transp. Porous Media 2009, 80 (2), 281-304.

(149) Gandossi, L. An Overview of Hydraulic Fracturing and other Formation Stimulation Technologies for Shale Gas Production; European Commisison Joint Reserach Center Technical. Publications Office of the European Union, 
Luxembourg, 2013.

(150) King, G. Hydraulic Fracturing 101: What Every Representative, Environmentalist, Regulator, Reporter, Investor, University Researcher, Neighbor and Engineer Should Know About Estimating Frac Risk and Improving Frac Performance in Unconventional Gas and Oil Wells. S. Proc. SPE Hydraul. Fract. Technol. Conf. 2012, SPE 152596.

(151) Patzek, T. W.; Male, F.; Marder, M. Gas Production in the Barnett Shale Obeys a Simple Scaling Theory. Proc. Natl. Acad. Sci. 2013, 110 (49), 19731-19736.

(152) Bažant, Z. P.; Salviato, M.; Chau, V. T.; Visnawathan, H.; Zubelewicz, A. Why Fracking Works. J. Appl. Mech. 2014, 81 (10), 101010.

(153) Zoback, M. Reservoir Geomechanics; Cambridge University Press: New York, 2007.

(154) Bourg, I. C.; Beckingham, L. E.; DePaolo, D. J. The Nanoscale Basis of CO2 Trapping for Geologic Storage. Environ. Sci. Technol. 2015, 49 (17), 1026510284.

(155) Edwards, R. W. J.; Celia, M. A.; Bandilla, K. W.; Doster, F.; Kanno, C. M. A Model To Estimate Carbon Dioxide Injectivity and Storage Capacity for Geological Sequestration in Shale Gas Wells. Environ. Sci. Technol. 2015, 49 (15), 9222-9229.

(156) Chen, Z.; Liao, X.; Zhao, X.; Feng, X.; Zang, J.; He, L. A New Analytical Method Based on Pressure Transient Analysis to Estimate Carbon Storage Capacity of Depleted shales: A case study. Int. J. Greenh. Gas Control 2015, 42, 46-58.

(157) Godec, M.; Koperna, G.; Petrusak, R.; Oudinot, A. Potential for Enhanced Gas Recovery and CO2 Storage in the Marcellus Shale in the Eastern United States. Int. J. Coal Geol. 2013, 118, 95-104.

(158) Sun, H.; Yao, J.; Gao, S.-H.; Fan, D.-Y.; Wang, C.-C.; Sun, Z.-X. Numerical Study of CO2 Enhanced Natural Gas Recovery and Sequestration in Shale Gas Reservoirs. Int. J. Greenh. Gas Control 2013, 19, 406-419.

(159) Liu, F.; Ellett, K.; Xiao, Y.; Rupp, J. A. Assessing the Feasibility of CO2 Storage in the New Albany Shale (Devonian-Mississippian) with Potential Enhanced Gas Recovery Using Reservoir Simulation. Int. J. Greenh. Gas Control 2013, 17, 111126.

(160) Hughes, J. D. Post Carbon Institute. Drilling deeper A reality Check on U.S. Government Forcasts for a Lasting Tight Oil \& Shale Gas Boom Part 3: Shale Gas; Post Carbon Institute. Santa Rosa, California, US, 2014.

(161) Baihly, J.; Altman, R.; Malpani, R.; Lou, F. Study Assesses Shale Decline Rates. 
Am. Oil Gas Report. 2011.

(162) U.S. Energy Information administration. Oil and Gas Supply Module; US EIA: Washington, DC, 2012.

(163) U.S. Department of Energy - National Energy Technology Laboratory. Carbon Storage Atlas Fifth Edition; NETL: Pittsburgh, PA, 2015.

(164) D.J. Soeder, P. L. R. Porosity, Permeability, and Pore Structure of the Tight Mesaverde Sandstone, Piceance Basin, Colorado. Soc. Pet. Eng. Form. Eval. 1987, 2 (2), 129-136.

(165) Dilmore, R.; Bruner, K.; Wyatt, C.; Romanov, V. Experimental Characterization of Marcellus Shale Outcrop Samples, and their Interactions with Carbon Dioxide and Methane; NETL-TRS-1-2015; NETL Technical Report Series; NETL: Morgantown, WV, 2015.

(166) Kulga, B.; Dilmore, R.; Wyatt, C.; Ertekin, T. Investigation of CO2 Storage and Enhanced Gas Recovery in Depleted Shale Gas Formations Using a DualPorosity / Dual-Permeability, Multiphase Reservoir Simulator; NETL-TRS-42014; NETL Technical Report Series; U.S. NETL: Morgantown, WV, 2014.

(167) Jin, Z.; Firoozabadi, A. Effect of Water on Methane and Carbon Dioxide Sorption in Clay Minerals by Monte Carlo simulations. Fluid Phase Equilib. 2014, 382, 10 20.

(168) Kang, M.; Kanno, C. M.; Reid, M. C.; Zhang, X.; Mauzerall, D. L.; Celia, M. A.; Chen, Y.; Onstott, T. C. Direct Measurements of Methane Emissions from Abandoned Oil and Gas Wells in Pennsylvania. Proc. Natl. Acad. Sci. 2014, 111 (51), 18173-18177.

(169) Ellis, B. R.; Fitts, J. P.; Bromhal, G. S.; McIntyre, D. L.; Tappero, R.; Peters, C. A. Dissolution-Driven Permeability Reduction of a Fractured Carbonate Caprock. Environ. Eng. Sci. 2013, 30 (4), 187-193.

(170) Bredow, C. W.; Schindler, F. J. Polymer-Modified Cements with Improved Chemical Resistance. US 5162060 A, 1992.

(171) Deng, H.; Ellis, B. R.; Peters, C. A.; Fitts, J. P.; Crandall, D.; Bromhal, G. S. Modifications of Carbonate Fracture Hydrodynamic Properties by CO2-Acidified Brine Flow. Energy and Fuels 2013, 27 (8), 4221-4231.

(172) Tao, Z.; Fitts, P. J.; Clarens, F. A. Feasibility of Carbonation Reaction to Control Permeability in the Deep Subsurface. Environ. Eng. Sci. 2016, 33 (10), 778-790.

(173) Zhou, J.; Ye, G.; van Breugel, K. Characterization of Pore Structure in Cementbased Materials Using Pressurization-depressurization Cycling Mercury Intrusion Porosimetry (PDC-MIP). Cem. Concr. Res. 2010, 40 (7), 1120-1128. 
(174) Berg, R. Method for Determining Permeability from Reservoir Rock Properties. Transactions - Gulf Coast Association of Geological Societies. 1970, pp 303-335.

(175) Comisky, J. T.; Newsham, K. E.; Rushing, J. A.; Blasingame, T. A. A Comparative Study of Capillary-Pressure-based Empirical Models for Estimating Absolute Permeability in Tight Gas Sands. Proc. SPE Annu. Tech. Conf. Exhib. 2007, SPE 110050.

(176) King, H. E.; Plümper, O.; Putnis, A. Effect of Secondary Phase Formation on the Carbonation of Olivine. Environ. Sci. Technol. 2010, 44 (16), 6503-6509.

(177) Berge, P. A.; Bonner, B. P.; Berryman, J. G. Ultrasonic Velocity-Porosity Relationships for Sandstone Analogs Made from Fused Glass Beads. Geophysics 1995, 60 (1), 108-119.

(178) Alarcon-Ruiz, L.; Platret, G.; Massieu, E.; Ehrlacher, A. The Use of Thermal Analysis in Assessing the Effect of Temperature on a Cement Paste. Cem. Concr. Res. 2005, 35 (3), 609-613.

(179) Alizadeh, R.; Raki, L.; Makar, M. J.; Beaudoin, J. J.; Moudrakovski, I. Hydration of Tricalcium Silicate in the Presence of Synthetic Calcium-Silicate-Hydrate. $J$. Mater. Chem. 2009, 19, 7937-7946.

(180) Wilson, M. J.; Wilson, L.; Patey, I. The Influence of Individual Clay Minerals on Formation Damage of Reservoir Sandstones: a Critical Review with Some New Insights. Clay Miner. 2014, 49 (2), 147-164.

(181) Rammelberg, H. U.; Schmidt, T.; Ruck, W. Hydration and Dehydration of Salt Hydrates and Hydroxides for Thermal Energy Storage - Kinetics and Energy Release. Energy Procedia 2012, 30, 362-369.

(182) Wang, M.; Bao, W.; Wang, J.; Wang, K.; Xu, J.; Chen, H.; Xia, X. A Green Approach to the Synthesis of Novel "Desert Rose Stone"-like Nanobiocatalytic System with Excellent Enzyme Activity and Stability. Sci. Rep. 2014, 4 (6606), 18.

(183) Longo, R. C.; Cho, K.; Bruner, P.; Welle, A.; Gerdes, A.; Thissen, P. Carbonation of Wollastonite(001) Competing Hydration: Microscopic Insights from Ion Spectroscopy and Density Functional Theory. ACS Appl. Mater. Interfaces 2015, 7 (8), 4706-4712.

(184) Giraudo, N.; Krolla-Sidenstein, P.; Bergdolt, S.; Heinle, M.; Gliemann, H.; Messerschmidt, F.; Brüner, P.; Thissen, P. Early Stage Hydration of Wollastonite: Kinetic Aspects of the Metal-proton Exchange Reaction. J. Phys. Chem. C 2015, 119 (19), 10493-10499.

(185) Fratini, E.; Ridi, F.; Chen, S.-H.; Baglioni, P. Hydration Water and Microstructure in Calcium Silicate and Aluminate Hydrates. J. Phys. Condens. Matter 2006, 18 
(36), S2467-S2483.

(186) Edwards, H. G. M.; Villar, S. E. J.; Jehlicka, J.; Munshi, T. FT-Raman Spectroscopic Study of Calcium-rich and Magnesium-rich Carbonate Minerals. Spectrochim. Acta - Part A Mol. Biomol. Spectrosc. 2005, 61 (10), 2273-2280.

(187) Miller, Q. R. S.; Thompson, C. J.; Loring, J. S.; Windisch, C. F.; Bowden, M. E.; Hoyt, D. W.; Hu, J. Z.; Arey, B. W.; Rosso, K. M.; Schaef, H. T. Insights into Silicate Carbonation Processes in Water-bearing Supercritical CO2 Fluids. Int. J. Greenh. Gas Control 2013, 15, 104-118.

(188) Sharma, S. K.; Misra, A. K.; Clegg, S. M.; Barefield, J. E.; Wiens, R. C.; Acosta, T. E.; Bates, D. E. Remote-Raman Spectroscopic Study of Minerals Under Supercritical CO2 Relevant to Venus Exploration. Spectrochim. Acta - Part A Mol. Biomol. Spectrosc. 2011, 80 (1), 75-81.

(189) Black, L. Raman Spectroscopy of Cementitious Materials. Spectrosc. Prop. Inorg. Organomet. Compd. 2009, 40, 72-127.

(190) Liu, F.; Asce, S. M.; Sun, Z.; Qi, C. Raman Spectroscopy Study on the Hydration Behaviors of Portland Cement Pastes during Setting. 2015, 27 (1980), 1-10.

(191) Martinez-Ramirez, S.; Frías, M.; Domingo, C. Micro-Raman Spectroscopy in White Portland Cement Hydration: Long-term Study at Room Temperature. $J$. Raman Spectrosc. 2006, 37 (5), 555-561.

(192) Schott, J.; Pokrovsky, O. S.; Spalla, O.; Devreux, F.; Gloter, A.; Mielczarski, J. A. Formation, Growth and Transformation of Leached Layers Luring Silicate Minerals Dissolution: The Example of Wollastonite. Geochim. Cosmochim. Acta 2012, 98, 259-281.

(193) Daval, D.; Martinez, I.; Corvisier, J.; Findling, N.; Goffé, B.; Guyot, F. Carbonation of Ca-bearing Silicates, the Case of Wollastonite: Experimental Investigations and Kinetic Modeling. Chem. Geol. 2009, 265 (1-2), 63-78.

(194) Laidler, K. J. The Development of the Arrhenius Equation. J. Chem. Educ. 1984, $61,494-498$.

(195) Baker, D. R.; Mancini, L.; Polacci, M.; Higgins, M. D.; Gualda, G. A. R.; Hill, R. J.; Rivers, M. L. An Introduction to the Application of X-ray Microtomography to the Three-dimensional Study of Igneous Rocks. Lithos 2012, 148, 262-276.

(196) Nogues, J. P.; Fitts, J. P.; Celia, M. A.; Peters, C. A. Permeability Evolution due to Dissolution and Precipitation of Carbonates Using Reactive Transport Modeling in Pore Networks. Water Resour. Res. 2013, 49 (9), 6006-6021.

(197) Qin, C. Z.; Hassanizadeh, S. M. Pore-Network Modeling of Solute Transport and Biofilm Growth in Porous Media. Transp. Porous Media 2015, 110 (3), 345-367. 
(198) Lee, H.; Dellatore, S. M.; Miller, W. M.; Messersmith, P. B. Mussel-inspired Surface Chemistry for Multifunctional Coatings. Science 2007, 318 (5849), 426430 .

(199) Ma, Z.; Jia, X.; Hu, J.; Liu, Z.; Wang, H.; Zhou, F. Mussel-inspired Thermosensitive Polydopamine- graft -poly( $\mathrm{N}$-isopropylacrylamide) Coating for Controlled-Release Fertilizer. J. Agric. Food Chem. 2013, 61 (50), 12232-12237. 


\section{APPENDIX}

\section{A1 Comparison of ground shale and cemented shale column}

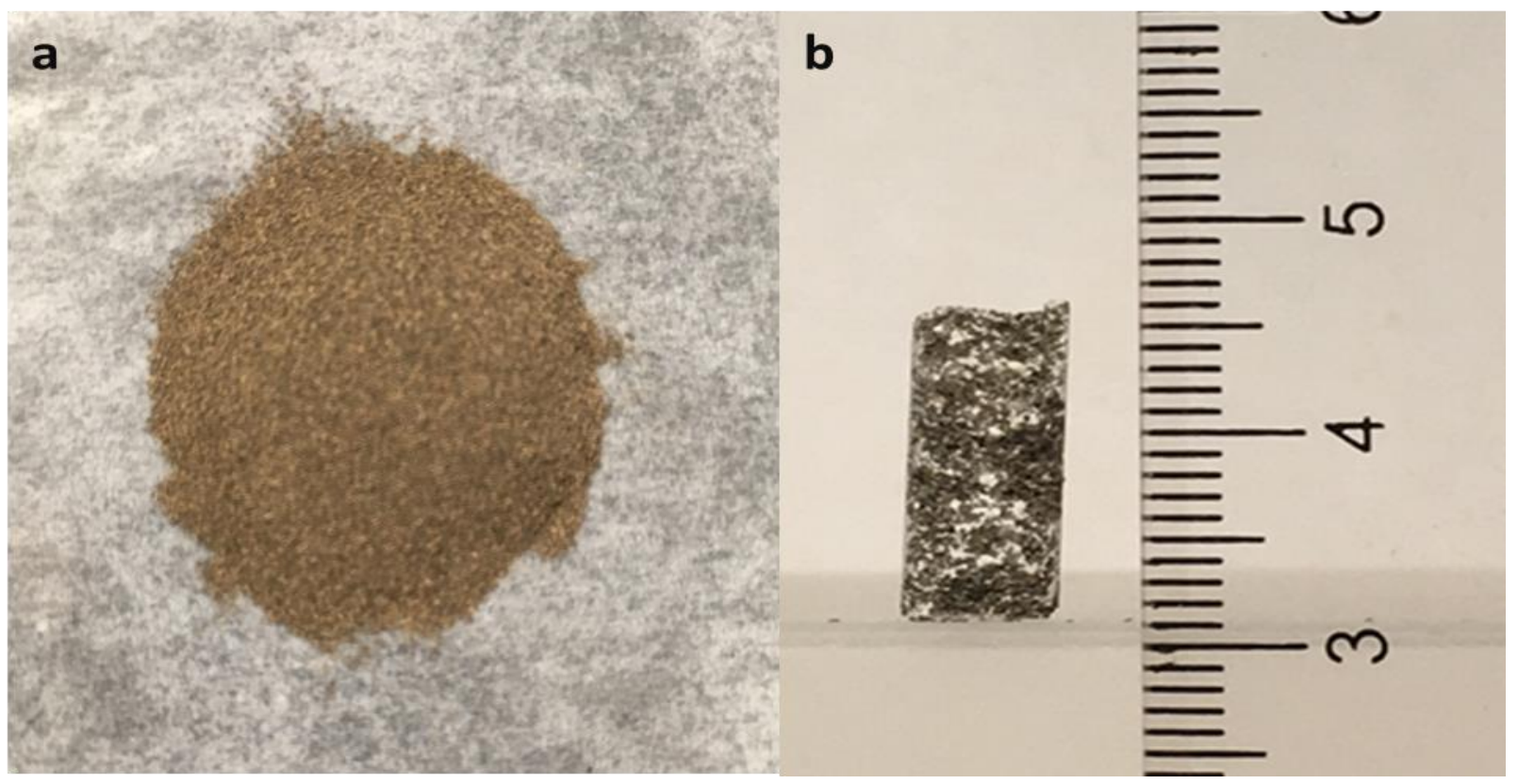

Figure.A1 (a) Grounded shale particles (b) shale particles together with carbonate after reaction. The white material in (b) is wollastonite or carbonate, according to XRD results. This is the evidence that the carbonate produced in the reaction is cementitious 


\section{A2 Stainless-steel tube used in diffusion controlled reaction and sintered glass beads}
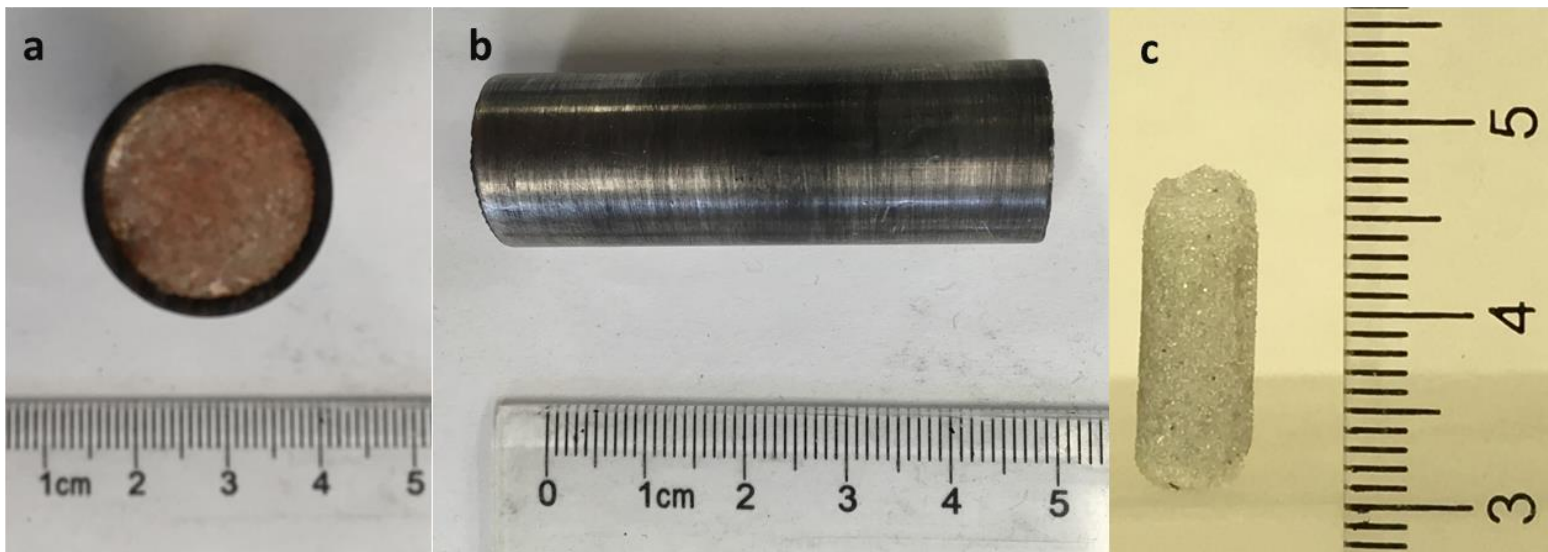

Figure.A2 (a) The top view of the stainless-steel tube. The materials in the middle is sintered glass beads. (b) The side view of the stainless-steel tube. (c) A sintered glass beads matrix which is moved out of the stainless-steel tube 


\section{A3 Setup of air -permeameter}

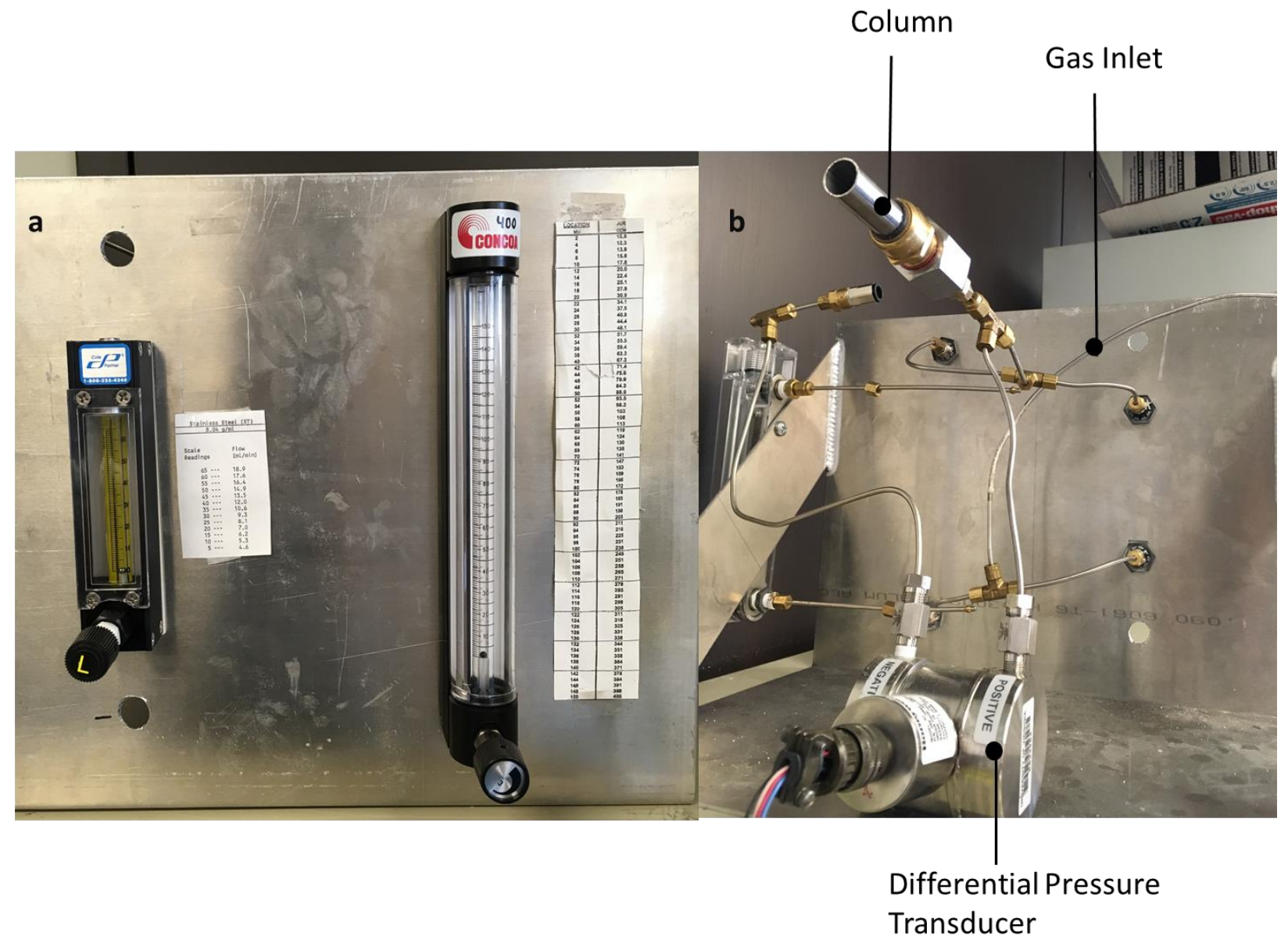

Figure. A3 (a) The front panel of the air permeameter. Two flow meters are used: one is for high flow velocity and one is for low value. (b) Back of the air permeameter.

\section{A4 Composition of soda-lime glass beads used in diffusion experiment}

Table A1 Composition of soda-lime glass beads from MO-SCI

\begin{tabular}{|l|l|}
\hline Composition & Weight percentage \\
\hline Silica $\left(\mathrm{SiO}_{2}\right)$ & $65-75 \%$ \\
\hline Aluminum Oxide $\left(\mathrm{Al}_{2} \mathrm{O}_{3}\right)$ & $0-5 \%$ \\
\hline Calcium Oxide $(\mathrm{CaO})$ & $6-15 \%$ \\
\hline Magnesium Oxide $(\mathrm{MgO})$ & $1-5 \%$ \\
\hline Sodium Oxide $\left(\mathrm{Na}_{2} \mathrm{O}\right)$ & $10-20 \%$ \\
\hline Iron Oxide $\left(\mathrm{Fe}_{2} \mathrm{O}_{3}\right)$ & $<0.8 \%$ \\
\hline
\end{tabular}

